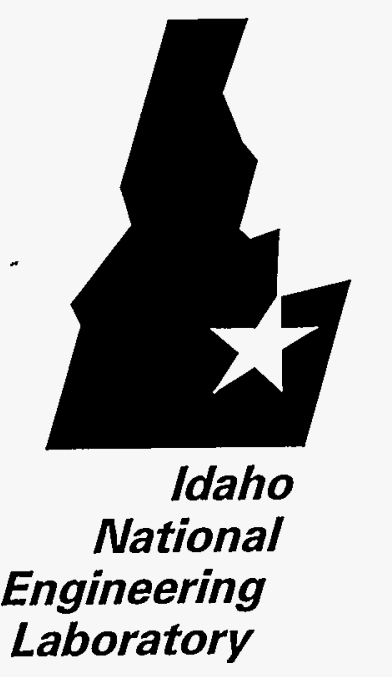

Engineering

Laboratory
INEL-96/0430

March 1997

\title{
Portable Treatment Systems Study
}

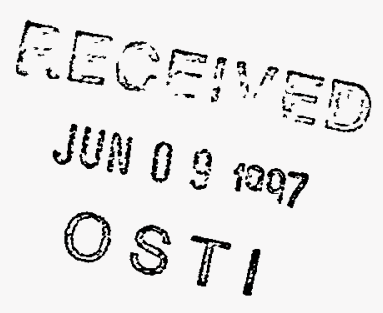

M. J. Sherick

W. E. Schwinkendorf

T. E. Bechtold

L. T. Cole

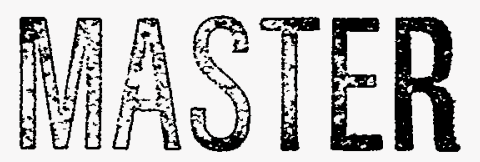

LOCKHEED MARTIN 


\section{Portable Treatment Systems Study}

M. J. Sherick

W. E. Schwinkendorf

T. E. Bechtold

L. T. Cole

March 1997

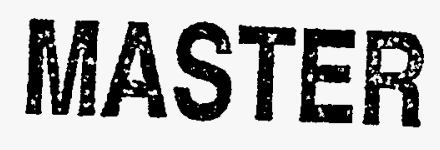

Idaho National Engineering Laboratory

Lockheed Martin Idaho Technologies Company

Idaho Falls, ID 83415

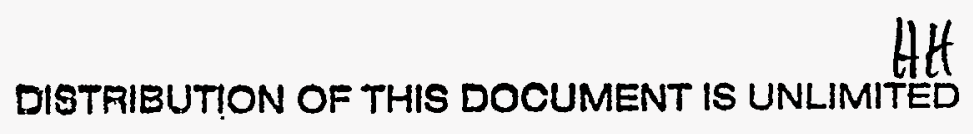

Prepared for the

U.S. Department of Energy

Idaho Operations Office

Under DOE Idaho Field Office

Contract No. DE-AC07-94ID13223 


$$
\begin{array}{llll}
\because & \ddots & \vdots \\
\therefore & \vdots & \vdots
\end{array}
$$

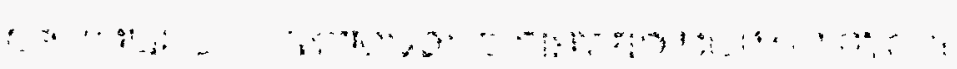




\begin{abstract}
In developing their Site Treatment Plans (STPs), many of the Department of Energy installations identified some form of portable treatment, to facilitate compliant disposition of select mixed low-level wastestreams. The Environmental Management Office of Science and Technology requested that a systems study be performed to better define the potential role of portable treatment with respect to mixed low-level waste, highlight obstacles to implementation, and identify opportunities for future research and development emphasis. The study was performed by first establishing a representative set of mixed waste, then formulating portable treatment system concepts to meet the required processing needs for these wastes. The portable systems that were conceptualized were evaluated and compared to a fixed centralized treatment alternative. The system evaluations include a life-cycle cost analysis and an assessment of regulatory, institutional, and technical issues associated with the potential use of portable systems. The results of this study show that when all costs are included, there are no significant cost differences between portable systems and fixed systems. However, it is also emphasized that many uncertainties exist that could impact the cost of implementing portable treatment systems. Portable treatment could be made more attractive through private sector implementation, although there is little economic incentive for a commercial vendor to develop small, specialized treatment capabilities with limited applicability. Alternatively, there may also be valid reasons why fixed units cannot be used for some problematic wastestreams. In any event, there are some site-specific problems that still need to be addressed, and there may be some opportunity for research and development to make a positive impact in these areas.
\end{abstract}




\section{EXECUTIVE SUMMARY}

The Department of Energy (DOE) Environmental Management Office of Science and Technology (EM-50) established this Portable Treatment system (PTS) Study task to evaluate the feasibility of using a portable treatment system comprised of several mobile treatment units (MTUs) rather than a fixed central treatment facility. Both the PTS and the central treatment facility are designed to treat the same contact-handled (non-alpha) mixed low-level waste (MLLW) streams. This study was performed in three phases:

- $\quad$ Phase I-Waste Stream Analysis: The current mixed waste inventory was analyzed to identify MLLW streams that could be targeted for portable treatment. The analysis focused on the MLLW designated by the Site Treatment Plans for treatment by planned or existing portable treatment units. These MLLW streams were compiled into physical matrix sets for existing and projected 5-year inventories that was then used to establish the PTS needed to meet the treatment requirements. Soils/gravel are not included in the study since it is assumed that sites will develop on-site treatment capabilities for these wastes. The recommendations from this phase of the study were to provide the following treatment modules:

- Treatment of organic liquids and sludges by thermal desorption, organic destruction, and macroencapsulation. The organics MTU will treat aqueous and pure organic liquids, and organic and inorganic homogeneous solids.

- Debris segregation, size reduction, and stabilization. This MTU will treat all debris including organic and inorganic debris with and without organic contamination.

- Wastewater treatment with organic destruction and stabilization capabilities. This MTU will treat aqueous liquids and slurries including wastes generated by the other modules.

- Labpack sorting and pretreatment of all labpack contents.

- Phase II-Formulation of PTS Concepts and Requirements: Functional and operational requirements (F\&ORs) and design concepts were developed for the PTS to serve as the basis for evaluation and comparison. The unit operations and requirements were developed for four MTUs, and process flows were developed. Material balances were developed to determine the throughput requirements of each MTU including the incoming waste and secondary waste transfers between MTUs. The concept is to treat the existing and 5-year projected inventory over 5 years operating $800 \mathrm{hrs} / \mathrm{yr}$. The four MTUs are as follows: 
- Organics MTU: The organics treatment MTU is designed to treat $730 \mathrm{~m}^{3} / \mathrm{yr}(665 \mathrm{~kg} / \mathrm{hr})$ of incoming waste plus $223 \mathrm{~m}^{3} / \mathrm{yr}(204 \mathrm{~kg} / \mathrm{hr})$ of sludges and solids from the labpack and wastewater treatment MTUs and $4 \mathrm{~m}^{3} / \mathrm{yr}(5 \mathrm{~kg} / \mathrm{hr}$ ) of organic liquids from the labpack MTU. This MTU includes delumping, crushing and thermal desorption of incoming sludges, condensing of the vapor and thermal oxidation of incoming and condensed organic liquids, and treatment of the offgas from these operations. Condensed aqueous waste is sent to the wastewater treatment MTU, and treated solids are stabilized in polymer.

- Wastewater Treatment MTU: This MTU treats $400 \mathrm{~m}^{3} / \mathrm{year}(545 \mathrm{~kg} / \mathrm{hr})$ of incoming waste plus $655 \mathrm{~m}^{3} / \mathrm{yr}(821 \mathrm{~kg} / \mathrm{hr})$ of aqueous/organic liquids from the organics treatment MTU and $9 \mathrm{~m}^{3} / \mathrm{yr}(11 \mathrm{~kg} / \mathrm{hr})$ from the labpack MTU. The wastewater is treated in a redox tank, is neutralized and filtered, and then is treated in a hydrothermal (supercritical water oxidation) process. The output from the hydrothermal process is treated in a reverse osmosis unit; the clean water is recycled or discharged and the brine is evaporated to further concentrate the solids. Solids from this MTU are sent to the organic treatment MTU and the offgas passes through HEPA filters before being discharged.

- Labpacks MTU: This unit treats $80 \mathrm{~m}^{3} / \mathrm{yr}(79 \mathrm{~kg} / \mathrm{hr})$ of incoming waste. The labpacks are opened and sorted. Large solids are sent to the debris MTU, liquids are dumped into a holding tank and subsequently filtered with the filtrate and solids sent to the organic MTU. Inorganics are chemically deactivated, as required, and the resulting solution filtered with the filtrate sent to the wastewater MTU and solids to the organics MTU.

- Debris MTU: This unit treats $240 \mathrm{~m}^{3} / \mathrm{yr}(114 \mathrm{~kg} / \mathrm{hr})$ of incoming waste, and $80 \mathrm{~m}^{3} / \mathrm{yr}(33 \mathrm{~kg} / \mathrm{hr}$ ) of packaging material from the labpack MTU. Debris is manually sorted, size reduced by shearing and crushing, and encapsulated in cement grout.

- Phase III-System Evaluation: Life cycle costs for the proposed PTS and for a fixed centralized facility with a comparable waste throughput capacity were developed for a 5 year life. Technical, regulatory, and institutional issues were also evaluated. The life-cycle costs included studies and bench-scale tests; demonstration; construction costs including equipment; pre-operations costs such as permitting, safety assurance, conceptual design, etc.; operating and maintenance; and decontamination and decommissioning. In addition to one control trailer, the four MTUs required the following number of trailers and lifecycle costs (LCCs):

- $\quad$ Organics MTU: Four trailers required with a LCC of $\$ 47,546,700$. 
- Wastewater Treatment MTU: Four trailers required with a LCC of $\$ 52,449,400$.

- LabpackMTU: Two trailers required with a LCC of $\$ 29,985,700$.

- Debris MTU: Two trailers required with a LCC of $\$ 30,707,300$.

The total PTS cost of four MTUs plus the control trailer is $\$ 161,222,900$ and the centralized facility cost is $\$ 179,091,800$. However, the life-cycle costs for the PTS did not include site support and utility hookups, security and fire protection, waste characterization, certification and shipping of stabilized and packaged wastes, and overall administration which were assumed to be provided by the site. These functions were included in the cost of the fixed centralized treatment facility. If the costs associated with these functions born by the sites are added to the PTS costs, the PTS cost would rise to approximately $\$ 217,624,033$ (about a 35\% increase).

Thus, no significant cost advantage or disadvantage will be realized by the use of a PTS rather than a centralized treatment facility. The life-cycle costs, excluding site support costs, for the design waste throughput $(2919 \mathrm{lbs} / \mathrm{hr}$ ) are within $10 \%$ of each other. However, if site costs to support the PTS are included, the PTS costs about $20 \%$ more than the centralized facility making the economic viability of a PTS questionable. Although there are no economic incentives for a PTS, other non-economic issues may make portable systems attractive including niche applications for small and difficult to treat waste streams or waste streams that are difficult to transport (e.g., reactive metals, gas cylinders, liquids, etc.), equity issues, stakeholder opposition to a centralized facility in their neighborhood, etc.

The PTS has less on-line availability than a centralized facility due to the required teardown, decontamination, transportation, and set-up operations. It has been assumed that these operations require two weeks to complete, and that the portable system will perform a total of 60 campaigns over 5 years with an average of 12 campaigns per year. This translates to an average of 2 weeks of operation and 2 weeks of downtime for each campaign for a $50 \%$ availability at best. On a site-by-site basis, the availability will depend on the amount of waste to be treated at a particular site, the operating time required for treatment, and the frequency of transport between sites.

Considerable time and expense may also be incurred if the PTS must be brought to a steady state before it can be operated. Maintenance costs may be higher than for a fixed unit because of the constant cycling of equipment as it is operated and shut-down for transport to another site. Thus, a centralized facility with an equivalent feed rate potential of a PTS can process more waste than a PTS due to less downtime.

The conclusions that can be derived from this study are as follows:

1. No significant cost advantage or disadvantage will be realized by the use of a PTS rather than a centralized treatment facility. 
2. Although there are no economic incentives for a PTS, other non-economic issues may make portable systems attractive.

3. No significant technical obstacles were identified to designing and implementing equipment to treat the identified waste streams in either the PTS or centralized facility.

4. More risk/uncertainty is attributed to the implementation of a PTS than to a centralized facility because permitting/NEPA documentation must be developed for multiple sites. A major permitting issue may be the incinerator associated with the organic MTU; however, stakeholders may accept this if they know it will be removed after treating the local waste.

5. The uncertainty associated with the use of a PTS could be reduced by procuring the required services from a commercial vendor, thereby eliminating some of the administrative obstacles associated with DOE facilities. 


\section{CONTENTS}

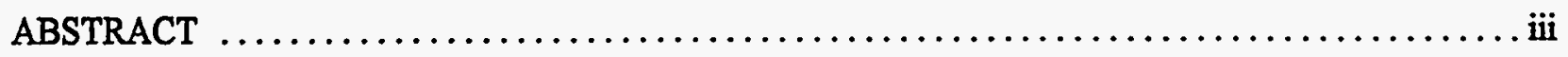

EXECUTIVE SUMMARY $\ldots \ldots \ldots \ldots \ldots \ldots \ldots \ldots \ldots \ldots \ldots \ldots \ldots \ldots \ldots \ldots, \mathbf{v}$

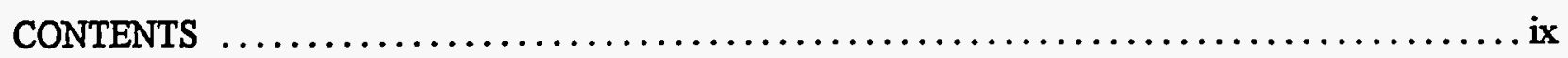

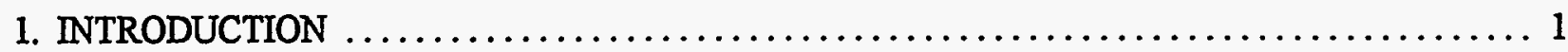

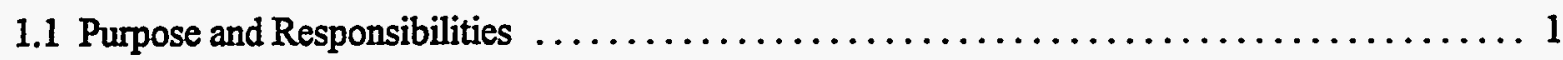

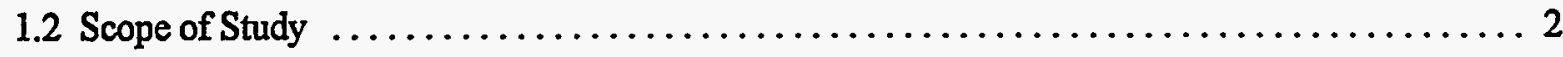

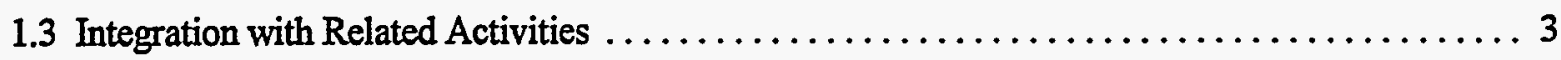

2. PHASE I - WASTESTREAM ANALYSIS $\ldots \ldots \ldots \ldots \ldots \ldots \ldots \ldots \ldots \ldots \ldots \ldots \ldots \ldots \ldots$

3. PHASE II - FORMULATING PTS CONCEPTS AND REQUIREMENTS $\ldots \ldots \ldots \ldots \ldots \ldots \ldots 7$

3.1 PTS Design Concepts . . . . . . . . . . . . . . . . . . . . . . . . . . . . . . . 7

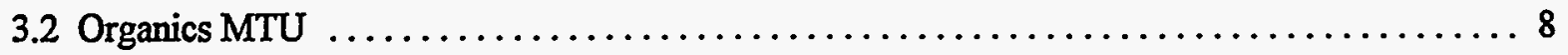

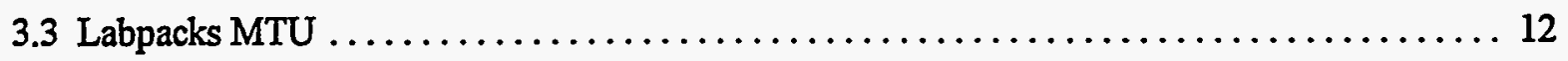

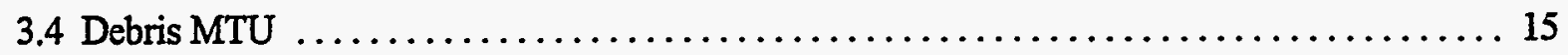

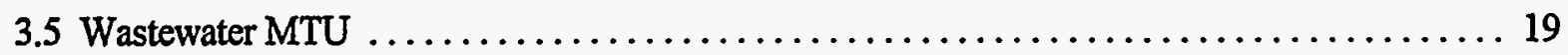

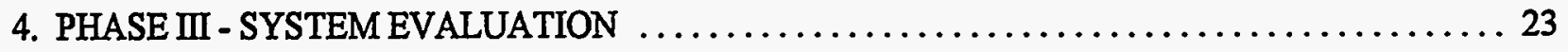

4.1 Total Life-Cycle Cost Estimates ................................. 23

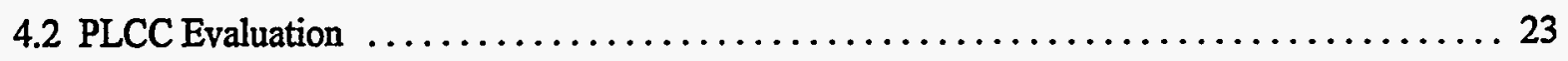

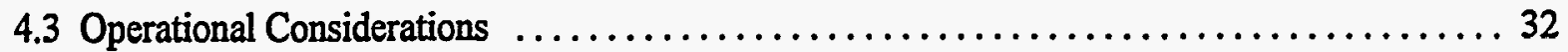

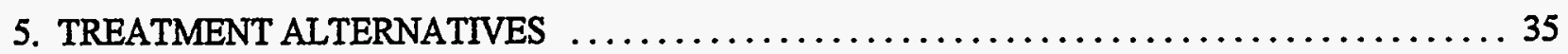

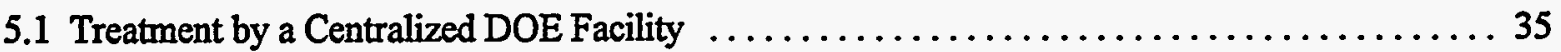

5.2 Use of Existing Commercial Treatment Facilities ......................... 36

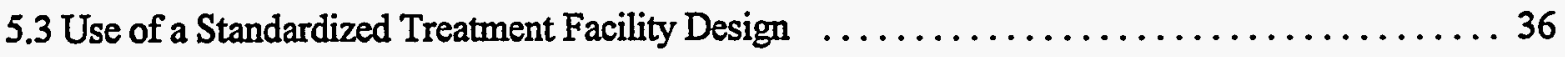




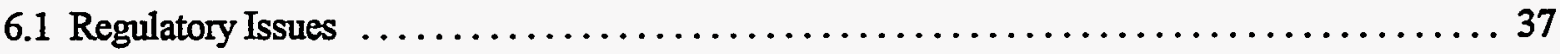

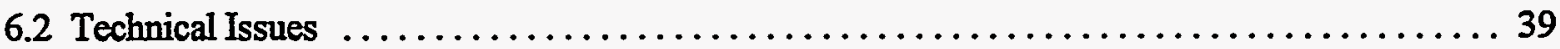

6.3 Institutional Issues $\ldots \ldots \ldots \ldots \ldots \ldots \ldots \ldots \ldots \ldots \ldots \ldots \ldots \ldots \ldots \ldots \ldots \ldots \ldots \ldots \ldots \ldots \ldots \ldots \ldots$

7. TECHNOLOGY DEVELOPMENT OPPORTUNITIES $\ldots \ldots \ldots \ldots \ldots \ldots \ldots \ldots \ldots \ldots \ldots$

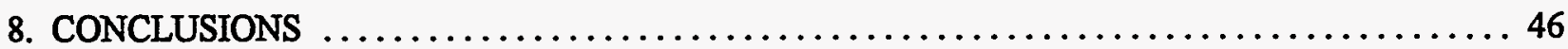

9. RECOMMENDATIONS $\ldots \ldots \ldots \ldots \ldots \ldots \ldots \ldots \ldots \ldots \ldots \ldots \ldots \ldots \ldots \ldots \ldots \ldots \ldots \ldots$

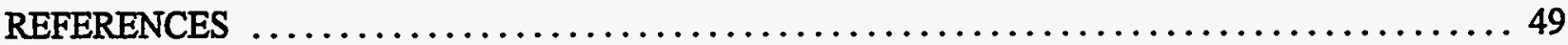

Appendix A-Wastestream Analysis Report

Appendix B-Design Concepts and Requirements Report

Appendix C - Design Summary and Total Life-Cycle Cost Report

Appendix D-Technical Issues Assessment

\section{TABLES}

1. Portable treatment facilities referenced as preferred options in the proposed site treatment plans ... 4

2. Mobile treatment units and primary waste compositions $\ldots \ldots \ldots \ldots \ldots \ldots \ldots \ldots \ldots \ldots$

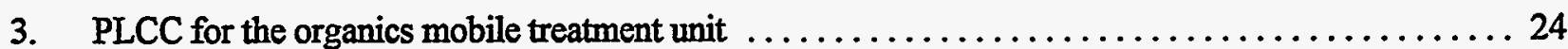

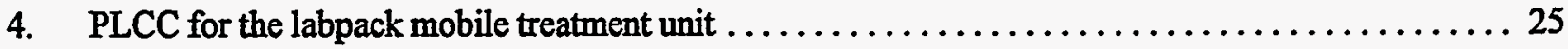

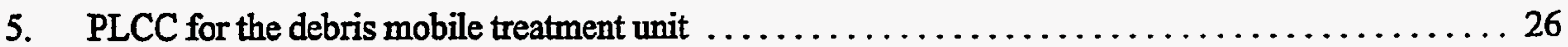

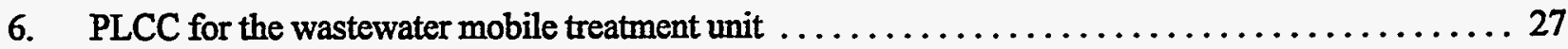

7. PLCC for the centralized treatment facility $\ldots \ldots \ldots \ldots \ldots \ldots \ldots \ldots \ldots \ldots \ldots \ldots \ldots \ldots$

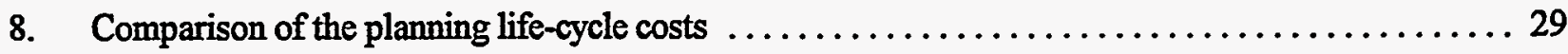

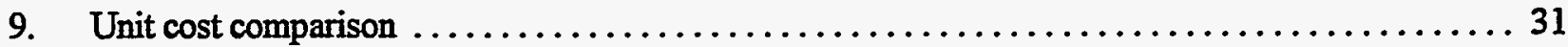

10. Primary proposed technologies for the conceptualized MTUs $\ldots \ldots \ldots \ldots \ldots \ldots \ldots \ldots \ldots . \ldots 4$ 


\section{FIGURES}

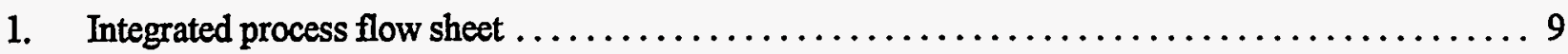

2. Block flow diagram for the organics MTU $\ldots \ldots \ldots \ldots \ldots \ldots \ldots \ldots \ldots \ldots \ldots \ldots \ldots$

3. Block flow diagram for the labpacks and debris $M T U \ldots \ldots \ldots \ldots \ldots \ldots \ldots \ldots \ldots$

4. Block flow diagram for the wastewater MTU $\ldots \ldots \ldots \ldots \ldots \ldots \ldots \ldots \ldots \ldots \ldots \ldots \ldots \ldots$

5. Comparison of mobile systems with a fixed facility $\ldots \ldots \ldots \ldots \ldots \ldots \ldots \ldots \ldots \ldots \ldots \ldots$ 


\section{DISCLAMMER}

Portions of this document may be illegible in electronic image products. Images are produced from the best available original document. 


\section{Portable Treatment Systems Study (Draft)}

\section{INTRODUCTION}

\subsection{Purpose and Responsibilities}

The Department of Energy (DOE) Environmental Management Office of Science and Technology (EM50) has established this Portable Treatment System Study (PTSS) task to examine the feasibility of utilizing a portable treatment system (PTS) comprised of several mobile treatment units, rather than permanently located (fixed) central processing facilities to perform required treatment of mixed-low-level waste (MLLW). Specific objectives of the study are to give recommendations on the following:

- Is use of a PTS economically and technically justified?

- What wastes or combinations of wastes should be treated with a PTS?

- What existing or new technologies are applicable to a PTS for treating mixed wastes?

- What are the institutional and political barriers and/or technical/operational challenges to using a PTS?

- Where should future research and development efforts be focused in order to facilitate implementation of needed PTS capabilities?

This report is used as a source of information to be used by national planners and policy makers including DOE-Headquarters. The report will identify research and development (R\&D) roles that EM-50 should consider to support treatment of select problematic or small quantity mixed wastestreams.

EM-50 assigned Lockheed Martin Idaho Technologies Company (LMITCO) the task of preparing a written report providing the above recommendations and the basis for those recommendations. Multiple contractors were utilized in preparation of information used in this report in an effort to utilize specific expertise found in the private sector. Three distinct phases of information development were performed as the primary basis for this report.

- $\quad$ Phase I Wastestream Analysis - Analysis of the current mixed waste inventory to identify mixed low-level waste (MLLW) streams which should be targeted for portable treatment.

- $\quad$ Phase II Formulating PTS Concepts and Requirements - Formulation of functional and operational requirements (F\&ORs) and design concepts for the PTS to serve as the basis for evaluation and comparison to alternatives..

- Phase III System Evaluation - Evaluation of life cycle costs for the proposed PTS and for a fixed centralized facility with comparable waste throughput capacity. Also evaluated were 
technical, regulatory, and institutional issues, including the development stages of proposed treatment technologies and operational uncertainties/problems that need to be resolved by research and development or by other means.

The final reports of the three contractors who developed this information are included as appendices to this document, and each of the three phases of the PTSS are discussed in more detail in later sections of this document.

\subsection{Scope of Study}

This PTSS focused on the treatment of contact-handled ( $<200 \mathrm{mrem} / \mathrm{hr}$ at contact) MLLW found within the DOE complex. Due to resource and schedule constraints, the study did not address transuranic or alpha-contaminated wastes.

Treatment requirements for MLLW waste are imposed by the Resource Conservation and Recovery Act (RCRA) as specified in 40 CFR 268. Other treatment considerations include waste form requirements imposed by prospective disposal site waste acceptance criteria which may include requirements beyond those imposed by RCRA. Examples are requirements for disposal package integrity and/or weight bearing characteristics to minimize subsidence in the disposal horizon.

\subsection{Integration with Related Activities}

In response to the Federal Facilities Compliance Act, the DOE sites have examined various mixed waste treatment alternatives as part of the development of their STPs. The PTSS was not intended to replace or duplicate any of these efforts, but to build upon work that was already performed, and identify where any future emphasis from EM-50 is needed. Many of the sites identified portable equipment as the preferred treatment option for select wastestreams. The PTSS builds on previous work that was done by using the identified wastestreams as the basis for the systems that are conceptualized and evaluated. The PTSS also references several related efforts that have been performed, most notably work done on mobile treatment systems at the Department of Energy, Albuquerque Field Office (DOE-AL). 


\section{PHASE I - WASTESTREAM ANALYSIS}

The wastestream analysis (found in Appendix A) was performed in order to establish a representative set of mixed waste that could be used as the basis for PTSS design. The analysis started with approximately $10,000 \mathrm{~m}^{3}$ of waste, designated by STPs for treatment by planned (and existing in a few cases) portable treatment units shown in Table 1 . These DOE mixed wastestreams were compiled into physical matrix sets with identification of both existing and projected near-term (5-year) inventories of mixed wastes. This data set was then used to establish the PTS needed to meet the identified treatment requirements.

The waste stream analysis task concludes by recommending that the treatment trains be used to treat the mixed waste described in Table 2. This table lists waste descriptions, matrix parameter codes (MPC) ${ }^{1}$, and anticipated annual volumes for treatment by a PTS. The study makes the following recommendations concerning breakdown of treatment trains for these wastestreams:

1. Integrate treatment of organic liquids, soils, and sludges (organic and inorganic) for thermal desorption, organic destruction, and stabilization of residues. It is suggested that these treatments provide thermal desorption, organic destruction, macroencapsulation, and onsite stabilization capabilities.

2. Develop a module to perform debris segregation, size reduction, and stabilization.

3. Develop a general water treatment module with organic destruction and stabilization capabilities. The unit will include capabilities to handle and treat labpacks contents, scintillation vials and neutralize acids, bases, water reactives, and strong oxidizers.

4. Develop a module for labpack sorting and pretreatment of labpack contents. 
:Table 1. Portable treatment facilities referenced as preferred options in the proposed site treatment plans.

\begin{tabular}{|c|c|c|c|c|}
\hline SITE & $\begin{array}{l}\text { PORTABLE TREATMENT SYSTEMS } \\
\end{array}$ & OWNER & STATUS & TOTAL VOLUME (M3) \\
\hline $\mathrm{DP}$ & Transportable Vitrification System (TVS) & DOE & $\mathbf{N}$ & $1,015.1$ \\
\hline FM & Ohio Option-Mobile Chem. Tmt Project & Vendor & $\mathbf{N}$ & 716.2 \\
\hline FM & Thorium Nitrate Tank T-2 & Vendor & $E$ & 22.0 \\
\hline GJ & Mobile Thermal Desorption Process & DOE & $\mathbf{N}$ & 111.3 \\
\hline GJ & Mobile Evaporative Oxidation Process & DOE & $\mathbf{N}$ & 185.1 \\
\hline GJ & Mobile Sort/Survey/Char./Decon. & DOE & $E$ & 253.3 \\
\hline IN & Portable Water Treatment Unit (PWTU) & DOE & $E$ & 655.1 \\
\hline LA & Mobile Lead Decontamination Trailer LANL & DOE & $\bar{E}$ & 74.4 \\
\hline LA & Mobile Reactive Metals Skid & DOE & $N$ & 7.0 \\
\hline LA & Mobile Plating Wastes Acids/Bases Skid & DOE & $\bar{N}$ & $\overline{7.1}$ \\
\hline LA & Mobile Gas Scrubbing Skid & DOE & $\mathbf{N}$ & 0.6 \\
\hline LA & Mobile Hydrothermal Processing & DOE & $\bar{N}$ & 60.3 \\
\hline$F M$ & Ohio Option - Stabilization Project & Vendior & $\bar{N}$ & 249.1 \\
\hline $\mathrm{PI}$ & Mobile Amalgamation Process (Bench Scale) & DOE & $\mathbf{N}$ & 1.6 \\
\hline PO & Pretreatment/Regeneration & Vendor & $N$ & 240.5 \\
\hline PO & Repackage & Vendor & $\mathbf{N}$ & 0.2 \\
\hline PO & Deactivate Reactive Metals & Vendor & $\bar{N}$ & 0.6 \\
\hline PO & Decontaminating Containers & Vendor & $\mathbf{N}$ & 7.7 \\
\hline PO & Lab Packs Treatment & Vendor & $N$ & 30.9 \\
\hline $\mathrm{PO}$ & Metal Recovery & Vendor & $N$ & 62.3 \\
\hline PO & Physical Chemical Treatment & Vendor & $\mathrm{N}$ & 78.0 \\
\hline PO & On-Site Stabilization & Vendor & $N$ & $5,484.9$ \\
\hline$P X$ & Mobile Macroencapsulation & DOE & $\mathbf{N}$ & 782.9 \\
\hline $\mathbf{S A}$ & Mobile Treatability Study: Solidification/Neutralizatio & DOE & $\mathbf{N}$ & 1.0 \\
\hline \multirow[t]{2}{*}{ SA } & Mobile Packed Bed Reactor/Silent Discharge Plasma Treat & DOE & $\mathbf{N}$ & 26.5 \\
\hline & & & & $10,073.4$ \\
\hline
\end{tabular}

DP Oak Ridge $R-25$

FM Fernald

GJ Grand Junction

IN Idaho

IA Los Alamos

PI - Pinellas

PO Portsmouth

PX Pantex

SA Sandia.

Status

N Planned

E Existing 
Table 2. Mobile treatment units and primary waste compositions.

\begin{tabular}{||l|l|c|c||}
\hline Mobile Treatment Unit & \multicolumn{1}{|c|}{ Waste Description } & MPC & $\begin{array}{c}\text { Vol. Rate } \\
\left.\text { ( } \mathbf{m}^{3} / \mathbf{y r}\right)\end{array}$ \\
\hline \hline Organics & Aqueous Organic Liquid & 2100 & 80 \\
& Pure Organic Liquid & 2200 & 40 \\
& Inorganic Homogeneous Solids & 3100 & 70 \\
& Inorganic Homogeneous Solids & 3100 & 500 \\
& Organic Homogeneous Solids & 3200 & 40 \\
\hline Labpacks & Organic & 6100 & 5 \\
& Aqueous & 6200 & 10 \\
& Solid & 6300 & 5 \\
& Scintillation Cocktail & 6400 & 15 \\
& Undefined & 6000,6900 & 45 \\
\hline \multirow{5}{*}{ Debris } & Inorganic (Org. Contam.) & 5100 & 10 \\
& Organic (Org. Contam.) & 5300 & 45 \\
& Heterogeneous (Org. Contam.) & 5400 & 65 \\
& Inorganic & 5100 & 10 \\
& Organic & 5300 & 45 \\
& Heterogeneous & 5400 & 65 \\
\hline Wastewater & Aqueous Liquids & 1100 & 200 \\
& Aqueous Slurries & 1200 & 200 \\
\hline
\end{tabular}




\section{PHASE II - FORMULATING PTS CONCEPTS AND REQUIREMENTS}

\subsection{PTS Design Concepts}

The Phase II pre-conceptual design effort was performed to define the operating concepts, fundamental process flows, and functional and operational requirements (F\&ORs) for the PTS. Details of the design are found in the reports found in Appendices B and C.

The design for the PTS centers around the concept of having processing units mounted on trailers. Multi-trailer configurations will be necessary to provide all the processing units required for treatment. Each Mobile Treatment Unit (MTU) consists of one or more trailer-mounted process systems to treat specific waste matrix sets. Processing trains are sized to accommodate equipment having the largest reasonable throughput rate possible, given the size constraint of the semi-trailers. These processing units will be monitored and controlled by the use of a stand-alone control trailer, functioning as a control center. Trailers will be connected using flexible piping between trailers and quick disconnects for instrument and electrical connections.

It is expected that any host site requiring a MTU will provide a location within the site for MTU set up. This location will typically be a curbed concrete pad and, as a minimum, sheltered by a roof structure. Additional weather proofing may be necessary for more severe climates. The location must also supply utility services (e.g., potable water, service water, and electrical power). The host site will provide security, fire protection support, and certification and shipping support of treated and stabilized or repacked waste.

The PTS will arrive at the host site with a dedicated crew capable of transporting, maintaining and setting up the PTS equipment, preparing the received waste for treatment, treating the waste, stabilizing the residues, and packaging the stabilized residues for certification and shipment to a storage or disposal site. It is assumed that the certification and shipping function will be done by the host site.

Upon completion of the waste treatment, the crew will decontaminate the PTS to meet Department of Transportation (DOT) shipping requirements and demobilize from the site. The wastewater MTU will be used to process flush solutions used in the decontamination efforts. Final flush water will be transported to a commercial facility for treatment and disposal.

The Phase II formulation and design efforts utilized the recommendations from the wastestream analysis to establish four distinct treatment trains to treat five waste matrix sets. These portable treatment trains are:

- Organics MTU

- Labpacks MTU

- Debris MTU

- Wastewater MTU. 
Table 2 relates the waste descriptions and associated MPCs to the four proposed MTUs. The integrated process flowsheet, presented in Figure 1, shows how these four MTUs interact to meet the treatment needs of all primary and secondary (effluent) streams. Short dashed lines designate intraprocess transfer streams between MTUs. A dashed line around each MTU defines its boundaries. Thus, the MTUs should be considered as a treatment system, not as "stand alone" units, since it may be necessary to use two or more of the MTUs to complete treatment requirements for a given wastestream. For example, the wastewater MTU may produce a solids effluent stream that must be treated by the organics MTU.

Treatment technologies chosen for use in the PTS are best demonstrated available technology (BDAT), and in some cases correspond to technologies selected by the DOE- AL to be used in their mobile treatment program $^{2}$. This was done intentionally to enable as much use as possible of design and cost information that has already been developed. The report found in Appendix B identifies assumptions, system boundaries, flow diagrams with preliminary material balances, unit capacities, and on-stream factors for each of the portable units. Appendix B also includes preliminary design criteria that includes functional, performance, and interface requirements.

It can be noted from Table 2 that the organics MTU accepts inorganic homogeneous solids for treatment. The rationale for sending these solids through the treatment unit is that even though these solids are free of organics, they still require drying prior to polymer microencapsulation. A separate drying operation is eliminated by sending the inorganic sludges through the thermal desorption process of the organics MTU.

The four MTUs are briefly described in the sections which follow. Other detailed system descriptions and design criteria may be found in Appendix B..

\subsection{Organics MTU}

The objectives of the organics MTU are (a) to accept and effectively process organic liquids, organic sludges, and inorganic sludges that are MLLW, and (b) to process the wastestreams on portable semi-trailers that can be moved from site to site. The primary function of the organics MTU is to destroy the organic fraction of the wastestreams by conversion to carbon dioxide, water, and hydrochloric acid, while retaining the inorganic fraction including RCRA metals and nonvolatile radionuclides in a stable final waste form for storage or disposal. The organics MTU will accept external transfer streams from the wastewater MTU and the labpacks MTU.

The organics MTU consists of two primary processing trains (a) thermal oxidation and (b) thermal desorption followed by polymer microencapsulation. The processing operations which take place in the MTU are briefly described below:

- Organic liquid streams are filtered to remove suspended solids. The wet solids from the filter are transferred to the thermal desorption portion of the MTU.

- Sludges (organic and inorganic) are also fed to the thermal desorption portion of the MTU, where they are indirectly heated to vaporize all volatile organic compounds (VOCs) and 


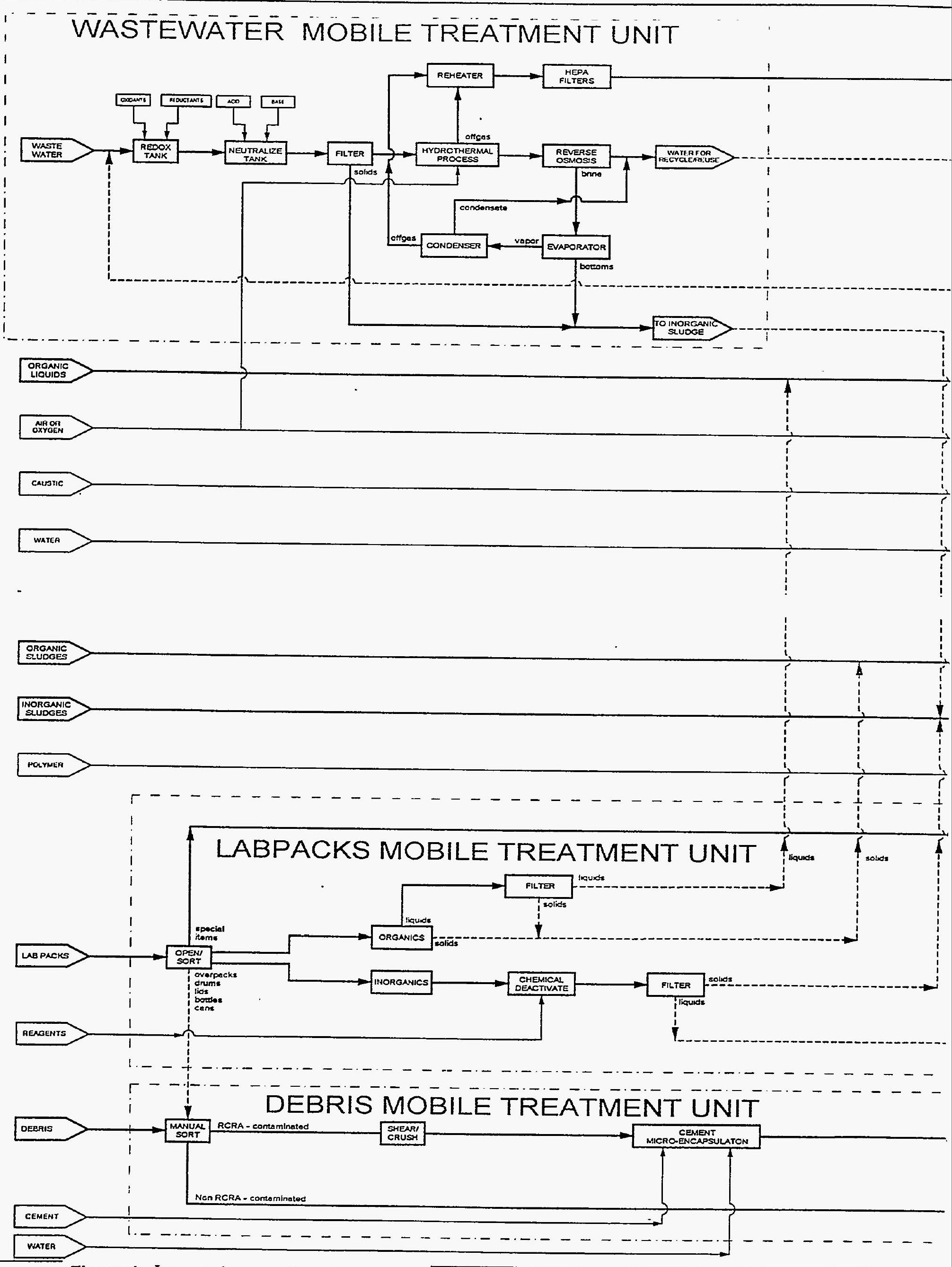

Figure 1. Integrated process flow sheet 


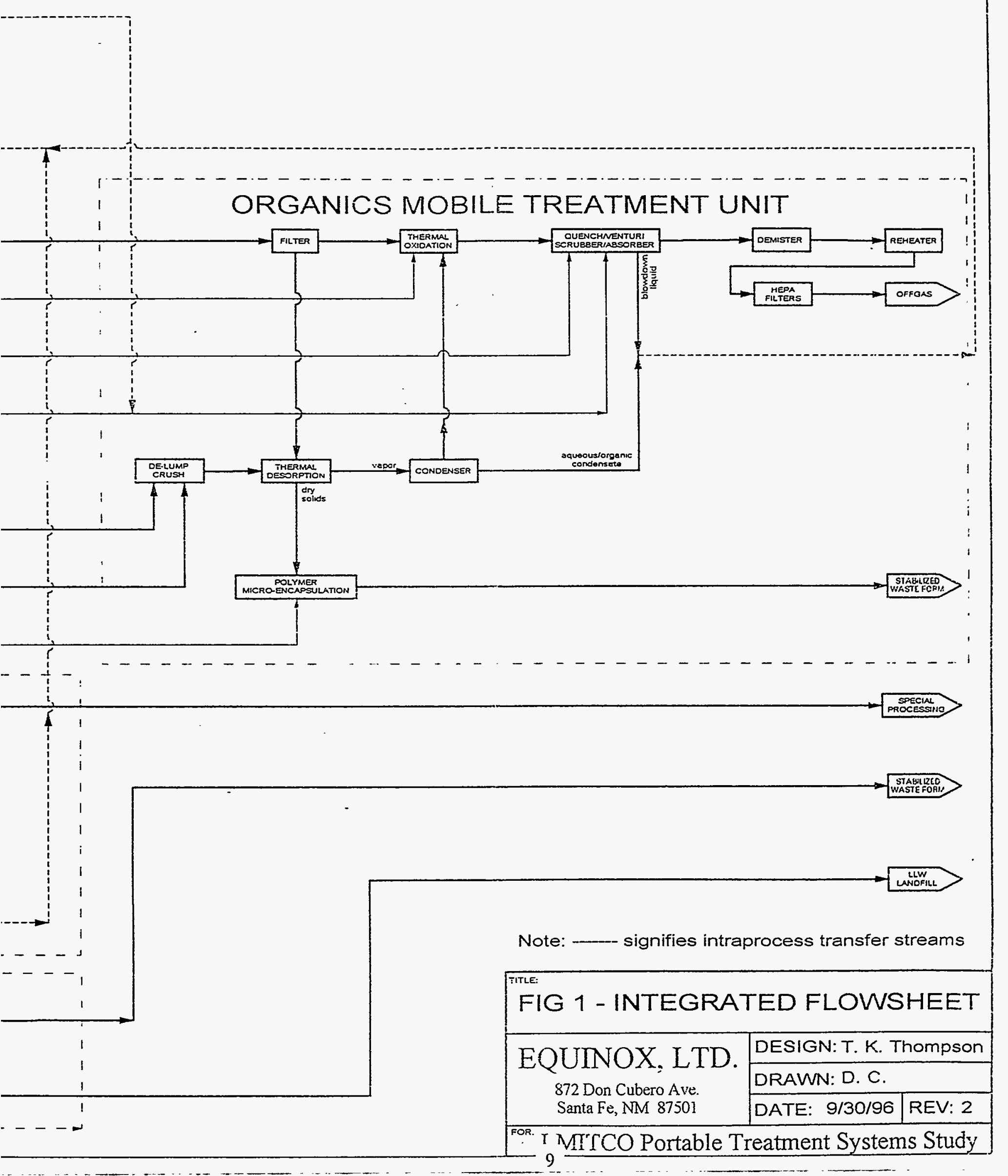


moisture. The vapor from thermal desorption is cooled in a condenser and the aqueous/organic condensate is transferred to the wastewater MTU for processing.

- Dry solids from thermal desorption are fed to the polymer microencapsulation portion of the MTU, where a polymer is blended with the feed materials to produce a stabilized final waste form.

- Clarified organic liquid is treated by thermal oxidation (e.g., liquid fume incinerator) in an open reactor chamber using air at a temperature of approximately $1100^{\circ} \mathrm{C}$. Offgas from the oxidizer is cooled to saturation in a quencher. Particulates are removed in a quench/venturi scrubber and acid gases (e.g., $\mathrm{HCl}$ and $\mathrm{SO}_{2}$ ) are removed by absorption in a packed tower absorber. The scrubbed saturated gases are heated above the dew point in a reheater before passing through the high-efficiency particulate air (HEPA) filters which exhaust to the atmosphere.

Figure 2 shows a flow diagram with processing steps.

\subsection{Labpacks MTU}

The objective of the labpacks MTU is to accept and effectively process MLLW radioactive organic, aqueous, solid, and scintillation vial wastes that are packaged in labpacks. The MTU meets this objective by providing equipment to safely open labpacks to allow separation and sorting of the chemical containers within the labpack. This MTU sends all of its processed wastestreams to other MTUs for final conversion to acceptable final waste forms. The labpacks MTU does not routinely accept transfer streams from other MTUs. However, it could receive wastes from other MTUs that meet its waste acceptance criteria on a caseby-case basis.

The labpack MTUs consist of a single processing train. The processing operations that take place are briefly described below:

- Each labpack is opened and the containers within the labpack are manually separated into organic and inorganic fractions. The organic fraction is further separated into liquid and solid fractions.

- All containers of organic liquids, including scintillation fluids, are drained into a holding tank and filtered for solids. The filtered organic solids and the containers of organic solids are sent to the organics MTU for processing.

- The packing material (vermiculite) is sent to the inorganic sludge processing station within the organics portable treatment unit.

- Both liquid and solid inorganic wastes are neutralized and/or deactivated as necessary for the specific material. Deactivation typically involves the mixing and subsequent reaction of the material with an appropriate reagent in a mix tank. The reaction product liquid is filtered to remove suspended solids, and they are sent the organics MTU for processing. 


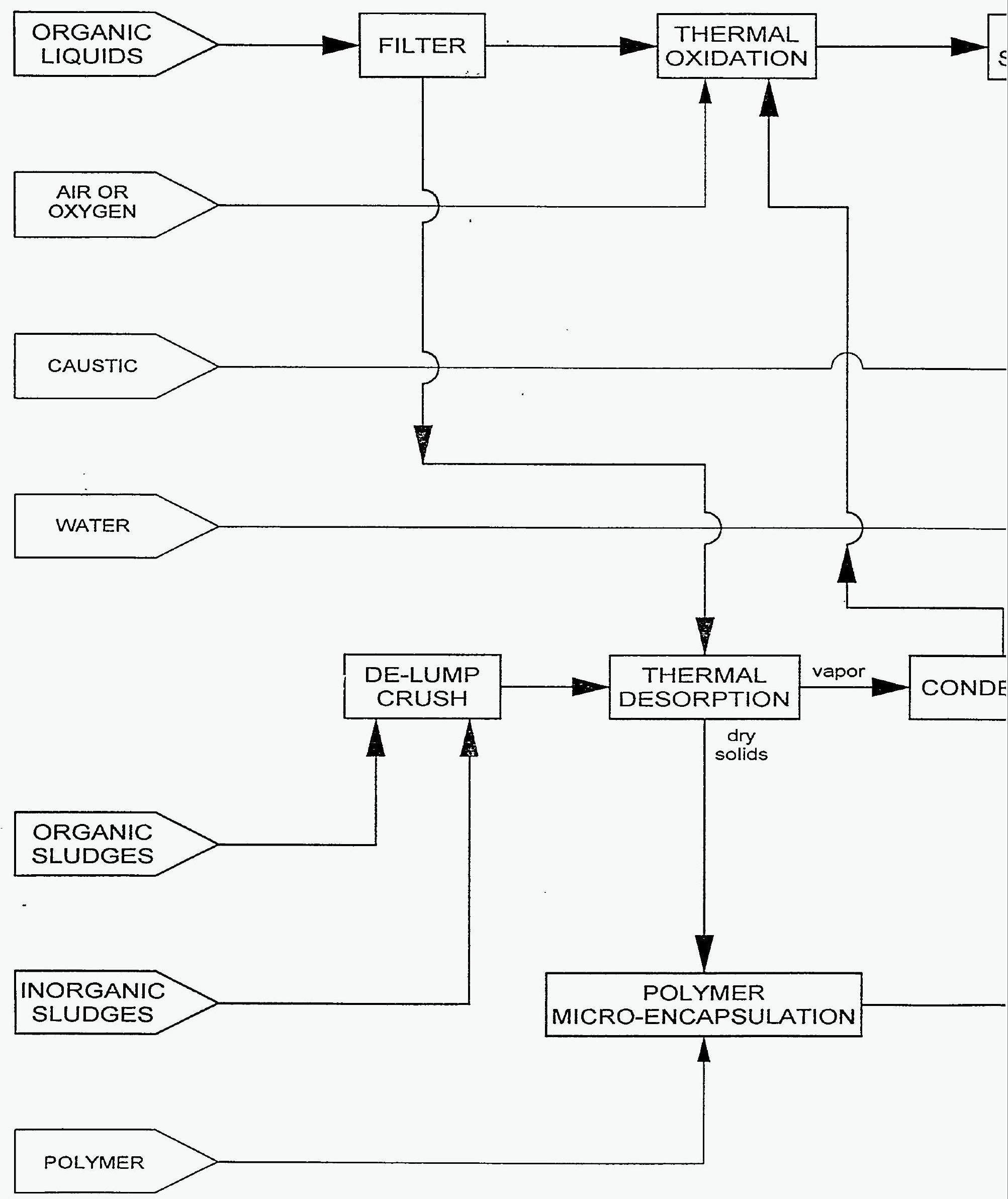

Figure 2. Block flow diagram for the organics MTU. 
- Items within labpacks that do not meet waste acceptance criteria are rejected, repackaged, and sent to unspecified special processing elsewhere.

- The labpack operations are performed within a ventilated enclosure for vapor containment. Ventilation air is directed to the unit ventilation system that provides activated carbon and HEPA filtration.

A flow diagram which shows these processing steps is provided in Figure 3.

\subsection{Debris MTU}

The function of the debris MTU is to microencapsulate debris in a Portland Cement-based (grout) media is to stabilize the RCRA hazardous constituents and radionuclides. As shown in Table 2, the unit accepts both inorganic and organic debris, some of which may be contaminated with regulated organics. The debris MTU accepts an external transfer stream from the labpacks MTU, which includes the labpack packaging materials (e.g., course packing material, overpacks, drums, lids, bottles, and cans).

The debris MTU operations consist of waste receiving and transfer, manual sorting, shearing/crushing, and cement microencapsulation unit operations. The processing operations that take place are briefly described below:

- Received materials are first processed through a manual sorting operation. The purpose of the sorting operation is to open the containers of debris and sort out any materials that cannot be accepted by the shearing/crushing operation, or which do not meet the $60 \mathrm{~mm}$ minimum size for debris.

- Large objects that are not subjected to size reduction but that fit into a 55-gal drum are cemented in the drum.

- After sorting, materials requiring size reduction are transferred by belt conveyor to the shearing/crushing portion of the MTU. At this station, the materials are reduced to a size that can be readily blended with Portland Cement. Both a jaw crusher and counter rotating shredder are supplied to size reduce the debris, since it can consist of a wide range of object sizes, shapes, and hardnesses.

- The size reduced material is conveyed to the cement microencapsulation portion of the MTU. In this station, the sized debris is blended with Portland Cement to produce the final waste form.

- All debris processing operations are performed within a ventilated enclosure for vapor containment. Ventilation air is directed to the unit ventilation system that provides activated carbon and HEPA filtration.

A flow diagram that shows these processing steps is provided in Figure 3. 


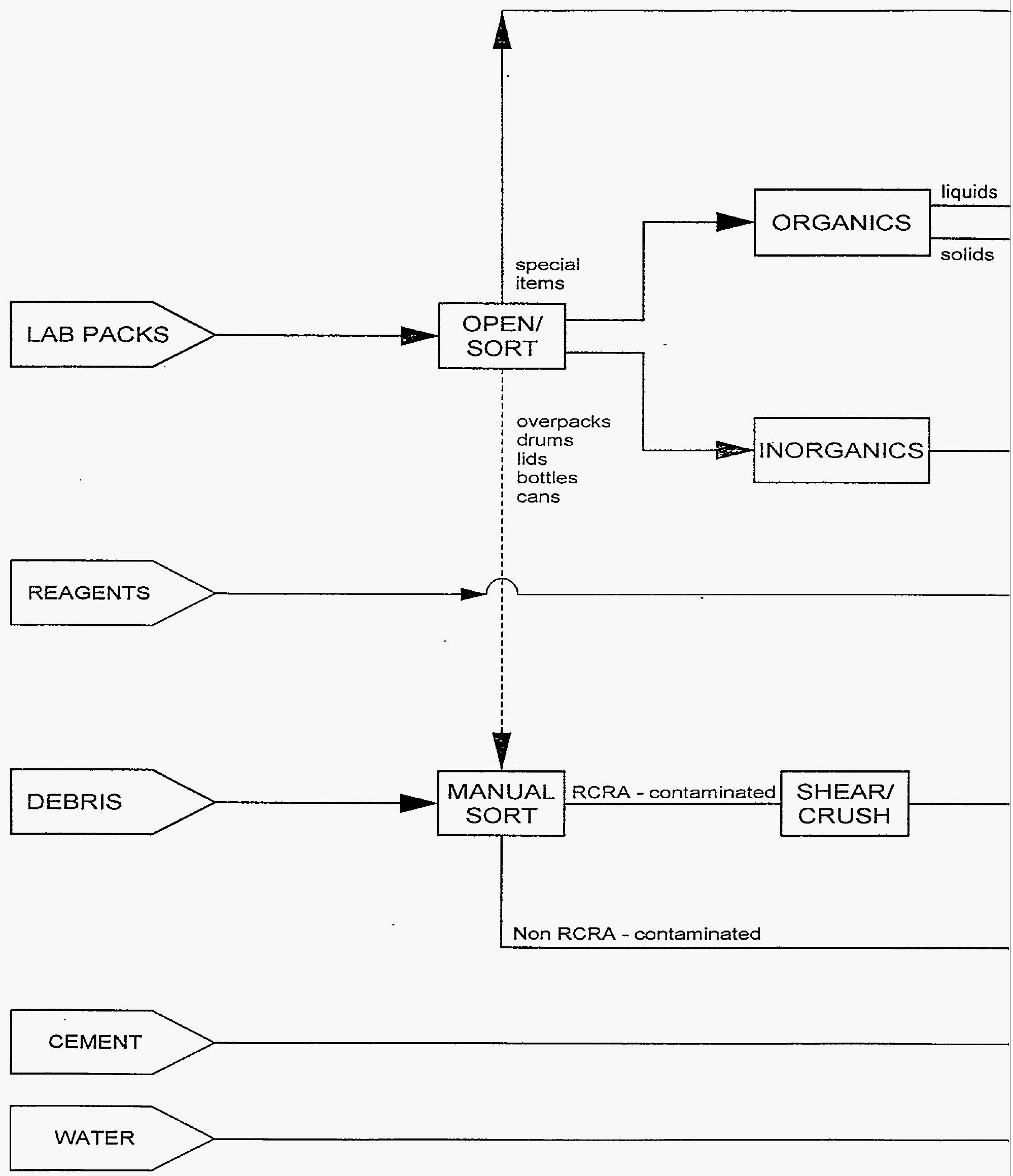




\subsection{Wastewater MTU}

The major roles of the wastewater MTU are to (a) accept and effectively process wastewaters and aqueous slurries that are MLLW, and (b) meet these objectives by processing the wastestreams on portable semi-trailers that can be moved from site to site. The functions of the wastewater MTU are to:

1. Destroy the organic faction of the wastestreams by conversion to carbon dioxide, water, and hydrochloric acid.

2. Separate the inorganic fraction that consists of undissolved solids including RCRA metals and nonvolatile radionuclides for transfer to inorganic sludge treatment in the organics MTU.

3. Produce a water from the processing unit that is suitable for recycle, reuse within the PTSs, or disposal.

The wastewater accepts external transfer streams from the organics MTU and the labpacks MTU. The operations performed by this unit require the use of multiple semi-trailers.

The MTU consists of one primary processing train. The processing operations that take place are briefly described below:

- All primary and external transfer streams enter the unit via one or more holding tanks. Holding tanks are agitated to maintain suspension of solids and for representative sampling.

- The first unit operation consists of a batch Redox tank in which either oxidants or reductants are added with agitation to adjust the Redox potential of the liquid batch.

- The Redox-adjusted liquid is then pumped to a batch neutralization tank where the $\mathrm{pH}$ is adjusted.

- After $\mathrm{pH}$ adjustment, the liquid is filtered through a cartridge type filter to remove suspended solids. Removed solids are sent to the organics MTU for final processing.

- Liquids with organic contamination are transferred to the Hydrothermal Process Reactor (e.g., supercritical water oxidation process) where the organics are destroyed to carbon dioxide, water, and hydrochloric acid.

- Offgas from the Hydrothermal Process Reactor is vented through a reheater and then passed through HEPA filters before discharge to the atmosphere.

- Liquid from the Hydrothermal Process Reactor is transferred to a reverse osmosis (RO) unit where the dissolved solids in the liquid are separated from the water. The water from the RO is then available for recycle or reuse by the PTSs or for discharge. 
- Concentrated salt solution from the RO unit is transferred to an evaporator for further concentration of the solids. These inorganic solids are transferred to the organics MTU for final processing.

- Offgas from the evaporator is routed to a condenser before being routed to the same reheater and HEPA filters used by the Hydrothermal Process Reactor. Condensate from the condenser is combined with water discharged from the RO.

A flow diagram that shows these processing steps is provided in Figure 4. 


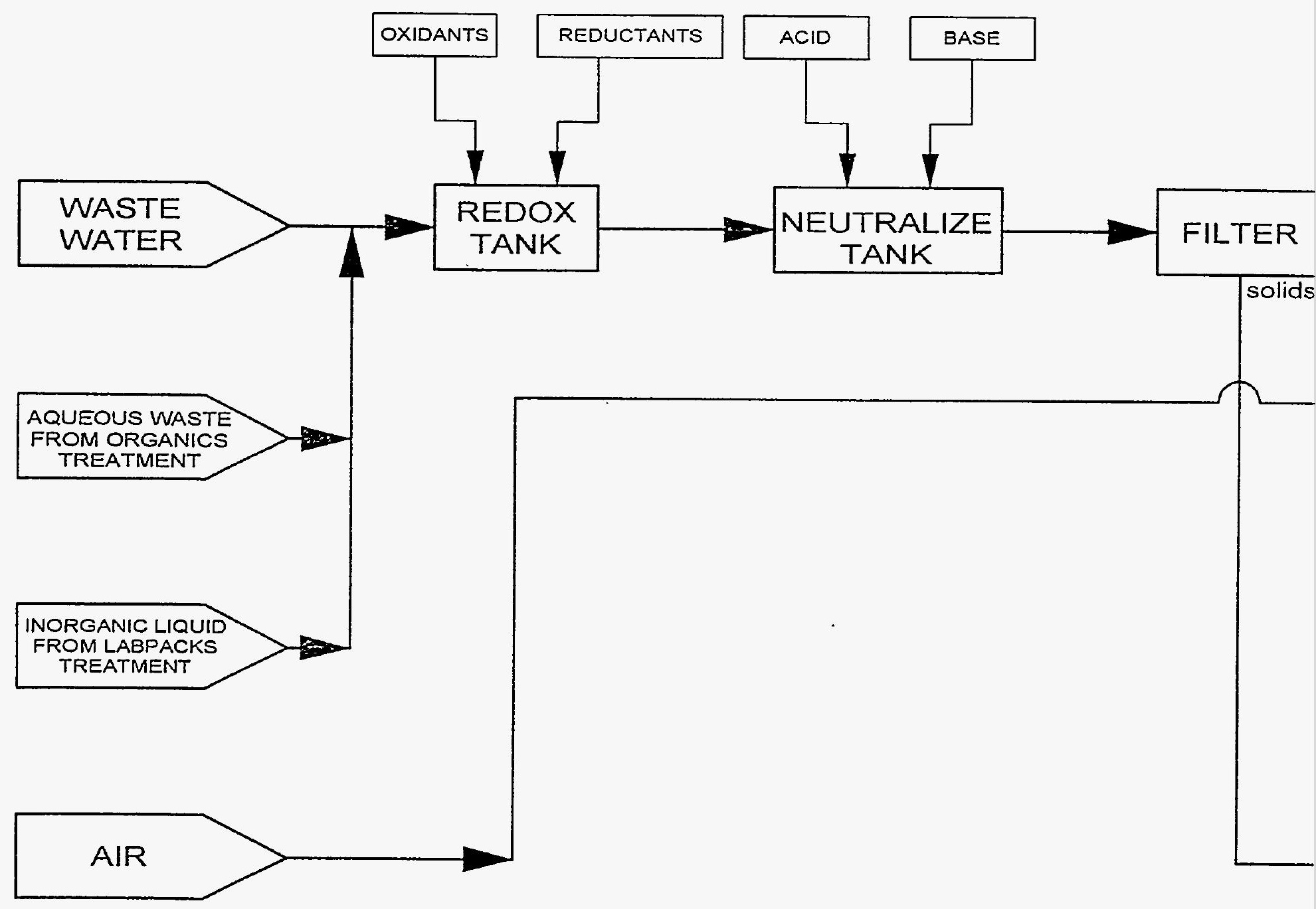

Figure 4. Block flow diagram for the debris MTU. 


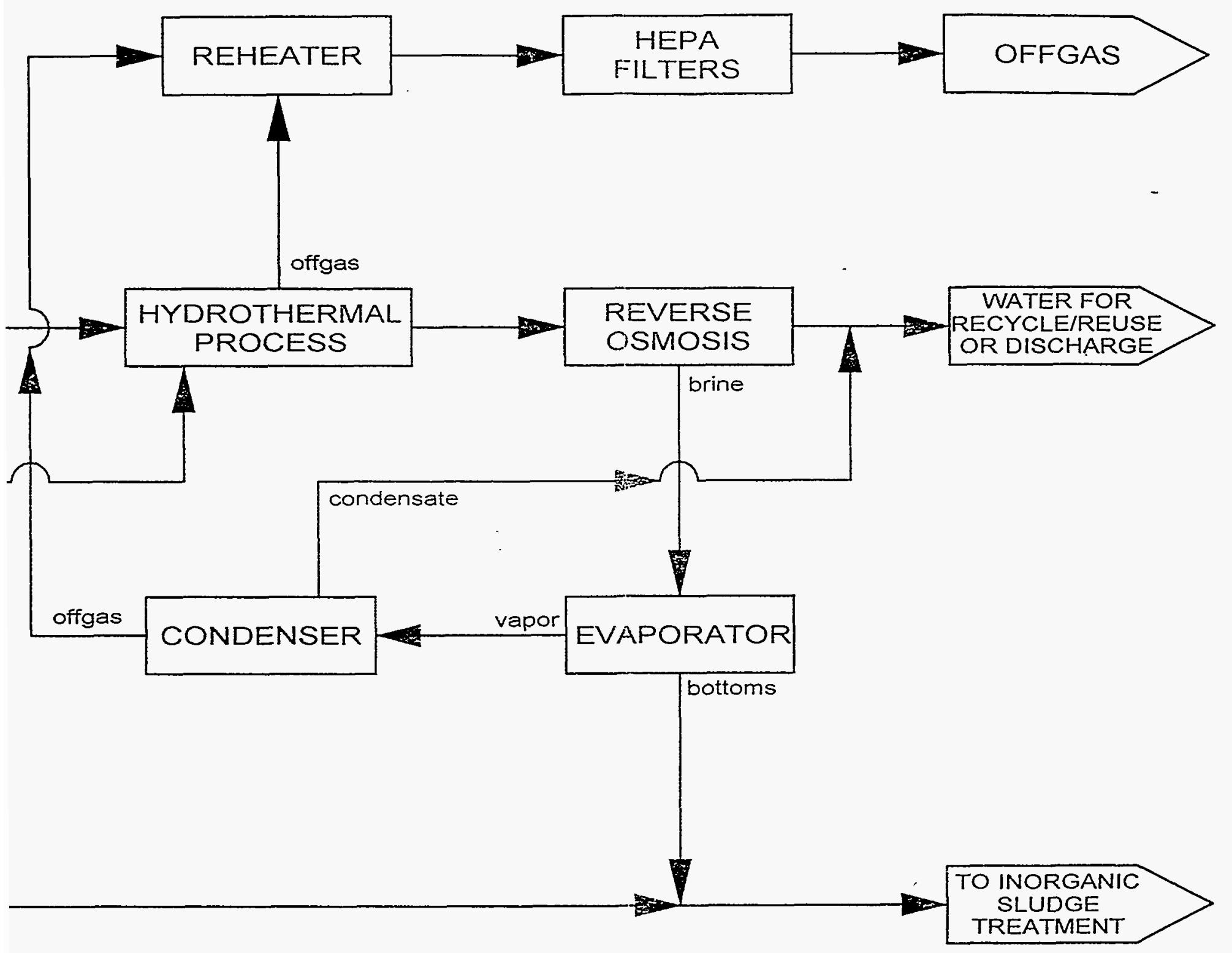

FIG 4 - WASTEWATER TREATMENT FLOWSHEET

EQUINOX, LTD.

872 Don Cubero Ave. Santa Fe, NM 87501

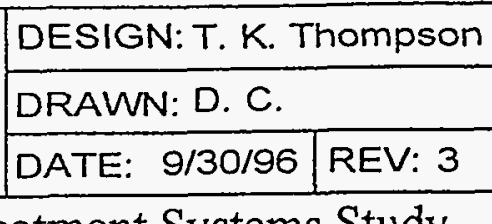




\section{PHASE III - SYSTEM EVALUATION}

The system evaluation effort included the estimation of the total life-cycle cost (TLCC) for the proposed PTS, and for a centralized (fixed) processing system having the same throughput capabilities as the PTS. The PLCCs were developed to determine the economic differences between portable and fixed processing facilities.

Additionally, regulatory, institutional and technical issues associated with implementing the use of the PTS were evaluated. These issues are discussed later in this report.

\subsection{Total Life-Cycle Cost Estimates}

System design information created during the Phase II activities was used as the basis for preparing of total life-cycle cost (TLCC) estimates for each of the four MTUs. The PLCC estimates for each MTU and for the fixed processing facility are shown in Tables 3-7. These estimates are considered to be rough-orderof-magnitude $( \pm 30 \%)$ since they are based on pre-conceptual design criteria. The PLCC is divided into six work breakdown structure (WBS) elements. The six elements are:

1. Studies and bench scale tests

2. Demonstration costs

3. Facility construction costs

4. Preconstruction and preoperational activities

5. Operations and maintenance costs

6. Decontamination and decommissioning.

The portable system costs determined in Section 4.2 do not include costs associated with site support such as space and utility hookups to be provided by the sites. The MTU set-up area is to include a curbed concrete pad sheltered by a roof structure as a minimum, and additional weather proofing may be required for severe climatic conditions. Utility services include potable water, service water, electrical power, and natural gas. Certification and shipping of the stabilized and packaged wastes is also provided by the sites and is not included in the PTS costs. Additional administrative costs are born by the sites to track the wastes and provide security and fire protection.

In the centralized system administrative and certification and shipping costs are included. Both systems include receiving and inspection costs, and it is assumed that the waste is adequately characterized and delivered by the sites to allow appropriate treatment. Thus, no allowance is made for instrumentation such as gamma spectroscopy, passive active neutron assay, real time radiography, etc. in either the portable or centralized systems.

Details of the life-cycle cost work are included in Appendix C.

\subsection{PLCC Evaluation}

Table 8 shows a summary of the PLCC for each of the MTUs, the combined estimates for the four MTUs and the estimated cost for the Centralized Facility. The estimated life-cycle cost for the PTS, 
Table 3. PLCC for the organics MTU.

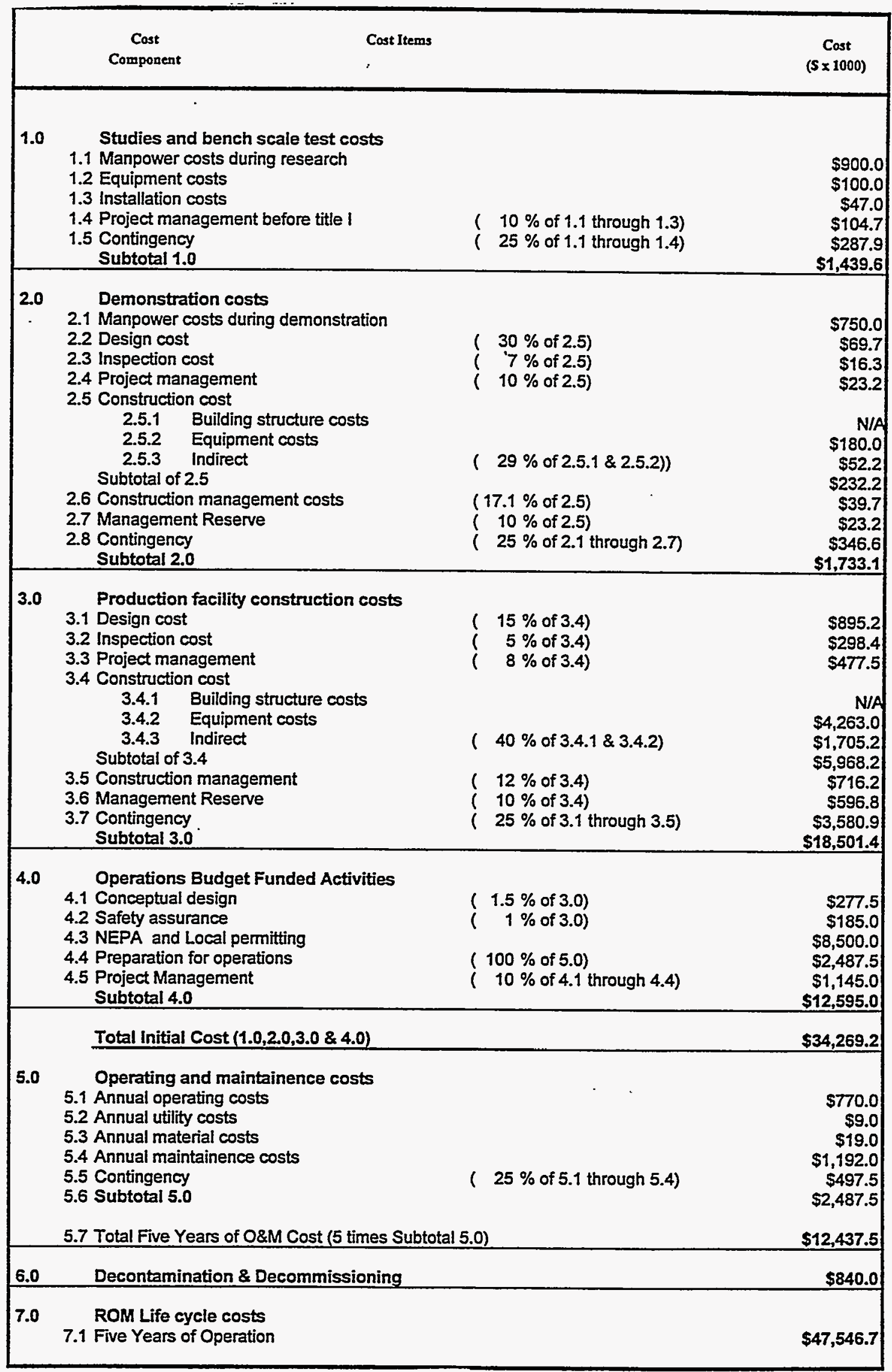


Table 4. PLCC for the labpacks MTU.

\begin{tabular}{|c|c|c|c|}
\hline \multicolumn{3}{|c|}{ Cost Items } & \multirow{2}{*}{$\begin{array}{l}\text { Cost } \\
(\$ \times 1000)\end{array}$} \\
\hline 1.0 & $\begin{array}{l}\text { Studies and bench scale test costs } \\
\text { 1.1 Manpower costs during research } \\
\text { 1.2 Equipmient costs } \\
\text { 1.3 Installation costs } \\
\text { 1.4 Project management before title I } \\
\text { 1.5 Contingency } \\
\text { Subtotal } 1.0 \\
\end{array}$ & $\begin{array}{l}(10 \% \text { of } 1.1 \text { through } 1.3) \\
(25 \% \text { of } 1.1 \text { through } 1.4)\end{array}$ & \\
\hline 2.0 & \multicolumn{3}{|c|}{ 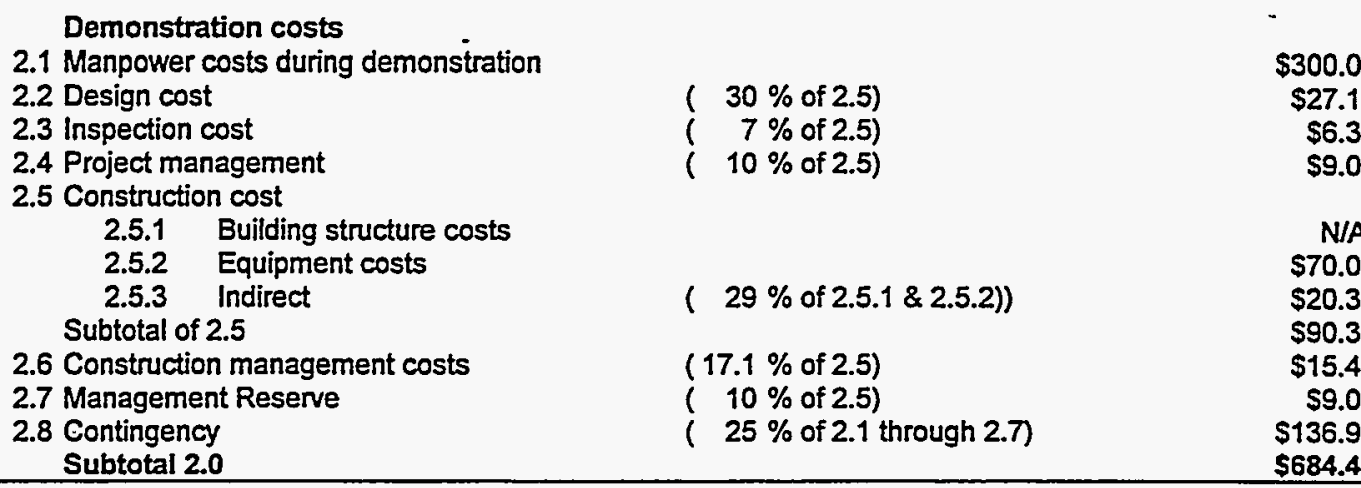 } \\
\hline 3.0 & \multicolumn{2}{|c|}{ 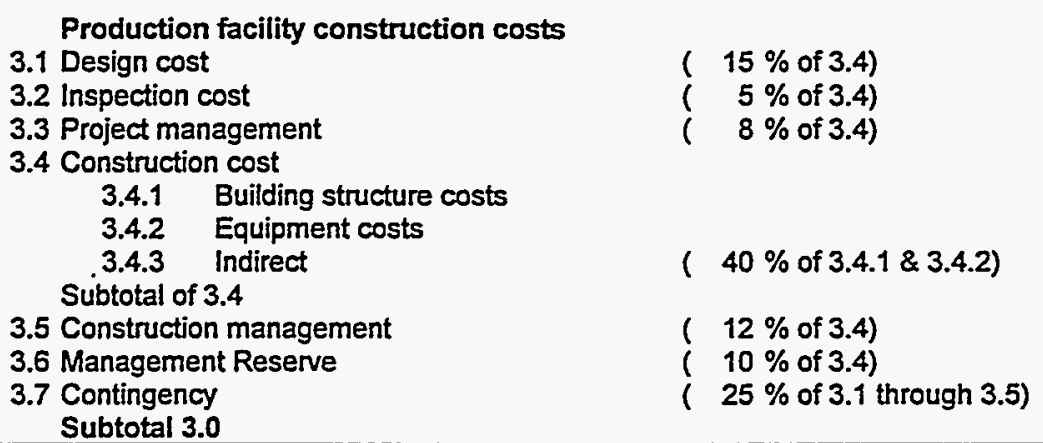 } & $\begin{array}{r}\$ 635.9 \\
\$ 212.0 \\
\$ 339.1 \\
N / A \\
\$ 3,028.0 \\
\$ 1,211.2 \\
\$ 4,239.2 \\
\$ 508.7 \\
\$ 423.9 \\
\$ 2,543.5 \\
\$ 13,141.5\end{array}$ \\
\hline 4.0 & \multicolumn{2}{|l|}{$\begin{array}{l}\text { Operations Budget Funded Activities } \\
\text { 4.1 Conceptual design } \\
\text { 4.2 Safety assurance } \\
\text { 4.3 NEPA and Local permitting } \\
\text { 4.4 Preparation for operations } \\
\text { 4.5 Project Management } \\
\text { Subtotal 4.0 }\end{array}$} & $\begin{array}{r}\$ 197.1 \\
\$ 131.4 \\
\$ 3,500.0 \\
\$ 1,765.0 \\
\$ 559.4 \\
\$ 6,152.9 \\
\end{array}$ \\
\hline \multicolumn{3}{|c|}{ Total Initial Cost $(1.0,2.0,3.0 \& 4.0)$} & $\$ 20,656.7$ \\
\hline 5.0 & \multirow{2}{*}{\multicolumn{2}{|c|}{$\begin{array}{l}\text { Operating and maintainence costs } \\
\text { 5.1 Annual operating costs } \\
\text { 5.2 Annual utility costs } \\
\text { 5.3 Annual material costs } \\
\text { 5.4 Annual maintainence costs } \\
\text { 5.5 Contingency } \\
\text { 5.6 Subtotal } 5.0\end{array}$}} & $\begin{array}{r}\$ 560.0 \\
\$ 3.0 \\
\$ 5.0 \\
\$ 844.0 \\
\$ 353.0 \\
\$ 1,765.0\end{array}$ \\
\hline & & & $\$ 8,825.0$ \\
\hline 6.0 & \multicolumn{2}{|l|}{ Decontamination \& Decommissioning } & $\$ 504.0$ \\
\hline 7.0 & \multicolumn{2}{|l|}{$\begin{array}{l}\text { ROM Life cycle costs } \\
7.1 \text { Five Years of Operation }\end{array}$} & $\$ 29,985.7$ \\
\hline
\end{tabular}


Table 5. PLCC for the debris MTU.

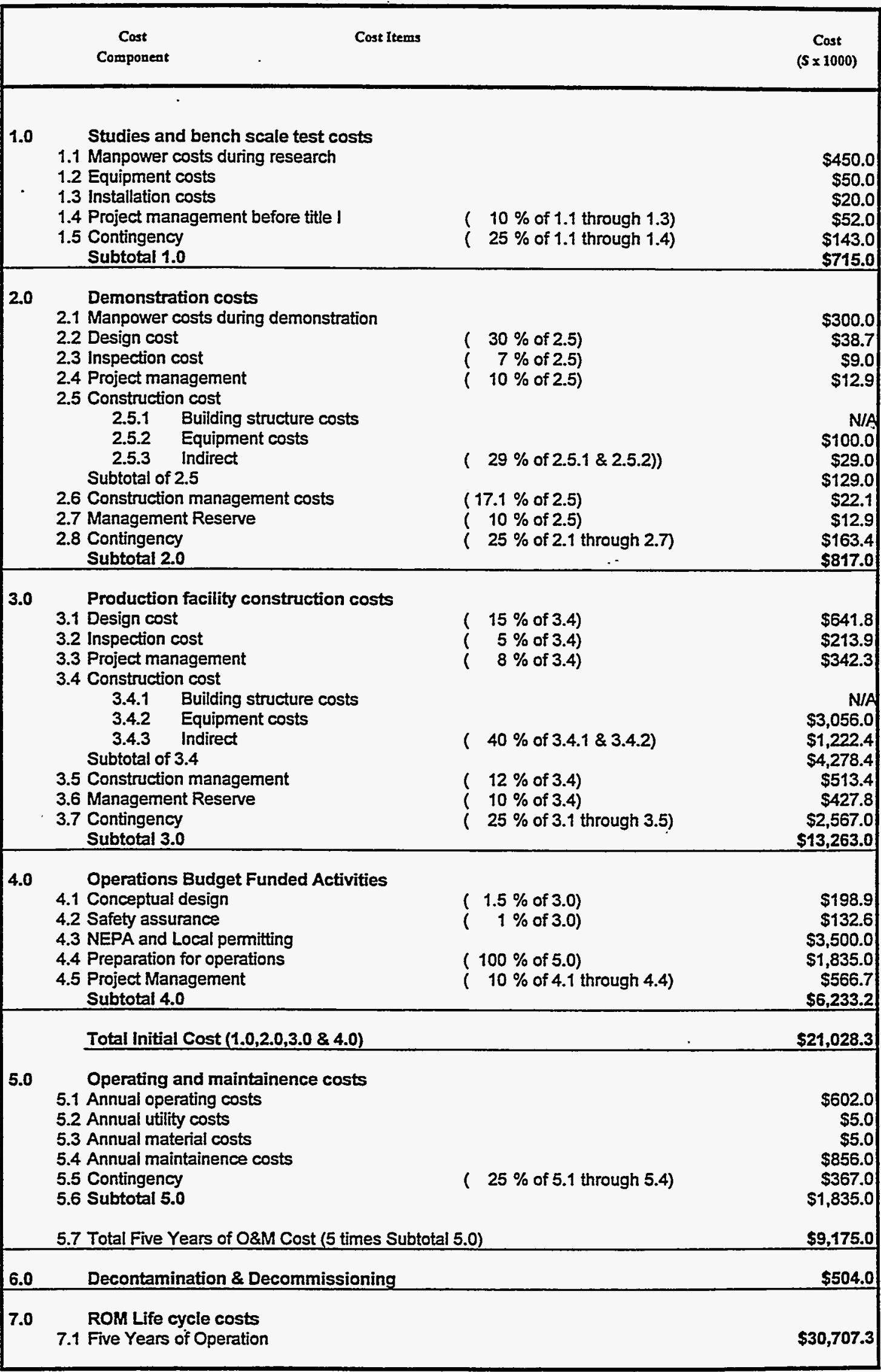


Table 6. PLCC for the wastewater MTU.

\begin{tabular}{|c|c|c|c|}
\hline & $\begin{array}{c}\text { Cost } \\
\text { Component }\end{array}$ & & $\begin{array}{c}\text { Cost } \\
(s \times 1000)\end{array}$ \\
\hline 1.0 & $\begin{array}{l}\text { Studies and bench scale test costs } \\
\text { 1.1 Manpower costs during research } \\
\text { 1.2 Equipment costs } \\
\text { 1.3 Installation costs } \\
\text { 1.4 Project management before title I } \\
\text { 1.5 Contingency } \\
\text { Subtotal } 1.0 \\
\end{array}$ & $\begin{array}{l}(10 \% \text { of } 1.1 \text { through } 1.3) \\
(25 \% \text { of } 1.1 \text { through } 1.4)\end{array}$ & $\begin{array}{r}\$ 900.0 \\
\$ 70.0 \\
\$ 14.0 \\
\$ 98.4 \\
\$ 270.6 \\
\$ 1,353.0 \\
\end{array}$ \\
\hline 2.0 & $\begin{array}{l}\text { Demonstration costs } \\
\text { 2.1 Manpower costs during demonstration } \\
\text { 2.2 Design cost } \\
\text { 2.3 Inspection cost } \\
\text { 2.4 Project management } \\
\text { 2.5 Construction cost } \\
2.5 .1 \quad \text { Building structure costs } \\
2.5 .2 \quad \text { Equipment costs } \\
2.5 .3 \quad \text { Indirect } \\
\text { Subtotal of } 2.5 \\
\text { 2.6 Construction management costs } \\
\text { 2.7 Management Reserve } \\
\text { 2.8 Contingency } \\
\text { Subtotal } 2.0\end{array}$ & 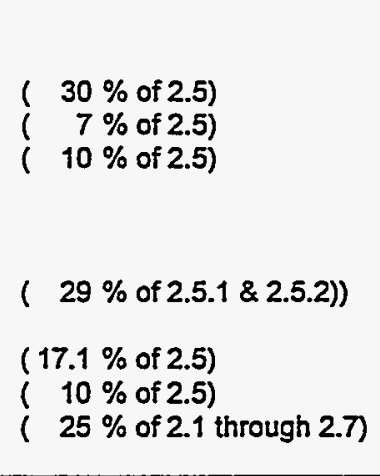 & $\begin{array}{r}\$ 675.0 \\
\$ 69.7 \\
\$ 16.3 \\
\$ 23.2 \\
\\
\mathbf{N} / A \\
\$ 180.0 \\
\$ 52.2 \\
\$ 232.2 \\
\$ 39.7 \\
\$ 23.2 \\
\$ 327.9 \\
\$ 1,639.3\end{array}$ \\
\hline 3.0 & 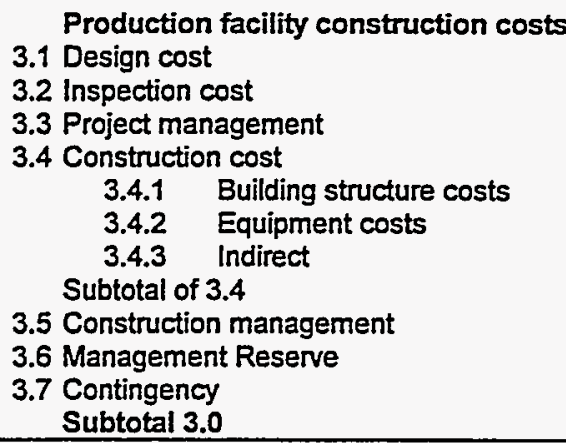 & 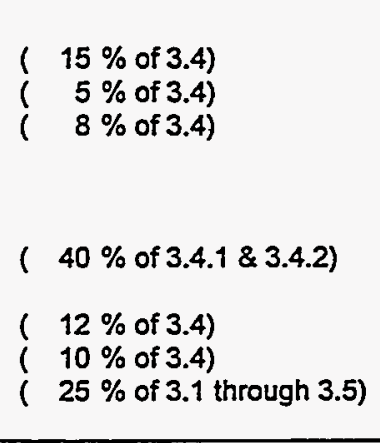 & $\begin{array}{r}\$ 1,250.3 \\
\$ 416.8 \\
\$ 666.8 \\
\\
N / A \\
\$ 5,954.0 \\
\$ 2,381.6 \\
\$ 8,335.6 \\
\$ 1,000.3 \\
\$ 833.6 \\
\$ 5,001.4 \\
\$ 25,840.4\end{array}$ \\
\hline 4.0 & $\begin{array}{l}\text { Operations Budget Funded Activities } \\
\text { 4.1 Conceptual design } \\
\text { 4.2 Safety assurance } \\
\text { 4.3 NEPA and Local permitting } \\
\text { 4.4 Preparation for operations } \\
\text { 4.5 Project Management } \\
\text { Subtotal 4.0 } \\
\end{array}$ & 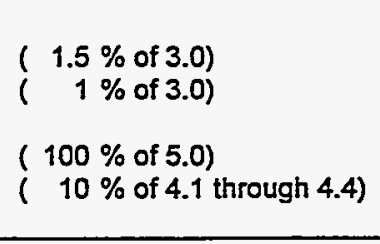 & $\begin{array}{r}\$ 387.6 \\
\$ 258.4 \\
\$ 3,500.0 \\
\$ 3,073.8 \\
\$ 722.0 \\
\$ 7,941.7 \\
\end{array}$ \\
\hline & Total Initial Cost $(1.0,2.0,3.0 \& 4.0)$ & & $\$ 36,774.4$ \\
\hline 5.0 & $\begin{array}{l}\text { Operating and maintainence costs } \\
\text { 5.1 Annual operating costs } \\
\text { 5.2 Annual utility costs } \\
5.3 \text { Annual material costs } \\
\text { 5.4 Annual maintainence costs } \\
\text { 5.5 Contingency } \\
\text { 5.6 Subtotal } 5.0\end{array}$ & $(25 \%$ of 5.1 through 5.4$)$ & $\begin{array}{r}\$ 770.0 \\
\$ 11.0 \\
\$ 10.0 \\
\$ 1,668.0 \\
\$ 614.8 \\
\$ 3,073.8\end{array}$ \\
\hline & 5.7 Total Five Years of O\&M Cost ( 5 times $S$ & 5.0) & $\$ 15,368.8$ \\
\hline 6.0 & Decontamination \& Decommissioning & & $\$ 840.0$ \\
\hline 7.0 & $\begin{array}{l}\text { ROM Life cycle costs } \\
\text { 7.1 Five Years of Operation }\end{array}$ & & $\$ 52,983.2$ \\
\hline
\end{tabular}


Table 7. PLCC for the centralized treatment facility.

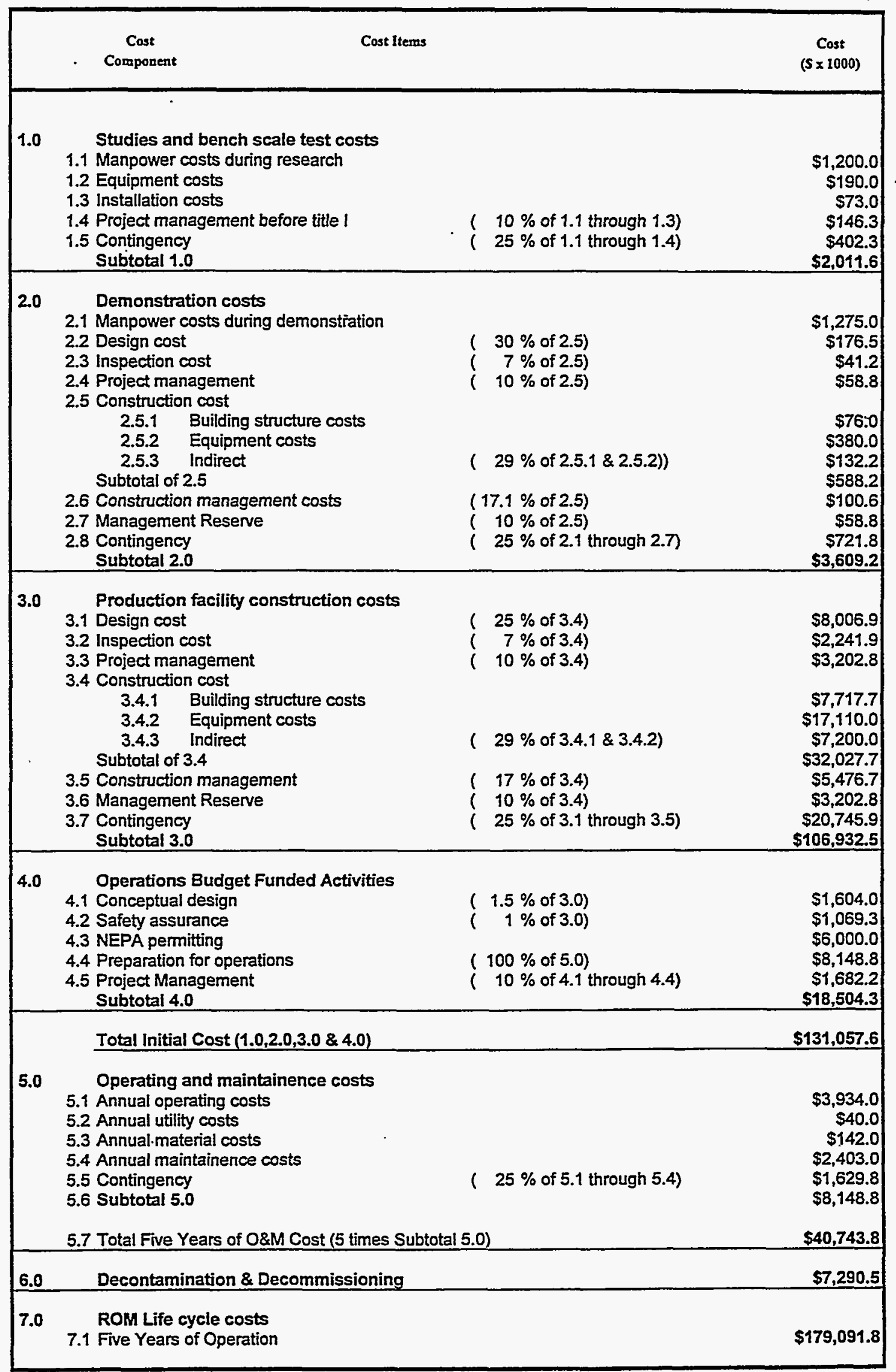


Table 8. Comparison of the planning life-cycle costs.

\begin{tabular}{|l|l|r|r|r|r|r|r|}
\hline & Cost Component & \multicolumn{1}{|c|}{$\begin{array}{c}\text { Organics } \\
\text { MTU }\end{array}$} & $\begin{array}{c}\text { Labpacks } \\
\text { MTU }\end{array}$ & Debris MTU & $\begin{array}{c}\text { Wastewater } \\
\text { MTU }\end{array}$ & $\begin{array}{c}\text { Total PTS } \\
\text { Facility }\end{array}$ \\
\hline 1.0 & $\begin{array}{l}\text { Studies and } \\
\text { bench scale tests }\end{array}$ & $1,439,600$ & 677,900 & 715,000 & $1,353,000$ & $4,185,500$ & $2,011,600$ \\
\hline 2.0 & $\begin{array}{l}\text { Demonstration } \\
\text { costs }\end{array}$ & $1,733,100$ & 684,400 & 817,000 & $1,639,300$ & $4,873,800$ & $3,609,200$ \\
\hline 3.0 & $\begin{array}{l}\text { Production facility } \\
\text { construction costs }\end{array}$ & $18,501,400$ & $13,141,500$ & $13,263,000$ & $25,840,400$ & $70,746,300$ & $106,932,500$ \\
\hline 4.0 & $\begin{array}{l}\text { Operations } \\
\text { budget }\end{array}$ & $12,595,000$ & $6,152,900$ & $6,233,200$ & $7,941,700$ & $32,922,800$ & $18,504,300$ \\
\hline 5.0 & $\begin{array}{l}\text { Operating and } \\
\text { maintenance costs }\end{array}$ & $12,437,500$ & $8,825,000$ & $9,175,000$ & $15,368,800$ & $45,806,300$ & $40,743,800$ \\
\hline 6.0 & $\begin{array}{l}\text { Decontamination } \\
\text { and } \\
\text { Decommissioning }\end{array}$ & 840,000 & 504,000 & 504,000 & 840,000 & $2,688,000$ & $7,290,500$ \\
\hline 7.0 & $\begin{array}{l}\text { ROM Life cycle } \\
\text { costs }\end{array}$ & $47,546,600$ & $29,985,700$ & $30,707,200$ & $52,983,200$ & $161,222,700$ & $179,091,900$ \\
\hline
\end{tabular}


excluding site support costs, is within $10 \%$ of the Centralized Facility cost of $\$ 179.1$ million. These totals are surprisingly close. However, the assumptions used and the details of the individual estimates must be examined before any comparisons can be made or understood. The largest cost difference between the PTS and the centralized facility appears under Work Breakdown Structure (WBS) element 3.0, Construction Costs. The cost estimate for the centralized facility is approximately $\$ 36$ million higher than the construction cost for the portable systems. These results are consistent with expectations. It should be noted, however, that the centralized facility constructed in this example is only operated for 5 years (in order to be consistent with the operating time frame used as the basis for the PTS costs). It is unlikely that a large capital commitment would be made for a permanent facility unless there was a demand for the capacity over a larger period of time (greater than 10 years).

The cost estimate assumes that permit modifications required to allow use of portable systems within a state can be obtained at $\$ 250,000$ per state for 10 states. The estimate also assumes that an Environmental Impact Statement (EIS) (at an estimated cost of $\$ 6,000,000$ ) was required for the organics MTU, due to the thermal destruction unit included in the design. The other three MTUs are assumed to require an environmental assessment (at an estimated cost of $\$ 1,000,000$ ) since these units had no thermal destruction unit included in the design.

As discussed in Section 6.3.4, other ownership documents (e.g., the safety analysis report, operating procedures, maintenance procedures) may be reviewed and possibly revised to meet the elements of the DOE field office governing the treatment site to which the PTS has been relocated. The cost estimate does not include the cost of performing these reviews, if required. These costs will likely vary significantly between the PTS and the Centralized Facility unless a memorandum of understanding (MOU) is adopted between all DOE field offices eliminating the normal oversight functions of the field office for the treatment operations.

Additional insights can be obtained by evaluating the cost estimates on a per unit basis. Table 9 provides a total unit cost for each of the MTUs and for the centralized alternative. The unit costs for the MTUs range from $\$ 6.22 / \mathrm{lb}$ to $\$ 75.72 / \mathrm{lb}$, with a composite average of $\$ 20.60 / \mathrm{lb}$. This compares to a unit cost of $\$ 22.88 / \mathrm{lb}$ for the centralized facility.

Breakdown of the central facility cost estimate reveals that over $\$ 70$ million can be attributed to administration and certification/shipping activities. It could be argued that these functions are not provided in the basis used to estimated costs for the MTUs. Therefore, it may be valuable to examine the unit cost of the centralized facility excluding administration and certification/shipping costs. As can be seen from the bottom line of Table 9, the revised unit cost for the centralized treatment drops to $\$ 13.77 / 1 \mathrm{~b}$. This is about $1 / 3$ less than the equivalent PTS combined unit cost of $\$ 20.33 / \mathrm{lb}$.

Additionally, as was previously mentioned, the centralized facility is somewhat underutilized in this example. The unit cost could be lower if the facility life was extended to a more realistic length of time.

If, instead of subtracting administration and certification and shipping costs from the centralized facility estimate, the site support costs were added to the portable treatment systems, then a more accurate picture of the total PTS treatment costs might be approached. To develop these total support costs for all ten sites, an estimate must be made of the construction costs for the pad and shelter containing the PTS modules, 
Table 9. Unit cost comparison.

\begin{tabular}{|c|c|c|c|c|c|c|}
\hline & \multicolumn{6}{|c|}{ Treatment Systems } \\
\hline & \multicolumn{5}{|c|}{ Mobile Treatment Units } & \multirow{2}{*}{$\begin{array}{c}\text { Central } \\
\text { Fixed }\end{array}$} \\
\hline & Waste Water & Organics & Debris & Labpack & $\begin{array}{l}\text { Four Units } \\
\text { Combined }\end{array}$ & \\
\hline Treatment & $\$ 52,449,400$ & $\$ 47,012,900$ & $\$ 30,173,500$ & $\$ 29,451,900$ & $\$ 159,087,700$ & $\$ 107,764,600$ \\
\hline Administration & $\$ 533,800$ & $\$ 533,800$ & $\$ 533,800$ & $\$ 533,800$ & $\$ 2,135,200$ & $\$ 38,649,700$ \\
\hline $\begin{array}{l}\text { Certification/ } \\
\text { Shipping }\end{array}$ & -- & - & -- & - & - & $\$ 32,677,500$ \\
\hline Life-Cycle Cost & $\$ 52,983,200$ & $\$ 47,546,700$ & $\$ 30,707,300$ & $\$ 29,985,700$ & $\$ 161,222,900$ & $\$ 179,091,800$ \\
\hline Cost per pound & $\$ 6.22$ & $\$ 7.13$ & $\$ 29.99$ & $\$ 75.72$ & $\$ 20.60$ & $\$ 22.88$ \\
\hline $\begin{array}{l}\text { Cost per pound } \\
\text { (excluding } \\
\text { Administration and } \\
\text { Cert/Shipping) }\end{array}$ & $\$ 6.15$ & $\$ 7.05$ & $\$ 29.47$ & $\$ 74.37$ & $\$ 20.33$ & $\$ 13.77$ \\
\hline
\end{tabular}

administration costs, and certification and shipping costs. These estimates are developed from the detailed centralized facility costs in Appendix C.

The assumptions used to develop these estimates are as follows:

- Space and utility hookups provided by the site will be an average of $5 \%$ of the centralized facility construction cost. This single site cost will be multiplied by ten, reflecting the ten sites proposing portable treatment, and added to the PTS cost.

- Note that security and fire protection are not explicitly included in the centralized facility O\&M costs and therefore cannot be explicitly identified for site support costs. However, it is assumed that the total administration costs for the centralized facility must be added to the PTS costs to gain a picture of the total administrative support provided by the sites for portable treatment.

- Administration and certification and shipping costs associated with the centralized facility will be added to the PTS cost. It is assumed that these costs are the sum of the costs at the ten sites and no additional costs will be incurred by the sites due to a lesser scale of operation.

- The open/sort and repackaging costs associated with the centralized facility will not be added to the PTS cost. These costs are already included in the debris and labpack PTS modules.

- Waste characterization is done by the sites for both PTS and a centralized facility prior to shipment. Therefore, this cost will not be added to the PTS cost since it would increase the cost of both the PTS and the centralized facility equally. 
Using these assumptions, site support will cost approximately $\$ 56,401,130$ over 5 years to support the PTS operation. Thus, the total cost of portable treatment systems is $\$ 161,222,900$ (the life-cycle cost from Table 2) plus $\$ 56,401,130$ for a TLCC of $\$ 217,624,033$ (about a $35 \%$ increase).

This additional site cost may be low because auxiliary systems required by a fixed facility may also be required for portable treatment; however, these systems were assumed to be provided by the site as required and were not included in the PTS cost. Such auxiliary systems are identified in Section 6.2.3.

Figure 5 is a plot of the centralized facility cost, the PTS cost, and the PTS plus site costs versus design capacity in lbs/hr. The cost versus capacity was determined using an exponential scaling of the cost estimates in Table 9 (i.e., $\$ 161,222,900$ for the four PTS modules, and $\$ 179,091,000$ for the centralized facility). For example, if the cost of a treatment facility component of capacity $q_{1}=C_{1}$, then the cost of a similar treatment facility component of capacity $\mathrm{C}_{2}=\mathrm{C}_{1}\left(\mathrm{q}_{2} / \mathrm{q}_{1}\right)^{\mathrm{n}}$ where $\mathrm{n}$ is the scaling factor which was assumed to be 0.5 . The base cost for the PTS plus site costs is $\$ 217,624,033$.

These systems were designed to treat a total of $2919 \mathrm{lbs} / \mathrm{hr}$ of incoming waste. If a greater waste throughput (or capacity) is required for the PTS then it was assumed that two PTS systems would be required whereas the centralized facility cost simply increases exponentially as stated above. Thus, the PTS has an exponential increase in cost between $500 \mathrm{lbs} / \mathrm{hr}$ and $2900 \mathrm{lbs} / \mathrm{hr}$, then a jump due to an additional system, followed by another exponential increase in cost. This additional system includes only construction, O\&M and D\&D costs. It is assumed that the costs for test, demonstration and the operations budget items (safety assurance, permitting, etc.) will not need to be incurred again for the second system.

The conclusion is that if site costs are excluded from consideration, the PTS costs slightly less than a centralized facility (but within 10\%) up to the design capacity of $2900 \mathrm{lbs} / \mathrm{hr}$. If a higher capacity is required, thereby requiring an additional system, then the centralized facility costs less. However, if site costs are

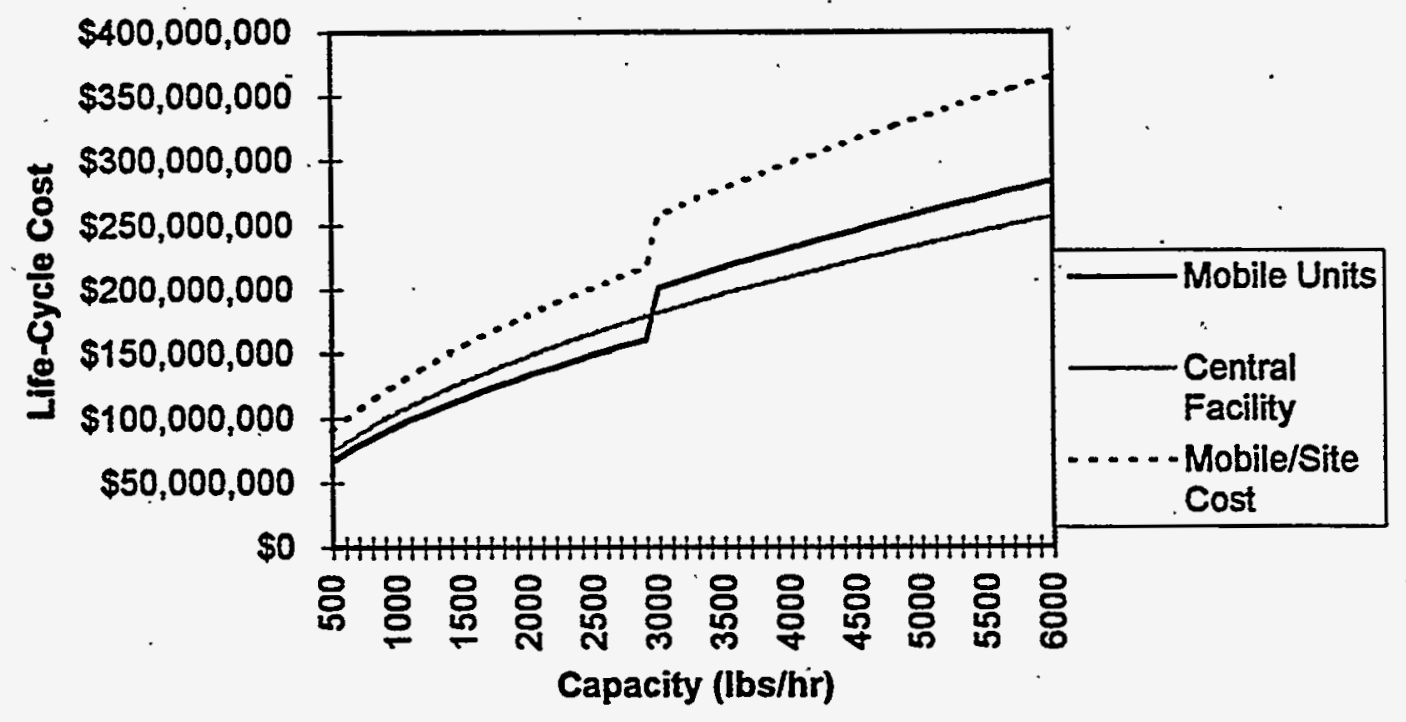

Figure 5. Comparison of mobile systems with a fixed facility. 
included in the PTS cost, then the centralized facility costs less regardless of capacity. At the design point of $2900 \mathrm{lbs} / \mathrm{hr}$ capacity, the total PTS cost (including site costs) is about $22 \%$ greater than the centralized facility cost.

\subsection{Operational Considerations}

As already discussed, a major consideration in utilizing the PTS at multiple DOE sites is obtaining the required permits and governing documentation for the operation. In fact, the PTS option inherently has the risk that operational approval at some sites may not be granted. It is difficult to say how likely this occurrence would be since it is dependent on the political climate, intervention by special interest group, relationships with governing authorities, and the operating history (good or bad) of the PTS at previous sites.

It is likely that some form of operational readiness review will be required each time the PTS is set up at a new site for operation. The degree of participation of the local field office is not well defined. This also will be dependent to a large degree upon the operating history and reputation of the unit's previous operations. If problems were incurred at previous sites, a newly involved field office is likely to use more review than if the operational history has no unusual occurrences.

The PTS inherently has less online availability than a centralized unit, due to the activities necessary for tear down, decontamination, transportation, and set up operations. It has been assumed that these operations require two weeks to complete, and that the portable system will perform a total of 60 campaigns over 5 years with an average of 12 campaigns per year. This translates to an average of 2 weeks of operation and 2 weeks of downtime for each campaign for a $50 \%$ availability. On a site-by-site basis, the availability will depend on the amount of waste to be treated at a particular site, the operating time required for treatment, and the frequency of transport. Thus, a centralized facility with an equivalent feed rate potential of a PTS can process more waste than the PTS due to less down-time.

Considerable time and additional operational expense may be incurred if the PTS must be brought to a steady state before it can be operated. This may be the case for the proposed incinerator, thermal desorption unit, and hydrothermal reactor. Maintenance costs may also be increased over those of a fixed unit by the constant cycling of treatment equipment as it is operated and then shutdown for movement to another facility. A centralized facility can stockpile waste and avoid some of the cycling that must be accommodated by a portable system. 


\section{TREATMENT ALTERNATIVES}

Alternative treatment options to the PTS are discussed briefly below. The first alternative, use of a centralized DOE treatment facility, was considered the most viable DOE treatment option and therefore used as a basis for cost comparison in this study. The potential and advantages offered for privatization of a PTS are discussed in Section 6.3.5.

\subsection{Treatment by a Centralized DOE Facility}

The alternative of utilizing a centralized DOE treatment facility rather than a PTS is currently being practiced at some DOE sites, including the INEL Waste Experimental Reduction Facility (WERF) and the TSCA incinerator at Oak Ridge. Both facilities are currently taking wastes for incineration from other DOE sites. Accepting waste from out-of-state generators normally requires coordination with the state oversight groups. For example, the WERF is actively coordinating with the Regional Administrator concerning waste that is accepted from other states for treatment. The Administrator requires that the STP be amended to include wastes which will be accepted from out of state for treatment to ensure that the State is cognizant of wastes being processed. In addition, the State has imposed requirements that the waste be incinerated within 6 months of receipt and the residual of the treatment must be properly disposed of or returned to the generator within a second 6-month period.

Significant shipping limitations will be encountered for liquid waste forms which have radioactive concentrations that exceed the values for exception to DOT Type A packaging requirements (see $49 \mathrm{CFR}$ 173). Although it is possible to ship liquids requiring Type A containers, the volumes are normally limited to small amounts (e.g., pint size or less) due to the test requirements which the package and contents must meet to qualify as a DOT Type A package. The Richland DOE field office (DOE-RL) follows Type A container testing activities and maintains a list and descriptive documentation of Type A containers available for use by DOE operations. ${ }^{3}$

For cases where the limitations of shipping these higher activity liquid wastes poses a difficulty, some form of absorption or stabilization pretreatment may be required to allow the waste to be shipped as a solid rather than as a liquid. Allowable shipping volumes for solids in Type A packages are much less restrictive than the limits imposed for liquids.

Generators having small quantities of a waste type might accomplish treatment of their entire inventory of the waste form in a treatability study. This offers no real advantage other than the fact that the waste may be shipped as a sample under applicable DOT regulations, rather than as a manifested hazardous waste shipment. If a PTS is brought to the generator's site, it must obtain a RCRA permit from the Regional Administrator before it will be permitted to perform treatability tests.

The Environmental Protection Agency (EPA) allows laboratories and testing facilities having an EPA identification number to conduct treatability studies on a sample of hazardous waste. The Regional Administrator must be notified of the intent to perform treatability studies, at least 45 days before conducting studies. The regulations [ 40 CFR $261.4(f)$ ] specifically state that mobile treatment units may qualify as a testing facility. Normal allowable quantity limits for treatability studies [stated in 40 CFR 261.4(e)] are $10,000 \mathrm{~kg}$ of media contaminated with nonacute hazardous waste, $1,000 \mathrm{~kg}$ of nonacute hazardous waste 
other than contaminated media, $1 \mathrm{~kg}$ of acute hazardous waste, $2500 \mathrm{~kg}$ of media contaminated with acute hazardous waste for each process being evaluated for each generated wastestream.

\subsection{Use of Existing Commercial Treatment Facilities}

Due to the relatively small quantities and diversity of MLLWs, commercial industry has little incentive to pursue developing treatment capabilities unless the conditions are just right. Limited commercial treatment and treatability testing capabilities do exist at the following facilities for mixed wastes having very low concentrations of radioactivity as specified by the facility RCRA permit: ${ }^{4}$

- Diversified Scientific Services, Inc. (DSSI), Kingston, TN - has an industrial boiler to combust solvents. The facility can accept mixed waste solvents and bulked scintillation liquids.

- Quadrex Corporation, Gainsville, FL - accepts liquid scintillation vials and fluids with limited amounts of tritium and carbon-14 for incineration in a rotary cement kiln. It is considering expanding the type of mixed waste its will accept.

- Envirocare of Utah, Inc., Salt Lake City, UT - accepts solid matrix mixed waste for stabilization.

- $\quad$ RAMP Industries, Inc., Denver, Colorado - accepts liquid scintillation vials and fluids with limited amounts of tritium, carbon-14, and isotopes with less than 120-day half-life for incineration in a rotary cement kiln.

- International Technology Corporation, Knoxville, TN - accepts samples of mixed waste for treatability studies.

- Nuclear Fuel Services, Inc., Erwin, TN - has conducted mixed waste treatability studies for the Pinellas Plant in the past.

Thus, although the use of commercial facilities is desirable, it is not considered a primary option due to the fact that only limited mixed waste treatment capability exists in the commercial sector at present. As discussed in Section 6.3.5, it might be possible to entice private industry to provide treatment capabilities if solicitations for treatment were tendered offering a contract to treat the entire DOE inventory of these wastes.

\subsection{Use of a Standardized Treatment Facility Design}

The use of standardized designs for fixed treatment units at DOE sites was considered but was not kept as a primary alternative. The standardized facility requires high initial construction costs for multiple facilities, redundant operational and maintenance crews at each facility, upkeep during both idle and operating periods, and decontamination and decommissioning upon completion of its mission. These costs are born only one time for the PTS and Centralized Facility options. 


\section{OPERATIONAL CHALLENGES/IMPLEMENTATION OBSTACLES}

\subsection{Regulatory Issues}

\subsubsection{RCRA Permitting}

A RCRA permit is required before treatment of MLLW, subject to RCRA jurisdiction, can be performed. To obtain a RCRA permit, the owner or operator of the facility must submit an application containing information specified in 40 CFR 270 and applicable subparts of 40 CFR 264 and 40 CFR 266. It should be noted that a different RCRA permit is required for each location at which the PTS is operated, even within the same state, due to the fact that RCRA permits are site specific.

From a regulatory perspective, very little information exists on the subject of obtaining a RCRA permit for mobile treatment units. This is primarily due to the fact that the EPA does not differentiate between the regulatory requirements for permitting mobile and fixed stationary treatment units.

On June 3, 1987, the EPA proposed that an expedited and abbreviated permit be provided for mobile treatment units expected to operate on a site for a limited period of time (52 FR 20914). These proposed rules were never promulgated and there are no plans to do so.,6

The failed proposal promoted developing a common portion of the permit to address the technical details of the treatment process and to then use a site-specific portion of the permit, which would have to be resubmitted for each new location. Support for this concept diminished when it became apparent that the permitting process could not be divided in this manner, and that each agency and the affected public would like the opportunity to address all issues and details each time the mobile unit would be permitted. These issues include assessing cumulative site emissions and corrective action plans.

Permits may be designed to cover the operation of a discrete treatment, storage, and disposal (TSD) unit or multiple TSD operations. Existing facilities operating under a RCRA permit, may request a permit modification under the provisions of 40 CFR 270.42 to add a portable treatment unit to its existing permit. This would be considered a major (Class 3 ) permit modification which requires full compliance with normal administrative permitting procedures.

The level of effort, time, and expense required to proceed with a Class 3 permit modification would likely be somewhat less than with an entirely new permit. Most of the information present in the original permit would not need to be reiterated in order to include a new treatment unit into the permit. The Part A portion of the permit would require minimal revision, as well as the waste analysis plan and contingency plan of the Part $B$ portion of the permit.

Based on the above discussion, it can be seen that the effort to obtain the required RCRA permit for operation of a PTS at a single site is the similar to that required for installation of a fixed unit. Permitting will be more costly for the PTS option than for a centralized fixed facility due to the fact that the PTS permitting process must be duplicated at each treatment location. 
Some advantage is gained in the permit application preparation stage by the fact that once a PTS is permitted, the permit application may prove beneficial to the permit application writers for the next permit application. Permit application and approval time-frames for a PTS may be shortened slightly from that of a newly designed fixed treatment unit if a favorable operating history exists to give regulators confidence in the PTS design.

\subsubsection{National Emissions Standards for Hazardous Air Pollutants (NESHAPs)}

National standards for emissions of hazardous air pollutants, as defined by the EPA, are given in 40 CFR 61. These hazardous pollutants include radionuclides, asbestos, benzene, beryllium, coke oven emissions, arsenic, mercury, and vinyl chloride. Owners and operators of facilities which exceed defined threshold limits are required to submit an application to the Administrator for approval of the construction of any new source or modification of any existing source. Thus, the National Emission Standards for Hazardous Air Pollutants (NESHAPs) permitting activities or notifications will likely be required before moving the PTS to a new treatment site, even if the expected emissions will be very small.

\subsubsection{Air Permitting}

Title $\mathrm{V}$ of the Clean Air Act (CAA) Amendments establishes a Federal permitting program which is to be administered by the states. The state programs must be substantially equivalent to the requirements found in the federal regulations. The state program can impose additional or more stringent requirements than those of the EPA. Title V declares that after the effective date of any approved or promulgated permit program, it will be unlawful to operate a major source, affected source, or any other source, including an area source, subject to the regulation under the CAA unless the source is in compliance with all air quality requirements and has an operating permit. Any facility which meets threshold emission limits established in the federal regulations is subject to Title V permitting requirements ( 40 CFR 70.2). The treatment of mixed wastes is subject to this threshold standard because of the potential emission of both radionuclides and hazardous constituents.

Under Title V, if a PTS is brought to a facility, the potential emissions from the unit must be considered in the total facility emission calculation to determine the appropriate permitting status. Permit modifications will likely be required for facilities with existing permits and facilities not exceeding threshold limits may add sufficient emissions to the total to require the facility to obtain an air permit. Thus, as with RCRA permitting considerations, the use of a PTS will require the same air permitting considerations and efforts similar to those which would be required when constructing a fixed treatment unit.

\subsubsection{Clean Water Act}

DOE sites which discharge wastewater to any waterway are required to obtain a National Pollutant Discharge Elimination System (NPDES) permit under section 402 of the Clean Water Act. Sites discharging directly to a municipal or publicly-owned wastewater treatment facility are subject to the Section 307 Toxic and Pretreatment Effluent Standards. A PTS operating as part of a wastewater treatment unit (as defined in 40 CFR 260.10) with an NPDES permit or subject to Section 307 pretreatment regulations would be exempt from RCRA permitting requirements, provided the site has obtained a NPDES permit and complies with the 
conditions as outlined. ${ }^{6}$ This exemption only applies if the PTS is physically located within the facility boundary as defined under 40 CFR 260.10 .

\subsubsection{National Environmental Policy Act}

NEPA requires that all Federal decision makers examine the impacts of a proposed action on the environment. Utilizing a PTS to treat mixed waste at Federal facilities would be considered a Federal action significantly affecting the environment and could, therefore, require preparation of either an EIS or an environmental assessment (EA).

DOE implements NEPA requirements in 10 CFR 1021. Appendix D to Subpart D of this regulation specifies that the siting/construction/operation of incinerators (other than research and development, other than non-hazardous) will normally require an EIS. Since the proposed PTS utilizes an incinerator, modification of an existing site-wide EIS or preparation of an EIS to cover the operation of the PTS may be required for each DOE site. Thus, use of a PTS will require the same NEPA documentation revisions for each DOE site as installation of a fixed unit.

\subsubsection{State Requirements}

EPA requirements are often, but not always, administered by the state after the state has demonstrated to the EPA that it has a program that contains requirements that are substantially equivalent to the requirements found in the Federal regulations. The state program can impose, and often do, additional or more stringent requirements than those of the EPA. For example, some states impose requirements for a permit to begin construction of a RCRA treatment/storage/disposal facility. These state-specific requirements must also be met before a PTS can be utilized at a new site.

\subsection{Technical Issues}

\subsubsection{Development Status Of Technologies}

No high risk design issues were found concerning the conceptualized PTS. No attempt was made to seriously consider technology alternatives or to optimize selection of technologies for the PTS. The technologies were chosen as plausible means of achieving the portable treatment of the identified wastes and as a reasonable basis for cost estimation. Should the decision be made to move forward with a PTS program for the DOE complex, alternative technologies should be thoroughly investigated. Of the technologies used in the proposed design, all are considered readily available except the Hydrothermal and the Thermal Desorption technologies.

The hydrothermal processing technology is proven but will have to be optimized for the wastestream compositions proposed for the PTS. Los Alamos National Laboratory (LANL) has operated small scale (0.1 - $10 \mathrm{~L} / \mathrm{min}$ ) hydrothermal reactors and Texaco has a large scale unit (built by Eco Waste Technologies) in operation in Austin, Texas. The major design uncertainties are selection of acceptable materials of construction, equipment life, and the capital equipment costs for chlorinated organics. Chloride corrosion poses a design concern which is accentuated by the high operating pressure (approximately $400 \mathrm{~atm}$ ) and the safety consequences of a reactor rupture. 
The Thermal Desorption technology is commercially available and has been used in soil remediation work for years. A skid mounted unit is currently under construction at the DOE Grand Junction facility. The primary design uncertainties are associated with defining the operating envelope for the types of wastes which the MTU will receive.

\subsubsection{Design Constraints}

The survey performed on the small generator wastestreams was a very general study to categorize the waste so that treatment trains could be proposed. It will be necessary to perform an in-depth inventory of the wastes and to identify those waste constituents which are important to detailed design and specification of equipment. This would include such things as emission and corrosion concerns associated with volatiles (e.g., mercury, chlorides, or acids); high radiation considerations; and unusually hard metals which will be hard to size. This information will be important to establishing the design materials and specifications and in formulating the waste acceptance criteria for the PTS.

Space constraints (footprint and height) for operation on trailers may preclude the use of certain technologies or unit operations that would otherwise be preferred in fixed treatment systems. The equipment used in the PTS will likely be similar equipment to that used in fixed facilities. All of the equipment must be designed to withstand the rigors of transportation and the frequent on-off cycling which the equipment will experience during shut-down and start-up at different sites. Maintenance programs should be included to provide for inspections, calibrations, and repair of disorders caused by the vibrations and stresses induced during transportation and by the operational cycling.

Appendix D discusses other detailed design considerations, including some of the major design assumptions and considerations which affected equipment sizing, specification, and estimated cost of the PTS to meet the processing throughput requirements stated in Table 2. Readers wishing more details concerning the design considerations should refer to Appendices $B, C$, and D.

\subsubsection{Operational Constraints}

The auxiliary systems that are required for treatment at fixed facilities may also be required for portable treatment, if not provided by the site at which the waste is processed. These may include portable HEPA/activated carbon filtered ventilation systems, emergency electric generators, uninterruptible power supplies, auxiliary fuel supply, caustic supply, water (potable and process), deionized water, compressed dried air, steam generator, spare parts storage, onsite analytical laboratory, shower and change facilities with capability for personnel decontamination, etc.

Successful operation of a PTS will require well defined waste processing requirements, scheduling of processing campaigns, and timely dispatching the mobile equipment for transport from site to site. Coordination must also be made with the host site to provide the area where the processing equipment will be setup, the utility hookups, and the process feed lines. To the extent possible, waste feed characterization, sorting, and repackaging must be performed by the host facility, rather than in the PTS. If these pretreatment steps are not performed correctly, the PTS may not meet the design on-stream factors which are crucial to meeting the waste treatment schedule requirements. 
The nature of the PTS operation requires frequent cycling of the equipment. This will require operators to bring the equipment to steady state and to begin operations. This process is not only potentially hard on equipment, from a maintenance stand-point, but may also result in off-specification product. Operational plans must be made to disposition any potential off-specification materials.

The operational reliability of the PTS processes and equipment will be directly related to uncertainties in the physical characteristics and chemical composition of the waste feed. Good characterization through waste assay and assessment will be critical in assuring the safety and reliability of these processes. A waste acceptance program and waste certification program will be required.

\subsection{Institutional Issues}

\subsubsection{EPA Policy}

On May 19, 1993, the EPA Administrator published the current EPA policy on combustion strategy which called for a moratorium on permitting of all new incinerators and for a reevaluation of the standards applicable to existing permits, as well as those for new permits. The impact of this decision was that all pending permit applications were frozen nationwide. ${ }^{5}$

The Environmental Technology Council has petitioned the EPA to include thermal desorbers and sludge dryers within the regulated community. The exact nature of the regulations cannot be ascertained at this time, but it seems reasonable to assume that standards will be set concerning air emissions, probably including at least particulates, volatile organic compounds, mercury and other metals, and dioxins and other specific compounds. 5

The EPA policy regarding standards for incinerators has not yet been finalized. When final, the policy and resultant regulations may contain both technology-based emission standards and a requirement for a detailed risk analysis for each source in the permit. The first proposed rule regarding revised standards for hazardous waste incinerators was issued on April 19, 1996 (61 FR 17358). In this proposed rule, the EPA is proposing to subject all hazardous waste incinerators, hazardous waste-burning cement kilns, and hazardous waste-burning lightweight aggregate kilns to regulation as major sources. The proposed rule states: "Todays proposal constitutes one of many EPA actions to ensure that sources accounting for at least $90 \%$ of emissions of Part 112(c)(6) pollutants are subject to MACT standards."

The April 19, 1996 proposed standard limits emissions of chlorinated dioxins and furans, other toxic organic compounds, toxic metals, hydrochloric acid, chlorine gas, and particulate matter. These standards reflect the performance of Maximum Achievable Control Technologies (MACT) as specified by the Clean Air Act.

The above sequence of events leads to the conclusion that the current EPA policy is to discourage the permitting of any new incinerator and, by association, other thermal treatment units if there is any possibility of hazardous and/or radioactive air emissions from the unit. It seems clear that the present standards for these units will become more stringent if current trends continue. 


\subsubsection{State Equity}

States have an interest in cooperating with DOE to accomplish implementation of treatment strategies for mixed waste. Each DOE site must negotiate a STP with its respective state. By accepting the STP, the state has acknowledged and accepted the schedule and approach to accomplishing treatment of the waste so that land disposal storage prohibition requirements (40 CFR 268.50) are met. Failure to meet treatment schedules causes the need to renegotiate the STP, which is undesirable, costly, and potentially embarrassing to both the DOE and the state. Thus, it is in both the DOE's and the state's best interest for DOE to accomplish treatment of its wastes in a timely manner.

States have less vested interest in allowing wastes from DOE sites outside of the state to be transported into the state for treatment at a centralized facility. States have indirect control of this influx of mixed waste since they approve and enforce STPs, RCRA permits, and air permits which may be affected by inventories introduced by "outside the state" generators. Thus, if permit writers did not originally anticipate and allow for treatment of inventories of waste from outside of their local realm, it is possible that renegotiation of the STPs and permits may be required. As discussed in Section 5.1, this may mean employing restrictions to insure that wastes are treated and disposed of in a timely manner with treatment residuals properly disposed of in a permitted land disposal unit or returned to the generator for storage. This helps state regulators . address the "not in my backyard" political sentiment for nuclear activities. In this respect, a PTS may offer an advantage since they reduce the need for waste transfers between sites/states.

\subsubsection{Public Stake Holder Issues}

The potential emissions from the treatment unit frequently form the basis for the intensity of public interest. Incinerators are perceived as large quantity emitters, while other thermal treatment units are perceived as emission-controlled devices. Therefore, the former are more actively opposed by the public than the latter, making it incumbent on the applicant to carefully design and explain all emission control devices associated with the thermal treatment unit.

Citizen groups (e.g., the Citizens Clearinghouse for Hazardous Waste) are actively seeking ways to fight incinerators that burn medical, hazardous, and solid wastes, including cement kilns burning waste fuels. These groups are becoming more numerous and active nationwide and can be expected to take an active interest in any mobile treatment unit application that is perceived as having any potential hazardous emissions. $^{5}$

Citizen groups can be expected to pay particular attention to any mobile thermal treatment proposed for treating mixed waste. The potential of both hazardous and radioactive materials in the treatment unit emissions will provoke intense interest and opposition will likely occur. 


\subsubsection{Ownership and Maintenance of Equipment}

The fact that the PTS will be moved from one DOE site to another raises some unusual considerations concerning normal requirements for ownership, operation, and maintenance of the equipment associated with the PTS. Some issues which must be addressed include:

- Will the safety analysis report, technical safety requirements, and procedures approved by one DOE field office be accepted automatically by another field office or will these documents have to undergo review, possible modification, and approval by each field office utilizing the PTS?

- Will an operational readiness review (as required in DOE Order 425.1, "Startup and Restart of Nuclear Facilities") be performed each time the PTS is moved to a new location to ensure that the people (supervisors and operators), equipment, and operating documentation are ready prior to startup?

It is unlikely that any DOE field office or operating contractor will blindly accept the operational responsibility for the treatment units without routing the controlling documentation through their normal review and approval channels and participating in an operational readiness review.

The above discussions suggest that some form of cooperation between the DOE field offices is necessary, in the interest of cost and time savings, if the PTS is to be used. This would require memorandums of understanding (MOUs) between each of the field offices to assign authority and responsibility for operation of the PTS to DOE-HQ (or an appointed field office). Basically, this would make the operation of the PTS a stand-alone operation with operational approval authority and control at some centralized point within the DOE system. The centralized authority for the units must address requirements such as:

- Scheduling use of the PTS

- Transportation of the units between sites

- Controlling and engineering modification to the units

- Maintaining documentation and configuration control

- Storage of the units when not in use.

Similar considerations exist for providing an adequate maintenance program for the PTS. If local maintenance crews and equipment are used to maintain the equipment, maintenance procedures will likely have to be converted to meet normal site format and content requirements and some training may be required for the local maintenance personnel to familiarize them with specific hazards of the PTS.

One option to minimize the cost of preparation of NEPA, RCRA, and other safety documentation for use of a PTS is to assemble a team to prepare or aid in the preparation of required documentation. This approach lessens the learning curve and maximizes consistency. 


\subsubsection{Privatization Opportunities}

Based on the above discussion, the ownership and operation of a PTS by a private firm, selling the services to each DOE site, is a logical approach. Commercial contractors might be enticed to build, permit, and maintain a treatment capability if the DOE establishes a contract with guaranteed waste volumes.

As already discussed, a privatized PTS will face many of the same permitting issues as DOE. However, they will enjoy some advantage in the required permitting and documentation, since they are not subject to NEPA review requirements or DOE orders. The permit application information for the commercial unit will not include the cumulative emissions from the associated DOE site, although the DOE cumulative emissions may be a consideration factor when the state reviews and approves the permits for the treatment unit.

Commercial contractors will likely have less difficulty in accomplishing startup of the PTS at each site due to the fact that they are not subject to different oversight organizations, as is the case with DOE field offices. Also, a privatized operation inherently uses a common crew of supervisors, operators, and maintenance personnel and accepts the responsibilities for safe start-up and operation of the facility. This concept of using a continually mobile, dedicated crew is uncommon to DOE operations which are normally performed at a single location.

Use of commercial treatment facilities offers other advantages to the DOE including:

- It eliminates the need for a large DOE initial capital expenditure to build, permit, and prepare necessary documentation to operate an equivalent treatment facility.

- It eliminates the large DOE expenditure at the end of the equipment operating life for final decontamination and decommissioning.

- The subcontractor, not DOE, assumes the financial risk if the PTS does not operate successfully.

- Many difficulties associated with multiple DOE field office owners of safety concerns are eliminated by the introduction of the traditional DOE/sub-contractor interface.

- The sub-contractor assumes legal liability in terms of proper operation of the treatment facility and compliance with associated permits.

Perhaps, the more distinctive advantage offered to DOE by privatization of treatment of small site MLLW streams is that it allows DOE to minimize its financial risks and, in effect, amortize the cost of treatment over many years rather expending capital equipment dollars at the beginning and end of the PTS life. 


\section{TECHNOLOGY DEVELOPMENT OPPORTUNITIES}

The approach taken for the design of the PTS made use of demonstrated available technologies (BDAT) and technologies selected by the Albuquerque Operations Office to be used in mobile treatment units. Table 10 shows the technologies proposed for the conceptualized PTS. These technologies utilize proven chemical and mechanical techniques including neutralization, precipitation, filtration, evaporation, gas scrubbing, ion exchange, activated carbon adsorption, polymer microencapsulation, and cement microencapsulation. Underdeveloped technologies included in the PTS design include the hydrothermal process, the liquid fume incinerator, and the thermal desorption unit.

As discussed in Section 6.3.1, incinerators are under significant regulatory pressure. The proposed liquid and fume incinerator and thermal desorption unit of the Organics MTU present potential permitting difficulties. The controlled oxidation of organics is a very necessary part of the treatment of the identified inventories of mixed wastes. $R \& D$ efforts should be directed at providing a means of incineration or controlled oxidation and thermal desorption which will meet the anticipated more stringent requirements of the EPA.

Advantages could be realized if a single technology could be developed which could replace or eliminate the need for multi-step process requirements for the technologies identified in Table 10. Technologies which can accept a great variety of feed materials with minimal conditioning or sorting requirements could eliminate some of the undesirable, labor intensive manual sorting, handling, sizing, and/or bulking of wastes. For example, an oxidation technology that accepts solids with organics can eliminate the need for a thermal desorption unit and its associated condensers and offgas train as a pre-treatment step to oxidation.

The conceptual design of the PTS did not take final waste volume as a primary design consideration. For example, stabilizing debris by cementation in a drum presents a major increase in volume and weight of the original waste form. $R \& D$ efforts should consider processes which offer more efficient waste minimization alternatives to see if political and/or cost trade-off advantages can be enjoyed. Technologies which could reduce characterization analysis requirements, due to a less restrictive waste acceptance criteria, should be considered to minimize characterization expenses. Designs for new and existing technologies should consider ways to minimize decontamination costs and considerations of the PTS. Improvements in these technologies will be of benefit to not only low-level mixed waste treatment, but also to alpha-low-level and transuranic waste treatment.

MLLW treatment offers the logical proving ground to technologies for treatment of alpha-low-level and/or transuranic wastes. Advances in minimizing waste volumes and characterization costs may be more significant for these wastes than for low-level wastes.

The EPA is working to establish requirements for regulating incinerators, including risk assessment requirements. DOE could work with the EPA in establishing requirements and acceptable technology solutions to the environmental concerns, especially with regard to new oxidation technologies suitable for mixed waste. 
Table 10. Primary proposed technologies for the conceptualized MTUs.

\begin{tabular}{|c|c|}
\hline MTU & Proposed Technology \\
\hline Organics & $\begin{array}{l}\text { 1) Liquid fume incinerator } \\
\text { 2) Thermal Desorption } \\
\text { 3) Polymer Microencapsulation }\end{array}$ \\
\hline Labpacks & $\begin{array}{l}\text { 1) Manual sorting and segregation of organic and inorganic containers. } \\
\text { 2) Organic solids filtration. } \\
\text { 3) Inorganic chemical deactivation in mix tanks } \\
\text { 4) Inorganic solids filtration. }\end{array}$ \\
\hline Debris & $\begin{array}{l}\text { 1) Manual sorting } \\
\text { 2) Shearing and crushing } \\
\text { 3) Cement Mircroencapsulation }\end{array}$ \\
\hline Wastewater & $\begin{array}{l}\text { 1) Redox adjustment } \\
\text { 2) pH neutralization } \\
\text { 3) Liquid filtration } \\
\text { 4) Hydrothermal organics destruction } \\
\text { 5) Reverse osmosis (RO) dissolved salt removal } \\
\text { 6) Evaporator concentration (of RO output) }\end{array}$ \\
\hline
\end{tabular}




\section{CONCLUSIONS}

The information in this report compares the economic, technical, and institutional aspects of implementing a PTS, or a centralized treatment facility to treat the wastestreams designated for portable treatment in the 1995 STPs. Three major conclusions were reached from the information presented in this report:

- If site costs are not considered, then no significant cost advantage or disadvantage will be realized by the use of a PTS rather than a centralized treatment facility for the design capacity of 2900 $\mathrm{lbs} / \mathrm{hr}$. In this case, the total life-cycle costs are within $10 \%$ of each other. However, if site costs are included then the total costs of implementing a PTS are approximately $20 \%$ greater than the centralized facility costs, and it is economically more effective to use a centralized facility.

- No significant technical obstacles were identified to designing and implementing equipment to accomplish treatment of the wastes streams identified as candidates for PTS treatment, either in a PTS or a centralized facility. All proposed technologies are either available as standard items or proven in both pilot and full scale operations.

- More risk/uncertainty is attributed to the implementation of a PTS than to a centralized facility due to the fact that the permitting/NEPA documentation process must be performed multiple times for the PTS. The incinerator associated with the Organic MTU poses the most probable point of dissension due the fact that incinerator use is opposed by special interest groups and more stringent regulatory requirements are anticipated to be promulgated that will make it more difficult to obtain necessary permits for incinerator operations. The successful permitting of a single centralized facility is deemed more probable than the successful permitting of a PTS at multiple treatment sites located within multiple states.

- The uncertainty associated with use of a PTS could be reduced by procuring the required services from a commercial vendor. This would eliminate some of the administrative obstacles that are required for DOE facilities.

It should be recognized that the waste inventory utilized as the basis for the treatment systems considered in this study is changing rapidly. The waste inventories currently present in the DOE complex have decreased significantly from those represented in the 1995 waste data set used for this study. Individual DOE sites are actively seeking means of treating mixed wastes and are finding avenues for treatment including arrangements with existing DOE treatment facilities, commercial facilities, and onsite treatability studies for very small quantities. Thus, as the available avenues are utilized, the waste inventory composition will change and many of the remaining wastestreams will be those having characteristics which make them difficult to treat. Thus, the study should not be viewed as the final recommendation for what treatment trains are needed in either a PTS or a centralized unit. Rather, the study should be used to recognize the advantages and disadvantages of a PTS over a centralized system.

One aspect of this study that could use further attention is what are the characteristics of existing wastestreams that make centralized treatment unattractive? Uncertainty exists concerning why site personnel 
designated wastes for portable treatment in their STPs rather than identifying transport to other offsite treatment facilities. Detailed wastestream examination will be required to answer this question. 


\section{RECOMMENDATIONS}

This study identifies that existing technology can provide the needed treatment of most candidate MLLW streams. The fact that the inventories of MLLW contain relatively small volumes of many wastestreams makes it difficult to propose treatment options which have small unit treatment costs. The cost for treatment of MLLW from small sites seems to be similar for the available options. The authors of this report have concluded that centralized treatment of MLLW, when technically feasible, is preferable to portable treatment due primarily to the fact that fewer permitting difficulties are anticipated with this option.

The above recommendation assumes that no waste-specific considerations impair the ability to transport and treat these wastes. Wastestream-specific study and input is needed to identify those wastes which present specific transportation and treatment problems. Examples of problematic wastes might include reactives which cannot be shipped, incinerable wastes which do not meet acceptance criteria for available incinerators, or liquids which have small allowable shipping allowances if a DOT Type A shipping container is required. Recognizing problematic wastes will require in-depth knowledge of the properties of each wastestream. Some or all of this knowledge may be available from the mixed waste focus area, and should be compiled with specific transportation and treatment considerations in mind. Treatment of these wastes may require $R \& D$ efforts to identify acceptable methods of pretreatment to make a waste acceptable for transportation or to treat the waste at or near the storage location. This information may identify a needed and specific role which is best suited for a PTS.

Portable treatment systems might be justified if either of the following are true:

- Transportation of the waste is not feasible and/or common treatment requirements exist at two or more sites.

- Treatment technology for DOE wastes can be applied to other industries or customers.

R\&D efforts could have a positive impact on permitting uncertainties. Efforts which would be beneficial include:

- Reducing incinerator effluents consistent with the anticipated future regulatory requirements.

- Providing oxidation technologies which pose an alternative to open flame incineration.

- Providing treatment technologies which reduce the multi-step treatment requirements for waste treatment, (e.g., in this conceptualized PTS).

- Provide technologies which reduce the final treated waste volume offered by traditional cement and polymer encapsulation and stabilization technologies.

Better alternatives for these issues will be useful in gaining the acceptance of treatment facilities by the public and regulators. 


\section{REFERENCES}

1. T. D. Kirkpatrick, DOE Waste Treatability Group Guidance, DOE/LLW-217, Revision 0, Lockheed Martin Idaho Technologies Company, Idaho National Engineering Laboratory, January, 1995.

2. Mixed-Waste Treatment Program Waste Treatment Technologies Plan and Technical Summary, PGJPO-1926, U.S. Department of Energy, Grand Junction Projects Office, Prepared by Rust Geotech, August 31, 1995.

3. Test and Evaluation Document for DOT Specification 7A Type A Packaging, DOE/RL-96-57, Revision 0, prepared for the U.S. Department of Energy, Office of Transportation, Emergency Management, and Analytical Services, August, 1996.

4. ALMixed Waste Treatment Plan, report of the Treatment Selection Team, prepared by Larbi Bounini, Grand Junction Project Office, and others, final issue, March, 1994.

5. Regulatory Issues Relating To Mobile Thermal Treatment Units, prepared for Martin Marietta Energy Systems, Oak Ridge National Laboratory by IT Corporation, April, 1995.

6. Kenneth A. Kuzio, Survey of Mixed Waste Treatment Technologies For Mobile Treatment, Sandia National Laboratories, prepared for the U.S. Department of Energy, May 1994. 



\section{Appendix A \\ Wastestream Analysis Report}


- 


\section{Appendix A \\ Wastestream Analysis Report \\ By}

B. C. Musgrave, Inc.

\section{A-1. Background and Rationale for the Use of Mobile}

Treatment Units in the Current Site Treatment Plans

\section{A-1.1 Background: Technology Selection}

Mobile treatment units are considered reasonable alternatives for treating mixed wastes at several Department of Energy (DOE) facilities. The DOE Albuquerque Operations Office (AL) sponsored the main effort of analyzing potential applications of mobile treatment units. A series of reports from the DOE-AL effort display the evolution of planning within this program. A Treatment Selection Team matched a list of 32 selected treatments to mixed waste streams requiring treatment, Table A-1 ${ }^{1}$. The treatments included multi-step processes. Included in the treatments list were potential new facilities, the existing DOE Controlled Air Incinerator at Los Alamos National Laboratory, Glass Melter at Mound, and commercial facilities, Quadrex/DSSI incineration and Envirocare stabilization and disposal. A set of treatment technologies for further development and possible implementation was identified based on indicated treatment needs. This consolidated list contained 24 technologies to be pursued initially, with decision on continued development delayed to a later date, Table A-2. Technologies in Table A-2 are numbered 1 through 24 for tracking technologies through the following discussion and the related Tables A-3 through A5. Most of the list was made up of technologies that would require some development before decisions could be made on design and fabrication of operating units.

A June, 1995 draft report listed 13 mobile waste treatment units that were being developed for use by DOE-AL sites to treat wastes in accordance with their proposed site treatment plans, Table A-3. ${ }^{2}$ Refinement of the proposed list continued in parallel with the preparation of site treatment plans. Four units were dropped from further development support, because commercial vendors had been identified. Two units were to be resized to fit current waste quantity projections. A total of eight mobile treatment units were still being proposed for development and implementation by DOE Government-owned contractor-operated (GOCO) sites, Table A-4. The STPs from some non-Albuquerque sites also contain references to mobile or transportable treatment units. One unit the Transportable Vitrification Facility at Oak Ridge is mounted on trailers but is to large to be considered in the evaluation of applications of MTUs. Eight MTUs were identified in the Portsmouth STP. And one, a water treatment unit was identified by INEL, Table I-5. Two facilities identified as mobile technologies in the Ohio Sites' Treatment Plans require multiple technologies, but the specific technologies were not defined. Wastes assigned to the Ohio mobile option need to be examined for assignment to mobile units within the technology set in the AL analyses. Treatment of laboratory packs and the recovery of metals, primarily silver, appear as unique waste treatments for mobile units and do not fit into any of the better defined MTUs. 
Table A-1. Selected treatment system ${ }^{1}$

\begin{tabular}{|c|c|}
\hline Treatment & number \\
\hline Amalgamation (AMLGM) & 1 \\
\hline Biodegradation & 2 \\
\hline Calcining & 3 \\
\hline Chelating fo Decontamination & 4 \\
\hline Chelating fb Stabilization & 5 \\
\hline Decontamination only & 6 \\
\hline DETOX & 7 \\
\hline Evaporative Oxidation fo STABL & 8 \\
\hline Gas Treatment Skid & 9 \\
\hline Hydrothermal Oxidation & 10 \\
\hline MACRO (macroencapsulation) & 11 \\
\hline Molten Salt & 12 \\
\hline Neutralization fb STABL & 13 \\
\hline Nitrate to Ammonia Ceramic & 14 \\
\hline Ozone, UV & 15 \\
\hline Packed Bed Reactor/Silent Discharge Plasma & 16 \\
\hline Plating Skid (Plating waste treatment) & 17 \\
\hline Reactive Metals Skid & 18 \\
\hline Retort fb AMLGM & 19 \\
\hline Retort fb Recovery (mercury) & 20 \\
\hline Separate, Survey, Decon & 21 \\
\hline Stabilization (STABL) & 22 \\
\hline Steam Reforming & 23 \\
\hline Sulfate Precipitation (of Barium) & 24 \\
\hline Super Critical $\mathrm{CO}_{2}$ & 25 \\
\hline Super Critical Water & 26 \\
\hline Thermal Desorption & 27 \\
\hline Triple Distillation Recovery (Mercury) & 28 \\
\hline Uranium Chips Skid & 29 \\
\hline CAI, Controlled Air Incinerator LANL & 30 \\
\hline Envirocare & 31 \\
\hline Quadrex/DSSI & 32 \\
\hline
\end{tabular}


Table A-2. Technology information sheets from Al MWT Plan².

\begin{tabular}{|c|c|c|}
\hline & Technology & AL \# \\
\hline Amalgamation & & 1 \\
\hline Barium Treatment & & 2 \\
\hline Chemical Precipitation & & 3 \\
\hline Controlled Air Incinerator & & 4 \\
\hline DETOX & & 5 \\
\hline Electroplating Skid & & 6 \\
\hline Evaporative Oxidation & & 7 \\
\hline Gas Treatment Skid & & 8 \\
\hline Hydrothermal Processing & & 9 \\
\hline Mound Glass Melter & & 10 \\
\hline Lead Decontamination Trailer & & 11 \\
\hline Macroencapsulation & & 12 \\
\hline Mercury Retorting & & 13 \\
\hline Neutralization & & 14 \\
\hline Packed Bed Reactor & & 15 \\
\hline Reactive Metals Skid & & 16 \\
\hline Silent Discharge Plasma & & 17 \\
\hline Solidification/Stabilization & & 18 \\
\hline Sort, Survey, Decon & & 19 \\
\hline Steam Reforming & & 20 \\
\hline Treated Water Evaporation & & 21 \\
\hline Triple-still Mercury Distillation & & 22 \\
\hline Uranium Metal Oxidation Skid & & 23 \\
\hline Vacuum Thermal Desorption & & 24 \\
\hline
\end{tabular}


Table A-3. Waste treatment technologies from MWTP Waste Treatment Technology Summary. ${ }^{2}$

\begin{tabular}{|l|r||}
\hline & AL\# \\
\hline Amalgamation of Elemental Mercury & 1 \\
\hline Chemical And Plating Waste (Electroplating Skid) & 6 \\
\hline Evaporative Oxidation & 7 \\
\hline Gas Treatment Skid & 8 \\
\hline Hydrothermal Processing & 9 \\
\hline Lead Decontamination Trailer & 11 \\
\hline Macroencapsulation & 12 \\
\hline Packed Bed Reactor/Silent Discharge Plasma & 15,17 \\
\hline Stabilization Barium Precipitation & 2 \\
\hline Thermal Desorption & 24 \\
\hline Tritium Capture (added to PBR/SDP) & new \\
\hline Uranium Chips Skid & 22 \\
\hline Waste Water Evaporation & 21 \\
\hline Water-Reactive Waste (Reactive Metals Skid) & 16 \\
\hline & total number of technologies \\
\hline
\end{tabular}

*Number is that assigned in Table 2 for correlation of treatment technologies through out the tables. 
Table A-4. Mobile treatment units supported in AL STPs *

\begin{tabular}{|l|r|}
\hline \multicolumn{1}{|c|}{ Technology } & AL\# \\
\hline Amalgamation of Elemental Mercury & 1 \\
\hline Chemical And Plating Waste (Electroplating Skid) & 6 \\
\hline Evaporative Oxidation & 7 \\
\hline Gas Treatment Skid & 8 \\
\hline Hydrothermal Processing & 9 \\
\hline Lead Decontamination Trailer & 11 \\
\hline Macroencapsulation & 12 \\
\hline Packed Bed Reactor/Silent Discharge Plasma/Tritium Capture & 15,17 \\
\hline Sort, Survey, Decon & 19 \\
\hline Thermal Desorption & 24 \\
\hline Treatability study & New? \\
\hline Water-Reactive Waste (Reactive Metals Skid) & 16 \\
\hline & 15 \\
\hline
\end{tabular}

*Number is that assigned in Table 2 for correlation of treatment technologies through out the tables. 
Table A-5. Mobile treatment units recommended by AL August $95^{3}$.

\begin{tabular}{|l|r|r||}
\hline & STP \# & \multicolumn{1}{c|}{ AL\# } \\
\hline Amalgamation of Elemental Mercury & PI-S801 & 1 \\
\hline Chemical And Plating Waste (Electroplating Skid) & LA-S004 & 6, resize \\
\hline Evaporative Oxidation & GJ-S801C & Cóm \\
\hline Gas Treatment Skid & LA-S801 & Com \\
\hline Hydrothermal Processing & LA-S804 & Com \\
\hline Lead Decontamination Trailer & LA-S001 & 11 \\
\hline Macroencapsulation & PX-S803 & 12 \\
\hline Packed Bed Reactor/Silent Discharge Plasma/Tritium Capture & SA-S801 & 15,17 \\
\hline Stabilization & (PX-S803++) & Com \\
\hline Treatability Study Solidification/ Neutralization & SA-S807 & \\
\hline Thermal Desorption & GJ-S801 B & 24 \\
\hline Waste Water Evaporation & & -- \\
\hline Water-Reactive Waste (Reactive Metals Skid) & LA-S003 & 16, resize \\
\hline total number of units & & 12 \\
\hline
\end{tabular}

*Number is that assigned in Table A-2 for correlation of treatment technologies through out the tables.

\section{B . Background: Basis and Assumptions}

DOE-AL presented the assumptions and basis for proceeding with metric tons of uranium (MTU) as a key element of the plan.

Portable treatment units. First the size, diversity, and economy of waste streams justify the use of packaged, portable treatment units. In all cases, a treatment unit sized to work off the accumulated backlog of waste is oversized for the ongoing waste stream. The unit would have appreciable down time, allowing use at other sites. Even if movement of the treatment unit becomes impractical, the design of portable packaged treatment units allows rapid and economic replication of additional units for other sites. ${ }^{\text {? }}$

The assumptions in these statements seem appropriate at first glance but are not necessarily correct.

1. The size, diversity, and economy of waste streams justify the use of packaged, portable treatment units.

An examination of the tradeoffs of size, diversity, and cost of operating MTUs is not apparent in the documentation that has been prepared by the Albuquerque or any other program so far. 
Economics: A detailed discussion of the assumptions supported by an economic analysis was not presented, but there seem to be several implicit assumptions behind the statement.

- The cost of equipment is a major factor in life cycle costs for mixed waste treatment.

- Permitting MTUs will be faster and cheaper than for an equivalent "fixed" treatment facility.

- Site support costs continue for fixed treatment units that do not have a corresponding cost for a mobile unit.

- By making the skid mounted unit "one size fits all" there will be significant cost reductions to the overall system.

Because the equipment cost is a minor fraction of life cycle costs for waste treatment, it may be less expensive to commit (essentially expending) a set of modular equipment for the one time work off of a small, difficult stream that exists only in inventory. For the same reasons, fixed small sized equipment for a stream that is generated at a very low rate also may be less costly in time and resources than the cost and difficulty of moving contaminated treatment modules.

Size: For almost any waste matrix there are DOE mixed low-level waste streams of a wide range of sizes. The apparent key determinant used in the DOE-AL analyses is the waste stream size at any particular site. The question of whether the stream will be generated on a continuing basis at the site, and, therefore, there would be a continuing need for treatment of this waste stream, is of equal importance.

Diversity: Wastes in the DOE inventory cover a similar range of waste matrices and contaminants although the quantities at the different sites vary widely. There are very few truly unique wastes, wastes that will require one of a kind processing. Some $2000 \mathrm{DOE}$ mixed wastes streams are distributed into about 150 different matrix categories with various EPA regulated properties and an array of radionuclide levels; these can all be treated through some dozen or less treatment trains. Wastes which appear to be different will still have the same matrix-contaminant-treatment requirement and will be treatable in a generic treatment process.

2. In all cases, a treatment unit sized to work off the accumulated backlog of waste is oversized for the ongoing waste stream.

This also is not strictly correct and therefore is misleading. The total DOE 5-year projection of waste generation is about $25 \%$ of the current inventory. When there is an large inventory only with very little future generation it may be reasonable to bring in a moderate sized MTU to work off the backlog and install a very small local fixed unit to support the continuing waste treatment requirement. In many cases there is no future generation expected so work off of the inventory is all that is required. The time assumed in the $\mathrm{AL}$ analyses for work off of the backlog is not provided and could be varied over a reasonably wide range to optimize use of treatment units. In some instances the stored waste inventory is quite small compared to the projected future generation. In this case a unit sized to handle the projected generation of wastes could work off the 
backlog without particular increase in capacity or significant increase in operating time. The projected future waste generation data are very difficult to pin down and therefore a difficult basis for providing treatment capacity.

3. The unit would have appreciable down time, allowing use at other sites.

If a unit is apparently oversized for the onsite waste treatment obligation, available time for possible use at another site does not guarantee it is practical to use this slack time. Evaluation of the costs impacts and difficulties of relocating the unit to another site have not been presented. Operating effectiveness, or net waste treated per year, is certainly an important parameter to be used in evaluating options for treatment of wastes. Some down time is required for any processing operation. Down time allows time for maintenance, upgrading, and staff training. Key operating staff are assumed to travel with the MTU. Some of the human power required for operation of the unit should be available for assignment to other duties, and should not represent an ongoing cost. Much focus of site thinking and planning is on primary treatment (e.g., organic destruction and organic separation). Complimentary units are also provided in the DOE-AL analysis. Support efforts like waste feed preparation residue and waste water treatment may be assigned to separate units to be operated by the site resident staff.

4. Even if movement of the treatment unit becomes impractical, the design of portable packaged treatment units allows rapid and economic replication of additional units for other sites.

This certainly is correct and is reasonable where the module sizes are appropriate. Savings will be in equipment costs only; realistic cost estimates still must be used for the remainder of project costs for any waste treatment alternative. This assumption needs to be thoroughly tested in the Mobile Treatment Unit Study. The assumption that "one size fits all" modules will significantly decrease equipment costs may be overwhelmed by the problem of fitting fixed-size modules to widely varied local needs.

\section{Other considerations not explicitly addressed in the DOE-AL reports}

There should be a regulatory advantages for small dedicated facilities.

Potential advantages of keeping wastes segregated into small groups to take advantage of simpler regulatory approvals has not been addressed except for treatability studies. Certainly the better defined and better controlled (small variation in matrix and contaminants) a waste stream is the easier it is to prepare permit applications and for regulatory agencies to review and approve those applications. Generally also, a treatment process is easier to operate with a narrowly defined feed stream. These costs are quickly offset by the increased effort required to permit multiple treatment units with different technologies. The advantage of easier permitting of small limited processing units may be fully realized if standardized applications and permitting of common units at different DOE sites in different states could be achieved.

All of the above factors must be weighed in the decisions to select treatment technologies. The situation and considerations will be quite different for wastes that have a difficult matrix and are primarily 
stored in inventory with little or no future generation projected compared to a waste that has a relatively simple treatment requirement but will be generated indefinitely.

II. Highlights Of Recommendations For Combining Waste Streams and a discussion of the question, b) "Does it make sense to combine any of the waste streams with each other or with larger mixed waste streams destined for nonmobile DOE or commercial treatment facilities?" follows.

\section{A. Considering all mixed low level wastes in the DOE complex}

From a examination of the best DOE wide alternatives the answer to item II and question $b$ for is 1 ) to send any stream to any permitted commercial sector treatment and 2) to send various waste streams from the small sites to the larger nearest-neighbor DOE sites much like was done in the PEIS. This provides an optimum utilization of treatment capabilities throughout DOE. The preferred case for the DOE PEIS made no use of Mobile Treatment Units. The Site Treatment Plans used mobile units for some wastes at some sites. The approach was not consistent throughout the DOE.

Constraints placed on the assignment of wastes from small sites to larger sites in the PEIS cases were that the large site needed the treatment capability for on-site wastes and that the small site waste stream radionuclide content were consistent with the those at the larger site. The assumption used for defining which wastes were treated on-site and which were to be shipped in the PEIS analyses was that all sites would have a basic or minimum aqueous waste treatment capability. The waste water treatment sludges or filtered solids would be stabilized at the site in the base treatment alternative. For the case involving thermal treatment these filtered solids and sludges would be sent to one of the larger sites that provided vitrification. Organic matrix wastes and or wastes with RCRA organic constituents requiring incineration were assigned to the nearest neighbor with incineration capability. Besides the existing incinerators, it was assumed that one would operate at INEL and one at Hanford for most PEIS cases.

It makes sense to send wastes from the smaller sites and wastes with particular contaminant problems or special treatment requirements from any site to the larger sites where the appropriate treatment capability would exist. A good example of this is for all sites with small quantities of wastes with RCRA organics and PCBs or other TSCA regulated constituents to send these wastes to the TSCA incinerator at Oak Ridge. That is basis for analysis in the PEIS and in the Draft Site Treatment Plans. Even INEL, with plans for thermal treatment capability for most of their own wastes, planned to ship some wastes to the TSCA unit. This allows DOE to avoid the cost of permitting additional incinerators for destruction of small amounts of PCB wastes at other sites.

Mixed low-level wastes with PCBs and PU-alpha activity were to be sent to the CAI at Los Alamos. This make sense. There are very few waste streams in the complex with both PCBs and PU-alpha contamination. DOE would have no need for another facility. Now, with the decision made to abandon CAI, DOE does need another capability. The commercial sector facilities are not qualifiable for PU-alpha containment; TSCA and CIF at Savannah River also are not qualifiable for handling PU-alpha contamination. Should a facility ever be built to incinerate the TRU wastes at INEL, this could become the de facto DOE facility for alpha-PCB wastes. 
In another example, liquid or elemental mercury was assigned to a single site, Oak Ridge, assumed to have the greatest need and the greatest potential capacity for elemental mercury management. The (MK) treatment modules used in the PEIS analyses at all sites had mercury stabilization as an integral part of the offgas treatment system for management of any tramp mercury released during treatment of mixed wastes.

The assumptions in the Site Treatment Plans were similar to those in the PEIS 11 site case. In the STPs, wastes were not necessarily assigned to the nearest-neighbor expected to have the appropriate capability. Assignments were based on waste stream by waste stream specific considerations and preliminary agreements with the "receiving" site; if a site seemed willing to treat an off-site waste and had, or planned to have, the capability those considerations over rode the question of proximity. The facilities in the STPs consist of a large number of mostly single technology facilities where by contrast the facilities in the PEIS were generally multipurpose integrated facilities providing capability to treat all MW physical matrices with any possible RCRA characteristic or constituent.

\section{B. Considering only the wastes identified for transportable treatment units in the STPs}

The STPs from some Non-Albuquerque sites also identified Mobile Treatment Units that would handle small quantity wastes. These units are identified in Table II-1. The right hand column in this table shows the identification numbers for AL MTUs that provide equivalent treatment. Three Ohio MTUs appear to be different from any treatment provided with the Albuquerque MTUs. These are Pretreatment Regeneration PO-S802, Laboratory Packs Treatment PO-S806, and Metal Recovery PO-S807.

The only waste stream to the Pretreatment Regeneration unit is a granular carbon sludge contaminated with regulated organics only; this waste should be treated easily at the TSCA incinerator. The recovered value of the carbon adsorbent is certainly much less than the cost of construction, permitting and operation of a single purpose unit.

Feed to the Metal Recovery unit is primarily silver bearing waste. It is not possible from the available data to determine the economic tradeoffs of discard rather than recovery of these metal values. Feed to this unit is 62 cubic meters of grindings, turnings, shavings, scrap, and sludge. There could be enough value here to justify processing if the metal can be returned to use.

The Laboratory Packs Treatment unit is unique and identifies a general need through out the complex; again the technology and intended treatment is not described. This unit and the total demand for laboratory packs management will be looked at in section IV Sizing The Treatment Systems. 
Table A-6. Mobile treatment units from non-Albuquerque site treatment plans.

\begin{tabular}{||l|r|r||}
\hline \multicolumn{1}{|c|}{ Technology } & \multicolumn{1}{c|}{ STP \# } & \multicolumn{1}{c|}{ AL \#* } \\
\hline Portable Water Treatment Unit & IN-S006 & LA-S004 \\
\hline Pretreatment Regeneration & PO-S802 & new \\
\hline Repackage & PO-S803 & LA-S801 \\
\hline Deactivate Reactive Metals & PO-S804 & LA-S003 \\
\hline Decontaminate Cylinders & PO-S805 & LA-S801? \\
\hline Laboratory Packs Treatment & PO-S806 & new \\
\hline Metal Recovery & PO-S807 & new \\
\hline Physical Chemical Treatment & PO-S808 & LA-S004 \\
\hline On-Site Stabilization & PO-S809 & Com \\
\hline & & \\
\hline
\end{tabular}

* Number is that assigned in Table A-2 for correlation of treatment technologies through out the tables.

** Here "new" means addition to the DOE-AL list.

\section{Alternative destinations for waste assigned to Mobile Treatment Units}

Reexamination of the waste streams assigned to mobile treatment units in the STPs shows that a number of the wastes could be reassigned to existing or simpler treatment operations. Following is a discussion, in alphabetical order, of the MTU waste assignments in the STPs.

DP-S809 Transportable Vitrification System initial obligation $1015.12 \mathrm{~m}^{3}$. This is a large multi vehicle system which is scheduled to operate at Oak Ridge for an extended period of time. It is not appropriately included in the analysis of applications of Mobile Treatment Units. (Private communication Jay Roach, LMITCo)

FM-S801 Ohio Option-Chem Treatment Project total obligation $716.15 \mathrm{~m}^{3}$. Wastes assigned to this project range from aqueous liquids through debris wastes with and without regulated organic contaminants. Included are some wastes that are similar to those assigned to the waste stabilization project OH-S001. Wastes with MPC 4000,5300 can be treated with thermal desorption with the condensate being sent to the TSCA incinerator. Most of the soil inventory appears to be organic contaminated. Debris constitutes a small fraction of the wastes identified for this project. About $5 \mathrm{~m}^{3}$ in inventory is described as contaminated rags, pads, and trash which should be processable in TSCA.

About $10 \%$ of the inventory is organic sludges that could be fed to TSCA or any operable incinerator. 
GJ-S801B Thermal Desorption total obligation $101.31 \mathrm{~m}^{3}$ total obligation reassigned $66.49 \mathrm{~m}^{3}$. At least two streams to this MTU seem incorrectly assigned. Unknown matrix material labeled "scintillation fluids" should not require thermal desorption. Ash, burning grounds indicated not to contain organic should go directly to stabilization. A third stream organic contaminated combustible debris will not behave well in thermal desorption and should be assigned to incineration if capacity were available.

GJ-S801C Evaporative Oxidation total obligation $185.06 \mathrm{~m}^{3}$. All of these waste could be assigned to any operable incinerator.

GJ-S804 Sort/Survey/Decon total obligation $253.27 \mathrm{~m}^{3}$. This is a function not a technology which provides a front end to any MTU or fixed base unit.

IN-S006 Water Treatment Unit total obligation $655.04 \mathrm{~m}^{3}$. The over whelming majority of the waste assigned to this MTU is one stream projected generation of $652 \mathrm{~m}^{3}$. A dedicated water treatment capability should be installed at NTS for continuing support.

LA-SO01 Lead Decontamination Trailer total obligation $7453^{\mathrm{me}}$ potential obligation $370 \mathrm{~m}^{3}$

This should be continued to treat any other waste stream in the complex should be treated if practical.

LA-S003 Water-Reactive Waste (Reactive Metals Skid) total obligation $7.03 \mathrm{~m}^{3}$.

PO-S804 Deactivate Reactive Metals total obligation $0.62 \mathrm{~m}^{3}$ potential obligation $756.42 \mathrm{~m}^{3}$.

These efforts should be combined. During the OAT evaluation of better configurations of treatment capability, consideration was given to expanding the reactive metal management program at ANL-W to include other reactive metals. Argonne West has an obligation for $730.33 \mathrm{~m}^{3}$ of the $765.42 \mathrm{~m}^{3}$ total for DOE. Assignment of this program to ANL-W seems to be a better option than establishing a number of separate small treatment units.

LA-S004 Chemical And Plating Waste total obligation $7.10 \mathrm{~m}^{3}$. PO-S808 Physical Chemical Treatment total obligation $77.95 \mathrm{~m}^{3}$.

SA-S807 Treatability Study Solidification/total obligation $1.02 \mathrm{~m}^{3}$. Neutralization

Some of the wastes assigned to PO-S808 are clearly marked as plating wastes. Other similar wastes in the PO-S808 list may require broader treatment capabilities than are planned for LA-S004. These are some what difficult wastes that require special consideration in processing. The small waste stream assigned to SAS807 looks like it could be handled in either of the other two units. The entire list of plating, cyanide, and reactive aqueous wastes should be evaluated along with the laboratory packs issue to optimize treatment of these wastes for DOE. That effort is beyond the scope of this task. 
LA-S801 Gas Scrubbing Skid total obligation $0.63 \mathrm{~m}^{3}$.

PO-S803 Repackage total obligation $0.21 \mathrm{~m}^{3}$.

PO-S805 Decontaminating Containers total obligation $7.70 \mathrm{~m}^{3}$, potential obligation $37.36 \mathrm{~m}^{3}$

This is another instance where the entire DOE gas cylinder and container set should be looked at together. There is little or no capability available. Commercial vendors offer support in this area.

LA-S804 Hydrothermal Processing total obligation $60.46 \mathrm{~m}^{3}$.

Wastes assigned include inorganic oxidizers $0.25 \mathrm{~m}^{3}$ and PCB wastes with RCRA components 0.94 $\mathrm{m}^{3}$. The inorganic oxidizers should go to special deactivation processing not to organic destruction or incineration units. The balance of the wastes assigned to LA-S804 could be processed by the TSCA incinerator.

OH-S001 Ohio Option-Stabilization Project total obligation $249.10 \mathrm{~m}^{3}$.

This "Option" has wastes from 3100 inorganic sludges to 4100 soils, 5000 s debris and not defined. Many are high salt or high oxide wastes, where the CPC is given, there are no wastes shown to contain organic contaminants; presumably that is the expectation for the remainder of the wastes. Organic destruction appears not required. These appear well assigned to stabilization and disposal.

PI-S801 Amalgamation of Elemental Mercury total obligation $1.57 \mathrm{~m}^{3}$, potential obligation $21.59 \mathrm{~m}^{3}$

This is another unique set of wastes with a specific treatment need. Using a DOE GOCO facility or a vendor operated treatment unit these wastes should be dealt with. The most practical answer would be to set a unit at one DOE site and ship all of the mercury wastes to that location. Two approaches are practical. The defined module has a projected through put of 1 liter/ 3 hours. Dedicated units of this small size could be located at some of the larger sites with the balance being worked off by a mobile unit. Using the previous estimate of 800 productive hours per year for any MTU, the PIS 801 unit could process 267 liter per year. Processing the $1.57 \mathrm{~m}^{3}$ obligation would require 6 years.

A slightly larger fixed-location unit operating at $1 \mathrm{~L} / \mathrm{hr}$ for the $4032 \mathrm{hr}$ (as used in the ITTS) would handle the entire $21.59 \mathrm{~L}$ in 5.4 years. This is a significantly better option but requires shipping elemental mercury from 23 sites to one. Most shipments would be less than $1 / 2$ a cubic meter.

PO-S802 Pretreatment Regeneration total obligation $240.46 \mathrm{~m}^{3}$.

The only waste stream to the Pretreatment Regeneration unit is a granular carbon sludge contaminated with regulated organics only; this waste should be treated easily at the TSCA incinerator. The recovered value of the carbon adsorbent is certainly much less than the cost of construction, permitting and operation of a single purpose unit. 
PO-S806 Laboratory Packs Treatment total obligation $30.88 \mathrm{~m}^{3}$, potential obligation $788.23 \mathrm{~m}^{3}$ The Laboratory Packs Treatment unit is unique and identifies a general need through out the complex; again the technology and intended treatment is not described. This unit and the total demand for laboratory packs management will be looked at in section IV Sizing The Treatment Systems.

PO-S807 Metal Recovery total obligation $62.25 \mathrm{~m}^{3}$, potential obligation uncertain. The feed to the Metal Recovery unit is primarily silver bearing waste. It is not possible from the available data to determine the economic tradeoffs of discard rather than recovery of these metal values. Feed to this unit is 62 cubic meters of grindings, turnings, shavings, scrap, and sludge. There could be enough value here to justify processing if the metal can be returned to use.

PO-S809 Onsite Stabilization total obligation $5484.85 \mathrm{~m}^{3}$.

Waste assigned to this treatment unit are largely salts and oxides. This stabilization treatment needs to be provided whether by DOE GOCO facility or a vendor provided operation. For some wastes chemical treatment many be required to allow safe stabilization.

PX-S803 Macroencapsulation total obligation $782.85 \mathrm{~m}^{3}$, potential obligation large. If macroencapsulaton is used as the basic treatment for all debris wastes in the DOE MLLW inventory, the potential need is very large. The justification for a separate small mobile unit is not clear. The projections of future debris waste generations are highly dependent on uncertain future program directions. It also may be difficult to put the appropriate size reduction capabilities on a module/trailer to be able to deal with any thing other than small drummed debris.

\section{SA-S810 Packed Bed Reactor/Silent Discharge total obligation $26.48 \mathrm{~m}^{3}$}

Plasma/Tritium Capture. The assigned wastes all appear to be readily dealt with at TSCA or CIF. The one exception is tritiated oil at SR. This may require a dedicated unit to destroy the organic however requires condensation of all water produced from oxidation of the organic to capture the tritium. Presumably the tritiated water will be stabilized as a grout. The simpler alternative of stabilization of the "oil" directly would be much less expensive if a stable product can be produced.

\section{Identifying Required Technologies.}

c) Given the sets of mixed waste streams under consideration and their associated characteristics and volumes,

i. how many different (potentially mobile) treatment "systems" are needed and,

ii. for each "system", what treatment technology and range of capacity is required?

d) What technologies are required to meet applicable treatment standards? 


\section{A. Preliminary assumptions for MTU study}

1. There will be a consistent line set at all sites between wastes that may be treated by Mobile treatment units and those which will be treated by fixed units.

2. Only units which treat natural uranium, or lower, alpha levels can be decontaminated and moved. Facilities that treat PU-alpha bearing wastes can not be decontaminated adequately for disassembly and relocating.

3. After working off backlog wastes containing fission products and/or uranium we should consider "parking" the MTU permanently at a site requiring treatment of compatible $\mathrm{Pu}$ alpha wastes.

\section{B. Waste streams on which to base the analysis}

Waste streams at the small sites cover a broad range of physical matrices from aqueous to compressed gases. MTUs designed to treat these wastes on site must provide a flexible array of technologies. Most DOE wastes do not have technology standards. Most do have concentration or TCLP standards. Mercury is the one constant exception; above 260ppm RCRA rules require the recycle of mercury. Recycle involves distillation for cleanup. Triple distillation was included in the original set of Albuquerque technologies for this purpose. It is unlikely that DOE can reuse internally or find an external market for reclaimed mercury. The DOE will have large quantities of mercury out of the Oak Ridge cleanup efforts that can supply any possible future needs. The small quantities of mercury that are contained in mixed wastes at the smaller sites should be amalgamated in the most direct manner possible and sent to disposal. This may require a regulatory variance in some cases.

Given that DOE has made the decision to "privatize" the waste treatment operations to the maximum extent practical, it is appropriate to reexamine treatment options for all DOE mixed waste streams regardless the assignments in the Site Treatment Plans (STPs).

Using STP data the mixed waste streams for each DOE site have been recompiled into physical matrix sets at the $100 \mathrm{~s}$ level. The data were tabulated showing for each matrix the presence or absence of regulated organic constituents, regulated metals, and RCRA characteristics. The inventory, projected and the sum of these was listed for all sites. The sum of inventory and $5 \mathrm{yr}$ projection was tabulated as " $5 \mathrm{yr}$ obligation". Facility sizes in the following discussions are based on this final figure. The data separate the sites readily into those with less than 500 usually about 100 cubic meters total obligation and those with larger amounts. These data were reviewed to establish the waste treatment processes for proper treatment of the wastes at the smaller sites.

\section{Portable Treatment System Study Flowsheets}

High level flowsheets have been created for the treatment of all of the DOE MLLW waste streams. These are Figure III-1. PTSS MLLW BASE FLOWSHEET-DEBRIS AND RESIDUE GROUTED this covers waste matrices 1000 through 5400 and Figure III-2. PTSS MLLW BASE FLOWSHEET SPECIAL PROCESSING this covers waste matrices 6000 through 7700 . 
Treatment requirements are defined using these comprehensive treatment flowsheet for the complete set of wastes. In these flowsheets process steps are show in the boxes. The process unique identification number is in the upper right hand corner. The operations occurring in each process box is identified in Table III-1, Unit Operations function in the PTSS Base Flowsheet. Included in Table III-1 is a correlation of the Albuquerque Mobile Treatment Units with the treatment processes in the flowsheet. Capacities of the Albuquerque MTUs is given in the right hand column

Treatment requirements for individual wastes are derived from these flowsheets by tracing an appropriate path through the flow sheet identifying the processes that will treat that given waste matrix with its unique contaminants. Two tables are provided to describe this process. Table III-2, Waste Matrix/Waste Contaminant Treatment Correlation Chart. This table identifies the key treatment unit operations by number from Table III-1 and the PTSS Flowsheets.

As an example, for matrix 1100 waste water with organic contaminants the key treatment is aqueous organic destruction, unit 270 identified as wet oxidation, in the base flowsheet. Examining Table III-2 we see that the MTU LAS804(hydrothermal treatment) provides that or equivalent treatment.

In the same manner the needed treatments for all waste categories can be found in Table III- 2 .

\section{Treatment Trains}

More detailed processing requirements are provided in Table III-3; here the route that each individual waste would follow through the treatment processes are given. Again this lists the unit operations by number. These series of process steps provide a treatment train for each waste.

MTU sizes needed for treatment of small site wastes has not been determined. Small sites with less than about $500 \mathrm{~m}^{3}$ total of mixed waste treatment obligation generally have to treat from a fraction of a cubic meter up to approximately $100 \mathrm{~m}^{3}$ of any one matrix. Table III-4 lists the approximate ranges of waste treatment obligation for the small sites by waste physical matrix code. For most waste categories something like 25 sites or fewer have waste treatment obligations for a single category; most of those obligations are around $10 \mathrm{~m}^{3}$ or even less. 
Table III-1 Unit Operations functions in the PTSS Base Flowsheet

\begin{tabular}{|c|c|c|c|}
\hline $\begin{array}{c}\text { Unit operations } \\
\text { number }\end{array}$ & Function & \begin{tabular}{|l|} 
AL Mobile \\
Treatment Unit
\end{tabular} & $\begin{array}{l}\text { Capacity/ } \\
\text { Feed Rate }\end{array}$ \\
\hline $\begin{array}{l}110,210,310, \text { etc } 1000, \\
2000,3000 \text { matrix }\end{array}$ & $\begin{array}{l}\text { receiving and sorting for } \\
\text { the corresponding }\end{array}$ & GJ-S804 & as needed \\
\hline $150,250,350$, etc & $\begin{array}{l}\text { solids separation operations for } \\
\text { the corresponding streams }\end{array}$ & $\begin{array}{l}\text { included in some } \\
\text { modules }\end{array}$ & as needed \\
\hline $140,340,440$ & neutralization & (LA-S004) & $400 \mathrm{gal} / 4 \mathrm{hr}$ \\
\hline 270 & $\begin{array}{l}\text { wet oxidation for destruction of } \\
\text { organics in waste waters }\end{array}$ & $\begin{array}{l}\text { LA-S804 } \\
\text { hydrothermal }\end{array}$ & $\begin{array}{l}120 \mathrm{gal} / \mathrm{hr} @ 5-10 \% \\
\text { organic } \\
\text { ie. } 6-12 \mathrm{gal} / \mathrm{hr} \\
\text { organic }\end{array}$ \\
\hline 180 & evaporation & IN-S006++ & $20-100 \mathrm{gal} / \mathrm{hr}$ \\
\hline 190 & condenser & IN-S006++ & $20-100 \mathrm{gal} / \mathrm{hr}$ \\
\hline 470 & incineration primary chamber & SA-S810 & $0.6-3 \mathrm{gal} / \mathrm{hr}$ \\
\hline 480 & $\begin{array}{l}\text { gas burner/secondary } \\
\text { combustion chamber }\end{array}$ & SA-S810 & $0.6-3 \mathrm{gal} / \mathrm{hr}$ \\
\hline 490 & off gas treatment & SA-S810 & $0.6-3 \mathrm{gal} / \mathrm{hr}$ \\
\hline 540 & debris shredding & Not required & \\
\hline 570 & thermal desorption & GJ-S801A & $14.8 \mathrm{ft}^{3} / 8 \mathrm{hr}$ \\
\hline $560 / 565$ & $\begin{array}{l}\text { mercury evaporation and } \\
\text { condensation }\end{array}$ & $\begin{array}{l}\text { TRIPLE } \\
\text { DISTILL }\end{array}$ & Not defined \\
\hline 640 & deactivation & (LAS004) & Not defined \\
\hline 695 & $\begin{array}{l}\text { pelletizing debris for volume } \\
\text { reduction }\end{array}$ & Not required & \\
\hline 195 & polymer solidification & PX-S803 & TBD \\
\hline $490 * / 595$ & mercury stabilization & PI-S801 & $11 / 3 \mathrm{hr}$ \\
\hline 795 & $\begin{array}{l}\text { grout stabilization of particulate } \\
\text { wastes }\end{array}$ & PX-S803+ & TBD \\
\hline 796 & $\begin{array}{l}\text { grout stabilization of debris } \\
\text { wastes }\end{array}$ & $\begin{array}{l}\text { PX-S803 } \\
\text { Modified }\end{array}$ & TBD \\
\hline \multirow[t]{3}{*}{1,000} & $\begin{array}{l}\text { chemical physical } \\
\text { decontamination of lead }\end{array}$ & LA-SOO1 & $600 \mathrm{lb} / \mathrm{hr}$ \\
\hline & Gas scrubbing skid & LA-S801 & 1 cylinder $/ 2 \mathrm{hr}$ \\
\hline & Stabilize Barium & & $60 \mathrm{~kg} / 5 \mathrm{hr}$ \\
\hline
\end{tabular}




\begin{tabular}{|c|c|c|c|c|c|c|}
\hline \multirow{3}{*}{ DOE WASTE TREATABILITY GROUP CODES } & \multirow{2}{*}{\begin{tabular}{|c|} 
Table Ill-2 \\
O11 organic
\end{tabular}} & \multicolumn{5}{|c|}{ Waste Matrix/Waste Contaminant Treatment Correlation Chart } \\
\hline & & O11 organic & C11C inorganic & C12 corrosive & $\mathrm{C} 13$ reactive & C13A,B acid \\
\hline & & C11 ignitable & ignitable & & & reactive \\
\hline EPACODES & D001A & D001A & $\mathrm{D} 001 \mathrm{C}$ & D002B & D003 & D003A,3B, \\
\hline & & & & & & \\
\hline & & & & & & \\
\hline & & & & & $\mathrm{P}, \mathrm{U}$ & $P, U$ \\
\hline WASTE MATRIX & & \multicolumn{4}{|c|}{ Key treatment unit operations numbers from Table III-1 } & \\
\hline CODES & & & & & & \\
\hline waste water 1100 & 270 & 270 & 640 & 140 & $150,640,180$ & $150,640,180$ \\
\hline aqueous slurries 1200 & 270 & 270 & 640 & 140 & $150,640,180$ & $150,640,180$ \\
\hline aqueous organic liq 2100 & 470 & 470 & 640 & $(240), 270$ & 250,640 & 250,640 \\
\hline pure organic liq 2200 & 470 & 470 & $x x x$ & $(240), 470$ & 250,640 & 250,640 \\
\hline uncategorized organic liq 2900 & 470 & 470 & $x x x$ & $(240), 470$ & 250,640 & 250,640 \\
\hline inorganic homogeneous solids 3100 & 470 & 470 & 640 & $(340), 640$ & 350,640 & 350,640 \\
\hline solidified homogeneous solids 3150 & 470 & 470 & 640 & $(340), 640$ & 350,640 & 350,640 \\
\hline organic homogeneous solids 3200 & 470 & 470 & 640 & $(340), 350$ & 350,640 & 350,640 \\
\hline contaminated soil 4100 & 470 & 470 & 640 & $(340)$, & 450,640 & 450,640 \\
\hline contaminated soil \& debris 4200 & 470 & 470 & 640 & $(340), 795$ & 450,640 & 450,640 \\
\hline soil (rock \& gravel) 4300 & 470 & 470 & 640 & $(340), 795$ & 450,640 & 450,640 \\
\hline inorganic debris 5100 & 470 & 470 & 640 & $(340), 795$ & 550,640 & 550,640 \\
\hline (debris 5200) & 470 & 470 & 640 & $(340), 795$ & 550,640 & 550,640 \\
\hline
\end{tabular}




\begin{tabular}{|c|c|c|c|c|c|c|c|}
\hline & Table III-2 & Waste Matrix/Waste & Contaminant & reatment Correla & tion Chart & & \\
\hline C13D water & C13C explosive & M12 toxic metal w Hg & M11 toxic metal & O11 organic & O11 organic & other & multiple \\
\hline reactive & & & $w / 0 \mathrm{Hg}$ & non halogenated & halogenated & list & list \\
\hline \multirow[t]{3}{*}{ D003D } & D003C & D004-11 & D004-8,10,11 & D018,23-26,30, & D012-17, 19-22, & & \\
\hline & & & & $35,35,38$ & $27-29,31-34,37$ & & \\
\hline & & F035,K069A,B & F035, K069A,B & & $39-43$ & & \\
\hline $\mathrm{P}, \mathrm{U}$ & & $P, U$ & $P, U$ & $F, P, U$ & $F, P, U$ & & \\
\hline & & & & & & & \\
\hline $150,640,180$ & $150,640,180$ & $150,180,490^{\star}, \quad 795$ & $150,180,795$ & $150,270,180,795$ & $150,270,180,195$ & & \\
\hline $150,640,180$ & $150,640,180$ & $150,180,490^{\star}, \quad 795$ & $150,180,795$ & $150,270,180,795$ & $150,270,180,195$ & & \\
\hline 640 & 640 & $150,490^{*}, 795$ & 250,795 & $250,470,795$ & $250,470,490,195$ & & \\
\hline 640 & 640 & $250,490^{\star}, 795$ & 250,795 & $250,470,795$ & $250,470,490,195$ & & \\
\hline 640 & 640 & $250,490^{\star}, 795$ & 250,795 & $250,470,795$ & $250,470,490,195$ & & \\
\hline 640 & 640 & $350,490^{\star}, 795$ & 350,795 & $350,470,795$ & $350,470,490,195$ & & \\
\hline 640 & 640 & $350,490^{*}, 795$ & 350,795 & $350,470,795$ & $350,470,490,195$ & & \\
\hline 640 & 640 & $350,490^{*}, 795$ & 350,795 & $350,470,795$ & $350,470,490,195$ & & \\
\hline 640 & 640 & $350,490^{*}, 795$ & 350,795 & $450,470,795$ & $450,470,490,195$ & & \\
\hline 640 & 640 & $350,490^{*}, 795$ & 350,795 & $450,470,795$ & $450,470,490,195$ & & \\
\hline 640 & 640 & $350,490^{*}, 795$ & 350,795 & $450,470,795$ & $450,470,490,195$ & & \\
\hline 640 & 640 & 550,795 & 550,795 & $550,470,795$ & $550,470,490,195$ & . & \\
\hline 640 & 640 & 550,795 & 550,795 & $550,470,795$ & $550,470,490,195$ & & \\
\hline & & & & & & & \\
\hline
\end{tabular}




\begin{tabular}{|c|c|c|c|c|c|c|}
\hline \multirow{3}{*}{ DOE WASTE TREATABILITY GROUP CODES } & \multirow{2}{*}{\begin{tabular}{|l} 
Table III-2 \\
O11 organic
\end{tabular}} & \multicolumn{5}{|c|}{ Waste Matrix/Waste Contaminant Treatment Correlation Chart } \\
\hline & & O11 organic & C11C inorganic & C12 corrosive & C13 reactive & C13A,B acid \\
\hline & & C11 ignitable & ignitable & & & reactive \\
\hline \multirow{4}{*}{ EPACODES } & D001A & D001A & D001C & D002B & D003. & D003A,3B, \\
\hline & & & & & & \\
\hline & & & & & & \\
\hline & & & & - & P,U & $P, U$ \\
\hline organic debris 5300 & 470 & 470 & 640 & $(340), 470$ & 550,640 & 550,640 \\
\hline heterogeneous debr 5400 & 470 & 470 & 640 & $(340), 470,795$ & 550,640 & 550,640 \\
\hline organic lab packs 6100 & $\begin{array}{l}610,270,140, \\
150,470, \text { etc }\end{array}$ & $\begin{array}{l}610,270,140, \\
150,470, \text { etc }\end{array}$ & $\begin{array}{l}610,270,140, \\
150,470 \text {,etc }\end{array}$ & $\begin{array}{l}610,270,140, \\
150,470, \text { etc }\end{array}$ & $\begin{array}{l}610,270,140, \\
150,470, \text { etc }\end{array}$ & $\begin{array}{l}610,270,140, \\
150,470, \text { etc }\end{array}$ \\
\hline aqueous lab packs 6200 & $\begin{array}{l}610,270,140, \\
150,470, \text { etc }\end{array}$ & $\begin{array}{l}610,270,140, \\
150,470, \text { etc }\end{array}$ & $\begin{array}{l}610,270,140, \\
150,470, \text { etc }\end{array}$ & $\begin{array}{l}610,270,140, \\
150,470, \text { etc }\end{array}$ & $\begin{array}{l}610,270,140 \\
150,470, \text { etc }\end{array}$ & $\begin{array}{l}610,270,140, \\
150,470, \text { etc }\end{array}$ \\
\hline elemental mercury 7100 & $\begin{array}{l}650,470,490^{*}, \\
1400\end{array}$ & $\begin{array}{l}650,470,490^{*}, \\
1400\end{array}$ & & & & \\
\hline elemental lead 7210 & $1000,470,795$ & $1000,470,795$ & & & & \\
\hline elemental cadmium 7220 & $1000,470,795$ & $1000,470,795$ & & & & \\
\hline beryllium 7300 & $650,470,795$ & $650,470,795$ & & & & \\
\hline batteries 7000 & $\begin{array}{l}640,470,795 \\
1000\end{array}$ & $\begin{array}{l}640,470,795, \\
1000 \\
\end{array}$ & & & & \\
\hline reactive metals 7500 & 640,795 & 640,795 & 640,795 & 640,795 & 640,795 & 640,795 \\
\hline explosives and propellants 7600 & 640,470 & 640,470 & & & & \\
\hline compressed gases \& aerosol cans 7700 & 640,470 & 640,470 & & & & \\
\hline final forms 9000 & & & & . & & \\
\hline
\end{tabular}




\begin{tabular}{|c|c|c|c|c|c|c|}
\hline Table III-2 & Waste Matrix/Wast & Contaminant & Treatment Correl & tion Chart & & \\
\hline \begin{tabular}{|l|} 
C13C explosive \\
\end{tabular} & M12 toxic metal $w \mathrm{Hg}$ & M11 toxic metal & O11 organic & \begin{tabular}{|l} 
O11 organic \\
\end{tabular} & other & multiple \\
\hline & & $w / o \mathrm{Hg}$ & non halogenated & halogenated & list & list \\
\hline$D 003 C$ & D004-11 & D004-8,10,11 & D018,23-26,30, & D012-17,19-22, & & \\
\hline & & & $35,35,38$ & 27-29,31-34,37, & & \\
\hline & F035,K069A,B & F035,K069A,B & & $39-43$ & & \\
\hline & $\mathrm{P}, \mathrm{U}$ & $\mathrm{P}, \mathrm{U}$ & $F, P, U$ & $F, P, U$ & & \\
\hline 640 & $550,470,490^{*}, \quad 795$ & $550,470,795$ & $550,470,795$ & $550,470,490,195$ & & \\
\hline 640 & $550,470,490^{*}, \quad 795$ & 550,795 & $550,470,795$ & $550,470,490,195$ & & \\
\hline $\begin{array}{l}610,270,140, \\
150,470, \text { etc } \\
\end{array}$ & $\begin{array}{l}610,270,140, \\
150,470 \text {,etc }\end{array}$ & $\begin{array}{l}610,270,140, \\
150,470, \text { etc }\end{array}$ & $\begin{array}{l}610,270,140,150, \\
470, \text { etc }\end{array}$ & $\begin{array}{l}610,270,140,150, \\
470, \text { etc }\end{array}$ & & \\
\hline $\begin{array}{l}610,270,140, \\
150,470, \text { etc }\end{array}$ & $\begin{array}{l}610,270,140 \\
150,470 \text {,etc }\end{array}$ & $\begin{array}{l}610,270,140 \\
150,470, \text { etc }\end{array}$ & & & & \\
\hline & & & $\begin{array}{l}650,470,490^{*}, \\
1400\end{array}$ & $\begin{array}{l}650,470,490^{*}, \\
1400\end{array}$ & & \\
\hline & & & $1000,470,795$ & $1000,470,795$ & & \\
\hline & & & $1000,470,795$ & $1000,470,795$ & & \\
\hline & & & $650,470,795$ & $650,470,795$ & & \\
\hline & & & $\begin{array}{l}640,470,795, \\
1000 \\
\end{array}$ & $\begin{array}{l}640,470,795, \\
1000 \\
\end{array}$ & & \\
\hline 640,795 & 640,795 & 640,795 & 640,795 & 640,795 & & \\
\hline & $640,470,795$ & & $640,470,795$ & 640,470 & & \\
\hline & $640,470,795$ & & $640,470,795$ & 640,470 & & \\
\hline & & & & & & \\
\hline
\end{tabular}




\begin{tabular}{|c|c|c|c|c|}
\hline \multirow{2}{*}{ DOE WASTE TREATABILITY GROUP CODES } & \multirow{2}{*}{\begin{tabular}{|l|} 
Table III-3 \\
011 toxic organic \\
\end{tabular}} & \multicolumn{3}{|c|}{ Waste stream contaminant treatment trains } \\
\hline & & 011 toxic organic & 011 toxic organic & 011 toxic organic \\
\hline & & C11 ignitable & C11 ignitable & C11 ignitable \\
\hline & & & M12 toxic metal $w \mathrm{Hg}$ & M11 toxic metal w/o Hg \\
\hline CONTAMINANT PARAMETER CATEGORIES & $\mathrm{RC}-011-\mathrm{M} 90-\mathrm{C} 90$ & RC-011-M90-C11 & $\mathrm{RC}-011-\mathrm{M} 12-\mathrm{C} 11$ & $\mathrm{RC}-011-\mathrm{M} 11-\mathrm{C} 11$ \\
\hline APPLICABLEEPA CODES & $D 001 A, 12-43$ & $\mathrm{D} 001 \mathrm{~A}, 12-43$ & $\mathrm{D} 001 \mathrm{~A}, 4-43$ & $D 004-8,10-43$ \\
\hline & & & & \\
\hline & $F, P, U$ & $F, P, U$ & $F, P, U$ & $F, P, U$ \\
\hline \multicolumn{5}{|l|}{ WASTE MATRIX } \\
\hline \multicolumn{5}{|l|}{ CODES } \\
\hline waste water 1100 & $\begin{array}{l}150,270,180,195 \\
795\end{array}$ & $\begin{array}{l}150,270,180,195 \\
795\end{array}$ & $\begin{array}{l}150,270,180 \\
195,795 \\
\end{array}$ & $150,270,180 \quad 195,795$ \\
\hline aqueous slurries 1200 & $\begin{array}{l}150,270,180,195 \\
795\end{array}$ & $\begin{array}{l}150,270,180,195 \\
795\end{array}$ & $\begin{array}{l}150,270,180 \\
195,795 \\
\end{array}$ & $150,270,180 \quad 195,795$ \\
\hline aqueous organic liq 2100 & $250,470,195,795$ & $250,470,195,795$ & $\begin{array}{l}250,470,490, \\
795\end{array}$ & $250,470,195,795$ \\
\hline pure organic liq 2200 & $250,470,195,795$ & $250,470,195,795$ & $\begin{array}{ll}250,470,490, & 195 \\
795 & \\
\end{array}$ & $250,470,195,795$ \\
\hline uncategorized organic liq 2900 & $350,470,195,795$ & $350,470,195,795$ & $\begin{array}{ll}250,470,490, & 195 \\
795 & \\
\end{array}$ & $250,470,195,795$ \\
\hline inorganic homogeneous solids 3100 & $350,470,195,795$ & $350,470,195,795$ & $\begin{array}{l}350,470,490,195 \\
795\end{array}$ & $350,470,195,795$ \\
\hline solidified homogeneous solids 3150 & $350,470,195,795$ & $350,470,195,795$ & $\begin{array}{l}350,470,490,195 \\
795\end{array}$ & $350,470,195,795$ \\
\hline organic homogeneous solids 3200 & $350,470,195,795$ & $350,470,195,795$ & $\begin{array}{l}350,470,490,195 \\
795\end{array}$ & $350,470,195,795$ \\
\hline contaminated soil 4100 & $450,470,195,795$ & $450,470,195,795$ & $\begin{array}{l}450,470,490,195 \\
795\end{array}$ & $450,470,195,795$ \\
\hline contaminated soil \& debris 4200 & $450,470,195,795$ & $450,470,195,795$ & $\begin{array}{l}450,470,490,195 \\
795\end{array}$ & $450,470,195,795$ \\
\hline soil (rock \& gravel) 4300 & $450,470,195,795$ & $450,470,195,795$ & $\begin{array}{l}450,470,490,195 \\
795\end{array}$ & $450,470,195,795$ \\
\hline inorganic debris 5100 & $\begin{array}{l}550,540,470,570 \\
695,195,797,796\end{array}$ & $\begin{array}{l}550,540,470,570 \\
695,195,797,796\end{array}$ & $\begin{array}{l}550,540,470,490 \\
570,195,695,795 \\
796\end{array}$ & $\begin{array}{l}550,540,470,570 \\
695,195,797,796\end{array}$ \\
\hline
\end{tabular}




\begin{tabular}{|c|c|c|c|c|}
\hline \multirow{2}{*}{$\begin{array}{l}\text { Table III-3 } \\
011 \text { toxic organic }\end{array}$} & \multicolumn{3}{|c|}{ Waste stream contaminant treatment trains } & \\
\hline & 011 toxic organic & & & \\
\hline C11 ignitable & C11 ignitable & & & \\
\hline M12 toxic metal $\mathrm{w} \mathrm{Hg}$ & M11 toxic metal w/o $\mathrm{Hg}$ & M12 toxic metal $w \mathrm{Hg}$ & M11 toxic metal w/o $\mathrm{Hg}$ & \\
\hline C12 corrosive & C12 corrosive & C12 corrosive & C12 corrosive & C12 corrosive \\
\hline $\mathrm{RC}-\mathrm{O} 11-\mathrm{M} 12-\mathrm{C} 11$ & $\mathrm{RC}-011-\mathrm{M} 12-\mathrm{C} 14$ & RC-O90-M12-C14 & $\mathrm{RC}-090-\mathrm{M} 11-\mathrm{C} 12$ & RC-O90-M90-C12 \\
\hline D002B,4-11 & Do02B,4-8,10,11 & $\mathrm{D} 002 \mathrm{~B}, 4-11$ & $\mathrm{D} 002 \mathrm{~B}, 4-8,10,11$ & D002B \\
\hline & & F035,K069A,B & F035, K069A,B & \\
\hline $\mathrm{P}, \mathrm{U}$ & $P, U$ & P,U & $P, U$ & \\
\hline & $\ldots \ldots$ & & & \\
\hline & & & & \\
\hline $\begin{array}{l}140,150,270,180, \\
195,795\end{array}$ & $\begin{array}{l}150,140,270 \\
180,195,795\end{array}$ & $\begin{array}{l}140,150,180 \\
195,795\end{array}$ & $140,150,180, \quad 195,795$ & $\begin{array}{l}150,140,180,195 \\
795\end{array}$ \\
\hline $\begin{array}{l}140,150,270,180 \\
195,795\end{array}$ & $\begin{array}{l}150,140,270 \\
180,195,795 \\
\end{array}$ & $\begin{array}{l}140,150,180 \\
195,795 \\
\end{array}$ & $140,150,180, \quad 195,795$ & $\begin{array}{l}150,140,180,195 \\
795\end{array}$ \\
\hline $\begin{array}{l}250,470,490 \\
195,795\end{array}$ & $250,470,490,195 \quad 795$ & $\begin{array}{l}250,195,470,490 \\
795\end{array}$ & $250,470,195 \quad 795$ & $250,470,195 \quad 795$ \\
\hline $\begin{array}{l}250,470,490 \\
195,795\end{array}$ & $250,470,490,195 \quad 795$ & $\begin{array}{l}250,195,470,490 \\
795\end{array}$ & $250,470,195 \quad 795$ & $250,470,195 \quad 795$ \\
\hline $\begin{array}{l}250,470,490 \\
195,795\end{array}$ & $250,470,490,195 \quad 795$ & $\begin{array}{l}250,195,470,490 \\
795\end{array}$ & $250,470,195 \quad 795$ & $250,470,195 \quad 795$ \\
\hline $\begin{array}{l}350,470,490,195 \\
795\end{array}$ & $350,195,795$ & 350,795 & 350,795 & 350,795 \\
\hline $\begin{array}{l}350,470,490,195 \\
795\end{array}$ & $350,195,795$ & 350,795 & 350,795 & 350,795 \\
\hline $\begin{array}{l}350,470,490,195 \\
795\end{array}$ & $350,470,195,795$ & $350,470,195,795$ & $350,470,195,795$ & $350,470,195,795$ \\
\hline $\begin{array}{l}450,470,490,195 \\
795\end{array}$ & $450,470,195,795$ & 450,795 & 450,795 & 450,795 \\
\hline $\begin{array}{l}450,470,490,195 \\
795\end{array}$ & $450,470,195,795$ & 450,795 & 450,795 & 450,795 \\
\hline $\begin{array}{l}450,470,490,195 \\
795\end{array}$ & $450,470,195,795$ & 450,795 & 450,795 & 450,795 \\
\hline $\begin{array}{l}550,540,470,490 \\
570,195,695,795 \\
796\end{array}$ & $\begin{array}{l}550,540,470,570 \\
695,195,797,796\end{array}$ & $\begin{array}{l}550,540,695,796 \\
795\end{array}$ & $550,540,695,796, \quad 795$ & $\begin{array}{l}550,540,695,796 \\
795\end{array}$ \\
\hline
\end{tabular}




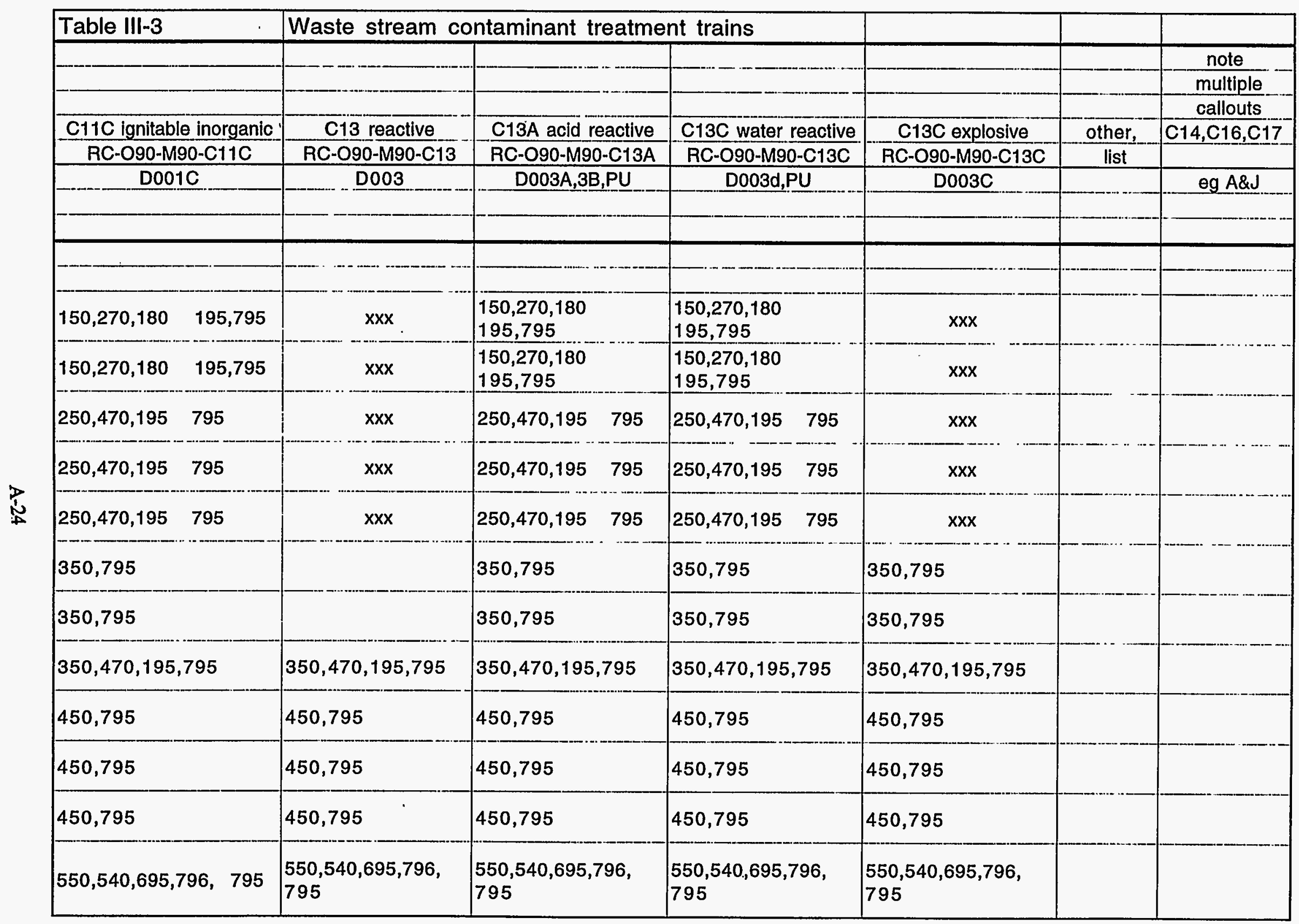




\begin{tabular}{|c|c|c|c|c|}
\hline \multirow[b]{2}{*}{ DOEWASTE TREATABILTTY GROUP CODES } & \multirow{2}{*}{\begin{tabular}{|l|} 
Table lll-3 \\
011 toxic organic \\
\end{tabular}} & \multicolumn{3}{|c|}{ Waste stream contaminant treatment trains } \\
\hline & & 011 toxic organic & 011 toxic organic & 011 toxic organic \\
\hline & & C11 ignitable & C11 ignitable & C11 ignitable \\
\hline & & & M12 toxic metal w Hg & M11 toxic metal w/o Hg \\
\hline CONTAMINANT PARAMETER CATEGORIES & RC-O11-M90-C90 & $\mathrm{RC}-011-\mathrm{M} 90-\mathrm{C} 11$ & RC-011-M12-C11 & RC-011-M11-C11 \\
\hline APPLICABLEEPACODES & $D 001 A, 12-43$ & $\mathrm{D} 001 \mathrm{~A}, 12-43$ & $D 001 A, 4-43$ & D004-8,10-43 \\
\hline & $F, P, U$ & $F, P, U$ & F,P,U & $F, P, U$ \\
\hline organic debris 5300 & $550,470,195,759$ & $550,470,195,759$ & $\begin{array}{l}550,470,490,195 \\
795\end{array}$ & $550,470,195,759$ \\
\hline heterogeneous debris 5400 & $550540, \cdots$ & $550540, \cdots$ & $550540, \cdots$ & $550540, \cdots$ \\
\hline organic lab packs 6100 & $\begin{array}{l}610,270,140,150 \\
470,195,695\end{array}$ & $\begin{array}{l}610,270,140,150 \\
470,195,695\end{array}$ & $\begin{array}{l}610,270,140,150 \\
470,195,695 \\
\end{array}$ & $\begin{array}{l}610,270,140,150 \\
470,195,695\end{array}$ \\
\hline aqueous lab packs 6100 & $\begin{array}{l}610,270,140,150 \\
470,195,695\end{array}$ & $\begin{array}{l}610,270,140,150 \\
470,195,695\end{array}$ & $\begin{array}{l}610,270,140,150 \\
470,195,695\end{array}$ & $\begin{array}{l}610,270,140,150 \\
470,195,695\end{array}$ \\
\hline elemental mercury 7100 & $x \times x$ & $x x x$ & $\begin{array}{l}750,560,565,470 \\
490^{*}, 1400\end{array}$ & $x x \times x x$ \\
\hline elemental lead 7210 & $750,470,795 \quad 1000$ & $750,470,795 \quad 1000$ & $750,470,490^{*}, \quad 1000$ & $750,470,795$ \\
\hline elemental cadmium 7220 & & & & \\
\hline beryllium 7300 & $750,640,795$ & $750,640,795$ & $750,640,795$ & $750,640,795$ \\
\hline batteries 7400 & $750,640,795,1000$ & $750,640,795, \quad 1000$ & $750,640,795,1000$ & $750,640,795,1000$ \\
\hline reactive metals 7500 & 640,795 & 640,795 & 640,795 & 640,795 \\
\hline explosives and propeliants 7600 & $\begin{array}{l}650,640,540 \\
195,795\end{array}$ & $\begin{array}{l}650,640,540 \\
195,795\end{array}$ & $\begin{array}{l}650,640,540,490 \\
195,795 \\
\end{array}$ & $650,640,540 \quad 195,795$ \\
\hline compressed gases \& aerosol cans 7700 & $\begin{array}{l}650,640,540 \\
195,795\end{array}$ & $\begin{array}{l}650,640,540 \\
195,795 \\
\end{array}$ & $\begin{array}{l}650,640,540,490 \\
195,795\end{array}$ & $650,640,540 \quad 195,795$ \\
\hline final forms 9000 & & & & \\
\hline
\end{tabular}




\begin{tabular}{|c|c|c|c|c|}
\hline \multirow{2}{*}{$\begin{array}{l}\text { Table III-3 } \\
011 \text { toxic organic }\end{array}$} & \multicolumn{3}{|c|}{ Waste stream contaminant treatment trains } & \\
\hline & 011 toxic organic & & & \\
\hline C11 ignitable & C11 ignitable & & & \\
\hline M12 toxic metal $w \mathrm{Hg}$ & M11 toxic metal w/o $\mathrm{Hg}$ & M12 toxic metal $\mathrm{w} \mathrm{Hg}$ & M11 toxic metal w/o $\mathrm{Hg}$ & \\
\hline C12 corrosive & C12 corrosive & C12 corrosive & C12 corrosive & C12 corrosive \\
\hline RC-O11-M12-C11 & $\mathrm{RC}-011-\mathrm{M} 12-\mathrm{C} 14$ & $\mathrm{RC}-090-\mathrm{M} 12-\mathrm{C} 14$ & RC-090-M11-C12 & RC-090-M90-C12 \\
\hline $\mathrm{D} 002 \mathrm{~B}, 4-11$ & D002B $, 4-8,10,11$ & D002B,4-11 & $\mathrm{D} 002 \mathrm{~B}, 4-8,10,11$ & D002B \\
\hline & & F035,K069A,B & $\mathrm{F} 035, \mathrm{~K} 069 \mathrm{~A}, \mathrm{~B}$ & \\
\hline$P, U$ & $\mathrm{P}, \mathrm{U}$ & P,U & $\mathrm{P}, \mathrm{U}$ & \\
\hline $\begin{array}{l}550,470,490,195 \\
795\end{array}$ & $550,470,195,759$ & $\begin{array}{l}550,470,490,195 \\
795 \\
\end{array}$ & $550,470,195,759$ & $550,470,195,759$ \\
\hline $550540,---$ & $550540, \cdots$ & $550540, \cdots$ & $550540, \cdots$ & $550540,---$ \\
\hline $\begin{array}{l}610,270,140,150, \\
470,195,695\end{array}$ & $\begin{array}{l}610,270,140,150 \\
470,195,695\end{array}$ & $\begin{array}{l}610,270,140,150, \\
470,195,695\end{array}$ & $\begin{array}{l}610,270,140,150, \\
470,195,695 \\
\end{array}$ & $\begin{array}{l}610,270,140,150, \\
470,195,695 \\
\end{array}$ \\
\hline $\begin{array}{l}610,270,140,150, \\
470,195,695\end{array}$ & $\begin{array}{l}610,270,140,150, \\
470,195,695\end{array}$ & $\begin{array}{l}610,270,140 ; 150, \\
470,195,695\end{array}$ & $\begin{array}{l}610,270,140,150, \\
470,195,695\end{array}$ & $\begin{array}{l}610,270,140,150, \\
470,195,695\end{array}$ \\
\hline $\begin{array}{l}750,560,565,470 \\
490^{*}, 1400\end{array}$ & $x x x$ & $750,560,565 \quad 1400$ & $x x x$ & $x x x$ \\
\hline $750,470,490^{*}, 1000$ & $750,470,795,1000$ & $750,795,1000$ & $x x x$ & $x x x$ \\
\hline $750,640,795$ & $750,640,795$ & $750,640,795$ & $750,640,795$ & $x x x$ \\
\hline $750,640,795, \quad 1000$ & $750,640,795, \quad 1000$ & $750,640,795, \quad 1000$ & $750,640,795,1000$ & $x x x$ \\
\hline 640,795 & 640,795 & 640,795 & 640,795 & 640,795 \\
\hline $\begin{array}{l}650,640,540,490 \\
195,795 \\
\end{array}$ & $650,640,540 \quad 195,795$ & $650,640,795$ & $650,640,795$ & $650,640,795$ \\
\hline $\begin{array}{l}650,640,540,490 \\
195,795\end{array}$ & $650,640,540 \quad 195,795$ & $650,640,795$ & $650,640,795$ & $650,640,795$ \\
\hline
\end{tabular}




\begin{tabular}{|c|c|c|c|c|c|c|}
\hline \multirow[t]{2}{*}{ Table III-3 } & \multicolumn{3}{|c|}{ Waste stream contaminant treatment trains } & & & \\
\hline & & & & & & note \\
\hline & & & & & & multiple \\
\hline & & & & & & callouts \\
\hline C11C ignitable inorganic & C13 reactive & C13A acid reactive & C13C water reactive & C13C explosive & other, & $\mathrm{C} 14, \mathrm{C} 16, \mathrm{C} 17$ \\
\hline $\mathrm{RC}-090-\mathrm{M} 90-\mathrm{C} 11 \mathrm{C}$ & RC-090-M90-C13 & RC-090-M90-C13A & $\mathrm{RC}-090-\mathrm{M} 90-\mathrm{C} 13 \mathrm{C}$ & RC-090-M90-C13C & list & \\
\hline D001C & $\mathrm{D} 003$ & D003A,3B,PU & D003d,PU & D003C & & eg $A \& J$ \\
\hline & & & & & & \\
\hline $550,470,195,759$ & $550,470,195,759$ & $550,470,195,759$ & $550,470,195,759$ & $550,470,195,759$ & & \\
\hline $550540,---$ & $550540,---$ & $550540, \cdots$ & $550540, \cdots$ & $550540,-\cdots$ & & \\
\hline $\begin{array}{l}610,270,140,150, \\
470,195,695\end{array}$ & $\begin{array}{l}610,270,140,150, \\
470,195,695\end{array}$ & $\begin{array}{l}610,270,140,150, \\
470,195,695\end{array}$ & $\begin{array}{l}610,270,140,150 \\
470,195,695\end{array}$ & $\begin{array}{l}610,270,140,150 \\
470,195,695\end{array}$ & & \\
\hline $\begin{array}{l}610,270,140,150, \\
470,195,695\end{array}$ & $\begin{array}{l}610,270,140,150 \\
470,195,695\end{array}$ & $\begin{array}{l}610,270,140,150 \\
470,195,695\end{array}$ & $\begin{array}{l}610,270,140,150 \\
470,195,695\end{array}$ & $\begin{array}{l}610,270,140,150 \\
470,195,695\end{array}$ & & \\
\hline$x x x$ & $x x x$ & $x x x$ & $x x x$ & $x x x$ & & \\
\hline$x x x$ & $x x x$ & $x x x$ & $x x x$ & $x x x$ & & \\
\hline$x x x$ & $x x x$ & $x x x$ & $x x x$ & $x x x$ & & \\
\hline$x x x$ & $x x x$ & $x x x$ & $x x x$ & $x x x$ & & \\
\hline 640,795 & 640,795 & 640,795 & 640,795 & 640,795 & & \\
\hline $650,640,795$ & $650,640,795$ & $650,640,795$ & $650,640,795$ & $650,640,795$ & & \\
\hline $650,640,795$ & $650,640,795$ & $650,640,795$ & $650,640,795$ & $650,640,795$ & & \\
\hline
\end{tabular}




\section{Sizing The Treatment Systems}

In the following we establish the first estimate of the total treatment obligation at the smaller sites and the number of treatment units that would be required to treat those wastes at the small sites. Table IV-1 tabulates the range and total quantity of waste for each waste matrix. The final column lists the total waste obligations as extracted from the STP data. This number is used for calculating the number of treatment units, as the MTUs are sized in the data available from the Albuquerque program.

\section{A. Required size, a generic calculation:}

1. Generic Waste Stream Sizing: Most small sites have only a few of the waste streams matrix categories; however, assume that some of the larger sites will need small rate processing of one or two streams. Assume that the average waste stream obligation ( 5 year treatment requirement) is $25 \mathrm{~m} 3$ or 25,000 liters or average of $5,000 \mathrm{~L} / \mathrm{yr} / \mathrm{site}$ of any one matrix.

Assume 40 sites 5,000 L/yr $=200,000 \mathrm{~L} / \mathrm{yr}$ per waste matrix type total small stream set at all DOE sites combined.

If operation is 20 weeks per year at 40 hours per week, or 800 hours, then the total capacity for each treatment type(each module) would need to be $250 \mathrm{~L} / \mathrm{hr}$.

This generic waste stream sizing approach over estimates the capacity requirement without providing any detail on specific treatment steps that must be provided.

2. Capacity requirement for key treatments based on specific waste obligations: The keys to sizing treatment trains is to provide the key treatment steps assuming the integrated treatment equipment will be appropriately sized. Therefore it is necessary to look into the treatment requirements for a waste matrix based on the contained contaminants. For example some 3000 category process residues and sludges or homogeneous solids require removal or destruction of organic contaminants. Looking in more detail at the 3000 stream data, only a smaller fraction of the total contains RCRA organics. This fixes the capacity requirement for thermal desorption of homogeneous solids with the small separated organic stream being added to the organic destruction load. The remainder of the homogeneous solids can be sent directly to final treatment for stabilization of metals. Following is a more detailed analysis based on specific treatment capacity requirements.

Assuming the treatment obligations listed in table IV-1 right hand column, sorting the streams for contaminants and key required treatment steps, and using 800 operating hours per year for 5 years as the operating period, the number of each type of MTUs required to treat these wastes is given in the right hand column of Table IV-2.

For amalgamation of elemental mercury, the four largest sites have 2.5 to $6.5 \mathrm{~m}^{3}$ each. These can be 
served with one dedicated AL MTU at each site or one unit of some what larger size. The remaining sites can be served with one mobile unit working over the 5-year period.

Table IV-1 Waste stream obligations at DOE small sites.

\begin{tabular}{|l|l|l||}
\hline & Range of Waste Obligation m3 & $\begin{array}{l}\text { Total m3 at } \\
\text { small sites }\end{array}$ \\
\hline 1,000 & & tbd \\
\hline 2,000 & & 21 \\
\hline 3100 organic contaminated & 0.3 to 10 & 87 \\
\hline 3100 no organic contamination & 0.5 to 50 & included \\
\hline 3200 with or w/o organic cont. & $1-50$ most are less than 5 & included \\
\hline $41,004,200$ & $1-40$ most less than 20 & 797 \\
\hline 5,100 & $1-70$ most less than 20 & 147 \\
\hline 5,300 & $1-40$ most less than 20 & 123 \\
\hline 5,400 & $1-20$ most less than 5 & 352 \\
\hline 6,100 & $1-10$ & 115 \\
\hline 6,200 & $1-15$ most none or less than 1 & included \\
\hline 6,300 & $0-5$ most none & included \\
\hline 7,200 & $1 @ 90,1 @ 80$, most less than 7 & 301 \\
\hline 7,100 & most less than 5 & 2.47 \\
\hline \hline
\end{tabular}


Table IV-2 Unit operations functions in the PTSS base flowsheet and MTU capacities.

\begin{tabular}{|c|c|c|c|c|}
\hline $\begin{array}{c}\text { Unit operations } \\
\text { number }\end{array}$ & Function & $\begin{array}{l}\text { AL Mobile } \\
\text { Treatment Unit }\end{array}$ & $\begin{array}{l}\text { Feed rate, } \\
\text { capacity }\end{array}$ & $\begin{array}{l}\text { \# units } \\
\text { required }\end{array}$ \\
\hline $110,210,310$, etc & $\begin{array}{l}\text { receiving and sorting for the } \\
\text { corresponding } 1000 \text { s matrix }\end{array}$ & GJ-S804 & as needed & as needed \\
\hline $150,250,350$, etc & $\begin{array}{l}\text { solids separation operations } \\
\text { for the corresponding streams }\end{array}$ & $\begin{array}{l}\text { included in some } \\
\text { modules }\end{array}$ & as needed & as needed \\
\hline $140,340,440$ & neutralization & (LA-S004) & $400 \mathrm{gal} / 4 \mathrm{hr}$ & 1 \\
\hline 270 & $\begin{array}{l}\text { wet oxidation for destruction } \\
\text { of organics in waste waters }\end{array}$ & $\begin{array}{l}\text { LA-S804 } \\
\text { hydrothermal }\end{array}$ & $\begin{array}{l}120 \text { gal/hr@5-10 } \\
\text { \% organic ie. } \\
6-12 \text { gal/hrorganic }\end{array}$ & $\begin{array}{l}\text { To be } \\
\text { defined }\end{array}$ \\
\hline 180 & evaporation & IN-S006+4 & $20-100 \mathrm{gal} / \mathrm{hr}$ & $1-5$ \\
\hline 190 & condenser & IN-S006+4 & $20-100 \mathrm{gal} / \mathrm{hr}$ & $1-5$ \\
\hline 470 & $\begin{array}{l}\text { incineration primary } \\
\text { chamber }\end{array}$ & SA-S810 & $0.6-3 \mathrm{gal} / \mathrm{hr}$ & 2 units $5 y r s$ \\
\hline 480 & $\begin{array}{l}\text { gas burner/secondary } \\
\text { combustion chamber }\end{array}$ & SA-S810 & $0.6-3 \mathrm{gal} / \mathrm{hr}$ & 2 units $5 y r s$ \\
\hline 490 & off gas treatment & SA-S810 & $0.6-3 \mathrm{gal} / \mathrm{hr}$ & 2 units $5 y r s$ \\
\hline 540 & debris shredding & Not required & & \\
\hline 570 & thermal desorption & GJ-S801A & $14.8 \mathrm{ft}^{3} / 8 \mathrm{hr}$ & 2 \\
\hline $560 / 565$ & $\begin{array}{l}\text { mercury evaporation } \\
\text { and condensation }\end{array}$ & $\begin{array}{l}\text { TRIPLE } \\
\text { DISTILL }\end{array}$ & Not defined & tbd \\
\hline 640 & deactivation & (LAS004) & Not defined & tbd \\
\hline 695 & $\begin{array}{l}\text { pelletizing debris for } \\
\text { volume reduction }\end{array}$ & Not required & & \\
\hline 195 & polymer solidification & PX-S803 & TBD & tbd \\
\hline $490 * / 595$ & mercury stabilization & PI-S801 & $11 / 3 \mathrm{hr}$ & 1 \\
\hline 795 & $\begin{array}{l}\text { grout stabilization of } \\
\text { particulatewastes }\end{array}$ & PX-S803+ & TBD & tbd \\
\hline 796 & $\begin{array}{l}\text { grout stabilization of } \\
\text { debris wastes }\end{array}$ & $\begin{array}{l}\text { PX-S803 } \\
\text { Modified }\end{array}$ & TBD & tbd \\
\hline \multirow[t]{3}{*}{1000} & $\begin{array}{l}\text { chemical physical } \\
\text { decontamination of lead }\end{array}$ & LA-SOO1 & $600 \mathrm{lb} / \mathrm{hr}$ & tbd \\
\hline & Gas scrubbing skid & LA-S801 & 1 cylinder $/ 2 \mathrm{hr}$ & tbd \\
\hline & Stabilize Barium & & $60 \mathrm{~kg} / 5 \mathrm{hr}$ & tbd \\
\hline
\end{tabular}




\section{Memo 2.3.2}

Recommending mixed waste streams for treatment in portable systems (and why)

Which sets of mixed waste streams should be carried forward and used as the basis for portable system conceptualization and alternative evaluation in this study?

Identify 3-5 waste steam groups that are recommended to be considered for portable treatment.

Provide rational for selecting these sets of wastes.

\section{A. Treatment needs and waste stream data}

Treatment needs are based on the data in the Site Treatment Plans. Summary data showing the matrix and contaminant codes for all waste stream assigned to the various mobile treatment units in the STPs are presented in Table V-1. These data are rearranged in Table V-2 to cluster data for MTUs accepting the same or very similar waste matrices and contaminant codes.

column 1 lists the name/technology in the MTU;

columns 2 and 3 list the treatment unit ID number; column 4 lists the Matrix Parameter Codes for one or more of the wastes assigned to this unit; column 5 -10 list the Contaminant Parameter Codes associated with one or more waste assigned to this unit; column 11 lists the volume of the wastes assigned to the treatment units in the STPs.

In the analyses that follow, all data from the waste streams in the STP have been included.

\section{B. Options to set aside}

Mobile treatment processes for most of the 6000 and 7000 wastes address narrowly defined problems. There has been very little waste assigned to each of these processes. Of the waste treatment options presented in Table IV-3, a few are essentially dedicated or required for a specific treatment of a narrow set of wastes; while useful and necessary, these are not flexible and cannot be easily reworked to treat other waste matrices. These would include: 
Table V-1. Mobile Treatment Units Matrix Correlations

\begin{tabular}{|c|c|c|c|c|c|c|c|c|c|c|}
\hline Technology & AL\# & NonAL\# & Assigned Waste MPCs & 011 & $\mathrm{O} 90$ & M11 & M12 & M90 & $\alpha x$ & Vol. $\mathrm{M}^{3}$ \\
\hline Amalgamation of Elemental Mercury & PI-S801 & & 7100 & $\mathrm{x}$ & $\mathrm{x}$ & & $\mathrm{x}$ & & 90 & 1.7 \\
\hline $\begin{array}{l}\text { Chemical And Plating Waste (Electroplating } \\
\text { Skid) }\end{array}$ & LA-S004 & & 1140,1290 & $\mathrm{x}$ & $\mathrm{x}$ & & $\mathrm{x}$ & $\mathrm{x}$ & 17 & 7 \\
\hline Evaporative Oxidation & GJS-801C & & $1190,1210,2190$ & $\mathrm{X}$ & & $\mathrm{X}$ & $\mathrm{x}$ & $\mathrm{x}$ & 14 & 185 \\
\hline Decontaminate Cylinders (aerosol cans) & & PO-S805 & 7700 & $\mathrm{x}$ & & $\mathrm{X}$ & & & 11 & 7.7 \\
\hline Gas Treatment Skid & LA-S801 & & 7700 & $\mathrm{x}$ & $\mathrm{x}$ & & & $\mathrm{x}$ & 14 & 0.6 \\
\hline Hydrothermal Processing & LA-S804 & & $\begin{array}{r}2210,2220,2900,6100 \\
7590^{*} \\
\end{array}$ & $\mathrm{x}$ & $\mathrm{x}$ & $\mathrm{x}$ & $\mathrm{x}$ & $\vec{x}$ & 17 & 60 \\
\hline Lab Packs Treatment & & PO-S806 & 6900 & $\mathrm{x}$ & & $\mathrm{X}$ & $\mathrm{x}$ & & 17 & 31 \\
\hline Lead Decontamination Trailer & LA-S001 & & 7211,7219 & & $\mathrm{X}$ & $\mathrm{X}$ & & & 90 & $74(6)$ \\
\hline Metal Recovery & & PO-S807 & $3119,3129,3190,3290$ & $\mathrm{x}$ & $\mathrm{x}$ & $\mathrm{x}$ & & & 90 & 62 \\
\hline Macroencapsulation & PX-S803 & & $\begin{array}{r}5100,9300,5400,5900 \\
7219 \\
\end{array}$ & $\mathrm{x}$ & $\mathrm{x}$ & $\mathrm{x}$ & $\mathrm{x}$ & & 17 & 783 \\
\hline $\begin{array}{l}\text { Packed Bed Reactor/Silent Discharge } \\
\text { Plasma/Tritium Capture }\end{array}$ & SA-S801 & & $2200,2220,3139,6400$ & $\mathrm{x}$ & $\mathrm{x}$ & & $\mathrm{x}$ & & 11 & 26 \\
\hline Physical Chemical Treatment & & PO-S808 & $\begin{array}{r}1110,1120,1230,1190 \\
1290 \\
\end{array}$ & $\mathrm{x}$ & $\mathrm{x}$ & $\mathrm{x}$ & & $\mathrm{x}$ & 12 & 78 \\
\hline Portable Water Treatment Unit & & IN-S006 & $1100,1110,1120,6200$ & $\mathrm{x}$ & $\mathrm{X}$ & $\mathrm{x}$ & $\mathrm{x}$ & $\mathrm{x}$ & 12 & 655 \\
\hline Pretreatment $\quad$ Regeneration & & PO-S802 & 3211 & $\mathrm{x}$ & & & & $\mathrm{x}$ & 90 & 240 \\
\hline Repackage & & PO-S803 & 7700 & & $\mathrm{X}$ & & & $\mathrm{x}$ & 13 & .2 \\
\hline Sort, Survey, Decon & 19 & & $4100,6000,7000,9999$ & $\mathrm{x}$ & $\mathrm{x}$ & $\mathrm{x}$ & $\mathrm{X}$ & $\mathrm{x}$ & 17 & 253 \\
\hline On-site Stabilization & & PO-S809 & $3100 \mathrm{~s}, 4100 \mathrm{~s}, 53-5400 \mathrm{~s}$ & $\mathrm{x}$ & $\mathrm{x}$ & $\mathrm{x}$ & $\mathrm{x}$ & & 17 & 5,485 \\
\hline Thermal Desorption & GJ-S801B & & $3111,5390,5900,59000$ & $\mathrm{x}$ & $\mathrm{x}$ & & $\mathrm{x}$ & $\mathrm{x}$ & 15 & 111 \\
\hline Thorium Nitrate Tank T-2 & & FM-S805 & 1210 & & $\mathrm{x}$ & $\mathrm{x}$ & & & 12 & 22 \\
\hline $\begin{array}{c}\text { Treatability Study Solidification/ } \\
\text { Neutralization }\end{array}$ & SA-S807 & . & 1190 & & $\mathrm{x}$ & & $\mathrm{x}$ & & 12 & 1 \\
\hline Deactivate Reactive Metals & & PO-S804 & 7590 & & $\mathrm{x}$ & & & $\mathrm{x}$ & 13 & 0.6 \\
\hline Water-Reactive Waste (Reactive Metals Skid) & LA-S003 & & 5900,7500 & & $\mathrm{x}$ & & & $\mathrm{x}$ & 15 & 7 \\
\hline
\end{tabular}

* MPC 7590 is LA-W923 Inorganicsolid oxidizers; should be MPC 3160 or 3230, CPC RC-090-M90-C11C 
Table V-2 Mobile Treatment Units Matrix Correlations/Matrix Order

\begin{tabular}{|c|c|c|c|c|c|c|c|c|c|c|}
\hline Technology & AL\# & NonAL\# & Assigned Waste MPCs & 011 & 090 & M11 & M12 & M90 & $\mathrm{CXX}$ & Vol. $M^{3}$ \\
\hline $\begin{array}{l}\text { Chemical And Plating Waste (Electroplating } \\
\text { Skid) }\end{array}$ & LA-S004 & & 1140,1290 , & $\mathrm{x}$ & $\mathrm{x}$ & & $\mathrm{x}$ & $\mathrm{x}$ & 17 & 7 \\
\hline Evaporative Oxidation & GJS-801C & & $1190,1210,2190$ & $\mathrm{x}$ & & $\mathrm{x}$ & $\mathrm{x}$ & $\mathrm{x}$ & 14 & 185 \\
\hline Physical Chemical Treatment & & PO-S808 & $\begin{array}{r}1110,1120,1230,1190 \\
1290\end{array}$ & $\mathrm{x}$ & $x$ & $x$ & & $x$ & 12 & 78 \\
\hline Portable Water Treatment Unit & & IN-S006 & $1100,1110,1120,6200$ & $\mathrm{X}$ & $\mathrm{X}$ & $\mathrm{x}$ & $\mathrm{x}$ & $\mathrm{x}$ & 12 & $655^{\circ}$ \\
\hline $\begin{array}{l}\text { Treatability Study Solidification/ } \\
\text { Neutralization }\end{array}$ & $\mathrm{SA}-\mathrm{S} 807$ & & 1190 & & $\mathrm{X}$ & & $\mathrm{x}$ & & 12 & 1 \\
\hline Thorium Nitrate Tank T-2 & & FM-S805 & 1210 & & $\mathrm{x}$ & $\mathrm{X}$ & & & 12 & 22 \\
\hline Hydrothermal Processing & LA-S804 & & $\begin{array}{r}2210,2220,2900,6100 \\
7590 *\end{array}$ & $\mathrm{x}$ & $\mathrm{x}$ & $\mathrm{x}$ & $\mathrm{x}$ & $\mathrm{x}$ & 17 & 60 \\
\hline $\begin{array}{l}\text { Packed Bed Reactor/Silent Discharge } \\
\text { Plasma/Tritium Capture }\end{array}$ & SA-S801 & & $2200,2220,3139,6400$ & $\mathrm{x}$ & $\mathrm{x}$ & & $\mathrm{x}$ & & 11 & 26 \\
\hline Metal Recovery & & PO-S807 & $3119,3129,3190,3290$ & $\mathrm{x}$ & $\mathrm{x}$ & $\mathrm{x}$ & & & 90 & 62 \\
\hline Pretreatment Regeneration & & PO-S802 & 3211 & $\mathrm{X}$ & & & & $\mathrm{X}$ & 90 & 240 \\
\hline Thermal Desorption & GJ-S801B & & $3111,5390,5900,59000$ & $\mathrm{x}$ & $\mathrm{x}$ & & $\mathrm{x}$ & $\mathrm{x}$ & 15 & 111 \\
\hline Sort, Survey, Decon & 19 & & $4100,6000,7000,9999$ & $x$ & $X$ & $\mathrm{x}$ & $\mathrm{x}$ & $x$ & 17 & 253 \\
\hline Lab Packs Treatment & & PO-S806 & 6900 & $\mathrm{x}$ & & $\mathrm{x}$ & $\mathrm{x}$ & & 17 & 31 \\
\hline Lead Decontamination Trailer & LA-S001 & & 7211,7219 & & $\mathrm{x}$ & $\mathrm{x}$ & & & 90 & $74(6)$ \\
\hline On-site Stabilization & & PO-S809 & $3100 s, 4100 s, 53-5400 s$ & $\mathrm{x}$ & $\mathrm{x}$ & $\mathrm{x}$ & $\mathrm{x}$ & & 17 & 5,485 \\
\hline Macroencapsulation & PX-S803 & & $\begin{array}{r}5100,5300,5400,5900 \\
7219\end{array}$ & $\mathrm{x}$ & $\mathrm{x}$ & $\mathrm{x}$ & $\mathrm{x}$ & & 17 & 783 \\
\hline Amalgamation of Elemental Mercury & PI-S801 & & 7100 & $\mathrm{x}$ & $\mathrm{X}$ & & $\mathrm{x}$ & & 90 & 1.7 \\
\hline Deactivate Reactive Metals & & PO-S804 & 7590 & & $\mathrm{X}$ & & & $\mathrm{x}$ & 13 & 0.6 \\
\hline Water-Reactive Waste (Reactive Metals Skid) & LA-S003 & & 5900,7500 & & $\mathrm{X}$ & & & $\mathrm{x}$ & 15 & 7 \\
\hline Repackage & & PO-S803 & 7700 & & $\mathrm{X}$ & & & $\mathrm{X}$ & 13 & .2 \\
\hline Decontanninate Cylinders & & PO-S805 & 7700 & $\mathrm{x}$ & & $\mathrm{X}$ & & . & 11 & 7.7 \\
\hline Gas Treatment Skid & LA-S80I & & 7700 & $\mathrm{x}$ & $\mathrm{x}$ & & & $\mathrm{x}$ & 14 & 0.6 \\
\hline
\end{tabular}

* MPC 7590 is LA-W923 Inorganic solid oxidizers; should be MPC 3160 or 3230, CPC RC-O90-M90-C11C 
Table V-3. MTUs to set aside and not consider in the PTSS

\begin{tabular}{||l|r|r||}
\hline Lead Decontamination Trailer & LA-S001 & \\
\hline Amalgamation of Elemental Mercury & PI-S801 & \\
\hline Deactivate Reactive Metals & & PO-S804 \\
\hline Water-Reactive Waste (Reactive Metals Skid) & LA-S003 & \\
\hline Repackage & & PO-S803 \\
\hline Decontaminate Cylinders (aerosol cans) & & PO-S805 \\
\hline Gas Treatment Skid & LA-S801 & \\
\hline
\end{tabular}

Some special considerations:

Decontamination of bulk lead items at Los Alamos has successfully completed using the lead decon trailer. If it can be moved, this unit should be used at any other site where the operation is practical. The trailer is configured to include grout stabilization of solids generated in the cleaning of bulk lead. Encapsulation of these wastes in polymer could be substituted for grout at any site where polymer might be preferred.

Mercury amalgamation should also be deployed at those sites with enough stored mercury to justify the units. The 4 largest sites have 2.5 to 6.5 cubic meters each. These can be served with a dedicated AL type mercury amalgamation MTU at each site or perhaps a unit of some what larger size. All of the remaining sites can be served with one mobile unit working over the 5 year period. Again there seems little value in further evaluation of this MTU.

Because very little can be learned from further study of mercury amalgamation, lead cleaning, gas bottle handling, and reactive metal treatment processes those should not be included in the PTSS.

Laboratory pack treatment presents a special issue worth further consideration. Laboratory packs are made up of small containers of materials most of which can be assigned to one of the matrix categories 1000-5000. The laboratory pack module is identified only as "Laboratory Packs Treatment; all wastes assigned have the CPC 6900 which designates the waste matrix as "unknown or other". We will discuss these further in developing the recommended list of waste streams.

Soils are excluded because in this level of analysis handling and processing of soils is not very different from processing inorganic solids, 3100 s. 


\section{Data analysis for defining waste Streams for PTSS.}

Not all of the largest sites need the full range of treatment capabilities. Some of the larger sites do have requirements for treatment of large quantities of some matrices while they have among the smallest requirements for other wastes. For example INEL has one of the largest treatment requirements for debris but has one of the very smallest needs for laboratory pack treatment.

The data sets were examined for each matrix category at the 100 s level. Sites with the larger obligations were set aside and the data from the remainder of the sites totaled to provide a total obligation for MTU processing.

Calculation of the required treatment capacity is based on operating 20 weeks per year at 40 hours per week, or 800 net effective operating hours per year.

All treatment capacity values are in cubic meters per year.

\section{Recommended waste streams and sizes}

$\begin{array}{lll}\text { 1. Aqueous waste streams: } & \text { MPC } 1100 & 200 \mathrm{~m}^{3} / \mathrm{yr} \\ & \text { MPC } 1200 & 200 \mathrm{~m}^{3} / \mathrm{yr}\end{array}$

One third of both streams should be "tagged with" organics including halogenated organics at 1/3 of total regulated organic content which is $<1 \%$. All wastes are assumed to contain dissolved regulated inorganic constituents. The annul capacity estimate include allowance for intermodule aqueous streams

Rationale: Aqueous treatment capability is required as primary treatment for external wastes and for processing aqueous wastes from other treatment operations.

The general aqueous treatment capability can only be fully defined in conjunction with other MTUs that may require such support. A broader aqueous waste treatment capability than that identified for anyone of the STP MTUs should be developed.
2. Organic waste streams: $\quad$ MPC 2100
$80 \mathrm{~m}^{3} / \mathrm{yr}$
MPC 2200
$40 \mathrm{~m}^{3} / \mathrm{yr}$

Approximately $10 \%$ of the total organic waste steams are regulated for metals content only.

Rationale: Organic waste stream treatment capability is required as primary treatment for external wastes and for processing organic waste separated from other primary waste feed streams. Organic will be generated by thermal desorption treatment of inorganic residues, soils and debris where thermal desorption to remove excess organic is applied. 

3. Homogeneous solids:
MPC 3100
organic contaminated
$70 \mathrm{~m}^{3} / \mathrm{yr}$
MPC 3100
non organic contaminated
$500 \mathrm{~m}^{3} / \mathrm{yr}$
MPC 3200
organic contaminated
$40 \mathrm{~m}^{3} / \mathrm{yr}$

Rationale: Homogeneous solids present some of the more difficult problems in the waste stream set. This category covers very diverse set of materials ranging from sand, adsorbents, and stabilized sludge to organic and inorganic chemicals, some of which may be highly reactive. In a simplified categorization like this it is difficult to define a summary set of representative materials. See the discussion of laboratory packs below.

$\begin{array}{llll}\text { 4. Debris waste streams: } & \text { MPC 5100 } & \text { inorganic CPC organic } & 10 \mathrm{~m}^{3} / \mathrm{yr} \\ & \text { MPC 5300 } & \text { organic CPC organic } & 45 \mathrm{~m}^{3} / \mathrm{yr} \\ \text { MPC 5400 } & \text { heterog. CPC organic } & 65 \mathrm{~m}^{3} / \mathrm{yr} \\ \text { MPC 5100 } & \text { inorganic CPC no organic } & 10 \mathrm{~m}^{3} / \mathrm{yr} \\ \text { MPC 5300 } & \text { organic CPC non organic } & 45 \mathrm{~m}^{3} / \mathrm{yr} \\ \text { MPC 5400 } & \text { heterog. CPC non organic } & 65 \mathrm{~m}^{3} / \mathrm{yr}\end{array}$

Rationale: These wastes are located at many of the smaller sites. Debris wastes present a material handling challenge particularly to a smaller site. If the decision were made to treat all organic contaminated debris by thermal desorption, the material must be size reduced for feed to TD equipment. Some need for size reduction can be expected also to prepare debris for stabilization of contaminants. Appropriate material handling and size reduction should be an interesting challenge for a trailer mounted modular unit.

$\begin{array}{ll}\text { 5. Laboratory packs: } & 5 \mathrm{~m}^{3} / \mathrm{yr} \\ & \begin{array}{lll}\text { MPC 6100 } & \text { organic } & 10 \mathrm{~m}^{3} / \mathrm{yr} \\ \text { MPC 6200 } & \text { aqueous } & 5 \mathrm{~m}^{3} / \mathrm{y} \\ \text { MPC 6300 } & \text { solid } & 15 \mathrm{~m}^{3} / \mathrm{yr} \\ \text { MPC 6400 } & \text { scintillation cocktail } & 45 \mathrm{~m} 3 / \mathrm{yr}\end{array}\end{array}$

Rationale: Laboratory packs are located at several sites with only Richland having a large and continuing quantity indicated. The contents of most laboratory packs should be treatable in the other primary treatment module. The challenge with laboratory packs and reason for inclusion in analysis of the interactions with other processes. The "Laboratory Pack module" should have capability for opening and sorting containers, primarily drums. The estimates developed for the PEIS analysis gave the net chemical content of a laboratory pack as $40 \%$ or less. Laboratory Packed containers will present such diverse problems as destruction of inorganic oxidizers, destruction of solid cyanide salts, neutralization of hydrofluoric acid, and stabilization of the product salts. 


\section{E. Integrated treatment systems: turning modules into treatment trains}

A preliminary assignment of treatment modules to make up treatment trains can be made for the different waste matrix sets.

1. Integrate treatment organic liquids, soils and sludges (organic and inorganic) for thermal desorption, organic destruction, and stabilization of residues.

Combine:

Thermal Desorption GJ-S801B,

Organic Destruction (Hydrothermal Processing LA-S804 or alternative)

Macroencapsulation PX-S803 and/or

Onsite Stabilization PO-S809

2. Debris segregation, size reduction, and stabilization

3. Continue with the lead decon MTU.

4. Develop a general water treatment module 3-5 trailers and a laboratory packs module with organic destruction and stabilization. This will include scintillation vials. The water treatment module will have capability to neutralize acids, bases, and water reactives and strong oxidizers.

5. Expand the compressed gas MTU to treat aerosol cans.

6. Do a laboratory packs sorting and pretreatment module, PO-S806

Not all of the largest sites need the full range of capabilities. Some of the larger sites have smaller quantities of some waste matrices. For example INEL has large quantities of debris but has one of the smallest laboratoryoratory pack treatment requirements. 


\section{REFERENCES}

1. Report of the Treatment Selection Team, Final Issue, March 1994, Mixed Waste Treatment Plan, pages not numbered.

2. Mixed Waste Treatment Program Waste Treatment Technologies Summary, Department of Energy, Grand Junction Projects Office, draft, June 1995.

3. Albuquerque Needs Trip Report, August 1-3 1995, addendum B to INEL-95/0555.

4. STP Database, INEL. 


\section{Appendix B}

Design Concepts and Requirements Report 


\title{
DRAFT
}

(Version 2)

\section{FUNCTIONAL AND OPERATIONAL REQUIREMENTS FOR \\ FOUR PORTABLE TREATMENT SYSTEMS}

\author{
US DEPARTMENT OF ENERGY EM-50 \\ PORTABLE TREATMENT SYSTEMS STUDY \\ prepared for \\ Lockheed Martin Idaho Technologies Company \\ 2525 Fremont Avenue \\ P. O. Box 1625 \\ Idaho Falls, ID 83415
}

submitted by

J. S. Vavruska

T. K. Thompson

J. A. Pendergrass

Equinox, Ltd.

872 Don Cubero Avenue

Santa Fe, New Mexico 87501

under Subcontract No. C96-175971

September 1996

B-1 


\section{TABLE OF CONTENTS}

EXECUTIVE SUMMARY

FUNCTIONAL AND OPERATIONAL REQUIREMENTS FOR ORGANICS

PORTABLE TREATMENT..................................................................................................................................7

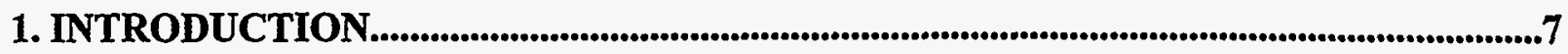

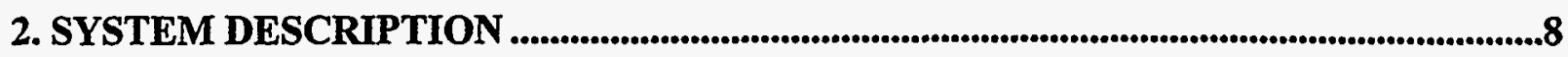

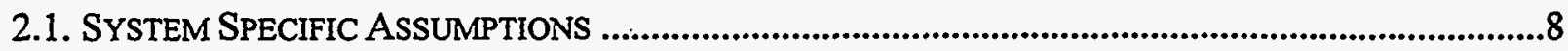

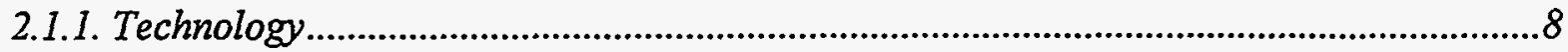

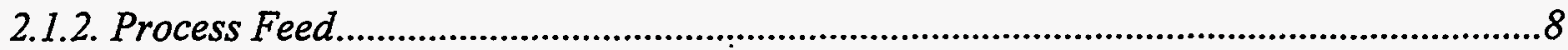

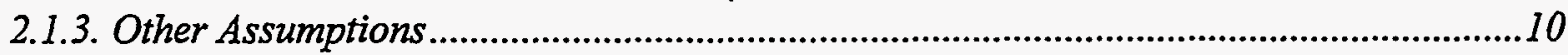

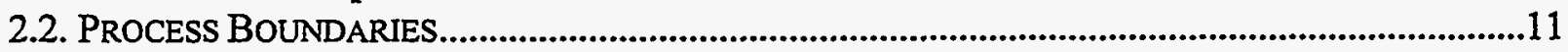

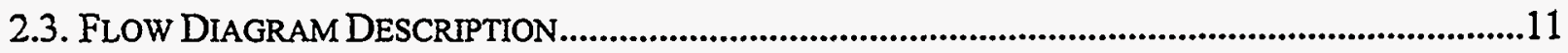

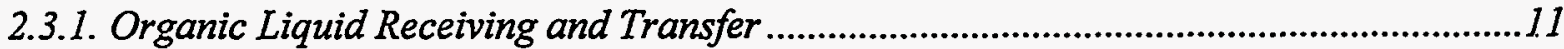

2.3.2. Filtration of Organic Liquids ............................................................................11

2.3.3. Thermal Oxidation.................................................................................................11

2.3.4. Quench/Venturi Scrubber/Absorber .......................................................................12

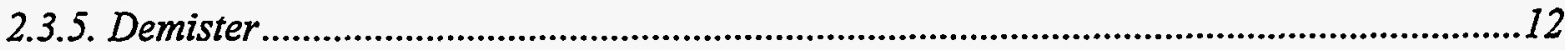

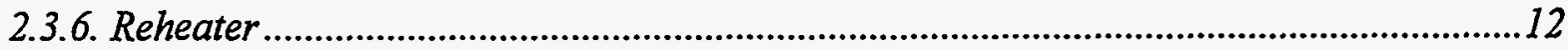

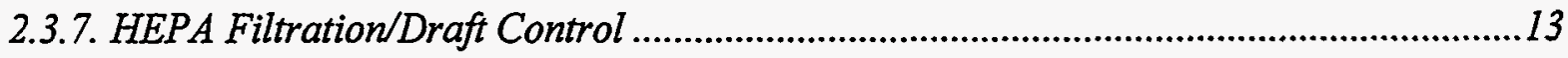

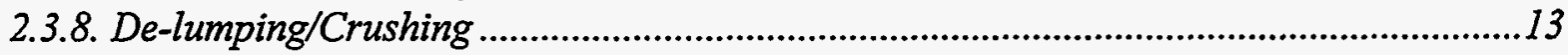

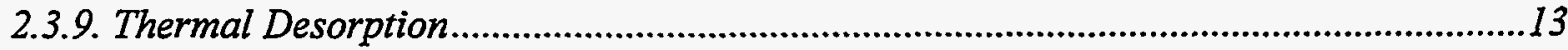

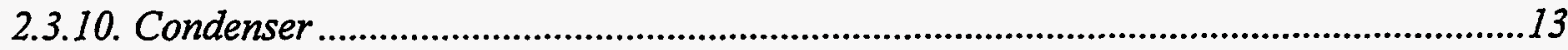

2.3.11. Polymer Microencapsulation...............................................................................14

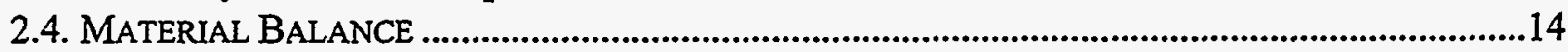

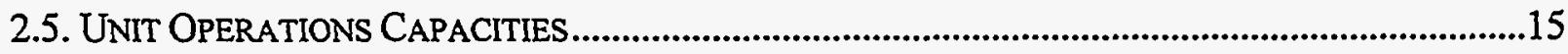

3. SYSTEM DESIGN CRITERIA.................................................................................................17

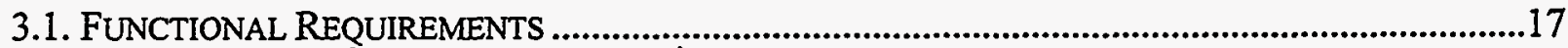

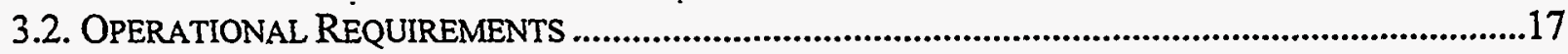

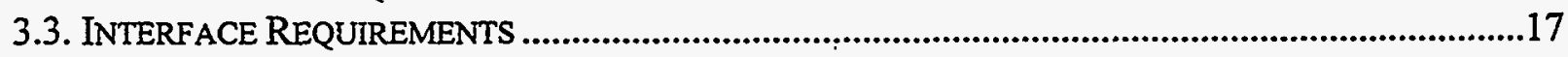

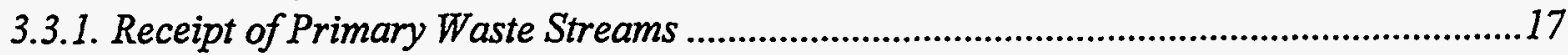

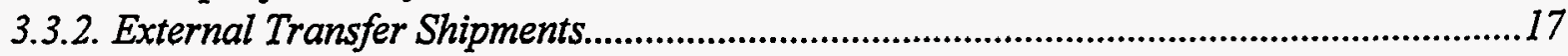

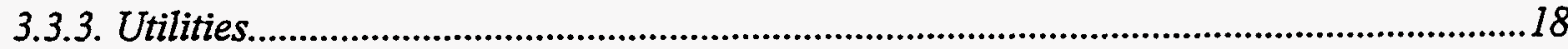

FUNCTIONAL AND OPERATIONAL REQUIREMENTS FOR LABPACKS

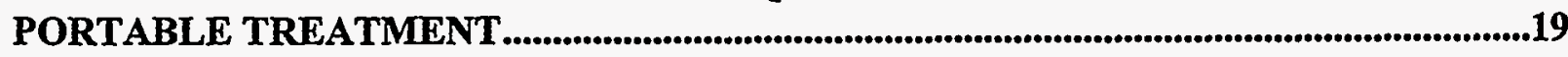

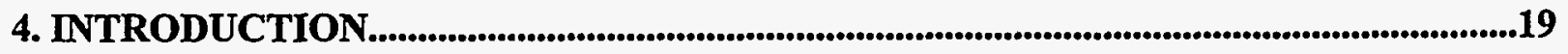

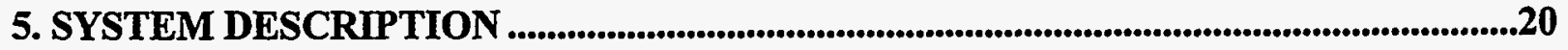

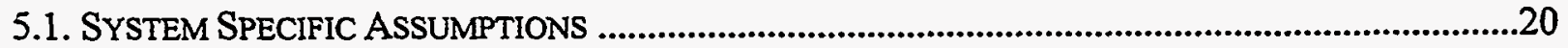




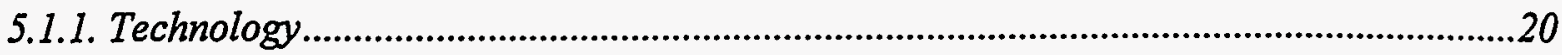

5.1.2. Process Feed ……….................................................................................................20

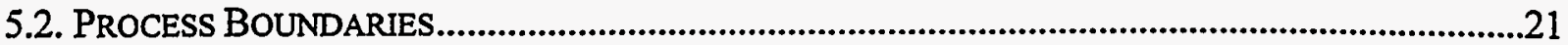

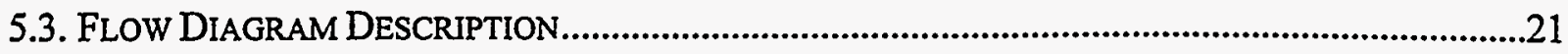

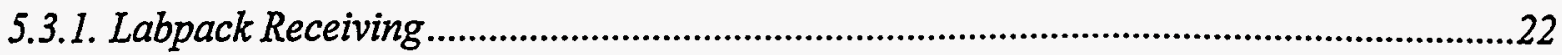

5.3.2. Opening/Sorting......................................................................................................22

5.3.3. Segregation of Solid and Liquid Organics ......................................................................22

5.3.4. Organic Liquid Filtration and Transfer .......................................................................22

5.3.5. Inorganic Chemical Deactivation..............................................................................2

5.3.6. Inorganic Liquid Filtration...................................................................................23

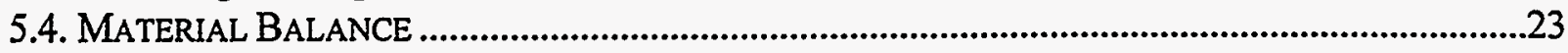

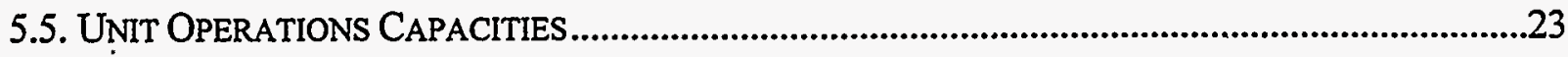

6. SYSTEM DESIGN CRITERIA....................................................................................................25

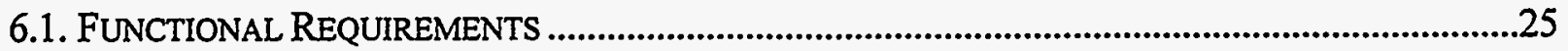

6.2. OPERATIONAL REQUIREMENTS ..........................................................................................25

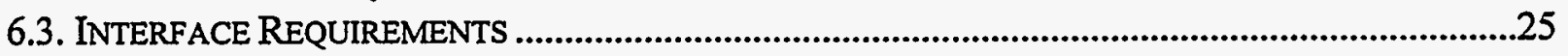

6.3.1. Receipt of Waste Streams.......................................................................................25

6.3.2. External Transfer Shipments.......................................................................................25

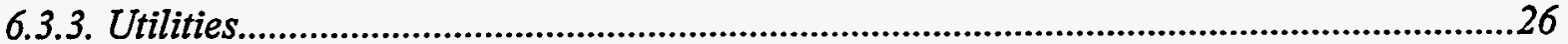

FUNCTIONAL AND OPERATIONAL REQUIREMENTS FOR DEBRIS PORTABLE TREATMENT .................................................................................................................................................27

7. INTRODUCTION...................................................................................................................................27

8. SYSTEM DESCRIPTION .....................................................................................................................27

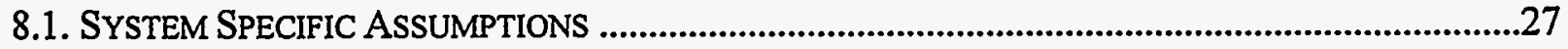

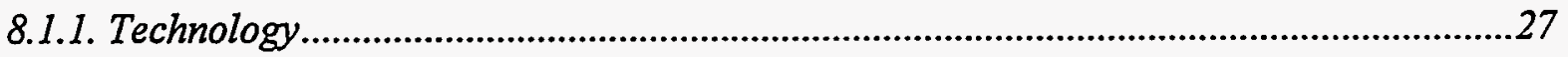

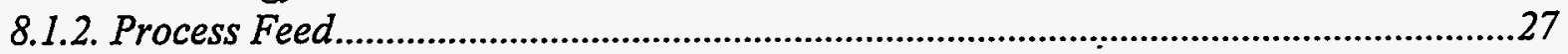

8.2. PROCESS BOUNDARIES......................................................................................................2

8.3. FLOW DIAGRAM DESCRIPTION...........................................................................................29

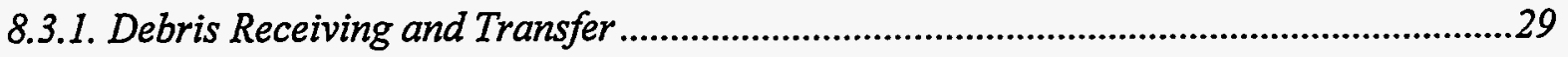

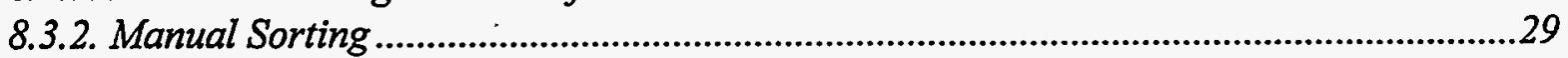

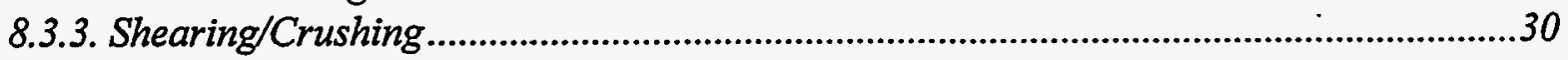

8.3.4. Cement Microencapsulation ............................................................................................30

8.4. MATERIAL BALANCE ...........................................................................................................31

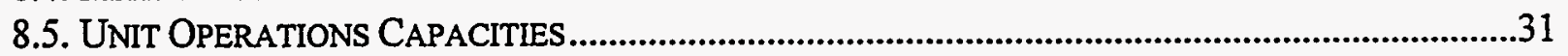

9. SYSTEM DESIGN CRITERIA.........................................................................................................32

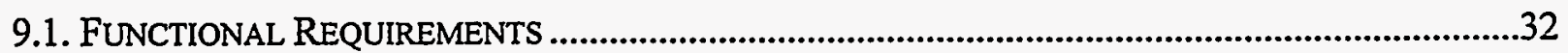

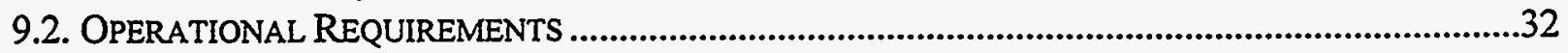

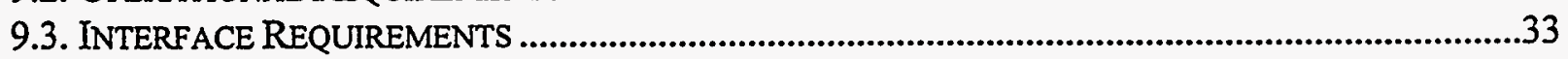

9.3.1. Receipt of Primary Waste Streams ....................................................................................3

9.3.2. External Transfer Shipments............................................................................................3 
FUNCTIONAL AND OPERATIONAL REQUIREMENTS FOR WASTEWATER PORTABLE TREATMENT.

10. INTRODUCTION...............................................................................................................................34

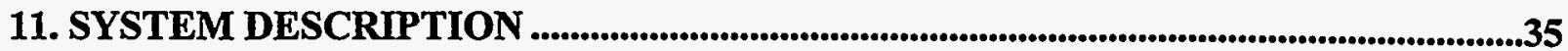

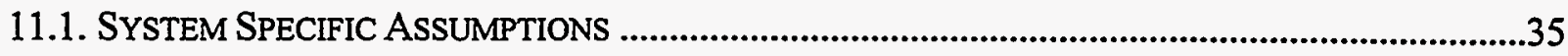

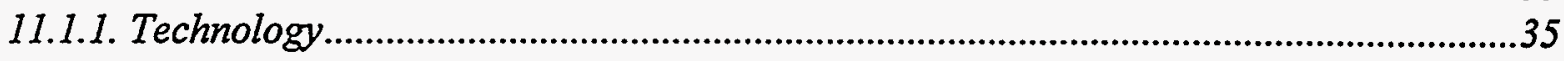

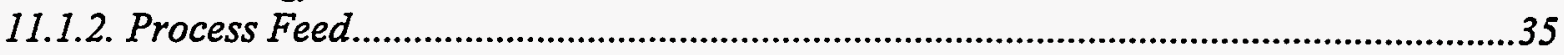

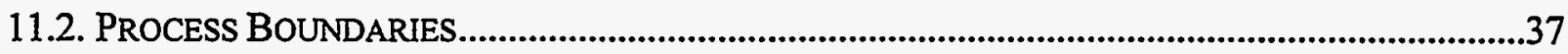

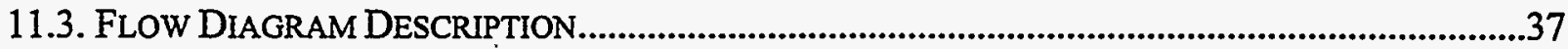

11.3.1. Liquid Receiving, Sampling, and Transfer ....................................................................38

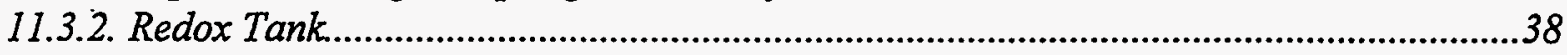

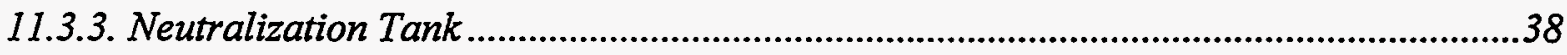

11.3.4. Filtration of Aqueous Liquids .................................................................................38

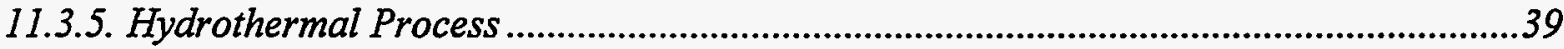

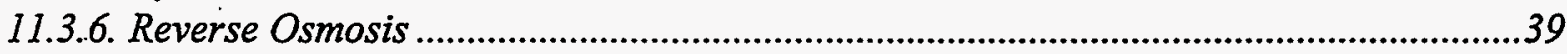

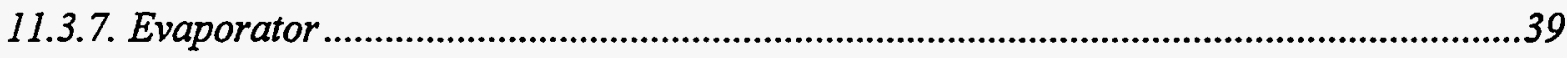

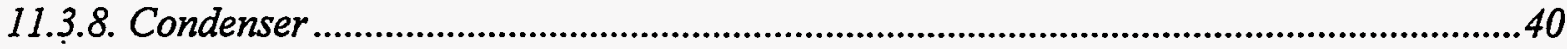

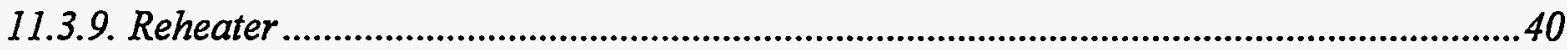

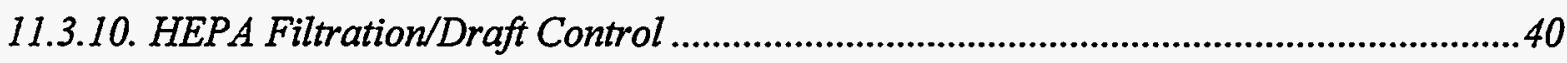

11.4. MATERIAL BALANCE ..............................................................................................40

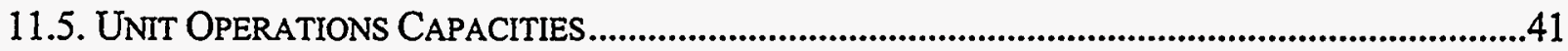

12. SYSTEM DESIGN CRITERIA..............................................................................................42

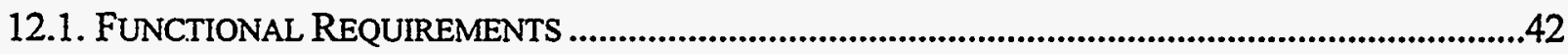

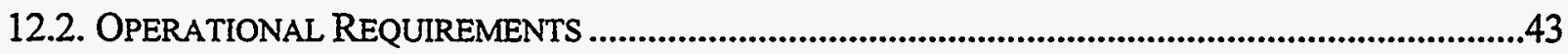

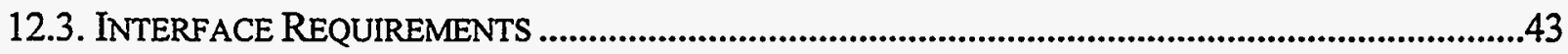

12.3.1. Receipt of Primary Waste Streams .........................................................................43

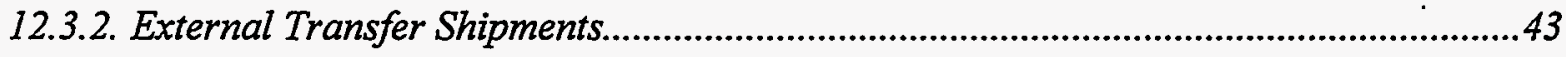

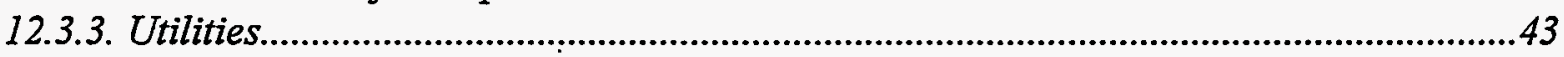

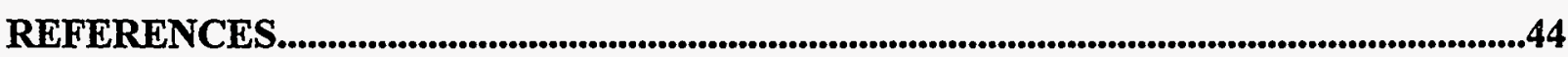




\section{EXECUTIVE SUMMARY}

The goal of the Portable Treatment Systems Study (PTSS) sponsored by the Department of Energy (DOE) Office of Technology Development (EM-50) is to identify where R\&D emphasis should be placed if portable treatment becomes a viable option for selected mixed waste streams within the complex. The PTSS comprises three phases. Phase I consisted of a waste stream analysis to identify mixed low-level waste streams targeted for portable treatment. Phase II of the study consists of system formulation and design. The work presented in this report contributes to the Phase II effort by formulating portable treatment system concepts to serve as a basis for Phase III. Phase III focuses on system evaluations including life cycle cost estimates, R\&D needs, and potential obstacles to implementation.

This document presents Functional and Operational Requirements for four hypothetical portable treatment units for treatment of a variety of the Department of Energy's mixed low level radioactive waste streams. This document is not a feasibility study nor does it provide commentary on the viability of portable treatment in this mixed waste application. Such analysis is the subject of the PTSS Phase III effort.

The composite set of F\&ORs presented here is a pre-conceptual design document that defines the functional and operational requirements for the portable treatment systems formulated to treat the selected waste streams. Where feasible, selection of technology is based on best demonstrated available technology (BDAT) as well as technologies selected by the Albuquerque Operations Office (AL) to be used in mobile treatment units (MTUs) at AL sites. Alternative technologies are also listed. These F\&OR documents also present assumptions, system boundaries, flow diagrams with preliminary material balances, unit capacities, and onstream factors for each of the portable units. Equipment layouts were beyond the scope of this work and hence are not included. Preliminary design criteria that include functional, performance, and interface requirements are presented.

Each portable treatment unit consists of one or more trailer-mounted process systems to treat specific waste matrix sets. A total of four Portable Treatment Units were selected to treat five waste matrix sets. Table A lists the Portable Treatment Units and the primary waste compositions and Matrix Parameter Codes (MPCs) for the waste streams selected as the F\&OR design basis. More detailed discussions of the waste compositions are included in the sections of the report dealing with the individual Portable Treatment Units. The Portable Treatment Units include those for Organics, Labpacks, Debris, and Wastewater. An integrated process flowsheet for the four Portable Treatment Units is shown in Figure 1. On-stream factors (based on 8,760 hours/yr) for the rate-limiting unit operations within the Portable Treatment Units, range from 25 to $40 \%$. The Labpacks Portable Treatment Unit has an on-stream factor of only $2 \%$. 
Table A

Portable Treatment Units and Primary Waste Compositions

\begin{tabular}{||l|l|c|c|}
\hline Portable Treatment Unit & \multicolumn{1}{|c|}{ Waste Description } & $\begin{array}{c}\text { MPC } \\
\text { Organics }\end{array}$ & $\begin{array}{c}\text { Vol. Rate } \\
\left(\mathbf{m}^{\mathbf{3}} / \mathbf{y r}\right)\end{array}$ \\
\hline \hline & Aqueous Organic Liquid & 2100 & 80 \\
& Pure Organic Liquid & 2200 & 40 \\
& Inorganic Homogeneous Solids & 3100 & 70 \\
& Inorganic Homogeneous Solids & 3100 & 500 \\
& Organic Homogeneous Solids & 3200 & 40 \\
\hline Labpacks & Organic & 6100 & 5 \\
& Aqueous & 6200 & 10 \\
& Solid & 6300 & 5 \\
& Scintillation Cocktail & 6400 & 15 \\
& Undefined & 6000,6900 & 45 \\
\hline Debris & Inorganic (Org. Contam.) & 5100 & 10 \\
& Organic (Org. Contam.) & 5300 & 45 \\
& Heterogeneous (Org. Contam.) & 5400 & 65 \\
& Inorganic & 5100 & 10 \\
& Organic & 5300 & 45 \\
& Heterogeneous & 5400 & 65 \\
\hline Wastewater & Aqueous Liquids & 1100 & 200 \\
& Aqueous Slurries & 1200 & 200 \\
\hline
\end{tabular}




\section{FUNCTIONAL AND OPERATIONAL REQUIREMENTS FOR ORGANICS PORTABLE TREATMENT}

\section{INTRODUCTION}

This document presents Functional and Operational Requirements (F\&ORs) for the Organics Portable Treatment Unit. This unit is part of the integrated Portable Treatment Systems Study (PTSS) sponsored by the US Department of Energy Office of Technology Development. The objectives of the Organics Portable Treatment Unit are: 1 ) to accept and effectively process organic liquids, organic sludges, and inorganic sludges that are mixed low level radioactive wastes, and 2) to meet these objectives by processing the waste streams on portable semi-trailers that can be moved from site to site. The function of the unit is to destroy the organic fraction of the waste streams by conversion to carbon dioxide, water, and hydrochloric acid while retaining the inorganic fraction including RCRA metals and non-volatile radionuclides in a stable final waste form for storage or disposal. The unit also accepts external transfer streams from two other portable units: the Wastewater Portable Treatment Unit and the Labpacks Portable Treatment Unit. The treatment unit comprises process equipment to perform the above functions mounted on multiple semi-trailers.

The operation consists of separate sequences of processing steps for each of the waste streams. Organic liquid streams are filtered to remove suspended solids; the wet solids from the filter are transferred to Thermal Desorption. Clarified organic liquid is treated by Thermal Oxidation in an open reaction chamber using air at a temperature of $1093{ }^{\circ} \mathrm{C}$. Offgas from the thermal oxidizer is cooled to saturation in a Quencher. Particulate is removed in a Quench/Venturi scrubber and acid gases such as $\mathrm{HCl}$ and $\mathrm{SO}_{2}$ are removed by absorption in a Packed Tower absorber. The scrubbed saturated gases are heated above the dew point in a Reheater followed by final filtration in High Efficiency Particulate Air (HEPA) Filters before discharge to the atmosphere. Sludges (organic and inorganic) are fed to Thermal Desorption in which they are indirectly heated to vaporize all volatile organic compounds (VOCs) and moisture. The vapor from Thermal Desorption is cooled in a Condenser and the aqueous/organic condensate is transferred to the front end of the Wastewater Portable Treatment Unit. The dry solids from Thermal Desorption are fed to Polymer Microencapsulation where a polymer is blended with the feed materials to produce a final stabilized waste form.

A fundamental assumption in this work is that the portable treatment units are assembled and fully operable on semi-trailers. Only utility hookups on-site are required for operability. The treatment units are not modular and are not intended to be off-loaded from the trailers for process service within on-site facilities. Also, specific processing trains are sized to accommodate equipment having the largest reasonable throughput rate possible given the size constraint of the semi-trailers. 


\section{SYSTEM DESCRIPTION}

\subsection{System Specific Assumptions}

\subsubsection{Technology}

The flow diagram for the Organics Portable Treatment Unit is provided in block form in Figure 2. Descriptions of the individual unit operations and the technologies selected for the Organics Portable Treatment Unit are provided in Section 3.1 Flow Diagram Description. The flowsheet and selection of the specific technologies within it are dependent upon the feed stream assumptions discussed in the following section.

\subsubsection{Process Feed}

The primary waste feed stream compositions and associated assumptions for the organics portable treatment unit are shown in Table 1 . The required treatment capacities $\left(\mathrm{m}^{3} / \mathrm{yr}\right)$ for each waste matrix set were obtained from Musgrave ${ }^{1}$. The waste stream summary report ${ }^{2}$ by Heubner et al was used as a guide for establishing the ultimate compositions (organics, inerts, water) for the waste streams. Densities $\left(\mathrm{kg} / \mathrm{m}^{3}\right)$ of the feed materials were taken from Perry ${ }^{3}$. Though the mixed waste soil/gravel inventory (MPC 4000,4100,4200,4300, 4900) is large $\left(12900 \mathrm{~m}^{3}\right)^{4}$, the majority of the soils resides at only a few sites. It is assumed that these sites would develop onsite soils treatment capability. Therefore, soils/gravel were not included in this study as candidates for portable treatment. Drum weights are excluded from the density assumptions and calculated mass throughput rates reported in Table 1.

In addition to these primary waste feed streams, the organics portable treatment unit accepts transfer streams from other portable units. These transfer streams are summarized in Table 2. 
Table 1

Waste Feed Streams for the Organics Portable Treatment Unit

\begin{tabular}{|c|c|c|c|c|c|}
\hline \multirow[b]{2}{*}{ Waste Stream } & \multirow{2}{*}{$\begin{array}{c}\text { Aqueous/ } \\
\text { Organic } \\
\text { Liquids } \\
\text { (a) }\end{array}$} & \multirow{2}{*}{$\begin{array}{l}\text { Pure } \\
\text { Organic } \\
\text { Liquids } \\
\text { (b) }\end{array}$} & \multicolumn{2}{|c|}{ Inorganic Homogeneous Solids } & \multirow{2}{*}{$\begin{array}{c}\text { Organic } \\
\text { Homogeneous } \\
\text { Solids (e) }\end{array}$} \\
\hline & & & $\begin{array}{c}\text { (Non-Organic } \\
\text { Contaminated) } \\
\text { (c) } \\
\end{array}$ & $\begin{array}{c}\text { (Organic } \\
\text { Contaminated) } \\
\text { (d) } \\
\end{array}$ & \\
\hline $\begin{array}{l}\text { Matrix Parameter Code } \\
\text { (MPC) }\end{array}$ & 2100 & 2200 & 3100 & 3100 & 3200 \\
\hline Treatment Input. $\mathrm{m}^{3} / \mathrm{yr}$ & \multicolumn{4}{|c|}{ (2) } & \\
\hline Density, $\mathrm{kg} / \mathrm{m}^{3}(\mathrm{f})$ & 966.0 & 1088.0 & 700 & 650 & 400 \\
\hline Annual Throughput, $\mathrm{kg} / \mathrm{yr}$ & 77,280 & 43,520 & 350,000 & 45,500 & 16,000 \\
\hline \multicolumn{6}{|c|}{\begin{tabular}{|l|l|} 
Elemental Composition & \\
\end{tabular}} \\
\hline \multicolumn{6}{|c|}{ Organics (wt\% of total stream) } \\
\hline Carbon & 38.6 & 76.7 & 0.0 & 3.2 & 57.88 \\
\hline Hydrogen & 3.4 & 6.7 & 0.0 & 0.3 & 5.06 \\
\hline Oxygen & 0.0 & 0.0 & 0.0 & 0.0 & 0.0 \\
\hline Nitrogen & 0.0 & 0.0 & 0.0 & 0.0 & 0.0 \\
\hline Sulfur & 0.0 & 0.0 & 0.0 & 0.0 & 0.0 \\
\hline Chlorine & 8.0 & 16.0 & 0.0 & 0.7 & 12.06 \\
\hline Total Organics & 50.0 & 99.4 & 0.0 & 4.2 & 75.0 \\
\hline \multirow{2}{*}{\multicolumn{6}{|c|}{ Inorganics (wt\% of total stream) }} \\
\hline & & & & & \\
\hline Water & 39.2 & 0.0 & 34.0 & 32.7 & 5.0 \\
\hline Inerts (ash) & 10.8 & 0.6 & 66.0 & 63.1 & 20.0 \\
\hline Total Inorganics & 50.0 & 0.6 & 100.0 & 95.8 & 25.0 \\
\hline Total for Stream & 100.0 & 1000 & 1000 & 1000 & 1000 \\
\hline & & & & & \\
\hline
\end{tabular}

(a) Liquid streams that are mixtures of aqueous and organic liquids with an average of 50 wt\% organic; here, organic is assumed to be 33.3 wt\% dichlorobenzene $\left(\mathrm{C}_{6} \mathrm{H}_{4} \mathrm{Cl}_{2}\right), 66.7$ wt\% toluene $\left(\mathrm{C}_{7} \mathrm{H}_{8}\right)$.

(b) Solvents containing halogens and PCBs; here, organic is assumed to be $33.3 w t \% 1,3$ dichlorobenzene $\left(\mathrm{C}_{6} \mathrm{H}_{4} \mathrm{Cl}_{2}\right), 66.7 \mathrm{wt} \%$ toluene $\left(\mathrm{C}_{7} \mathrm{H}_{8}\right)$.

(c) Inorganic homogeneous solids such as adsorbents, sand, ion exchange media, precipitates, etc. with no organic contamination.

(d) Inorganic homogeneous solids such as adsorbents, sand, ion exchange media, precipitates, etc. with some organic contamination.

(e) Organic homogeneous solids are non-debris solid matrices such as organic particulates, sludges, and solid organic chemicals.

(f) Densities include drum mass. 
PTSS Functional and Operational Requirements

Draft Version 2, 9/25/96

Table 2

External Transfer Streams to the Organics Portable Treatment Unit from Other Portable Treatment Units

\begin{tabular}{|c|c|c|c|c|}
\hline $\begin{array}{l}\text { Stream } \\
\text { Description }\end{array}$ & $\begin{array}{c}\text { Source from Other Portable } \\
\text { Treatment Unit }\end{array}$ & $\begin{array}{c}\text { Destination within } \\
\text { the Organics } \\
\text { Portable Treatment } \\
\text { Unit }\end{array}$ & $\mathbf{m}^{3} / \mathbf{y r}$ & kg/yr \\
\hline $\begin{array}{l}\text { Organic } \\
\text { Liquids }\end{array}$ & $\begin{array}{l}\text { Sorted, separated, and filtered } \\
\text { organic liquids from the Labpacks } \\
\text { Portable Treatment Unit }\end{array}$ & Thermal Oxidizer & $\overline{4.4}$ & $3, \overline{928}$ \\
\hline $\begin{array}{l}\text { Organic } \\
\text { Sludges }\end{array}$ & $\begin{array}{l}\text { Sorted and separated organic solids } \\
\text { and sludges from the Labpacks } \\
\text { Portable Treatment Unit }\end{array}$ & $\begin{array}{l}\text { De-lumper/Crusher } \\
\text { then to Thermal } \\
\text { Desorber }\end{array}$ & 18.2 & 18,332 \\
\hline $\begin{array}{l}\text { Inorganic } \\
\text { Sludges }\end{array}$ & $\begin{array}{l}\text { Sorted, separated and dewatered } \\
\text { inorganic solids and sludges from } \\
\text { the Labpacks Portable Treatment } \\
\text { Unit }\end{array}$ & $\begin{array}{l}\text { De-lumper/Crusher } \\
\text { then to Thermal } \\
\text { Desorber }\end{array}$ & 4.6 & 5,499 \\
\hline $\begin{array}{l}\text { Inorganic } \\
\text { Sludges }\end{array}$ & $\begin{array}{l}\text { Dewatered inorganic sludge from } \\
\text { filtration and evaporation in the } \\
\text { Wastewater Portable Treatment Unit }\end{array}$ & $\begin{array}{l}\text { De-lumper/Crusher } \\
\text { then to Thermal } \\
\text { Desorber }\end{array}$ & 199.7 & 138,981 \\
\hline
\end{tabular}

\subsubsection{Other Assumptions}

used:

In developing these F\&ORs, the following additional assumptions with rationales are

- Given the assumption that the aqueous/organic liquid waste stream (MPC 2100 has an organic concentration of $50 \mathrm{wt} \%$ ), it was assumed that this stream would be treated by thermal oxidation rather than by the Hydrothermal Process within the Wastewater Portable Treatment System. Also, chloride corrosion due to oxidation of the halogenated organic waste feed streams is less of a concern in the high temperature refractory-lined Thermal Oxidizer than in a Hydrothermal reactor.

- Polymer Microencapsulation requires that the solids to be encapsulated must be free of moisture. The rationale for sending all sludges and soils to Thermal Desorption is that even though inorganic sludges are considered free of organics, they still require drying prior to Polymer Microencapsulation. The assumption was made that a separate drying operation could be eliminated by sending the inorganic sludges to Thermal Desorption for drying. Though this puts a greater demand on Thermal Desorption, a separate unit operation is eliminated. If a dryer were chosen, it would be similar in size and utility requirements to the Thermal Desorber.

- There is no air in-leakage to the Thermal Oxidizer.

- A refractory-lined conventional liquid injection combustion chamber for thermal oxidation was assumed to be well demonstrated technology and perfectly acceptable from a performance standpoint compared to emerging technologies such as packed bed/silent discharge plasma. 
- $100 \%$ of the organics and water in the Thermal Desorber feed are vaporized and recovered in the condenser as condensate.

\subsection{Process Boundaries}

The input boundary for the Organics Portable Treatment Unit is where the primary waste streams and external transfer streams from other portable treatment units enter the treatment trains within the unit. Utilities to be supplied by the facility at the operations location include auxiliary fuel (if available), electricity, and water. Combustion air for the Thermal Oxidizer and purge air for the Thermal Desorber are introduced to the respective processes by forced and induced draft from the atmosphere within the enclosed trailers. Compressed air for instruments and for liquid atomization in the Thermal Oxidizer is provided by a compressor on the trailer. Caustic reagent and polymer reagent are delivered by separate vehicles to the Organics Portable Treatment Unit processing location. In-leakage air (to be minimized) to the Thermal Oxidizer and to the Thermal Desorber comes from the ambient air surrounding these units within the enclosed trailers.

The output boundary of the Organics Portable Treatment Unit is where the output streams leave the treatment trains within the unit. Cleaned offgas is released to the atmosphere. Combined condensate from Thermal Desorption and liquid blowdown from Thermal Oxidizer offgas treatment are recycled to the Wastewater Portable Treatment Unit. Stabilized waste form packages $\left(0.208 \mathrm{~m}^{3}\right.$ ( $\left.55 \mathrm{gal}\right)$ drums) from Polymer Microencapsulation are transported to the shipping area of the facility.

\subsection{Flow Diagram Description}

The flow diagram for the Organics Portable Treatment Unit is provided in block form as Figure 2.

\subsubsection{Organic Liquid Receiving and Transfer}

The process can receive bulked organic liquids from tank trucks, dumpster type tankage, and drums. Drummed or bulk concentrated pumpable organic liquids are transferred by an insertion type of pump from the container to the organic liquid holding/feed tank. The transfer operation is conducted within a ventilated enclosure for vapor containment. Ventilation air is directed to the unit ventilation system that provides activated carbon and HEPA filtration.

\subsubsection{Filtration of Organic Liquids}

Incoming organic liquid wastes are filtered in one of two parallel cartridge type filters to remove suspended solids before transfer to the organic holding/liquid feed tank. The filtration operation is within the same enclosure as that described in the previous section. Spent filter cartridges are manually removed from the filter housing and sent to Thermal Desorption.

\subsubsection{Thermal Oxidation}

The thermal oxidation process is a conventional combination organic liquid and fume incinerator. The unit is refractory-lined and oriented horizontally with an auxiliary fuel burner 
mounted at one end. Concentrated organic liquids, aqueous/organic liquids, combustion air, fumes from Thermal Desorption, and auxiliary fuel as required are fed into the thermal oxidizer at the burner end of the reactor. Organic liquid waste is metered to the thermal oxidizer with a positive displacement pump and compressed air is used for atomization. The thermal oxidizer is sized to process $56.7 \mathrm{~kg} / \mathrm{hr}(125 \mathrm{lb} / \mathrm{hr})$ of concentrated organic liquid or a mixture of concentrated organic liquid and aqueous/organic liquid. It operates at a temperature of $1,093{ }^{\circ} \mathrm{C}$ $\left(2,000^{\circ} \mathrm{F}\right)$ with an average gas residence time of 2.5 seconds and an average oxygen concentration in the hot flue gas of 9 vol\%.

The thermal oxidizer is approximately $1.34 \mathrm{~m}$ ( $4.4 \mathrm{ft})$ diam. and $4.7 \mathrm{~m}$ (15.4 ft) long with a steel shell and a uniform $20 \mathrm{~cm}$ (8 in.) thick high alumina refractory lining and an approximate total weight of $10,000 \mathrm{~kg}$. This vessel is the largest and heaviest individual piece of process equipment in the Organics Portable Treatment Unit.

Based on the throughput rate of $56.7 \mathrm{~kg} / \mathrm{hr}$, the on-stream factor for the Thermal Oxidizer will be approximately $25 \%$.

\subsubsection{Quench/Venturi Scrubber/Absorber}

The Quench/Venturi Scrubber/Absorber is designed to rapidly quench the flue gas from the thermal oxidizer to a saturation temperature of $82^{\circ} \mathrm{C}\left(180^{\circ} \mathrm{F}\right)$ to minimize the formation of dioxin and furan compounds and to remove entrained particulate and acid gas from the offgas stream. The quench section is refractory-lined in its upper (gas inlet) section and fabricated of a corrosion resistant alloy in its lower section. It is oriented vertically with cocurrent downward flow of flue gas and recycled scrubber liquid. A Venturi Scrubber just downstream of the quench section removes $>1 \mu \mathrm{m}$ particulate from the gas phase. A countercurrent Packed Tower Absorber vessel, oriented vertically, removes acid gases such as $\mathrm{HCl}$ and $\mathrm{SO}_{2}$ from the gas stream by intimate contact of the gas stream with recirculating scrubber liquid. The $\mathrm{pH}$ and dissolved solids concentration of the scrubber liquid are controlled by addition of caustic and by control of blowdown/makeup water flow rates respectively. Blowdown from the scrubber liquid loop is transferred to the front end of the wastewater portable treatment unit

\subsubsection{Demister}

A mesh type Demister is located at the exit of the packed tower absorber above downstream of the tower's packing section to remove entrained fine mist droplets from the gas stream. The Demister is irrigated semi-continuously with fresh water.

\subsubsection{Reheater}

An electrical resistance Reheater is installed in the duct immediately downstream of the Demister to heat the saturated offgas stream to $28^{\circ} \mathrm{C}\left(50^{\circ} \mathrm{F}\right)$ above the dew point. The purpose of the Reheater is to evaporate any entrained liquid droplets that pass through the Demister and to avoid condensation of moisture in the HEPA filter housings downstream. 


\subsubsection{HEPA Filtration/Draft Control}

The reheated offgas is passed through High Efficiency Particulate Air (HEPA) filters to remove entrained submicron particulate from the offgas stream. Spent filters are sent to Delumping/Crushing followed by Thermal Desorption. A minimum of one stage of HEPA filters is required. For processing of waste streams containing high concentrations of alpha-emitting isotopes, primarily plutonium, two stages of HEPA filters in series may be required. An induced draft fan and damper valve downstream of the HEPA filters maintain draft control through the Thermal Oxidation/air pollution control system.

\subsubsection{De-lumping/Crushing}

The De-lumper/Crusher receives organic sludges, inorganic sludges, and spent filter media from the organic liquid thermal oxidation process. The purpose of the De-lumper/Crusher is to reduce the size of large chunks of material to a consistent size for feeding to the Thermal Desorber. Thermal Desorption rates of organic compounds as well as moisture are enhanced when the surface area of the solids is increased by size reduction. The size reduction device may be a jaw crusher and/or a shredder.

\subsubsection{Thermal Desorption}

The purpose of Thermal Desorption is to vaporize volatile organic compounds (VOCs) and water from the matrix solids discharged from the de-lumper/crusher. The Thermal Desorber ${ }^{6}$ is a batch-operated stainless steel tumbling drum that is indirectly heated by recirculation of electrically heated hot oil. It operates at 107 to $315^{\circ} \mathrm{C}\left(225\right.$ to $\left.600{ }^{\circ} \mathrm{F}\right)$ and a vacuum of as low as $23 \mathrm{~mm} \mathrm{Hg}$ absolute pressure. A purge gas of either nitrogen or air is used to sweep the volatiles from the tumbling bed of solids. Air is assumed to be the purge gas for this work.

Three (3) Thermal Desorber units operating in parallel would be required. Given a single module's dimensions ${ }^{5}(8 \mathrm{ft}$ long $x 10 \mathrm{ft}$ wide by 11.5 high), the combined footprint of three desorbers would nearly fill the volume of a single semi-trailer. A special trailer would be required to accommodate the $11.5 \mathrm{ft}$. height. The batch size per single desorber is $0.42 \mathrm{~m}^{3}(14.8$ $\mathrm{ft}^{3}$ ) and requires approximately 7 hours duration per batch to complete the desorption cycle. The effective solids throughput rate for the three desorbers is $0.18 \mathrm{~m}^{3} / \mathrm{hr}\left(6.34 \mathrm{ft}^{3} / \mathrm{hr}\right)$ or approximately $212 \mathrm{~kg} / \mathrm{hr}(468 \mathrm{lb} / \mathrm{hr})$. The Thermal Desorber would have to operate approximately 2,703 hours/yr (an on-stream factor of about $31 \%$ ). It is likely and more practical from an operations and space constraint standpoint that a single desorber vessel of the required capacity would be developed and used for actual service. As an alternative to the Thermal Desorber described, commercially available indirectly heated kiln-type Thermal Desorption technologies should be considered that do not require vacuum operation.

\subsubsection{Condenser}

The purpose of the condenser is to cool the offgas exiting the Thermal Desorber and to condense water and volatile organic compounds. Chilled water at $35^{\circ} \mathrm{F}$ is circulated through the condenser for cooling. Offgas leaving the condenser, containing only trace volatile organic compounds, passes through a vacuum pump and is routed to the thermal oxidizer. Residual 
VOCs are oxidized in the thermal oxidizer. The oxygen content of the condenser ofiyas supplements fresh combustion air for oxidation in the thermal oxidizer. Liquid from the condenser, consisting of water with some organics, is sent to the front end of the Wastewater portable treatment unit.

\subsubsection{Polymer Microencapsulation}

The dry solids discharged from the Thermal Desorber are transferred to the Polymer Microencapsulation process. The purpose of the this step is to stabilize RCRA metals and nonvolatile radionuclides in a matrix that is also chemically compatible with salts such as sodium chloride and sodium sulfate that are present in sludges fed to the Thermal Desorber. In this process, the discharged dry solids are blended with a molten polymer (polyethylene) where the two streams are intimately mixed then cooled, resulting in a stable monolithic waste form packaged in $0.208 \mathrm{~m}^{3}$ ( $55 \mathrm{gal}$ ) drums for storage or disposal. The bulk density of the input solids stream is assumed to be $1,243 \mathrm{~kg} / \mathrm{m}^{3}$. The density of molten polyethylene is assumed to be 950 . $\mathrm{kg} / \mathrm{m}^{3}$. The void volume fraction within the feed solids is assumed to be $30 \%$. The volume increase factor associated with Polymer Microencapsulation is assumed to be 1.5:1.

\subsection{Material Balance}

Table 3 provides a material balance (input and output streams) for the Organics Portable Treatment Unit. Since an energy balance was not performed, Table 3 represents a preliminary material balance with an overall balance closure of $100 \pm 0.20 \%$, a satisfactory margin of error for this analysis. The values in Table 3 are based on the feed stream assumptions (Table 1) and other assumptions discussed previously and are reported as annual throughput rates $(\mathrm{kg} / \mathrm{yr})$. 
Table 3

Material Balance for the Organics Portable Treatment Unit

\begin{tabular}{|c|c|c|c|}
\hline Process Inputs, kg/yr & \begin{tabular}{l|} 
Primary \\
Streams
\end{tabular} & $\begin{array}{l}\text { From Other } \\
\text { PTUs }\end{array}$ & $\begin{array}{c}\text { Total to } \\
\text { Organics PTU }\end{array}$ \\
\hline $\begin{array}{l}\text { Aqueous/Organic liquids to Thermal } \\
\text { Oxidation }\end{array}$ & 77,280 & 0 & 77,280 \\
\hline $\begin{array}{l}\text { Pure Organic Liquids to Thermal } \\
\text { Oxidation }\end{array}$ & 43,520 & 3,928 & 47,448 \\
\hline $\begin{array}{l}\text { Inorganic Homogeneous Solids (non- } \\
\text { organic contaminated) }\end{array}$ & 350,000 & 144,480 & 494,480 \\
\hline $\begin{array}{l}\text { Inorganic Homogeneous Solids (organic } \\
\text { contaminated) }\end{array}$ & 45,500 & 0 & 45,500 \\
\hline Organic Homogeneous Solids & 16,000 & 18,332 & 34,332 \\
\hline Air to Thermal Oxidation & - & - & $1,707,986$ \\
\hline $\begin{array}{l}\text { Caustic to Thermal Oxidation Offgas } \\
\text { Treatment }\end{array}$ & - & - & 15,569 \\
\hline $\begin{array}{l}\text { Water to Thermal Oxidation Offgas } \\
\text { Treatment }\end{array}$ & - & - & $1,464,324$ \\
\hline Polymer to Microencapsulation & - & - & 323,762 \\
\hline \multicolumn{3}{|l|}{ Total Inputs } & $4,210,682$ \\
\hline \multicolumn{3}{|l|}{ Process Outputs, $\mathrm{kg} / \mathrm{yr}$} & $\begin{array}{l}\text { Total Leaving } \\
\text { Organics PTU }\end{array}$ \\
\hline \multicolumn{3}{|l|}{$\begin{array}{l}\text { Aqueous/Organic Condensate to } \\
\text { Wastewater PTU }\end{array}$} & 197,713 \\
\hline \multicolumn{3}{|l|}{$\begin{array}{l}\text { Scrubber Blowdown Liquid to Wastewater } \\
\text { PTU }\end{array}$} & 450,807 \\
\hline \multicolumn{3}{|l|}{ Stabilized Waste Form } & 694,327 \\
\hline \multicolumn{3}{|l|}{ Offgas from Thermal Oxidation } & $2,859,292$ \\
\hline \multicolumn{3}{|l|}{ Total Outputs } & $4,202,139$ \\
\hline
\end{tabular}

\subsection{Unit Operations Capacities}

The throughput capacity of each processing train (Thermal Oxidation and Thermal Desorption) was fixed by determining the limiting unit operation within the train based on its physical size (all three dimensions) and the ability to fit this unit operation into a semi-trailer. The Thermal Desorber is the throughput-limiting device in its train and the Thermal Oxidizer limits the throughput rate in its train. The other unit operations within each train are sized for compatibility with the capacity of the limiting unit operations. The result is that the processing trains do not necessarily have the same on-stream factor (hours per year of operation) to process the annual throughput rates shown in Tables 1 and 2 . Such variations in throughput capacity may require surge capacity to accommodate external transfer streams to and from other portable treatment units. 
Semi-trailers are assumed to have inside dimensions of $12.04 \mathrm{~m}$ ( $39.5 \mathrm{ft}$.) long, $2.36 \mathrm{~m}$ $(7.75 \mathrm{ft}$.) wide and $2.44 \mathrm{~m}(8 \mathrm{ft}$.) high. These general size guidelines were used to arrive at the limiting unit operations capacities for each processing train. Development of detailed equipment layouts were beyond the scope of this work. Therefore, no attempt was made to provide preliminary positioning of equipment on the trailers.

Table 4 gives the approximate capacities and process conditions of the unit operations within the Organics Portable Treatment Unit.

Table 4

Unit Operations Capacities in the Organics Portable Treatment Unit

\begin{tabular}{|c|c|}
\hline Unit Operation & Capacity and Process Conditions \\
\hline \multicolumn{2}{|l|}{ Thermal Oxidation Train } \\
\hline Organic Liquid Filter & $\begin{array}{l}\text { Two parallel redundant filters, } 2.1 \mathrm{gpm} \text { pure organic } \\
\text { liquid at } 20^{\circ} \mathrm{C}\end{array}$ \\
\hline Thermal Oxidizer & $\begin{array}{l}1.9 \mathrm{MMBtu} / \mathrm{hr} \text { heat release; } 56.7 \mathrm{~kg} / \mathrm{hr} \text { pure organic } \\
\text { liquid; } 2.5 \mathrm{sec} \text { gas residence time; exit gas: } 2740 \mathrm{ACFM} \\
\text { at } 1093^{\circ} \mathrm{C} \text { and } 9 \% \mathrm{O}_{2}\end{array}$ \\
\hline Quencher & $2740 \mathrm{ACFM}$ inlet gas at $1093^{\circ} \mathrm{C}$ \\
\hline Venturi Scrubber & $\begin{array}{l}1385 \text { ACFM inlet gas at } 82^{\circ} \mathrm{C} ; 60 \text { in. W.C. differential } \\
\text { pressure }\end{array}$ \\
\hline Packed Tower Absorber & 1385 ACFM inlet gas at $82{ }^{\circ} \mathrm{C}$ \\
\hline Demister & $1385 \mathrm{ACFM}$ inlet gas at $82^{\circ} \mathrm{C}$ \\
\hline Reheater & $\begin{array}{l}1385 \text { ACFM inlet gas at } 82^{\circ} \mathrm{C}, 1492 \text { ACFM exit gas at } \\
110^{\circ} \mathrm{C} \text {; }\end{array}$ \\
\hline HEPA Filters & $\begin{array}{l}1492 \mathrm{ACFM} \text { inlet gas at } 110^{\circ} \mathrm{C} ; \sim 20 \mathrm{~kW} \text { input electric } \\
\text { power to heater ( } 2 \text { standard HEPA filters in parallel } \\
\text { required) }\end{array}$ \\
\hline \multicolumn{2}{|l|}{ Thermal Desorption Train } \\
\hline De-lumper/Crusher & $212 \mathrm{~kg} / \mathrm{hr}\left(0.18 \mathrm{~m}^{3} / \mathrm{hr}\right)$ solids \\
\hline Thermal Desorber & $\begin{array}{l}\text { Three (3) desorbers operating in parallel; batch operation; } \\
0.42 \cdot \mathrm{m}^{3}\left(14.8 \mathrm{ft}^{3}\right) \text { solids per } 7 \text { hour period per desorber } \\
\text { vessel; effective throughput is } 212 \mathrm{~kg} / \mathrm{hr} \text { solids; } 445 \mathrm{~kW} \\
\text { total input power required (heating and refrigeration) }\end{array}$ \\
\hline Condenser & $\begin{array}{l}460 \text { SCFM purge air; } 48 \text { gpm chilled water at } 35^{\circ} \mathrm{F} ; 75.8 \\
\mathrm{~kg} / \mathrm{hr} \text { condensate (organics and water) }\end{array}$ \\
\hline Polymer Microencapsulation & $\begin{array}{l}134.3 \mathrm{~kg} / \mathrm{hr} \text { dry solids feed, } 117.4 \mathrm{~kg} / \mathrm{hr} \text { polymer based } \\
\text { on same on-stream factor }(31 \%) \text { as Thermal Desorber }\end{array}$ \\
\hline
\end{tabular}




\section{SYSTEM DESIGN CRITERIA}

\subsection{Functional Requirements}

The functions of the Organics Portable Treatment Unit are to:

- process the following mixed low level radioactive waste streams: pure organic liquids, aqueous organic liquids, homogeneous solids (organic and inorganic) as well as external transfer streams from other portable treatment units,

- clean the offgas generated from these processing operations,

- produce an acceptable stable final waste form for storage or disposal,

- meet all current and anticipated applicable requirements of DOE Orders, State, and Federal mixed waste regulations.

\subsection{Operational Requirements}

The Organics Portable Treatment Unit consists of two primary processing trains: 1) Thermal Oxidation and 2) Thermal Desorption followed by Polymer Microencapsulation. This Treatment Unit is to process the waste streams listed in Table 1 of this document at their respective annual throughput rates. The on-stream factors for the Thermal Oxidation and Thermal Desorption/Polymer Microencapsulation processing trains are 25 and $31 \%$, respectively.

\subsection{Interface Requirements}

\subsubsection{Receipt of Primary Waste Streams}

Receipt of primary waste streams will depend upon the waste stream and the site at which the portable treatment unit is operating. However, the processes must be designed to accommodate liquids and sludges in package sizes ranging from $0.019 \mathrm{~m}^{3}$ ( 5 gallon) cans to 55 gallon drums. Pumpable organic and aqueous/organic liquids, if stored in tanks on site, can be transferred by pipeline to the hold/feed tank within the portable treatment system trailer.

Homogeneous solids (both organic and inorganic sludges) present challenging materials handling problems due to the great variability in physical characteristics of these materials. These materials would arrive at the portable system in $0.208 \mathrm{~m}^{3}$ ( $55 \mathrm{gal}$ ) drums and possibly dumpster-type tankage. Special handling systems will be required to open and transfer the contents of these containers to the process. These operations must be carried out within proper radioactive containment inside the portable unit trailer. A de-watering step may be required for wet solids containing free water prior to transfer to the De-lumper/Crusher. The drained liquid would then be transferred batchwise or, if in sufficient quantity, by pipeline to the front end of the Wastewater Treatment Portable Unit.

\subsubsection{External Transfer Shipments}

External transfer shipments of waste streams from other portable treatment units (See Table 2) will be received in a fashion similar to that just described for primary waste streams. These streams will have similar physical handling characteristics as the primary waste streams. 
The streams that leave the Organics Portable Treatment Unit include: 1) the combined aqueous/organic condensate from Thermal Desorption and liquid blowdown from Thermal Oxidation, and 2) the stabilized waste form from Polymer Microencapsulation. Some surge capacity should be provided in the form of a tank to collect the liquid in item (1) above for pipeline transfer to the Wastewater Portable Treatment Unit. A staging area for the stabilized final waste form packaged in $0.208 \mathrm{~m}^{3}$ ( 55 gal) drums should be provided. These drums would be removed on pallets by forklift truck to the facility's shipping area.

\subsubsection{Utilities}

Electrical power from the facilities grid shall be provided in sufficient quantity to operate the Organics Portable Treatment Unit's auxiliary equipment, controls, lighting, alarm systems, etc., under normal operating conditions. Backup electrical power and an uninterruptible power supply (UPS) are required; the unit shall be designed to power down in a fail-safe condition in the event of loss of line power.

Other utilities to be provided by the site include auxiliary fuel (if available) and plant water. These utilities shall be provided in sufficient quantity to support the Unit's operations during normal and emergency conditions. If auxiliary fuel (natural gas or propane) is not available on-site, it must be transported to the site by trailer for hook-up to the Portable Treatment Unit's Thermal Oxidizer. Other utilities, including caustic reagent and polymer reagent, shall be delivered by separate vehicles to the Portable Treatment Unit processing location. 


\section{FUNCTIONAL AND OPERATIONAL REQUIREMENTS FOR LABPACKS PORTABLE TREATMENT}

\section{INTRODUCTION}

This document presents Functional and Operational Requirements (F\&ORs) for the Labpacks Portable Treatment Unit. This unit is part of the integrated Portable Treatment Systems Study (PTSS) sponsored by the US Department of Energy's Office of Technology Development. The objective of the Labpacks Portable Treatment Unit is to accept and effectively process low level radioactive mixed organic, aqueous, solid, and scintillation vial wastes that are packaged in Labpacks. This objective is met by safely separating and processing these waste streams on semi-trailers that can be moved from site to site for treatment. The Labpacks Portable Treatment Unit sends all of its processed waste streams to other Portable Treatment units for conversion to final waste forms. The Unit does not routinely accept external transfer streams from other Portable Units. However, it could receive wastes from other Portable Units that meet its waste acceptance criteria on a case by case basis. The Labpacks Portable Treatment Unit comprises process equipment to perform the above functions mounted on multiple semi-trailers.

The operation consists of a sequence of processing steps. The wastes are received by the Labpacks Portable Treatment Unit in overpack containers called Labpacks. Within each Labpack, the wastes are packaged in containers such as bottles, cans, jars, crucibles, etc. Packing material such as vermiculite is used to provide cushioning and absorbency for the waste containers within the Labpack. A manual Opening/Sorting operation opens each Labpack and removes the containers. The containers are separated into Organic and Inorganic fractions. The packing material (vermiculite) is sent to inorganic sludge processing within the Organics Portable Treatment Unit. The Organic fraction is further separated into liquid and solid fractions. All containers of free flowing organic liquid including scintillation fluids are drained into a holding tank and filtered. The filtered solids along with Organic solids that cannot be drained from containers are sent to the Homogeneous Organic Solids line in the Organics Portable Treatment Unit. The Inorganic fraction consists of aqueous liquids and solid chemical reagents or other solids. Inorganic wastes, both liquid and solid, may require some form of chemical deactivation before proceeding to any further processing. The deactivation method and reagents required must be determined for specific materials. The deactivation typically involves the mixing and subsequent reaction of the material with an appropriate reagent in an agitated tank. The reaction product liquid is then filtered to remove suspended solids. The solids are sent to the Homogeneous Inorganic Solids line in the Organics Portable Treatment Unit and the filtered liquid is sent to the Wastewater Portable Treatment Unit. Some special items within Labpacks that do not meet the waste acceptance criteria must be rejected, repackaged, and sent to unspecified special processing elsewhere.

A fundamental assumption in this work is that the portable treatment units are assembled and fully operable on semi-trailers. Only utility hookups on-site are required for operability. 
The treatment units are not modular and are not intended to be off-loaded from the trailers for process service within on-site facilities. Also, specific processing trains are sized to accommodate equipment having the largest reasonable throughput rate possible given the size constraint of the semi-trailers.

\section{SYSTEM DESCRIPTION}

\subsection{System Specific Assumptions}

\subsubsection{Technology}

The flow diagram for the Labpacks Portable Treatment Unit is provided in block form in Figure 3. Descriptions of the individual unit operations and the technologies selected for the Labpacks Portable Treatment Unit are provided in Section 5.3 -Flow Diagram Description. The flowsheet and selection of the specific technologies within it are dependent upon the feed stream assumptions discussed in the following section.

\subsubsection{Process Feed}

The primary waste feed stream compositions and associated assumptions for the Labpacks Portable Treatment unit are shown in Table 5. The required treatment capacities $\left(\mathrm{m}^{3} / \mathrm{yr}\right)$ for each waste matrix set were obtained from Musgrave ${ }^{1}$. The waste stream summary report ${ }^{2}$ by Heubner et al was used as a guide for establishing the ultimate compositions (organics, inerts, water) for the waste streams. Densities $\left(\mathrm{kg} / \mathrm{m}^{3}\right)$ of the feed materials were taken from Perry ${ }^{3}$. Drum weights are excluded from the density assumptions and calculated mass throughput rates reported in Table 5. The Labpacks Portable Treatment Unit receives no routine transfer streams from other portable units. 
Table 5

Waste Feed Streams for the Labpacks Portable Treatment Unit

\begin{tabular}{|c|c|c|c|c|c|}
\hline Waste Stream & $\begin{array}{l}\text { Organic } \\
\text { Labpacks } \\
\text { (a) }\end{array}$ & $\begin{array}{l}\text { Aqueous } \\
\text { Labpacks } \\
\text { (b) }\end{array}$ & $\begin{array}{c}\text { Solid } \\
\text { Labpacks } \\
\text { (c) } \\
\end{array}$ & $\begin{array}{l}\text { Scintillation } \\
\text { Cocktails } \\
\text { (d) } \\
\end{array}$ & $\begin{array}{l}\text { Undefined } \\
\text { Labpacks } \\
\text { (e), (f) }\end{array}$ \\
\hline Matrix Parameter Code (MPC) & 6100 & 6200 & 6300 & 6400 & $\begin{array}{l}6000 \\
6900 \\
\end{array}$ \\
\hline Input Flow, $\mathrm{m}^{3} / \mathrm{yr}$ & 5 & 10 & 5 & 15 & 45 \\
\hline Density, $\mathrm{kg} / \mathrm{m}^{3}$ & $\begin{array}{l}900 \text { Liquid } \\
1100 \text { Solid }\end{array}$ & 1050 & 1200 & $\begin{array}{l}800 \text { Liquid } \\
1000 \text { Solid }\end{array}$ & N/A \\
\hline Annual Throughput, kg/yr & 3,582 & 7,494 & 4,278 & 12,142 & 35,350 \\
\hline \multicolumn{6}{|l|}{ Composition } \\
\hline \multicolumn{6}{|l|}{ Organics (wt\% of total stream) } \\
\hline Total Organics & 30.0 & 1.0 & 0.0 & 10.0 & \\
\hline \multicolumn{6}{|l|}{ Inorganics (wt\% of total stream) } \\
\hline Water & 0.0 & 30.1 & 0.0 & 0.0 & \\
\hline Solids & 65.1 & 64.4 & 95.9 & 87.3 & \\
\hline Drum & 4.9 & 4.5 & 4.1 & 2.7 & \\
\hline Total Inorganics & 70.0 & 99.0 & 100.0 & 90.0 & \\
\hline Total for Stream & 100.0 & 100.0 & 100.0 & 100.0 & \\
\hline & & & & & \\
\hline
\end{tabular}

(a) Organic liquids only; excludes scintillation fluids in vials

(b) Aqueous liquids only; excludes scintillation fluids in vials

(c) Waste packages containing only solid chemicals or other solids within Labpacks

(d) Scintillation fluids in containers (i.e. plastic and glass vials) in Labpacks

(e) Consistent with MPC $6000^{\circ}$ category, but insufficient information to determine; does not meet MPC $6100-6400$ categories.

(f) For this study, undefined Labpacks are apportioned among each of the other MPC categories by proportionate volume

\subsection{Process Boundaries}

The input boundary for the Labpacks Portable Treatment Unit is where the primary Labpacks waste streams enter the treatment train within the Unit. Utilities to be supplied by the facility at the operations location include electricity and water. Compressed air for instruments is provided by a compressor on the trailer. Chemical deactivation reagents are delivered by separate vehicles to the Labpacks Portable Treatment Unit processing location.

The output boundary of the Labpacks Portable Treatment Unit is where the output streams leave the Unit for transfer to other Portable Treatment Units.

\subsection{Flow Diagram Description}

The flow diagram for the Labpacks Portable Treatment Unit is provided in block form as Figure 3. 


\subsubsection{Labpack Receiving}

The Labpacks Portable Treatment Unit receives wastes in overpack containers called Labpacks, which are typically $0.208 \mathrm{~m}^{3}$ (55 gal) drums or smaller containers. The Unit must provide sufficient staging area for Labpacks that will be opened within a few hour period.

\subsubsection{Opening/Sorting}

Within each Labpack, the wastes are packaged in containers such as bottles, cans, jars, crucibles, etc. Packing material such as vermiculite is used to provide cushioning and absorbency for the waste containers within the Labpack. The Opening/Sorting operation involves the manual opening of each Labpack to remove all containers and packaging material. The containers are separated into Organic and Inorganic fractions through identification of labeling, process knowledge, or through sampling and chemical analysis. The packing material, vermiculite or other absorbent material, is sent to Homogeneous Inorganic solids processing within the Organics Portable Treatment Unit. Because the packing material is typically less than $60 \mathrm{~mm}$ in average particle size, it cannot be sent to Debris processing. Some special items within Labpacks that do not meet the waste acceptance criteria must be rejected, repackaged, and sent to unspecified special processing elsewhere. The Labpack opening operation is conducted within a ventilated enclosure for vapor containment. Ventilation air is directed to the unit ventilation system that provides activated carbon and HEPA filtration.

\subsubsection{Segregation of Solid and Liquid Organics}

Containers of Organic wastes removed from the Labpacks are further segregated into liquid and solid fractions. All containers of free flowing organic liquid including scintillation fluids are opened and drained through a screen into an agitated holding tank. Containers of solid organic materials that cannot be readily removed from the container are temporarily repackaged into overpack $0.208 \mathrm{~m}^{3}$ ( $55 \mathrm{gal}$ ) drums for transfer to the Homogeneous Organic Solids line of the Organics Portable Treatment Unit. The containers with residual organic liquid contamination are temporarily repackaged into overpack $0.208 \mathrm{~m}^{3}$ ( $55 \mathrm{gal}$ ) drums for transfer to the Debris Portable Treatment Unit.

\subsubsection{Organic Liquid Filtration and Transfer}

The free flowing organic liquids that have been drained from their containers into the organics holding tank are filtered to removed suspended solids. The filtering is performed in one of two parallel cartridge type filters on the discharge line of the organics holding tank. Filtered Organic liquid waste is pumped into "Tuff Tank" type containers for transport to Thermal Oxidation within the Organics Portable Treatment Unit. Spent filter cartridges along with separated solids are manually removed from the filter housing and sent to De-lumping/Crushing in the Organics Portable Treatment Unit. The filtration operation is within the same enclosure as that for Opening/Sorting.

\subsubsection{Inorganic Chemical Deactivation}

The containers of Inorganic wastes that were segregated in the Opening/Sorting step are further segregated into those materials requiring some form of chemical deactivation and those 
that can bypass chemical deactivation. This inorganic fraction consists of aqueous liquids and solid chemical reagents or other solids. The chemical deactivation is considered necessary before the materials can be transferred to further processing. It is anticipated that the solids will more often require chemical deactivation than aqueous liquids. The identification of waste materials to be deactivated may require one or more of the following methods: positive identification of labeling, knowledge of the process from which the material was taken, and sampling/analysis. Upon identification, the most appropriate deactivation method and reagents required must be determined for each material.

Specific procedures that establish solvent selection, stoichiometry, safe addition rates of reagents, etc. must be developed for each material. The deactivation typically involves the mixing and subsequent reaction of the waste material with an appropriate reagent in an agitated tank. Cooling of the reaction tank may be required to remove heat generated in exothermic reactions. When reactions are complete, the aqueous liquid or slurry with suspended solids is ready for filtration.

\subsubsection{Inorganic Liquid Filtration}

The reaction product liquid from Chemical Deactivation is filtered to remove suspended solids. The filtering is performed in one of two parallel cartridge type filters on the discharge line of the Chemical Deactivation Tank. Filtered Aqueous liquid waste is pumped into "Tuff Tank" type containers for transport to the Wastewater Portable Treatment Unit. Spent filter cartridges along with separated solids are manually removed from the filter housing and sent to De-lumping/Crushing in the Organics Portable Treatment Unit.

\subsection{Material Balance}

Table 6 provides a material balance (input and output streams) for the Labpacks Portable Treatment Unit. The values in Table 6 are based on the feed stream assumptions (Table 5) and other assumptions discussed previously and are reported as annual throughput rates ( $\mathrm{kg} / \mathrm{yr})$.

\subsection{Unit Operations Capacities}

The throughput capacity of the Labpacks Portable Treatment Unit was fixed by determining the limiting unit operation within the train based on its physical size (all three dimensions) and the ability to fit this unit operation into a semi-trailer. The manual Opening/Sorting operation is the throughput-limiting operation in the Labpacks Portable Treatment train. It is assumed that two (2) men can open and sort two (2) 55 gal Labpacks per hour. Given the average gross weight of one 55 gal Labpack as $167.9 \mathrm{~kg}$, the effective Labpacks processing rate is $335.9 \mathrm{~kg} / \mathrm{hr}$ including the weight of the drums. The other unit operations within the train are sized for compatibility with the capacity of the Opening/Sorting operation. The Labpacks Opening/Sorting operation would need to operate for only 192 hours/year. The on-stream factor for the LabpacksUnit, based on 8,760 hours/year operation, is approximately 2 $\%$.

Semi-trailers are assumed to have inside dimensions of $12.04 \mathrm{~m}$ ( $39.5 \mathrm{ft}$.) long, $2.36 \mathrm{~m}$ $(7.75 \mathrm{ft}$.) wide and $2.44 \mathrm{~m}(8 \mathrm{ft}$.) high. These general size guidelines were used to arrive at the 
limiting unit operations capacities for each processing train. Development of detailec equipment layouts were beyond the scope of this work. Therefore, no attempt was made to provide preliminary positioning of equipment on the trailers.

Table 7 gives the approximate average capacities of the unit operations within the Labpacks Portable Treatment Unit.

Table 6

Material Balance for the Labpacks Portable Treatment Unit

\begin{tabular}{|c|c|c|c|}
\hline Process Inputs, kg/yr & Primary Streams & $\begin{array}{l}\text { From Other } \\
\text { PTUs }\end{array}$ & $\begin{array}{c}\text { Total to } \\
\text { Labpacks PTU }\end{array}$ \\
\hline $\begin{array}{l}\text { Organic Labpacks to } \\
\text { Manual Sort }\end{array}$ & $\overline{3,582}$ & 0 & 3,582 \\
\hline $\begin{array}{l}\text { Aqueous Labpacks to } \\
\text { Manual Sort }\end{array}$ & $\overline{7,494}$ & 0 & 7,494 \\
\hline $\begin{array}{l}\text { Solid Labpacks to Manual } \\
\text { Sort }\end{array}$ & 4,278 & 0 & 4,278 \\
\hline $\begin{array}{l}\text { Scintillation Cocktails to } \\
\text { Manual Sort }\end{array}$ & 12,142 & $\overline{0}$ & $\overline{12,142}$ \\
\hline $\begin{array}{l}\text { Undefined Labpacks to } \\
\text { Manual Sort }\end{array}$ & $\overline{35,350}$ & $\overline{0}$ & 35,350 \\
\hline Total Inputs & & & 62,838 \\
\hline \multicolumn{3}{|l|}{ Process Outputs, $\mathrm{kg} / \mathrm{yr}$} & $\begin{array}{l}\text { Total Leaving } \\
\text { Labpacks PTU }\end{array}$ \\
\hline \multicolumn{3}{|c|}{ Organic Liquids to Organics Treatment } & 3,928 \\
\hline \multicolumn{3}{|c|}{ Organic Sludges to Organics Treatment } & 18,332 \\
\hline \multicolumn{3}{|c|}{ Inorganic Sludges to Delumping/Crushing } & 5,499 \\
\hline \multicolumn{3}{|c|}{ Aqueous Liquids to Wastewater Treatment } & 8,874 \\
\hline \multicolumn{3}{|c|}{ Debris to Debris. Treatment } & 26,207 \\
\hline \multicolumn{3}{|l|}{ Total Outputs } & 62,840 \\
\hline
\end{tabular}

Table 7

Unit Operations Capacities in the Labpacks Portable Treatment Unit

\begin{tabular}{|l|l|}
\hline Unit Operation & Capacity \\
\hline \hline Opening/Sorting & $\begin{array}{l}2 \times 0.208 \mathrm{~m}^{3}(55 \text { gal) drums per hour; 335.9 } \\
\mathrm{kg} / \mathrm{hr} \text { Labpacks (gross weight including drums) }\end{array}$ \\
\hline $\begin{array}{l}\text { Segregation of Solid and Liquid } \\
\text { Organics }\end{array}$ & $118.9 \mathrm{~kg} / \mathrm{hr}$ organics \\
\hline Organic Liquid Filtration and Transfer & $14.3 \mathrm{~kg} / \mathrm{hr}$ organic liquids \\
\hline Inorganic Chemical Deactivation & $77.6 \mathrm{~kg} / \mathrm{hr}$ inorganic liquids and solids \\
\hline Inorganic Liquid Filtration & $47.9 \mathrm{~kg} / \mathrm{hr}$ inorganic aqueous liquids \\
\hline
\end{tabular}




\section{SYSTEM DESIGN CRITERIA}

\subsection{Functional Requirements}

The functions of the Labpacks Portable Treatment Unit are to:

- accept and effectively process low level radioactive mixed organic, aqueous, solid, and scintillation vial wastes that are packaged in Labpacks,

- prepare acceptable intermediate waste streams for transfer to other Portable Treatment units for final conversion to stable waste forms,

- perform these operations on semi-trailers that can be moved from site to site for treatment,

- meet all current and anticipated applicable requirements of DOE Orders, State, and Federal mixed waste regulations.

\subsection{Operational Requirements}

The Labpacks Portable Treatment Unit consists of a single processing train. This Treatment Unit is to process the waste streams listed in Table 5 of this document at their respective annual throughput rates. The on-stream factor for the Labpacks Portable Treatment Unit, based on 8,760 hours/yr operation, is approximately $2 \%$.

\subsection{Interface Requirements}

\subsubsection{Receipt of Waste Streams}

Receipt of Labpack waste streams will depend upon the waste stream and the site at which the portable treatment unit is operating. However, the Labpacks Portable Treatment Unit must be designed to accommodate wastes packaged in Labpacks that are $0.208 \mathrm{~m}^{3}$ (55 gal) drums and smaller.

Opening of the Labpacks, sorting, and transfer of the contents to the appropriate further processing steps will be performed manually. These operations must be carried out within proper radioactive containment inside the Portable Unit trailer. Proper ventilation of the area with activated carbon and HEPA filtration of the exhaust will be required.

\subsubsection{External Transfer Shipments}

The Labpacks Portable Treatment Unit does not routinely accept external transfer streams from other Portable Treatment Units. However, it could receive wastes from other Portable Units that meet its waste acceptance criteria on a case by case basis.

The streams that leave the Labpacks Portable Treatment Unit include: 1) filtered Organic liquids for transfer to Organics Portable Treatment Unit, 2) Organic solids and sludges for transfer to Delumping/Crushing within the Organics Portable Treatment Unit, 3) solid Inorganic sludges and filter residues for transfer to the Delumping/Crushing within the Organics Portable Treatment Unit, 4) Aqueous liquids for transfer to the Wastewater Portable Treatment Unit, and 
5)-packing material, containers, and drums (heterogeneous Debris) for transfer to the Debris Portable Treatment Unit.

Some surge capacity should be provided in the form of one or more tanks to collect the liquid in items (1) and (4) above for either pipeline transfer or batch transfer in "Tuff Tank" type containers to the respective Portable Treatment Units. A staging area should be provided for temporary storage of wastes that, when opened and examined, do not meet the acceptance criteria of the Labpacks Portable Treatment Unit. These repackaged and drummed Special wastes are removed from the Portable Unit on pallets by forklift truck to the facility's shipping area for unspecified special processing elsewhere.

\subsubsection{Utilities}

Electrical power from the facility's grid shall be provided in sufficient quantity to operate the Labpacks Portable Treatment Unit's auxiliary equipment, controls, lighting, alarm systems, etc., under normal operating conditions. Backup electrical power and an uninterruptible power supply (UPS) are required; the unit shall be designed to power down in a fail-safe condition in the event of loss of line power.

Plant water.shall also be provided by the site in sufficient quantity to support the Unit's operations during normal and emergency conditions. Other utilities, including reagents for chemical deactivation, shall be delivered by separate vehicles to the Labpacks Portable Treatment Unit processing location. 


\section{FUNCTIONAL AND OPERATIONAL REQUIREMENTS FOR DEBRIS PORTABLE TREATMENT}

\section{INTRODUCTION}

This document presents Functional and Operational Requirements (F\&ORs) for the Debris Portable Treatment Unit. This unit is part of the integrated Portable Treatment Systems Study (PTSS) sponsored by the US Department of Energy Office of Technology Development. The objectives of the Debris Portable Treatment Unit are: 1) to accept and effectively treat Debris that are mixed low level radioactive wastes, and 2) to meet these objectives by processing the waste streams on portable semi-trailers that can be moved from site to site. The function of the unit is to microencapsulate the Debris in a portland cement-based (grout) media to stabilize the RCRA hazardous constituents and radionuclides. The unit also accepts an external transfer stream from the Labpacks Portable Treatment Unit. The Debris Portable Treatment Unit consists of process equipment to perform the above functions mounted on one semi-trailer.

A fundamental assumption in this work is that the portable treatment units are assembled and fully operable on semi-trailers. Only utility hookups on-site are required for operability. The treatment units are not modular and are not intended to be off-loaded from the trailers for process service within on-site facilities. Also, specific processing trains are sized to accommodate equipment having the largest reasonable throughput rate possible given the size constraint of the semi-trailers.

\section{SYSTEM DESCRIPTION}

\section{1. . System Specific Assumptions}

\subsubsection{Technology}

The flow diagram for the Debris Portable Treatment Unit is provided in block form in Figure 3. Descriptions of the individual unit operations and the technologies selected for the Debris Portable Treatment Unit are provided in Section 8.3 - Flow Diagram Description. The flowsheet and selection of the specific technologies within it are dependent upon the feed stream assumptions discussed in the following section. Cement Microencapsulation was chosen as the stabilization technology. By encapsulating Debris the organic contaminated Debris does not require thermal desorption. An alternative stabilization technology is Macroencapsulation.

\subsubsection{Process Feed}

The primary waste feed stream compositions and associated assumptions for the Debris Portable Treatment Unit are shown in Table 8 . The required treatment capacities $\left(\mathrm{m}^{3} / \mathrm{yr}\right)$ for each waste matrix set were obtained from Musgrave ${ }^{1}$. Effective bulk densities $\left(\mathrm{kg} / \mathrm{m}^{3}\right)$ of the Debris feed streams were taken from the MWIR and PSTP ${ }^{4}$ databases and incorporate the fact that the drums containing the Debris are only partially full. Drum weights are excluded from the density assumptions and calculated mass throughput rates reported in Table 8. 
In addition to these primary Debris waste feed streams, the Debris Portable Treatment Unit accepts a single transfer stream from the Labpacks Portable Treatment Unit. This transfer stream is summarized in Table 9.

Table 8

Primary Waste Feed Streams for the Debris Portable Treatment Unit

\begin{tabular}{||l|c|c|c|c|c|c|c||}
\hline \multirow{2}{*}{ Debris Type } & \multicolumn{3}{|c|}{ ORGANIC CONTAMINATED } & \multicolumn{2}{|c|}{ NON-ORGANIC CONTAMINATED } & \\
\cline { 2 - 9 } & $\begin{array}{c}\text { Inorganic } \\
\text { Debris (a) }\end{array}$ & $\begin{array}{c}\text { Organic } \\
\text { Debris (b) }\end{array}$ & $\begin{array}{c}\text { Heterog. } \\
\text { Debris (c) }\end{array}$ & $\begin{array}{c}\text { Inorganic } \\
\text { Debris (a) }\end{array}$ & $\begin{array}{c}\text { Organic } \\
\text { Debris (b) }\end{array}$ & $\begin{array}{c}\text { Heterog. } \\
\text { Debris (c) }\end{array}$ & Total \\
\hline \hline $\begin{array}{l}\text { Matrix Parameter } \\
\text { Code (MPC) }\end{array}$ & 5100 & 5300 & 5400 & 5100 & 5300 & 5400 & \\
\hline & & & & & & & \\
\hline Treatment Input, $\mathrm{m}^{3} / \mathrm{yr}$ & 10 & 45 & 65 & 10 & 45. & 65 & 240 \\
\hline Density, $\mathrm{kg} / \mathrm{m}^{3}$ & 509 & 320 & 400 & 509 & 455 & 400 & \\
\hline Treatment Input, $\mathrm{kg} / \mathrm{yr}$ & 5,090 & 14,400 & 26,000 & 5,090 & 14,400 & 26,000 & 90,980 \\
\hline
\end{tabular}

(a) $>80$ vol\% inorganic debris (e.g. scrap metal, concrete, brick, glass)

(b) $>80$ vol\% organic debris (plastic, rubber, wood, paper, cloth, biological)

(c) $>50$ vol\% debris not meeting Inorganic Debris (MPC 5100) or Organic Debris (MPC 5300) definitions

Table 9

External Transfer Streams to the Debris Portable Treatment Unit from Other Portable Treatment Units

\begin{tabular}{||l|l|c|c|c||}
\hline \hline Stream Description & $\begin{array}{c}\text { Source from Other Portable } \\
\text { Treatment Unit }\end{array}$ & $\begin{array}{c}\text { Destination } \\
\text { within the Debris } \\
\text { Portable } \\
\text { Treatment Unit }\end{array}$ & $\mathbf{m}^{\mathbf{3} / \mathbf{y r}}$ & $\mathbf{k g} / \mathbf{y r}$ \\
\hline $\begin{array}{l}\text { Packaging materials } \\
\text { including, coarse } \\
\text { packing material, } \\
\text { overpacks, drums, } \\
\text { lids, bottles, and cans }\end{array}$ & $\begin{array}{l}\text { Opening/Sorting operation } \\
\text { within the Labpacks Portable } \\
\text { Treatment Unit }\end{array}$ & Manual Sorting & 80 & 26,207 \\
\hline \hline
\end{tabular}

\subsection{Process Boundaries}

The input boundary for the Debris Portable Treatment Unit is where the primary waste streams and external transfer stream from the Labpacks Portable Treatment Unit enter the Unit. Utilities to be supplied by the facility at the operations location include electricity and water. 
The output boundary of the Debris Portable Treatment Unit is where the stabiiized waste form packages $\left(0.208 \mathrm{~m}^{3}\right.$ ( $\left.55 \mathrm{gal}\right)$ drums) leave the unit. HEPA filtered offgas from ventilation of Manual Sorting and Shearing/Crushing operations is released to the atmosphere. Stabilized waste form packages from Cement Microencapsulation are transported to the shipping area of the facility.

\subsection{Flow Diagram Description} Figure 3.

The flow diagram for the Debris Portable Treatment Unit is provided in block form as

\subsubsection{Debris Receiving and Transfer}

All candidate Debris wastes for portable treatment that meet the Debris Rules are received by the Debris Portable Treatment Unit. It is assumed that any assaying of Debris waste for radioactivity has been done prior to staging for portable treatment at the facility. No radioactive assay capability is provided in the Debris Portable Treatment Unit. It is therefore assumed that all Debris received by the portable treatment unit is low level radioactive waste and, in addition, may or may not have hazardous (RCRA or TSCA) contamination. The primary Debris streams received for portable treatment will be principally packaged in $0.208 \mathrm{~m}^{3}$ (55 gal) drums and dumpster type containers.

The material received from the Labpacks Portable Treatment System consisting of packaging materials such as coarse packing material, overpacks, drums, lids, bottles, and cans is assumed to be a Heterogeneous Debris stream and will be received in $0.208 \mathrm{~m}^{3}$ (55 gal) drums. Any relatively fine packing materials such as vermiculite will have been previously separated in the Labpacks.Opening/Sorting operation prior to transfer to the Debris Portable Treatment Unit.

\subsubsection{Manual Sorting}

The purpose of the manual sorting operation is to open containers of Debris and sort out any materials that cannot be accepted by the Shearing/Crushing operation downstream or do not meet the $60 \mathrm{~mm}$ minimum size criteria for Debris. The materials that cannot be accepted by Shearing/Crushing may include but not be limited to large metal and concrete objects. These oversize materials are transferred directly to Cement Microencapsulation.

Equipment must be provided to lift and dump the Debris containers as received. These Debris containers are emptied onto a trommel screen sized to separate the $<60 \mathrm{~mm}$ (2.36 in.) and $>60 \mathrm{~mm}$ size fractions. Those materials less than $60 \mathrm{~mm}$ that fall through the trommel screen are not considered Debris due to the size constraint and, therefore, must be transferred to the Homogeneous Solids feed line for treatment in the Organics Portable Treatment Unit. Waste packages that are clearly non-RCRA wastes but remain low level radioactive waste can bypass the subsequent size reduction and Cement Microencapsulation steps and be sent to low level waste disposal. Such materials may include the drums and other containers from the Labpacks Portable Treatment Unit that have been cleaned of RCRA contamination. 
The sorting operation is conducted within a ventilated enclosure for vapor containment. Ventilation air is directed to the unit's ventilation system that provides activated carbon and HEPA filtration.

\subsubsection{Shearing/Crushing}

The purpose of the Shearing/Crushing step is to reduce the size of the Debris components to material larger than $60 \mathrm{~mm}$ ( $2.36 \mathrm{in}$.) that can be readily blended with portland cement in the Cement Microencapsulation step downstream. The $<60 \mathrm{~mm}$ size fraction must be transferred to De-lumping/Crushing within the Organcis Portable Treatment Unit. Because Debris can consist of a wide range of object sizes, shapes, and hardnesses more than one size reduction technique may be required. A jaw crusher may be required to reduce the size of large hard objects such as concrete, masonry, and natural geologic material (boulders, cobbles, and gravel). A counterrotating shredder is required for size reduction of relatively soft large materials such as wood, rubber, plastic, cellulosics (paper, cardboard), cloth, and biological materials, and hard smaller objects made of metal, glass, and ceramic.

The oversize material from the trommel screen in the manual sorting step is transferred by belt conveyor to the feed charging ports of the size reduction devices. Size-reduced material normally falls by gravity into a feed hopper for conveying to Cement Microencapsulation. A shredded material densification ratio of 2:1 is assumed. The average bulk densities of the shredder input and output Debris material are estimated to be 323.5 and $647 \mathrm{~kg} / \mathrm{m}^{3}$, respectively.

The Shearing/Crushing operation is conducted within a ventilated enclosure for vapor and entrained particulate containment. Ventilation air is directed to the unit's ventilation system that provides activated carbon and HEPA filtration.

\subsubsection{Cement Microencapsulation}

The purpose of the Cement/Microencapsulation system is to intimately blend the shredded Debris material with portland cement for setting to produce a stable final waste form for storage or disposal. The blending operation can be carried out either by mixing in a continuous feed device such as a pug-mill followed by batch loading of the blended material into a $0.208 \mathrm{~m}^{3}$ ( $55 \mathrm{gal}$ ) drum, or by blending the Debris and concrete (grout) materials together batchwise directly in the drum. Large objects that are not subjected to size reduction but that fit into a $55 \mathrm{gal}$ drum will require cementation in the drum. Assumed weight ratios ${ }^{5}$ for the constituents of the final waste form are water/dry cement $=0.4$, Debris/dry cement $=0.25$. The assumed density of the final waste form matrix (not including the drum volume) is $1,700 \mathrm{~kg} / \mathrm{m}^{3}$. The final waste form is assumed to occupy $85 \%$ of the volume of a $0.208 \mathrm{~m}^{3}(55 \mathrm{gal}) \mathrm{drum}$.

The Cement Microencapsulation operation is conducted within a ventilated enclosure for vapor and entrained particulate containment. Ventilation air is directed to the unit's ventilation system that provides activated carbon and HEPA filtration. 


\subsection{Material Balance}

Table 10 provides a material balance (input and output streams) for the Debris Portable Treatment Unit. The values in Table 10 are based on the feed stream assumptions (Table 8) and other assumptions concerning the unit operations discussed previously and are reported as annual throughput rates $(\mathrm{kg} / \mathrm{yr})$.

Table 10

\section{Material Balance for the Debris Portable Treatment Unit}

\begin{tabular}{|c|c|c|c|}
\hline Process Inputs, kg/yr & $\begin{array}{l}\text { Primary } \\
\text { Streams }\end{array}$ & $\begin{array}{c}\text { From Other } \\
\text { PTUs } \\
\end{array}$ & $\begin{array}{l}\text { Total to Debris } \\
\text { PTU } \\
\end{array}$ \\
\hline $\begin{array}{l}\text { Inorganic Debris (MPC 5100), organic } \\
\text { contaminated }\end{array}$ & 5,090 & 0 & 5,090 \\
\hline $\begin{array}{l}\text { Organic Debris (MPC 5300), organic } \\
\text { contaminated }\end{array}$ & 14,400 & 0 & 14,400 \\
\hline $\begin{array}{l}\text { Heterogeneous Debris (MPC 5400), } \\
\text { organic contaminated }\end{array}$ & 26,000 & 0 & 26,000 \\
\hline $\begin{array}{l}\text { Inorganic Debris (MPC 5100), non-organic } \\
\text { contaminated }\end{array}$ & 5,090 & 0 & 5,090 \\
\hline $\begin{array}{l}\text { Organic Debris (MPC 5300), non-organic } \\
\text { contaminated }\end{array}$ & 14,400 & 0 & 14,400 \\
\hline $\begin{array}{l}\text { Heterogeneous Debris (MPC 5400), non- } \\
\text { organic contaminated }\end{array}$ & 26,000 & 0 & 26,000 \\
\hline $\begin{array}{l}\text { Heterogeneous Debris from Labpacks } \\
\text { Portable Treatment }\end{array}$ & $\longrightarrow$ & 26,207 & 26,207 \\
\hline Water for Cement Microencapsulation & - & - & 165,611 \\
\hline Portland Cement for Microencapsulation & - & - & 414,029 \\
\hline 55 gal drums (for final waste form) & - & - & 65,005 \\
\hline \multicolumn{3}{|l|}{ Total Inputs } & 748,152 \\
\hline \multicolumn{3}{|l|}{ Process Outputs, kg/yr } & $\begin{array}{l}\text { Total Leaving } \\
\text { Debris PTU }\end{array}$ \\
\hline \multicolumn{3}{|l|}{$\begin{array}{l}\text { Stabilized Waste Form (not including } \\
\text { drums) }\end{array}$} & 683,147 \\
\hline \multicolumn{3}{|l|}{$\begin{array}{l}55 \text { gal drums (Final Waste Form } \\
\text { Containers) }\end{array}$} & 65,005 \\
\hline \multicolumn{3}{|l|}{ Waste to LLW Landfill } & 0 \\
\hline \multicolumn{3}{|l|}{ Total Outputs } & 748,152 \\
\hline
\end{tabular}

\subsection{Unit Operations Capacities}

The throughput capacity of the Debris Portable Treatment Unit was fixed by determining the limiting unit operation within the processing train based on its physical size (all three dimensions) and the ability to fit this unit operation into a semi-trailer. The Cement Microencapsulation unit is the throughput-limiting device in the Debris Portable Treatment Unit train. It is assumed that five 55 gal drums can be processed in an eight hour shift. This is an 
effective Debris processing rate of $28.5 \mathrm{~kg} / \mathrm{hr}$ and a net final waste form production rate of 187.9 $\mathrm{kg} / \mathrm{hr}$. The Microencapsulation process would need to be operated for 3,637 hours/yr (on-stream factor $=42 \%$ ). The other unit operations within the train, Manual Sorting and

Shearing/Crushing, are sized for compatibility with the capacity of Cement Microencapsulation.

Semi-trailers are assumed to have inside dimensions of $12.04 \mathrm{~m}$ (39.5 ft.) long, $2.36 \mathrm{~m}$ ( $7.75 \mathrm{ft}$.) wide and $2.44 \mathrm{~m}(8 \mathrm{ft}$.) high. These general size guidelines were used to arrive at the limiting unit operations capacity for this processing train. Development of detailed equipment layouts was beyond the scope of this work. Therefore, no attempt was made to provide preliminary positioning of equipment on the trailers.

Table 11 gives the approximate capacities of the unit operations within the Debris Portable Treatment Unit.

Table 11

Unit Operations Capacities in the Debris Portable Treatment Unit

\begin{tabular}{|l|l|}
\hline Unit Operation & Capacity \\
\hline \hline Manual Sorting & $28.5 \mathrm{~kg} / \mathrm{hr}$ Debris input \\
\hline Shearing/Crushing & $28.5 \mathrm{~kg} / \mathrm{hr}\left(0.044 \mathrm{~m}^{3} / \mathrm{hr}\right)$ sorted Debris input; assumes all \\
& material from Manual Sorting enters Shearing/Crushin \\
\hline Cement Microencapsulation & $\begin{array}{l}142.5 \mathrm{~kg} \text { of shredded Debris input per } 8 \mathrm{hour} \text { shift (28.5 } \\
\mathrm{kg} / \mathrm{hr} \text { avg. of shredded Debris); } 187.9 \mathrm{~kg} / \mathrm{hr} \text { of final waste } \\
\\
\text { form }\end{array}$ \\
\hline
\end{tabular}

\section{SYSTEM DESIGN CRITERIA}

\subsection{Functional Requirements}

The functions of the Debris Portable Treatment Unit are to:

- process the following mixed low level radioactive waste streams: Inorganic Debris (MPC 5100), Organic Debris (MPC 5300), and Heterogeneous Debris (MPC 5400) and the miscellaneous Debris stream from the Labpacks portable treatment unit,

- produce an acceptable stable final waste form by Cement Microencapsulation for storage or disposal,

- meet all current and anticipated applicable requirements of DOE Orders, State, and Federal mixed waste regulations.

\subsection{Operational Requirements}

The Debris Portable Treatment Unit consists of Debris Receiving and Transfer, Manual Sorting, Shearing/Crushing, and Cement Microencapsulation unit operations. This Treatment Unit shall process the waste streams listed in Tables 8 and 9 of this document at their respective 
annual throughput rates. The on-stream factor for the Cement Microencapsulation processing train is $44 \%$.

\subsection{Interface Requirements}

\subsubsection{Receipt of Primary Waste Streams}

The Debris Portable Treatment Unit must be designed to accommodate Debris in package sizes ranging from $0.208 \mathrm{~m}^{3}$ (55 gallon drums) to dumpster-type containers. Special handling systems will be required to open and transfer the contents of these containers onto the trommel screen in the Manual Sorting unit operation. These operations must be conducted within proper radioactive containment inside the portable unit trailer. Any free liquids collected in the bottoms of Debris containers would then be transferred batchwise to either the Wastewater or Organics Portable Treatment Unit depending on the level of organic contamination.

\subsubsection{External Transfer Shipments}

External transfer shipments of waste streams in $0.208 \mathrm{~m}^{3}(55 \mathrm{gal})$ drums from the Labpacks Portable Treatment unit (See Table 9) will be received in a fashion similar to that just described for primary Debris waste streams. It is anticipated that these streams will have physical handling characteristics similar to the primary waste streams.

The only routine stream leaving the Debris Portable Treatment Unit is the stabilized final waste form from the Cement Microencapsulation process. A staging area adjacent to the portable treatment unit for the stabilized final waste form packaged in $0.208 \mathrm{~m}^{3}$ (55 gal) drums should be provided. These drums would be removed on pallets by forklift truck to the facility's shipping area. Any materials that do not meet the waste acceptance criteria for the Debris Portable Treatment Unit must be rejected, repackaged if necessary, and returned to the storage area on site.

\subsubsection{Utilities}

Electrical power from the facilities grid shall be provided in sufficient quantity to operate the Debris Portable Treatment Unit's auxiliary equipment, controls, lighting, alarm systems, etc., under normal operating conditions. Backup electrical power and an uninterruptible power supply (UPS) are required; the unit shall be designed to power down in a fail-safe condition in the event of loss of line power.

The other utility to be provided by the site is plant water. These utilities shall be provided in sufficient quantity to support the Unit's operations during normal and emergency conditions. Other utilities, including portland cement, shall be delivered by separate vehicles to the Debris Portable Treatment Unit processing location. 


\section{FUNCTIONAL AND OPERATIONAL REQUIREMENTS FÖ WASTEWATER PORTABLE TREATMENT}

\section{INTRODUCTION}

This document presents Functional and Operational Requirements (F\&ORs) for the Wastewater Portable Treatment Unit. This unit is part of the integrated Portable Treatment Systems Study (PTSS) sponsored by the US Department of Energy Office of Technology Development. The objectives of the Wastewater Portable Treatment Unit are: 1) to accept and effectively process Wastewaters and Aqueous Slurries that are mixed low level radioactive wastes, and 2) to meet these objectives by processing the waste streams on portable semi-trailers that can be moved from site to site. The functions of the unit are:

- to destroy the organic fraction of the waste streams by conversion to carbon dioxide, water, and hydrochloric acid,

- to separate the inorganic fraction that consists of dissolved and suspended solids including RCRA metals and non-volatile radionuclides for transfer to inorganic sludge treatment within the Organics Portable Treatment Unit,

- to produce a water stream that is suitable for recycle or reuse within the Portable Treatment Systems, or disposal.

The treatment unit comprises process equipment to perform the above functions mounted on multiple semi-trailers. The unit also accepts external transfer streams from two other portable units: the Organics Portable Treatment Unit and the Labpacks Portable Treatment Unit.

The operation consists of a sequence of processing steps. All primary and external transfer streams enter the unit via one or more holding tanks. The first unit operation consists of a batch Redox Tank in which either oxidants or reductants can be added with agitation to adjust the Redox potential of the liquid batch. The Redox-adjusted liquid is then pumped to a batch Neutralization Tank where the $\mathrm{pH}$ is adjusted to the prescribed range for subsequent processing by adding either acid or base with agitation. After $\mathrm{pH}$ adjustment, the liquid is filtered through a cartridge type filter to remove suspended solids. Assuming the aqueous liquid has organic contamination, it is then transferred to a continuous Hydrothermal Process reactor where the organics are destroyed by conversion to carbon dioxide, water, and hydrochloric acid. The offgas from the Hydrothermal Process is vented through a Reheater followed by HEPA filters before discharge to the atmosphere. The liquid from the Hydrothermal Process is then transferred to a Reverse Osmosis (RO) unit where the dissolved solids in the liquid are separated from the water. The water from the RO unit is then available for recycle or reuse within the suite of Portable Treatment Units or for discharge. The brine from RO is transferred to an Evaporator where the liquid is further concentrated to the consistency of a sludge. This sludge from the Evaporator is transferred to inorganic sludge treatment within the Organics Portable Treatment Unit. The vapor from the Evaporator is cooled and condensed in a Condenser. Offgas from the Condenser is routed to the same offgas system for the Hydrothermal process consisting of a Reheater and HEPA filters before discharge to the atmosphere. 
A fundamental assumption in this work is that the Portable Treatment Units are assembled and fully operable on semi-trailers. Only utility hookups on-site and process line connections with the other Portable Treatment Units are required for operability. The treatment units are not modular and are not intended to be off-loaded from the trailers for process service within on-site facilities. Also, specific processing trains are sized to accommodate equipment having the largest reasonable throughput rate possible given the size constraint of the semitrailers.

\section{SYSTEM DESCRIPTION}

\subsection{System Specific Assumptions}

\subsubsection{Technology}

The flow diagram for the Wastewater Portable Treatment Unit is provided in block form in Figure 4. Descriptions of the individual unit operations and the technologies selected for the Wastewater Portable Treatment Unit are provided in Section 11.3 - Flow Diagram Description. The flowsheet and selection of the specific technologies within it are dependent upon the feed stream assumptions discussed in the following section.

\subsubsection{Process Feed}

The primary waste feed stream compositions and associated assumptions for the Wastewater Portable Treatment Unit are shown in Table 12. The required treatment capacities $\left(\mathrm{m}^{3} / \mathrm{yr}\right)$ for each waste matrix set were obtained from Musgrave ${ }^{1}$. The waste stream summary report ${ }^{2}$ by Heubner et al was used as a guide for establishing the ultimate compositions (organics, inerts, water) for the aqueous waste streams (MPC 1100, 1200).

In addition to these primary waste feed streams, the Wastewater Portable Treatment Unit accepts transfer streams from other Portable Treatment Units. These transfer streams are summarized in Table 13. 
Table 12

Primary Waste Feed Streams for the Wastewater Portable Treatment Unit

\begin{tabular}{|c|c|c|}
\hline Waste Stream & Aqueous-Liquids (a) & Aqueous Slurries (b) \\
\hline Matrix Parameter Code (MPC) & 1100 & 1200 \\
\hline Input Flow, $\mathrm{m}^{3} / \mathrm{yr}$ & 200 & 200 \\
\hline Density, $\mathrm{kg} / \mathrm{m}^{3}$ & 1050 & 1130 \\
\hline Annual Throughput, $\mathrm{kg} / \mathrm{yr}$ & 210,000 & 226,000 \\
\hline \multicolumn{3}{|l|}{ Elemental Composition } \\
\hline \multicolumn{3}{|l|}{ Organics (wt\% of total stream) } \\
\hline Carbon & 0.153 & 0.153 \\
\hline Hydrogen & 0.014 & 0.014 \\
\hline Oxygen & 0.0 & 0.0 \\
\hline Nitrogen & 0.0 & 0.0 \\
\hline Sulfur & 0.0 & 0.0 \\
\hline Chlorine & 0.167 & 0.167 \\
\hline Total Organics & 0.333 & 0.333 \\
\hline \multicolumn{3}{|l|}{ Inorganics ( $w$ t\% of total stream) } \\
\hline Water & 88.667 & 74.667 \\
\hline Dissolved Solids & 10.0 & 10.0 \\
\hline Suspended Solids & 1.0 & $15: 0$ \\
\hline Total Inorganics & 99.667 & 99.667 \\
\hline Total for Stream & 100.0 & 100.0 \\
\hline & & \\
\hline
\end{tabular}

(a) Aqueous Wastewaters having < 1\% total suspended solids (TSS) and may include the following MPC subcategories: MPC 1110 - Acidic (pH $\leq 2)$, MPC 1120 - Basic ( $\mathrm{pH} \geq 12.5)$, MPC 1130 Neutral $(2.0 \leq$ $\mathrm{pH} \geq 12.5$ ), MPC 1140 - Cyanide Aqueous Slurries, and MPC 1190 - Unknown/Other Wastewaters (b) Aqueous liquids and slurries having $>1 \%$ total suspended solids (TSS) 
Table 13

External Transfer Streams to the Wastewater Portable Treatment Unit from Other Portable Treatment Units

\begin{tabular}{|c|c|c|c|c|}
\hline $\begin{array}{c}\text { Stream } \\
\text { Description }\end{array}$ & $\begin{array}{c}\text { Source from Other } \\
\text { Portable Treatment } \\
\text { Unit }\end{array}$ & $\begin{array}{c}\text { Destination within the } \\
\text { Wastewater Portable } \\
\text { Treatment Unit }\end{array}$ & $\mathbf{m}^{3} / \mathbf{y r}$ & $\mathbf{k g} / \mathbf{y r}$ \\
\hline \hline $\begin{array}{c}\text { Aqueous/Organic } \\
\text { Liquids }\end{array}$ & $\begin{array}{c}\text { Aqueous/organic } \\
\text { condensate from the } \\
\text { Organics Portable } \\
\text { Treatment Unit }\end{array}$ & Holding Tank & 291 & 283,558 \\
\hline $\begin{array}{c}\text { Aqueous/Organic } \\
\text { Liquids }\end{array}$ & $\begin{array}{c}\text { Blowdown from the } \\
\text { Organics Portable } \\
\text { Treatment Unit }\end{array}$ & Holding Tank & 364 & 373,159 \\
\hline \hline Aqueous Liquids & $\begin{array}{c}\text { Aqueous liquids from } \\
\text { the Labpacks Portable } \\
\text { Treatment Unit }\end{array}$ & Holding Tank & 8.5 & 8,874 \\
\hline
\end{tabular}

\subsection{Process Boundaries}

The input boundary for the Wastewater Portable Treatment Unit is where the primary waste streams and external transfer streams from other Portable Treatment Units enter the treatment train within the Unit. Utilities to be supplied by the facility at the operations location include electricity and water. Air for oxidation of the organics in the Hydrothermal Process is introduced to the process by forced draft compressor from the atmosphere within the enclosed trailers. Compressed air for instruments is provided by a compressor on the trailer. All reagents required by the process are delivered by separate vehicles to the Wastewater Portable Treatment Unit processing location.

The output boundary of the Wastewater Portable Treatment Unit is where the output streams leave the treatment train within the Unit. Reheated and HEPA-filtered offgas from the Hydrothermal Process and the Condenser is released to the atmosphere. Purified water from Reverse Osmosis is available for internal recycle/reuse or transfer to other Portable Treatment Units including the Organics and Debris Portable Treatment Units. Surplus water beyond recycle/reuse requirements is transferred to disposal. Concentrated inorganic sludge from the Evaporator is transferred to the Homogeneous Inorganic Solids line for Delumping/Crushing within the Organics Portable Treatment Unit. Surge capacity for these liquid and solid output streams will be provided by the Portable Treatment Units to which they are transferred.

\subsection{Flow Diagram Description}

The flow diagram for the Wastewater Portable Treatment Unit is provided in block form as Figure 4. Following are descriptions of the individual unit operations that make up the Wastewater Portable Treatment Unit. 


\subsubsection{Liquid Receiving, Sampling, and Transfer}

The process can receive bulked aqueous liquids from tank trucks, dumpster type tankage, drums, or by pipeline. Drummed or bulk concentrated pumpable organic liquids are transferred by an insertion type of pump from the container to the aqueous liquid holding/feed tank. The transfer operation is conducted within a ventilated enclosure for vapor containment. Ventilation air is directed to the unit ventilation system that provides activated carbon and HEPA filtration. Sufficient tankage is required to accommodate the holding of more than one batch of liquid that require different treatments downstream. All holding tanks require agitation to maintain suspension of solids and for representative sampling.

Because the aqueous liquid waste feed streams can have a broad range of $\mathrm{pH}$, Redox potential, dissolved solids, suspended solids, organics content, and potentially other chemical properties, sampling is required. Representative sampling of each batch of aqueous liquid is required in order to assess its subsequent treatment strategy. After sampling and analysis, some blending of feed streams may be required to provide desirable composition adjustments in the holding tanks. Pumps for each holding tank are used to transfer liquid to subsequent treatment steps.

\subsubsection{Redox Tank}

The purpose of the Redox tank is to make adjustments to the oxidation/reduction potential of specific batches of aqueous liquid waste feeds. The tank must have agitation to thoroughly mix the oxidant and reductant reagents, added to the tank by pump, with the liquid. Either sampling or continuous measurement of the Redox potential of the liquid in a recycle line is required during reagent addition. When the Redox potential of the liquid is adjusted to the desired value, the batch can be transferred to the Neutralization Tank. If Redox adjustment is not required for specific batches of waste, this step can be deleted from the processing sequence and aqueous waste can be transferred directly to the Neutralizations Tank.

\subsubsection{Neutralization·Tank}

Adjustments to $\mathrm{pH}$ are made in the Neutralization Tank. Here, acid and base reagents may be added by metering pump to neutralize the liquid by $\mathrm{pH}$ adjustment to the desired $\mathrm{pH}$ range, typically $7 \pm 2$. Buffering agents may also be added so that the $\mathrm{pH}$ does not change significantly in subsequent process steps. The tank must have agitation to thoroughly mix the $\mathrm{pH}$ adjusting reagents with the liquid. Continuous $\mathrm{pH}$ measurement of the liquid in a recycle line for example is required during reagent addition. Basic neutralizing reagents for acidic solutions may include sodium hydroxide, sodium carbonate, ammonium hydroxide, and others. Acidic reagents for neutralizing basic solutions may include nitric acid, oxalic acid, and others.

\subsubsection{Filtration of Aqueous Liquids}

The liquid from the Neutralization Tank requires separation of the suspended solids from the liquid before subsequent processing. The suspended solids çan include those originally in the liquid feed streams as well as any salts that may have precipitated in the previous Redox and neutralization steps. The liquids are filtered in one or more parallel cartridge type filters to 
remove suspended solids. The filtration operation can be conducted batchwise so that the filtrate is stored in a holding tank prior to the Hydrothermal Process. Continuous filtration of the flowing liquid to the Hydrothermal Process is also an option. Alternative solid/liquid separation - technologies include backflush type filter membranes and centrifugation. Spent filter cartridges containing filtered solids are manually removed from the filter housing and sent to Delumping/Crushing in the Organics Portable Treatment System.

\subsubsection{Hydrothermal Process}

The Hydrothermal Process ${ }^{6}$ operates at a temperature of approximately $550^{\circ} \mathrm{C}\left(1022^{\circ} \mathrm{F}\right)$ and a pressure of $408 \mathrm{~atm}(6,000 \mathrm{psia})$ to destroy organic compounds and some inorganics in a predominantly aqueous waste stream. The process operates above the critical point of water in a regime where the critical mixture becomes a solvent for organics. Because the organic oxidation reactions occurs in a dilute system, the heat of reaction is absorbed by the solvent and temperature control is straightforward. The liquid from the Neutralization Tank is pumped at high pressure into the externally heated tubular Hydrothermal Process reactor along with air. Oxygen may also be used as the oxidant. Feed residence times within the reactor at supercritical operating conditions are on the order of $20 \mathrm{sec}$ to more than one minute. At the discharge end of the reactor, a heat exchanger cools the mixture and a let-down valve reduces the pressure to atmospheric. A knockout tank containing a mesh-type Demister separates the liquid from the gases exiting the reactor. The aqueous liquid containing dissolved salts is transferred to Reverse Osmosis. Offgas from the Hydrothermal process containing carbon dioxide, nitrogen, oxygen, trace hydrochloric acid, and water vapor is routed to the Reheater and HEPA filtration before discharge to the atmosphere. Due to the corrosive conditions in the Hydrothermal Process reactor, it must be constructed of corrosion resistant metal alloys such as titanium and Inconel. Alternatives to Hydrothermal Processing for organic destruction in aqueous feed streams include other wet air oxidation processes, the Detox process, and others.

\subsubsection{Reverse Osmosis}

The discharge liquid from Hydrothermal Processing, free of organics but still containing dissolved salts, is pumped to the Reverse Osmosis (RO) unit. In the RO unit, water is separated from the dissolved salts in solution by filtering through a semipermeable membrane at a pressure greater than the osmotic pressure of the dissolved salts in solution. The operating pressure may vary from atmospheric to 100 atm $(-1500$ psia) depending on the salt concentration, membrane material, membrane surface area selected, and liquid temperature. An alternative to Reverse Osmosis is evaporation of the entire stream leaving the Hydrothermal Process followed by condensation of the water. A capital/operating cost study would be required to assess the most appropriate method of dissolved solids/water separation for the Portable Treatment application. In the flowsheet, the concentrated salt solution leaving RO is transferred to the Evaporator for further concentration of the solids. The water leaving RO is transferred to the Organics Portable Treatment Unit to be used as makeup water in the Thermal Oxidation Offgas Treatment system.

\subsubsection{Evaporator}

The purpose of the Evaporator is to further concentrate the brine solution produced in the $\mathrm{RO}$ unit. The concentrated salt solution or brine discharged from the RO unit is transferred to the 
Evaporator by pump and pipeline. Either electrical resistance or steam heating is applied to a recirculation loop on the Evaporator to supply heat for evaporation of water from the brine solution. An alternative technology is a wiped film evaporator. Fully concentrated evaporator bottoms sludge consisting of salts, trace heavy metals, trace radionuclides, and some water is transferred to Homogeneous Inorganic Solids treatment within the Organics Portable Treatment Unit. Vapor from the Evaporator is routed to the Condenser.

\subsubsection{Condenser}

The purpose of the condenser is to cool the vapor exiting the Evaporator to condense water. Plant water is circulated through the condenser for cooling. Offgas leaving the condenser, primarily water vapor, is routed to the Reheater. Condensate water from the Condenser is combined with water discharged from the RO unit for transfer to the Organics Portable Treatment Unit to be used as makeup water in the Thermal Oxidation Offgas Treatment system.

\subsubsection{Reheater}

An electrical resistance Reheater is installed in the offgas duct just downstream of the Condenser and Hydrothermal Process. The purpose of the Reheater is to heat the saturated offgas stream to $28^{\circ} \mathrm{C}\left(50^{\circ} \mathrm{F}\right)$ above the dew point so that no condensation will result in the HEPA filters downstream.

\subsubsection{HEPA Filtration/Draft Control}

The reheated offgas is passed through High Efficiency Particulate Air (HEPA) filters to remove any entrained submicron particulate from the offgas stream. Though these filters should have an extended life because of the low particulate loading, spent filters are sent to Delumping/Crushing within the Organics Portable Treatment Unit. A minimum of one stage of HEPA filters is required. For processing of waste streams containing high concentrations of alpha-emitting isotopes, primarily plutonium, two stages of HEPA filters in series may be required. An induced draft fan and damper valve downstream of the HEPA filters maintain draft control through the offgas treatment system for the Hydrothermal Process and Evaporator.

\subsection{Material Balance}

Table 14 provides a preliminary material balance (input and output streams) for the Wastewater Portable Treatment Unit. The values in Table 14 are based on the feed stream assumptions (Table 12) and the following additional assumptions concerning the performance of the unit operations. These assumptions do not necessarily reflect typical operating. conditions.

- The concentrations of reagent for oxidant, reductant, acid, and base additive streams is $10 \mathrm{wt} \%$.

- The oxidants and reductants added to the primary waste streams (MPC 1100 and 1200 ) as a percentage of the total stream is $0.1 \%$

- The acid and base reagents added to the primary waste streams (MPC 1100 and 1200) as a percentage of the total stream is $1.0 \%$ 
- Solid-liquid separation efficiency of Aqueous Liquid Filtration is $99 \%$

- Organic destruction efficiency of the Hydrothermal Process is $99.9999 \%$.

- Reverse Osmosis salt separation efficiency is $99 \%$

- The dissolved salt concentration in the RO unit brine liquid discharge is $25 \mathrm{wt} \%$.

Table 14

Material Balance for the Wastewater Portable Treatment Unit

\begin{tabular}{|l|c|r|r|}
\hline \multicolumn{1}{|c|}{ Process Inputs, kg/yr } & Primary Streams & From Other PTUs & $\begin{array}{r}\text { Total to } \\
\text { Wastewater PTU }\end{array}$ \\
\hline \hline $\begin{array}{l}\text { Aqueous Liquids to Redox } \\
\text { Tank }\end{array}$ & 210,000 & 657,394 & 867,394 \\
\hline $\begin{array}{l}\text { Aqueous Slurries to Redox } \\
\text { Tank }\end{array}$ & 226,000 & 0 & 226,000 \\
\hline Oxidants to Redox Tank & - & - & 1,093 \\
\hline Reductants to Redox Tank & - & - & 1,093 \\
\hline Acid to Neutralization Tank & - & - & 10,934 \\
\hline $\begin{array}{l}\text { Base to Neutralization } \\
\text { Tank }\end{array}$ & - & - & 10,934 \\
\hline $\begin{array}{l}\text { Air to Hydrothermal } \\
\text { Treatment }\end{array}$ & - & & 694,371 \\
\hline Total Inputs & & & $1,811,819$ \\
\hline \multicolumn{2}{|l|}{} & & Total Leaving \\
\hline $\begin{array}{l}\text { Process Outputs, kg/yr } \\
\text { Wastewater PTU }\end{array}$ \\
\hline Water for Recycle/Reuse (to Organics Portable Treatment Unit) & 950,628 \\
\hline $\begin{array}{l}\text { Sludges to Inorganic Sludge Treatment (Organics Portable Treatment } \\
\text { Unit) }\end{array}$ & & 138,981 \\
\hline Offgas from Hydrothermal Treatment & & $\mathbf{7 2 2 , 2 1 0}$ \\
\hline Total Outputs & & $1,811,819$ \\
\hline
\end{tabular}

\subsection{Unit Operations Capacities}

The throughput capacity of the Wastewater Treatment processing train was fixed by determining the limiting unit operation within the train based on its physical size (all three dimensions) and the ability to fit this unit operation into a semi-trailer. The Hydrothermal Process is the throughput-limiting device in the Wastewater Portable Treatment Unit. The rated throughput capacity for the Hydrothermal Process is $2 \mathrm{gal} / \mathrm{min}$ for aqueous streams containing 5$10 \mathrm{wt} \%$ organic ${ }^{1,6}$. This rate corresponds to a total mass throughput rate for the stream of 467.6 $\mathrm{kg} / \mathrm{hr}$. The Hydrothermal Process is the throughput-limiting unit operation in the Wastewater Portable Treatment Unit. Based on the throughput rate of $467.6 \mathrm{~kg} / \mathrm{hr}$ and an annual processing requirement of $1,045,276 \mathrm{~kg} / \mathrm{yr}$, the Hydrothermal Process would have to operate for approximately 2,336 hours/year. The on-stream factor for the Hydrothermal Process, based on 8,760 hours/yr operation, is approximately $25.5 \%$. The other unit operations within the train are sized for compatibility with the capacity of the Hydrothermal Process. 
Semi-trailers are assumed to have inside dimensions of $12.04 \mathrm{~m}$ ( $39.5 \mathrm{ft}$.) long, $2.36 \mathrm{~m}$ ( $7.75 \mathrm{ft}$.) wide and $2.44 \mathrm{~m}(8 \mathrm{ft}$.) high. These general size guidelines were used to arrive at the limiting unit operations capacities for each processing train. Development of detailed equipment layouts were beyond the scope of this work. Therefore, no attempt was made to provide preliminary positioning of equipment on the trailers.

Table 15 gives the approximate capacities and process conditions of the unit operations within the Wastewater Portable Treatment Unit.

Table 15

Unit Operations Capacities in the Wastewater Portable Treatment Unit

\begin{tabular}{|l|l|}
\hline \hline Unit Operation & Capacity and Process Conditions \\
\hline \hline Redox Tank & $\begin{array}{l}478.8 \mathrm{~kg} / \mathrm{hr} \text { liquid feed; } ~ 0.5 \mathrm{~kg} / \mathrm{hr} \text { of either oxidants or } \\
\text { reductants }\end{array}$ \\
\hline Neutralization Tank & $\begin{array}{l}479.8 \mathrm{~kg} / \mathrm{hr} \text { liquid feed; } ~ 4.8 \mathrm{~kg} / \mathrm{hr} \text { of either acid or } \\
\text { based reagent for neutralization }\end{array}$ \\
\hline Aqueous Liquids Filtration & $489.4 \mathrm{~kg} / \mathrm{hr}$ liquids with; $21.8 \mathrm{~kg} / \mathrm{hr}$ solids separation \\
\hline Hydrothermal Process & $\begin{array}{l}\text { One reactor at } 467.6 \mathrm{~kg} / \mathrm{hr}\left(2 \mathrm{gal} / \mathrm{min} \text { ) feed; } 550^{\circ} \mathrm{C} \text { and }\right. \\
408 \mathrm{~atm} \text { pressure. }\end{array}$ \\
\hline Reverse Osmosis & $\begin{array}{l}437.6 \mathrm{~kg} / \mathrm{hr} \text { liquid feed (containing } 20.5 \mathrm{~kg} / \mathrm{hr} \text { dissolved } \\
\text { solids }+\sim 0.11 \mathrm{~kg} / \mathrm{hr} \text { suspended solids) }\end{array}$ \\
\hline Evaporator & $\begin{array}{l}81.7 \mathrm{~kg} / \mathrm{hr} \text { brine feed (containing } 20.3 \mathrm{~kg} / \mathrm{hr} \text { dissolved } \\
\text { solids }+\sim 0.11 \mathrm{~kg} / \mathrm{hr} \text { suspended solids) }\end{array}$ \\
\hline Condenser & $\begin{array}{l}61.3 \mathrm{~kg} / \mathrm{hr} \text { water vapor feed producing } 61.3 \mathrm{~kg} / \mathrm{hr} \\
\text { condensate water (assumed } 100 \% \text { removal) }\end{array}$ \\
\hline Reheater & $\begin{array}{l}776.8 \mathrm{~kg} / \mathrm{hr} \text { inlet gas (approx. } 440 \mathrm{ACFM} \text { inlet gas at } 40 \\
{ }^{\circ} \mathrm{C}, 467 \mathrm{ACFM} \text { exit gas at } 58^{\circ} \mathrm{C} \text { ) }\end{array}$ \\
\hline HEPA Filtration & $467 \mathrm{ACFM}$ inlet gas at $58^{\circ} \mathrm{C}$ \\
\hline
\end{tabular}

\section{SYSTEM DESIGN CRITERIA}

\subsection{Functional Requirements}

The functions of the Wastewater Portable Treatment Unit are to:

- process Aqueous Liquids (MPC 1100) and Aqueous Slurries.(MPC 1200) that are mixed low level radioactive waste streams of widely varying composition as well as external aqueous/organic transfer streams from other Portable Treatment Units,

- clean the offgas generated from these processing operations,

- produce an acceptable feed stream for other Portable Treatment Units which in turn produce a stable final waste form for storage or disposal,

- meet all current and anticipated applicable requirements of DOE Orders, State, and Federal mixed waste regulations. 


\subsection{Operational Requirements}

The Wastewater Portable Treatment Unit consists of one primary processing train. This Treatment Unit is to process the waste streams listed in Table 12 of this document at their respective annual throughput rates. The on-stream factor for the Wastewater Portable Treatment Unit processing train is approximately $38 \%$.

\subsection{Interface Requirements}

\subsubsection{Receipt of Primary Waste Streams}

Receipt of primary aqueous liquid and slurry waste streams will depend upon the waste stream and the site at which the portable treatment unit is to operate. However, the processes must be designed to accommodate liquids and slurries in package sizes ranging from $0.208 \mathrm{~m}^{3}$ ( $55 \mathrm{gal}$ ) drums to dumpster type packaging. Pumpable aqueous liquids, if stored in tanks on site, can be transferred by pipeline to a hold/feed tank within the Wastewater Portable Treatment Unit. These operations must be carried out within proper radioactive containment inside the portable - unit trailer.

\subsubsection{External Transfer Shipments}

External transfer shipments of aqueous liquid and slurry waste streams from other Portable Treatment Units (See Table 13) will be received either batchwise in containers or by pipeline similar to that described for primary waste streams. These streams will have similar physical handling characteristics as the primary liquid and slurry waste streams.

The liquid and solid streams that leave the Wastewater Portable Treatment Unit include: 1) water for reuse/recycle or discharge, and 2) concentrated salt sludge for transfer to the Homogeneous Solids line in the Organics Portable Treatment Unit. The sludge (Item 2 above) will likely be too concentrated to be pumpable and will be loaded into $0.208 \mathrm{~m}^{3}$ ( 55 gal) drums. Therefore, this material may need to be temporarily stored in a staging area prior to transfer to the Organics Portable Unit. These drums would be removed on pallets by forklift truck to the facility's shipping area.

\subsubsection{Utilities}

Electrical power. from the facilities grid shall be provided in sufficient quantity to operate the Wastewater Portable Treatment Unit's auxiliary equipment, controls, lighting, alarm systems, etc.; under normal operating conditions. Backup electrical power and an uninterruptible power supply (UPS) are required; the unit shall be designed to power down in a fail-safe condition in the event of loss of line power.

Other utilities to be provided by the site include plant water for cooling in the condenser of the Hydrothermal Process as well as the Condenser downstream of the Evaporator. This water shall be provided in sufficient quantity to support the Unit's operations during normal and emergency conditions. Air for oxidation in the Hydrothermal Process will be provided from the atmosphere and will be compressed prior to injection into the high pressure Hydrothermal 
Process reactor. Other utilities, including oxidants, reductants, acids, and base reageris, shall be delivered by separate vehicles to the Portable Treatment Unit processing location.

\section{REFERENCES}

1. Musgrave, B. C., "Waste Stream Analyses for Portable Treatment Systems Study", June 14, 1996.

2. Heubner, T. L, J. M. Wilson, A. H. Ruhter, and S. J. Bonney, "Quantities and Characteristics of the Contact-Handled Low-Level Mixed Waste Streams for the DOE Complex", EGG-MS11303, Idaho National Engineering Laboratory, August, 1993.

3. Perry's Chemical Engineer's Handbook, 6th Ed., Robert H. Perry and Don Green, Ed., McGraw-Hill, New York, 1984.

4. Proposed Site Treatment Plan (PSTP) Waste Stream Database, 1995.

5. Connor, Jesse, Chemical Fixation and Solidification of Hazardous Wastes, Van Nostrand Reinhold, New York, 1990.

6. "Mixed Waste Treatment Program Waste Treatment Technologies Plan and Technical Summary", US DOE Grand Junction Projects Office, P-GJPO-1926, August 31, 1995. 


\section{Appendix C}

\section{Design Summary and Planning Life-Cycle Cost Report}




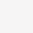$$
\text { ..., }
$$$$
=
$$ 


\title{
Mixed Low-Level Wastes Portable Treatment Systems Study
}

\author{
First Interim Draft
}

\author{
Prepared by \\ C. Biagi \\ Morrison Knudsen Corporation
}

October 1996

Idaho National Engineering Laboratory Lockheed Martin Idaho Technologies Company Idaho Falls, Idaho $\mathbf{8 3 4 1 5}$

Prepared for the U.S. Department of Energy Idaho Operations Office Under DOE Idaho Field Office Contract No. DE-AC07-94ID13223 


\section{Table of Contents}

Acronyms and Abbreviations $\ldots \ldots \ldots \ldots \ldots \ldots \ldots \ldots \ldots \ldots \ldots \ldots \ldots \ldots \ldots \ldots \ldots \ldots \ldots$

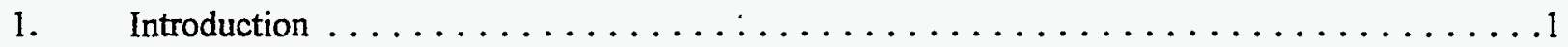

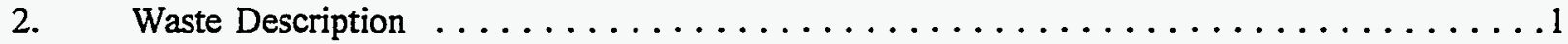

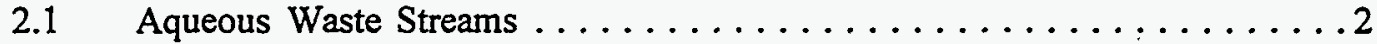

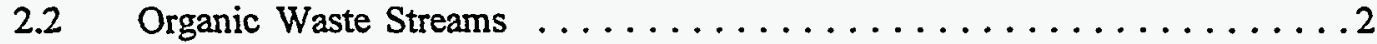

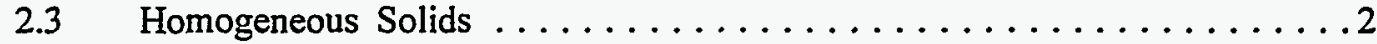

2.4 Debris Wastes . . . . . . . . . . . . . . . . . . .

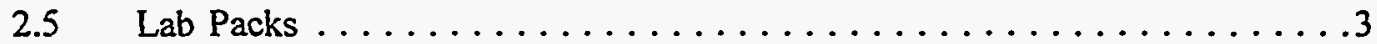

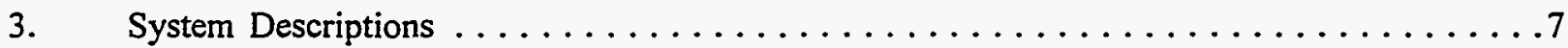

$3.1 \quad$ General . . . . . . . . . . . . . . . . . . . . . . .

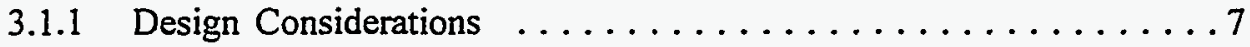

3.1.2 Mobile Treatment Unit Set Up Requirements $\ldots \ldots \ldots \ldots \ldots$. 8

3.1.3 Mobile Treatment Set $U p / D e m o b$ Operations $\ldots \ldots \ldots \ldots \ldots$

3.2 Wastewater MTU . . . . . . . . . . . . . . . . . . . . 9

3.2.1 Wastewater MTU Design Concept ................

3.3 Organics MTU . . . . . . . . . . . . . . . . . . 10

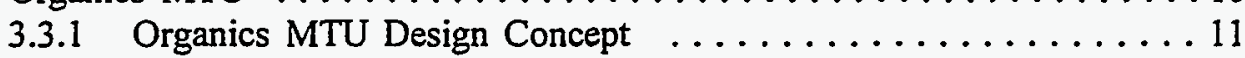

3.4 Debris MTU . . . . . . . . . . . . . . . . . . . . 12

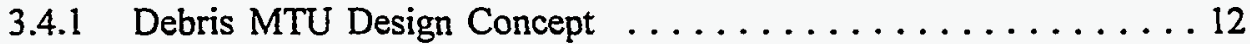

$3.5 \quad$ Labpack MTU . . . . . . . . . . . . . . . . . . . . . 13

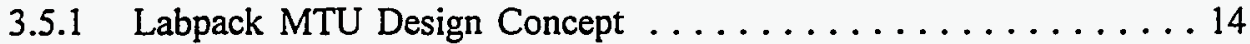

$3.6 \quad$ Centralized Facility . . . . . . . . . . . . . . . . . . 14

3.6.1 Centralized Facility Design Concept $\ldots \ldots \ldots \ldots \ldots \ldots$

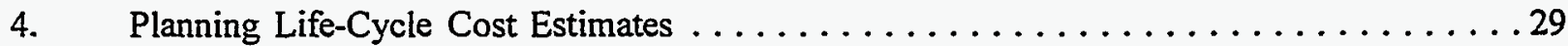

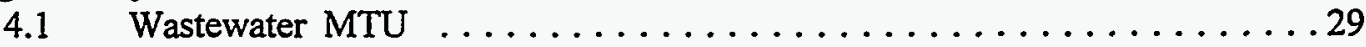

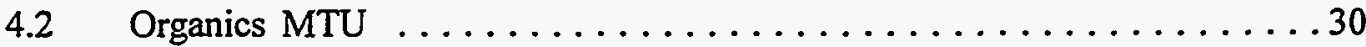

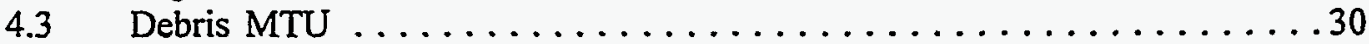

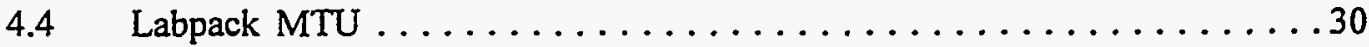

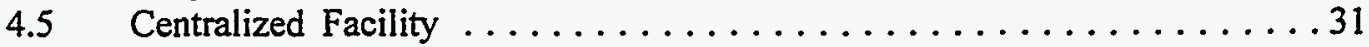

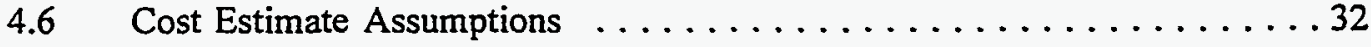

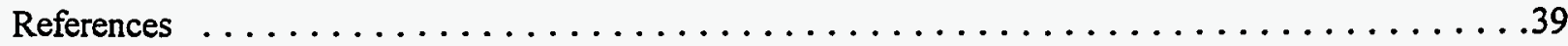

Appendix A $\quad$ Detailed Cost Tables $\ldots \ldots \ldots \ldots \ldots \ldots \ldots \ldots \ldots \ldots \ldots \ldots \ldots \ldots \ldots$ 


\section{Tables}

2-1. Waste Profile and Treatment Rates $\ldots \ldots \ldots \ldots \ldots \ldots \ldots \ldots \ldots \ldots \ldots \ldots$

4-1 PLCC for the Waste Water Mobile Treatment Unit . . . . . . . . . . . . . . . 33

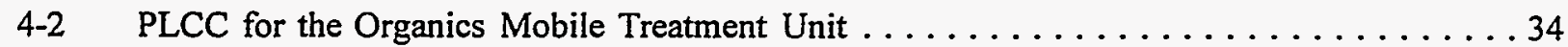

4-3 PLCC for the Debris Mobile Treatment Unit $\ldots \ldots \ldots \ldots \ldots \ldots \ldots \ldots \ldots \ldots$

4-4 PLCC for the Labpack Mobile Treatment Unit . . . . . . . . . . . . . . . . . . 36

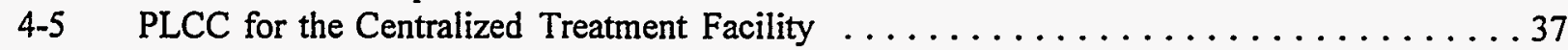

4-6 PLCC Cost and Unit Rate Treatment Cost Comparison . . . . . . . . . . . . 38

\section{Figures}

3-1.1 Waste Water MTU Process Flow Diagram ..................... 16

3-1.2 Waste Water MTU Conceptual Layout . . . . . . . . . . . . . . . . . . . . . 17

3-1.3 Typical Control Trailer for MTUs . . . . . . . . . . . . . . . . . . . . . . . . 19

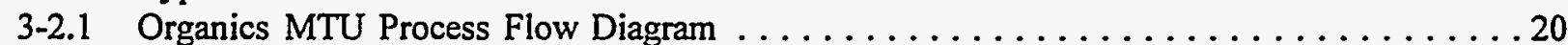

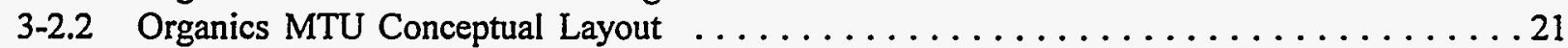

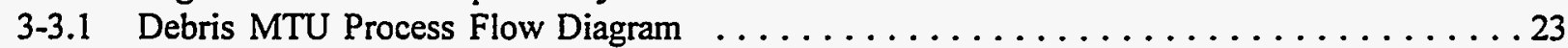

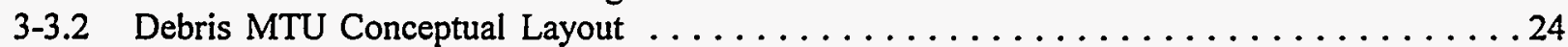

3-4.1 Lab Pack MTU Process Flow Diagram . . . . . . . . . . . . . . . . . . 25

3-4.2 Lab Pack Conceptual Layout . . . . . . . . . . . . . . . . . . . . . 26

3-5.1 Centralized Facility Process Flow Diagram $\ldots \ldots \ldots \ldots \ldots \ldots \ldots \ldots \ldots \ldots \ldots$

3-5.2 Centralized Facility Conceptual Layout $\ldots \ldots \ldots \ldots \ldots \ldots \ldots \ldots \ldots \ldots \ldots \ldots \ldots \ldots \ldots$ 


\section{Acronyms and Abbreviations}

$\begin{array}{ll}\text { APC } & \text { air pollution control } \\ \text { DOE } & \text { U.S. Department of Energy } \\ \text { F\&OR } & \text { functional and operational requirements } \\ \text { FTE } & \text { full-time equivalent } \\ \text { gpm } & \text { gallons per minute } \\ \text { HEPA } & \text { high-efficiency particulate air (filter) } \\ \text { INEL } & \text { Idaho National Engineering Laboratory } \\ \text { INTS } & \text { integrated nonthermal treatment system } \\ \text { ITTS } & \text { integrated thermal treatrient system } \\ \text { Kg/M } & \text { kilograms per cubic meter } \\ \text { Lbs/hr } & \text { pounds per hour } \\ \text { M } & \text { cubic meters } \\ \text { MLLW } & \text { mixed low-level (radioactive) waste } \\ \text { MPC } & \text { material process code } \\ \text { MTU } & \text { mobile treatment unit } \\ \text { O\&M } & \text { operations and maintenance } \\ \text { PFD } & \text { process flow diagram } \\ \text { PLCC } & \text { planning life cycle cost } \\ \text { psi } & \text { pounds per inch } \\ \text { R\&D } & \text { research and development } \\ \text { RCRA } & \text { Resource Conservation and Recovery Act } \\ \text { SCM } & \text { System Cost Model } \\ \text { TCLP } & \text { Toxicity Characteristic Leaching Procedure } \\ \text { TDS } & \text { total dissolved solids } \\ \text { TOC } & \text { total organic carbon } \\ \text { WBS } & \text { work breakdown structure } \\ { }^{\circ} & \text { degree } \\ { }^{\circ} \mathrm{C} & \text { degree Centigrade } \\ { }^{\circ} \mathrm{F} & \text { degree Fahrenheit } \\ { }^{\circ} \mathrm{K} & \text { degree Kelvin } \\ & \\ & \end{array}$




\section{INTRODUCTION}

The purpose of the Mixed Low-Level Wastes Portable Treatment Systems study is to evaluate the use of transportable treatment modules that can be moved to the smaller Department of Energy (DOE) sites for the purpose of treating small quantities of mixed low-level waste on site. Four different mobile treatment units (MTU) have been evaluated. For each MTU, documents were generated which include process flow diagrams (PFDs), layouts, system characteristics such as throughput and annual operating hours, and life-cycle cost estimates. Additionally, a single fixed system located at a generic central site, and having the same capabilities as the MTUs, was developed to serve as a comparison base for the four MTUs. This fixed site is referred to as the Centralized Facility.

This report is divided into four sections and an appendix. Section 1 is the Introduction. Section 2 presents the type and quantity of wastes expected to be treated by the MTUs. Section 3 gives the system descriptions. Section 4 presents the life-cycle cost for the four MTU systems as well as the centralized facility used for comparison. The appendix presents the supporting cost information summarized in Section 4.

\section{WASTE DESCRIPTION}

The waste that was selected for treatment in this study was derived by Mr. Don Musgrave after reviewing the types and quantities of waste that exist at the smaller sites, notably those sites which are part of the DOE Albuquerque District Office. The selected waste was assumed to be nonalpha mixed low-level waste, thus not requiring the type of containment system necessary for handling alpha contaminated wastes. The total waste upon which this study is based is presented in Table 2-1. The treatment rates are based upon processing the annual volume of wastes during over a 40 hour per week, 20 week annual period, or 800 operating hours per year. The total inventory of waste would be treated during a five year period. Stream densities, used to convert volumes to mass, are consistent with the density information used in the System Cost Model (SCM). 


\subsection{Aqueous Waste Streams}

Two streams make up this category; waste waters (1100) and aqueous slurries(1200). One third of both streams are "tagged" with organics, including halogenated organics, at $1 / 3$ of the total regulated organic content $(<1 \%)$. All wastes are assumed to contain dissolved regulated inorganic constituents.

\subsection{Organic Waste Streams}

Organic Waste has been categorized into two streams; aqueous/organic liquids (2100) and pure organic liquids (2200). Ten percent of the both organic waste streams are regulated for metals content only, having organics which are non-RCRA organics. The remaining $90 \%$ of both streams contain regulated organics. The aqueous/organics liquid stream is assumed to contain $50,000 \mathrm{ppm}$ of organics. The pure organics stream is assumed to be $100 \%$ organic.

\subsection{Homogeneous Solids}

Homogeneous Solid waste has been categorized into two streams; contaminated inorganic residue (3100) and organic homogeneous solids (3200). The inorganic homogeneous solids stream has both organic-contaminated and non-organic component fractions. The organic-contaminated component was assumed to have organic concentrations of $42,000 \mathrm{ppm}$. The organic homogeneous solids stream was assumed to have an organic concentration of $75,000 \mathrm{ppm}$.

\subsection{Debris Wastes}

The debris waste has been divided into three categories; inorganic debris (5100), which has an organic-free fraction and an organic-contaminated fraction, combustible debris (5300) which also has an organic-free and an organic contaminated fraction and, heterogeneous debris (5400) having an organic-free and an organic-contaminated fraction. The organic-contaminated component of each of these streams was assumed to have organic concentrations of $20,000 \mathrm{ppm}$. 


\subsection{Lab Packs}

The lab pack stream has five categories; organic lab packs (6100), aqueous lab packs (6200), solid lab packs (6300), scintillation cocktails (6400) and undefined lab packs (6900). Organic lab packs (6100) was assumed to be $30 \%$ by weight organics. Aqueous lab packs (6200) was assumed to have an organic concentration of $10,000 \mathrm{ppm}$. Solid lab packs (6300) were assumed to have no organic component. The scintillation cocktail stream (6400) was assumed to have an organic component concentration of $100,000 \mathrm{ppm}$. The undefined lab pack stream (6900) was assumed to have an organic concentration of $20,000 \mathrm{ppm}$. 
Table 2-1:

Waste Profile and Treatment Rates

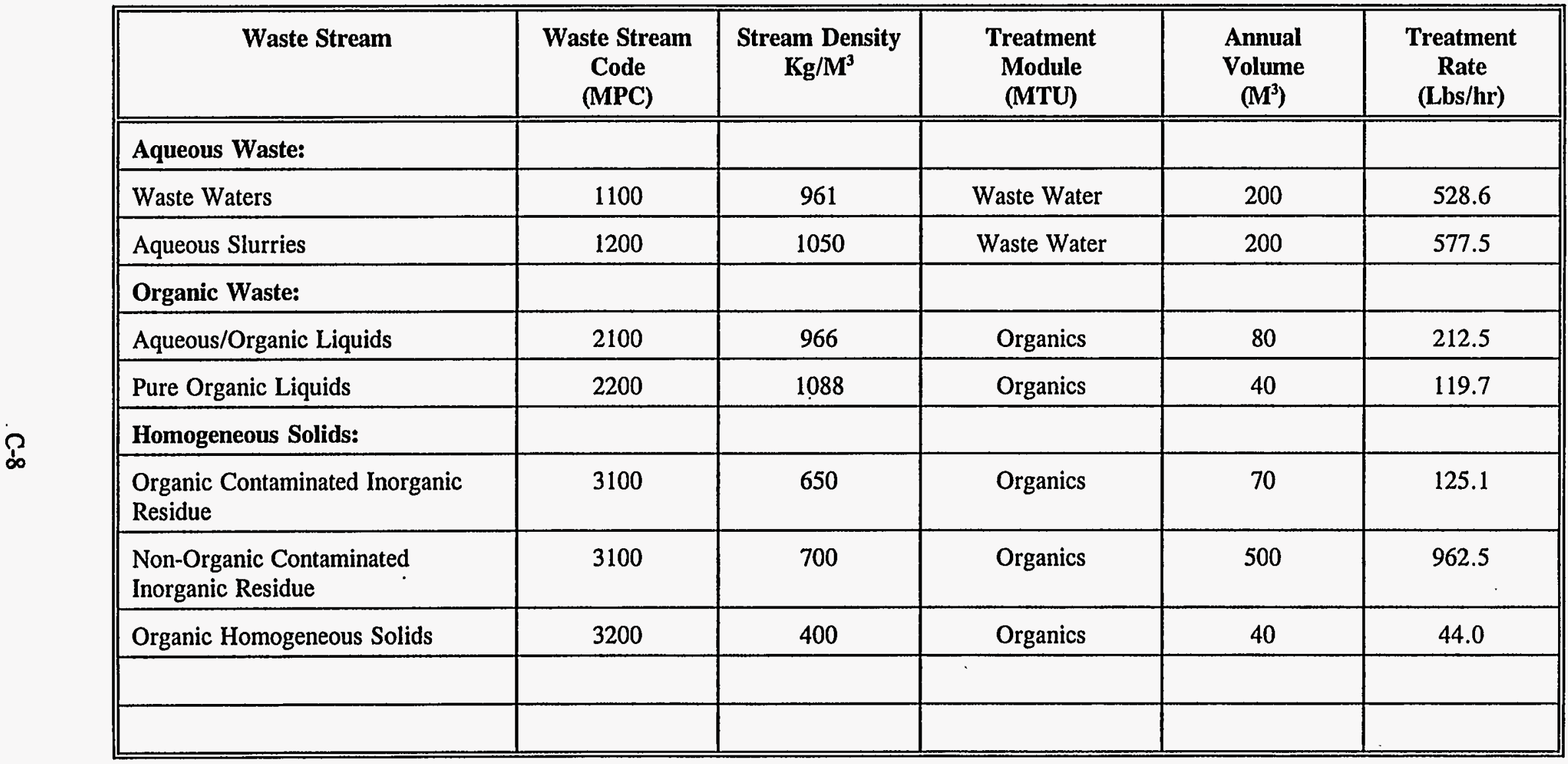


Table 2-1:

Waste Profile and Treatment Rates (Continued)

\begin{tabular}{|c|c|c|c|c|c|}
\hline Waste Stream & $\begin{array}{c}\text { Waste Stream } \\
\text { Code } \\
\text { (MPC) }\end{array}$ & $\begin{array}{l}\text { Stream Density } \\
\mathbf{K g} / \mathbf{M}^{3}\end{array}$ & $\begin{array}{c}\text { Treatment } \\
\text { Module } \\
\text { (MTU) } \\
\end{array}$ & $\begin{array}{c}\text { Annual } \\
\text { Volume } \\
\left(\mathrm{M}^{3}\right)\end{array}$ & $\begin{array}{c}\text { Treatment } \\
\text { Rate } \\
\text { (Lbs/hr) }\end{array}$ \\
\hline \multicolumn{6}{|l|}{ Debris Wastes: } \\
\hline $\begin{array}{l}\text { Inorganic Debris Contaminated with } \\
\text { Organic }\end{array}$ & 5100 & 509 & Debris & 10 & 14.0 \\
\hline Combustible Debris - Organic Free & 5300 & 320 & Debris & 45 & 39.6 \\
\hline $\begin{array}{l}\text { Heterogeneous Debris } \\
\text { Contaminated with Organic }\end{array}$ & 5400 & 400 & Debris & 65 & 71.5 \\
\hline
\end{tabular}


Table 2-1:

Waste Profile and Treatment Rates (Continued)

\begin{tabular}{||l|c|c|c|c|c||}
\hline \multicolumn{1}{|c|}{ Waste Stream } & $\begin{array}{c}\text { Waste Stream } \\
\text { Code } \\
\text { (MPC) }\end{array}$ & $\begin{array}{c}\text { Stream Density } \\
\mathbf{K g} / \mathbf{M}^{3}\end{array}$ & $\begin{array}{c}\text { Treatment } \\
\text { Module } \\
\text { (MTU) }\end{array}$ & $\begin{array}{c}\text { Annual } \\
\text { Volume } \\
\left(\mathbf{M}^{3}\right)\end{array}$ & $\begin{array}{c}\text { Treatment } \\
\text { Rate } \\
(\mathbf{L b s} / \mathbf{h r})\end{array}$ \\
\hline \hline Lab Packs: & & & & & \\
\hline Organic Lab Packs & 6100 & 450 & Labpack & 5 & 6.2 \\
\hline Aqueous Lab Packs & 6200 & 450 & Labpack & 10 & 12.4 \\
\hline Solids Lab Packs & 6300 & 450 & Labpack & 5 & 6.2 \\
\hline Scintillation Cocktails & 6400 & 450 & Labpack & 15 & 18.6 \\
\hline Undefined Lab Packs & 6900 & 450 & Labpack & 45 & 55.6 \\
\hline \hline
\end{tabular}

$\stackrel{?}{0}$ 


\section{SYSTEM DESCRIPTIONS}

Four mobile treatment units were conceptualized to treat the wastes stream presented above. The four treatment units were the Wastewater MTU, Organics MTU, Debris MTU and Labpack MTU. The technologies upon which these MTUs are based include currently available and proven technologies such as neutralization, precipitation, filtration, evaporation, gas scrubbing, ion exchange and granular activated carbon adsorption, and technologies such as the hydrothermal process or thermal oxidation which are currently undergoing development.

\subsection{General}

Each MTU is designed to handle the annual waste volume applicable for that MTU during a single annual campaign operating for 800 hours (20 weeks). In addition, the MTU will require set up time prior to the start of treatment and decontamination/demobilization time following treatment and prior to leaving the treatment site.

\subsubsection{Design Considerations}

The design for the MTUs centers around the concept of having processing units mounted on trailers. Multi-trailer configurations would be necessary to provide all the processing units required for treatment. These processing units would be monitored and controlled by the use of a stand-alone control trailer functioning as a control center. The use of trailer mounted units allows for quick set up by utilizing flexible piping between trailers and controls through the control trailer that can integrate the trailers into a single processing facility. Once treatment and decontamination has been completed the trailers can be quickly demobilized and transported off the site. Trailers have the advantage over skid-mounted units by having a quicker set up time, since skid-mounted units would require the use of cranes to remove the skids from their transport vehicles and position them in the proper pattern. Additionally, interconnection of each skid would require a longer set up time. 


\subsubsection{Mobile Treatment Unit Set Up Requirements}

It is expected that any host site requiring a MTU will provide a location within the site for MTU set up. This location would typically be a curbed concrete pad and, as a minimum, sheltered by a roof structure. For those sites located in areas where climatic conditions tend to be severe during treatment periods, additional weather proofing may be necessary.

The MTU set up location would need to be supplied with utility services such as potable water, service water, and electrical power. An effluent discharge tie-in point will also be necessary. In addition the site would need deliver the waste to the treatment location for processing and to provide security, fire protection support, and certification and shipping support of treated and stabilized or repacked waste.

\subsubsection{Mobile Treatment Unit Set Up/Demob Operations}

Each MTU would arrive at the host site with a dedicated crew capable of transporting the MTU, maintaining the MTU equipment both during campaign and non-campaign periods, setting up the MTU, preparing the received waste for treatment, treatment of the waste, stabilization of the residues and packaging of the stabilized residues for certification and shipment to a disposal site. It was assumed that the certification and shipping function would be provided by the host site. The MTU will have the capability to handle drummed wastes. Wastes that arrive in boxes will require sorting prior to treatment. Stabilized wastes will be placed in drums and the drums would be surface cleaned and placed in a location for removal to the certification and shipping area and subsequent disposal.

Upon completion of the waste treatment the crew would decontaminate the MTU and demobilize from the site. Decontamination will require extensive flushing and wipe down activities to remove all traces of toxic and radioactive chemicals and allow the MTU to meet Department of Transportation regulations for transport to a central storage yard or the next treatment site. It probably will be necessary for the Wastewater MTU to be at a site during decontamination and demobilization of the other MTUs, so as to allow the flush waters generated during decontamination to be treated. Flush waters generated during the decontamination of the Wastewater MTU could be treated on board the Wastewater MTU, except for the final flush batch. This final flush quantity of water would be essentially clean and could be transported to a commercial treatment facility for final 
treatment.

The operating personnel for the any of the MTUs would be a crew trained in the operation of the processing units, and have the additional training to maintain the equipment and control hardware. The crew would perform as an independent work force somewhat similar to that of a subcontractor but would coordinate their activities with the host site operating personnel.

\subsection{Wastewater MTU}

It was assumed that waste water streams processed through this MTU would contain acids, bases, water-reactive chemicals and waters having low concentrations of organics. The unit was conceptually designed to have the flexibility to treat a variety of waste streams containing any of the above components.

This MTU was designed to have the following unit operations:

- A redox tank in which oxidants and/or reactants would be added on a batch basis.

- A neutralization tank for the treatment of acids and bases or the precipitation of heavy metals.

- A particulate filter to remove suspended solids.

- A hydrothermal process unit to treat waste waters having low concentrations of organics; offgas from the hydrothermal unit would be heated above its dew point by a reheater and filtered through a HEPA filter.

- The aqueous liquid from the hydrothermal unit would be processed through a reverse osmosis unit; the clear water would pass through an ion exchanger prior to recycle or discharge. That portion of the aqueous liquid stream having the concentrated salts, would be processed through an evaporator with the salt sludge going to the Organics MTU for stabilization and the recovered water vapor condensed and recycled or discharged.

The Wastewater MTU will require the use of the Organic MTU operating concurrently for at least a portion of the operating period.

\subsubsection{Wastewater MTU Design Concept}


The Wastewater MTU was designed to handle non-alpha aqueous wastes could have organic concentrations up to $10,000 \mathrm{ppm}(1 \%)$. It was assumed that the waste would be received at the MTU in 55-gallon drums. The drums would be inspected and their contents would be pumped to a batch hold tank where any pretreatment or suspended solids removal would occur. From the batch tank the aqueous liquid would be transferred to the appropriate unit operation, such as, the redox/neutralizer or the hydrothermal unit for further processing. By these types of unit operations the inorganic toxic chemicals are either precipitated or changed so that further processing can easily remove them from solution, and the organic components are destroyed. The water undergoes further processing, such as, evaporation, reverse osmosis, carbon adsorption and ion exchange to remove dissolved components. The clean water is collected for sampling and testing prior to recycle or release. Solid residues are either transported to the Organics MTU, if on site, or repackaged for treatment by. the Organics MTU at later date.

The Wastewater MTU has all the mechanical and electrical hardware necessary to allow it to function as a complete treatment facility with the exception of certification and shipping capabilities. It is assumed that function will be provided by the host site.

Figure 3-1.1 presents the process flow diagram and Figure 3-1.2 presents a conceptual layout of the transportable Wastewater MTU. The layout of a typical control trailer is presented in Figure 3-1.3.

\subsection{Organics MTU}

This MTU has the flexibility to destroy organic compounds, volatilize organics from sludges or solids, treat the generated offgas and stabilize sludges and solids following organic removal.

The following unit operations were conceptualize for the MTU:

- Solids from filtration, soils and organic sludges would be treated in a thermal desorber. The solids/soils/sludges would be indirectly heated while under vacuum to volatilize the organic component. The organics and any water removed during desorption would be condensed. The organic would be physically separated from the water and further treated. Water having low concentrations of organic would be 
treated by the Wastewater MTU.

- Offgas from the desorber is condensed and combined with the offgas from the thermal oxidizer prior to final gas treatment.

- Organic liquids would be treated by thermal oxidation at $900^{\circ} \mathrm{C}\left(1652^{\circ} \mathrm{F}\right)$.

- Offgas from the thermal oxidizer is cooled in a quencher and acid gases removed by absorption in a scrubber. The scrubbed offgas is heated in a reheater and passed through a HEPA filter and granular activated carbon prior to discharge to the atmosphere.

- Dry solids from the thermal desorber, inorganic sludges and solids from the Labpack MTU are stabilized by a suitable matrix consisting of either grout or polymer. The stabilized solids are drummed and packed for disposal.

The Organics MTU will require the use of the Wastewater MTU operating concurrently for at least a portion of the operating period.

\subsubsection{Organics MTU Design Concept}

The Organics MTU was designed to handle non-alpha wastes including aqueous wastes which may have an organic concentration over $1 \%(10,000 \mathrm{ppm})$ and up to $100 \%$. It was assumed that the waste would be received at the MTU in 55-gallon drums. The drums would be inspected and the contents of any high organic aqueous wastes would be pumped to an organic/water separator where the organic phase can be removed from the aqueous component. The organic portion from this separation would be combined in the organics hold tank with any pure orgaincs received. The aqueous component from the separation would be transferred to a water hold tank and then to the Wastewater MTU for immediate treatment, or repackaged for later treatment by the Wastewater MTU. The organic component would be processed through the thermal oxidizer unit operating in an oxygen-rich atmosphere at an elevated temperature, to destroy the organics. The stream exiting the thermal oxidizer would be at a temperature of $900^{\circ} \mathrm{C}$. This stream would be quenched to reduce the temperature to near ambient, and then passed through a scrubbing and neutralization operation to remove all toxic particulates or gases.

Organic sludges, organic solids and debris contaminated with organics would be processed through the thermal desorber. Any organics removed as part of this operation would be combined 
with the pure organic stream described above. Inorganic residues from the organic destruction, inorganic sludges and solids from other operations would be stabilized in the drum encapsulation operation. These residues/solids would be placed into a drum and mixed with either a grout or polymer to stabilize them. The resulting stabilized residues/solids would be ready for certification and shipment by the host site.

Figure 3-2.1 presents the PFD and Figure 3-2.2 presents a conceptual layout of the transportable Organics MTU. The control trailer layout is presented Figure 3-1.3.

\subsection{Debris MTU}

Debris can consist of a wide variety of materials that result from construction, decommissioning and decontamination. These materials are could be radioactive and/or have slight concentrations of organic components.

The following unit operations were included in this MTU:

- Sorting operation that involves radioactive assay to determine for separation those wastes for separation that are not contaminated and can be repackaged for disposal at a Subtitle D Landfill.

- Contaminated materials are size-reduced by a shear/crush operation to allow materials to be fed to the thermal desorber with the Organic MTU.

The Debris MTU can be utilized without the other MTUs operating concurrently. The debris can be separated into fractions, which would be either transported directly to a disposal site, or repacked for later treatment by the Organics MTU.

\subsubsection{Debris MTU Design Concept}

The Debris MTU was designed to handle non-alpha organic-contaminated debris. The MTU would receive wastes in either boxes or 55-gallon drums. The container would be opened and the contents sorted into organic-contaminated or clean portions. The organic contaminated debris would be size reduced by a crushing/shearing operation and transferred to the thermal desorption unit associated with the Organics MTU or repackaged for later treatment by the Organics MTU. The 
clean debris would be repackaged for disposal at a subtitle $D$ landfill.

Figure 3-3.1 presents the PFD and Figures 3-3.2 presents a conceptual layout of the transportable Debris MTU. A typical control trailer layout is presented in Figure 3-1.3.

\subsection{Labpack MTU}

Lab packs, usually fabricated as fiber or plastic drums, are filled with adsorbent material that contain individually packaged chemical waste materials in a variety of container types. The operations involved in treating lab packs are mainly sorting and chemical deactivation.

The unit operations included in this MTU are as follows:

- Lab packs are received in a properly vented area where each lab pack is manually opened and sorted. The individual containers are removed and sorted into inorganic and organic fractions.

- The organic fraction is further separated into organic liquids and organic solids. The liquids are separated from their containers by crushing/shredding and screening. The liquids are sent to the thermal oxidation unit of the Organics MTU for further processing. The organic solids, including the shredded containers, are transferred to the thermal desorption unit operation of the Organics MTU.

- The liquid inorganic waste is separated from its container by crushing/shredding and screening and sent to a chemical deactivation unit operation included as part of this MTU. The residue from the deactivation is treated as inorganic sludge and separated into either an aqueous fraction, which is transferred to the Wastewater MTU, or a solids fraction, which is transferred to the stabilization operation on the Organics MTU.

- Some fraction of the materials sorted will require special processing determined only after sorting and further waste characterization.

- The packaging is sorted for possible recycle, sent to Debris MTU or repacked for disposal.

The Labpack MTU can be utilized without the other MTUs operating concurrently. The 


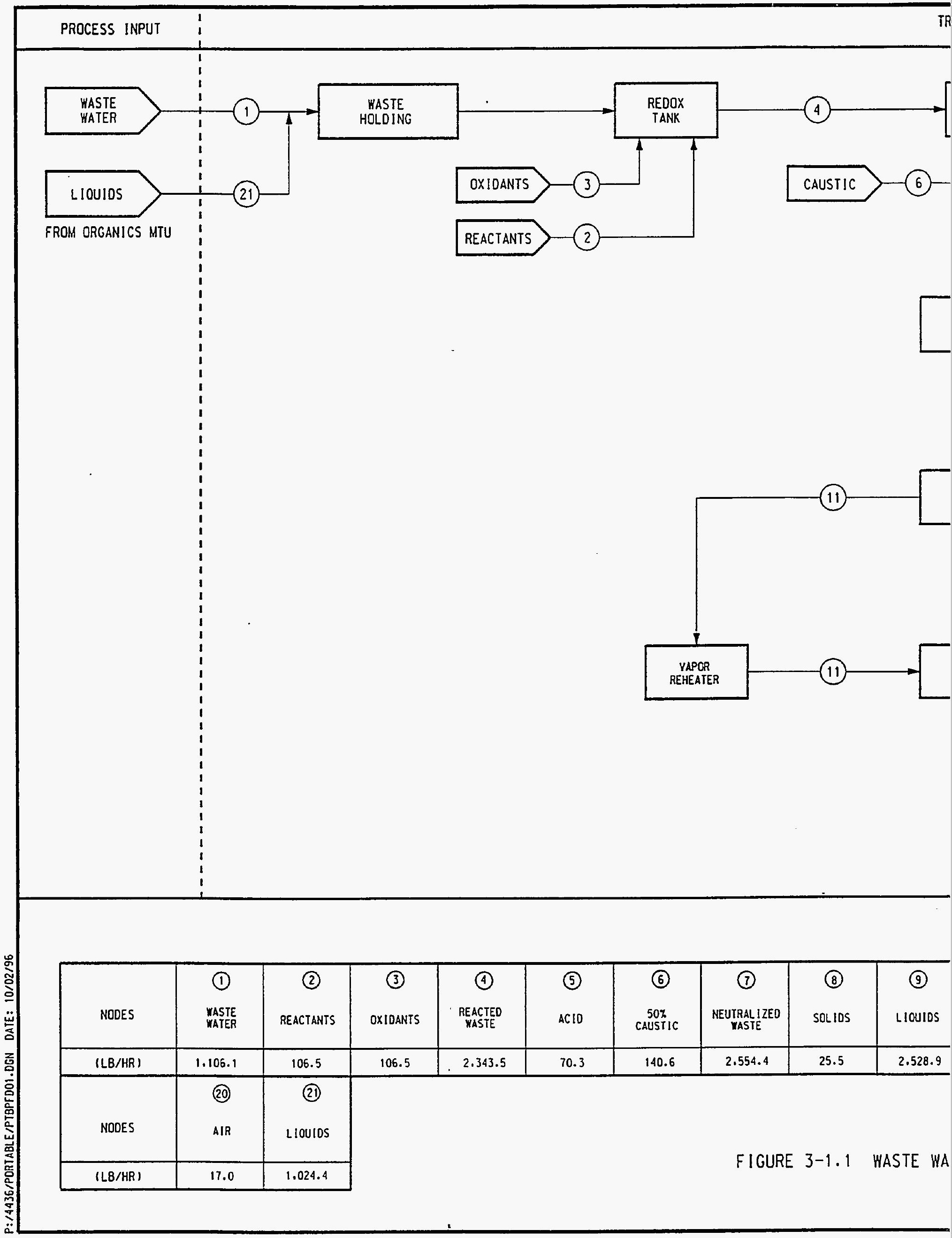




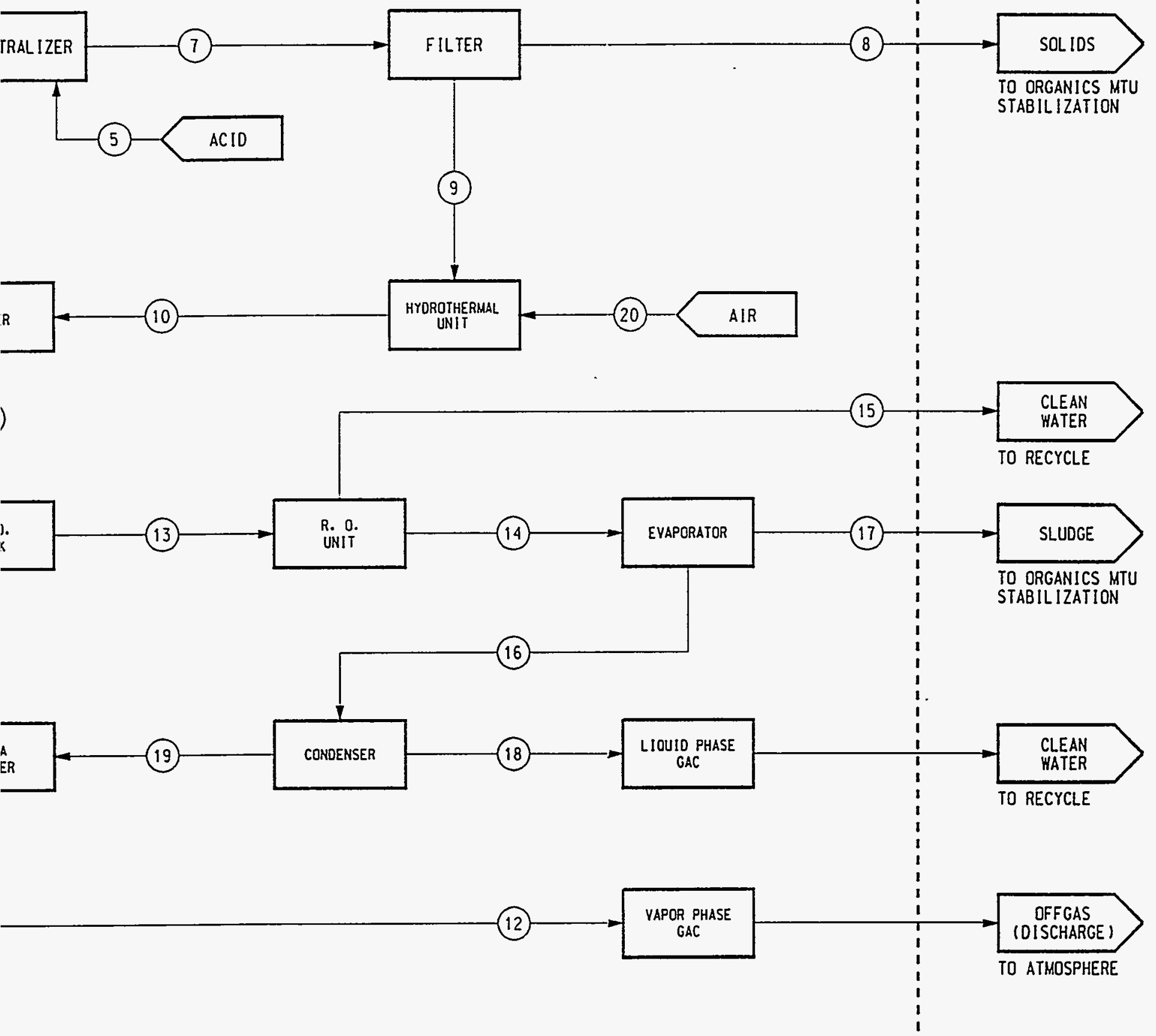

\begin{tabular}{|c|c|c|c|c|c|c|c|c|c|}
\hline $\begin{array}{c}\text { (10) } \\
\text { REACTED } \\
\text { LIOUIDS }\end{array}$ & VAPORS & $\begin{array}{c}\text { (11) } \\
\text { FILIERED } \\
\text { VAPORS }\end{array}$ & $\begin{array}{c}\text { (19) } \\
\text { CODLED } \\
\text { LIOUIDS }\end{array}$ & $\begin{array}{c}\text { (14) } \\
\text { CONCENTRATE }\end{array}$ & $\begin{array}{c}\text { (15) } \\
\text { WLEAN } \\
\text { WATER }\end{array}$ & $\begin{array}{c}\text { (16) } \\
\text { WATER } \\
\text { VAPOR }\end{array}$ & $\begin{array}{c}\text { (17) } \\
\text { SLUDGE }\end{array}$ & WATER & YAPORS \\
\hline 2.545 .9 & 16.9 & 17.3 & 2.529 .0 & 101.2 & 2.427 .8 & 75.9 & 25.3 & 24.9 & 0.4 \\
\hline
\end{tabular}


$\varepsilon \tau-\supset$

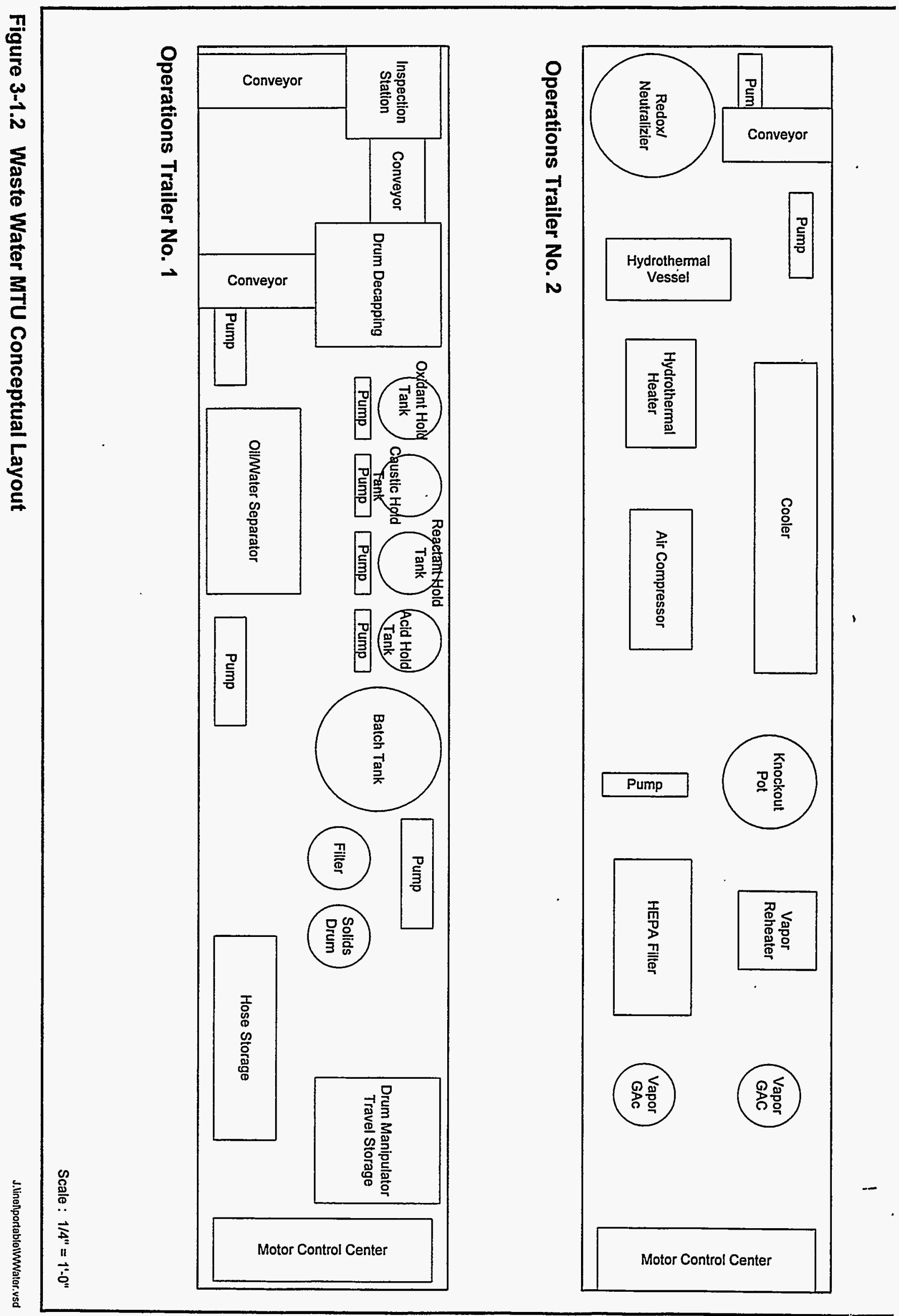




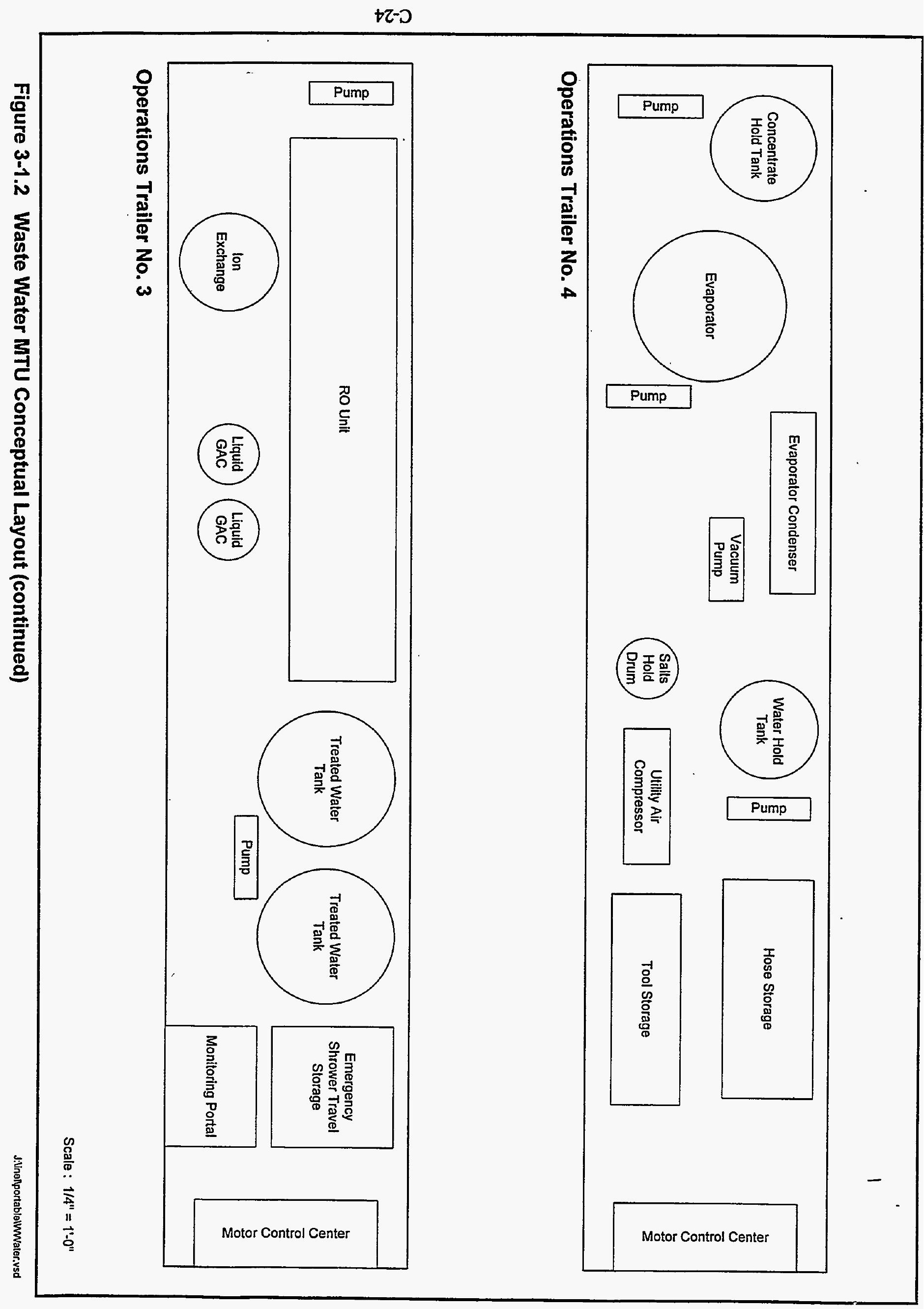




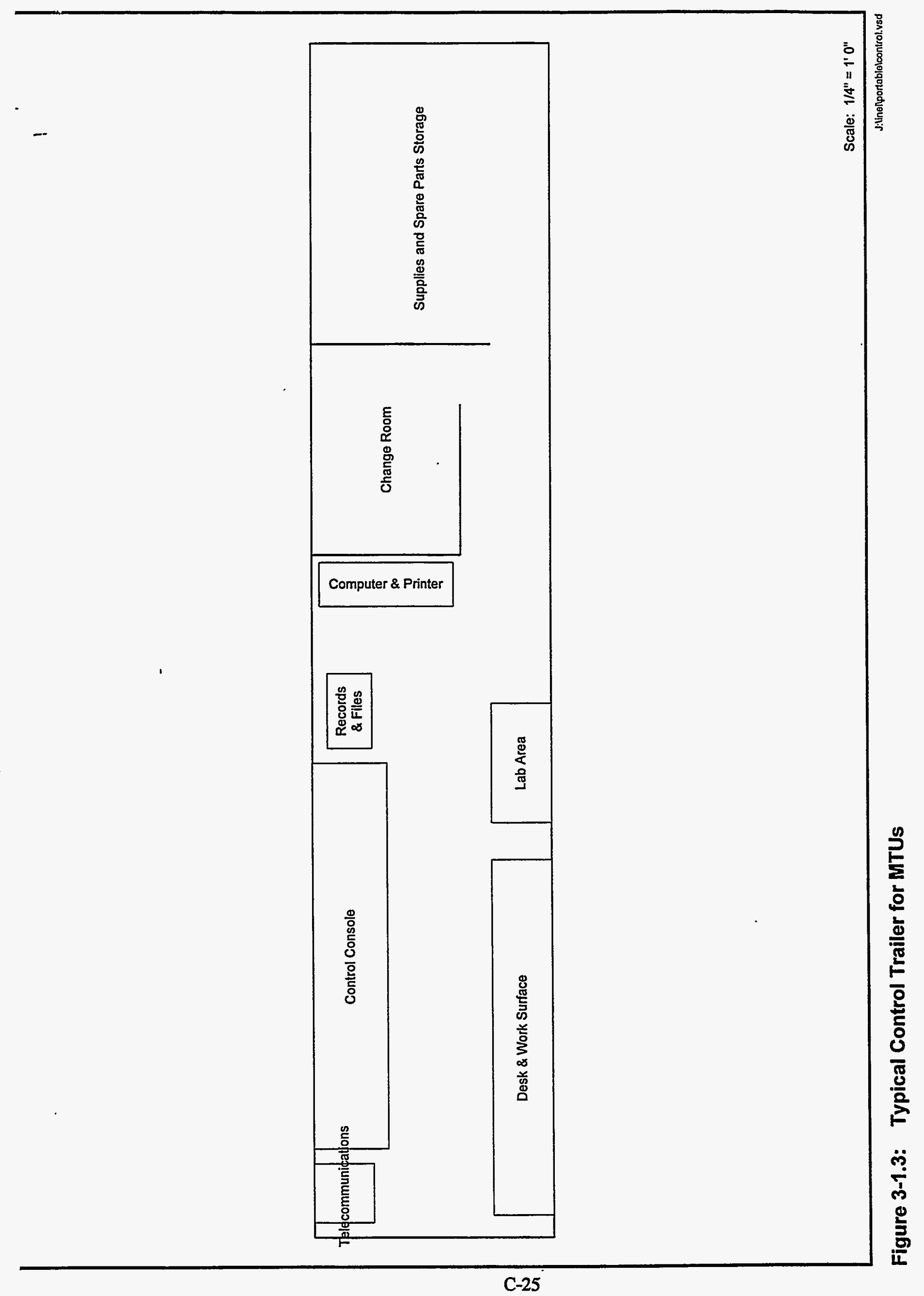




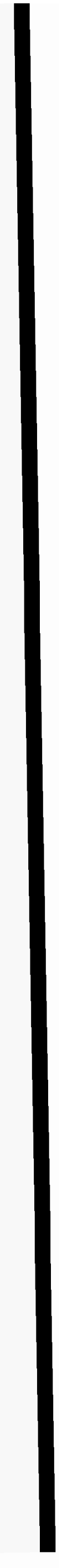




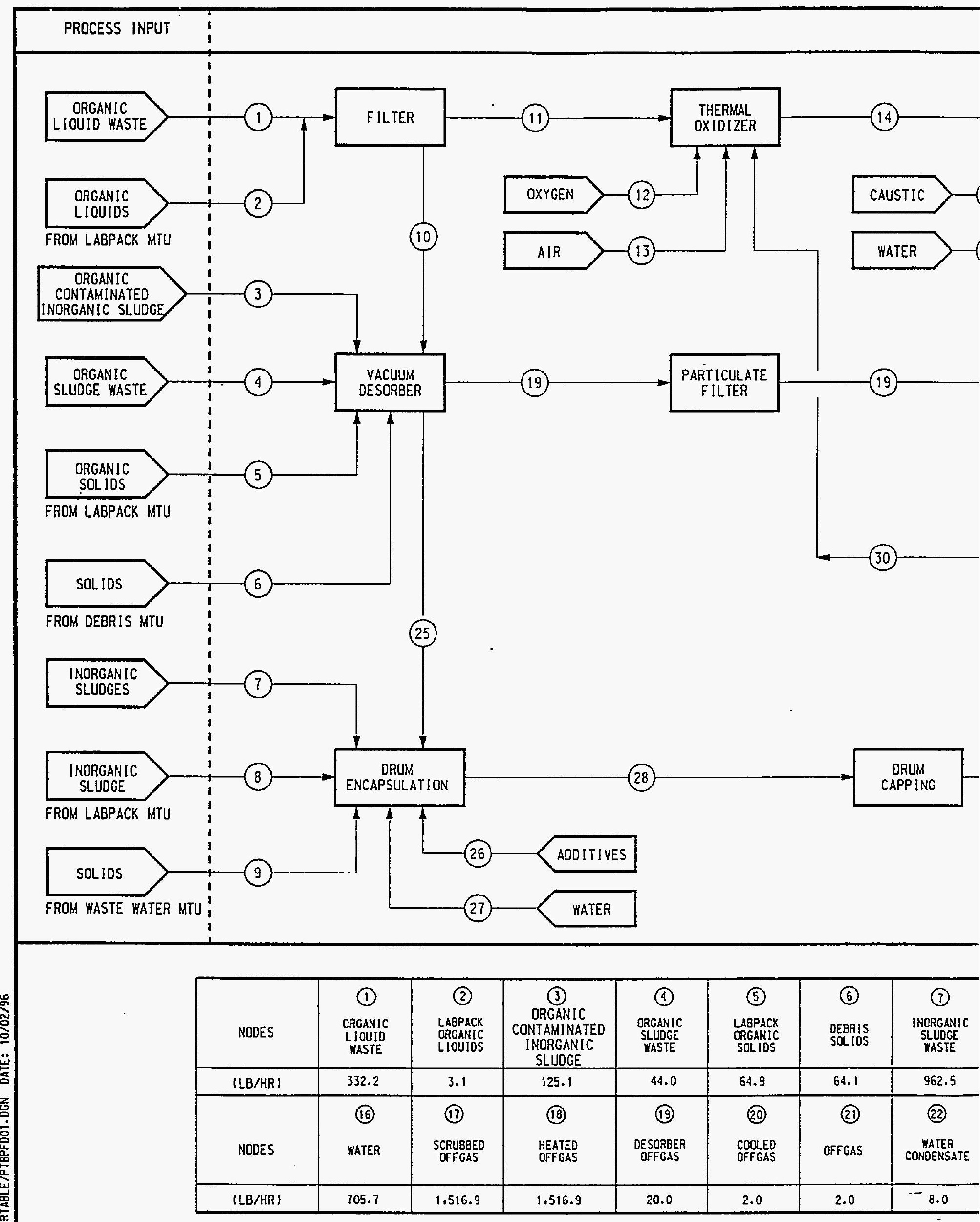

FIGURE $3-2.1$ ORGANIC 


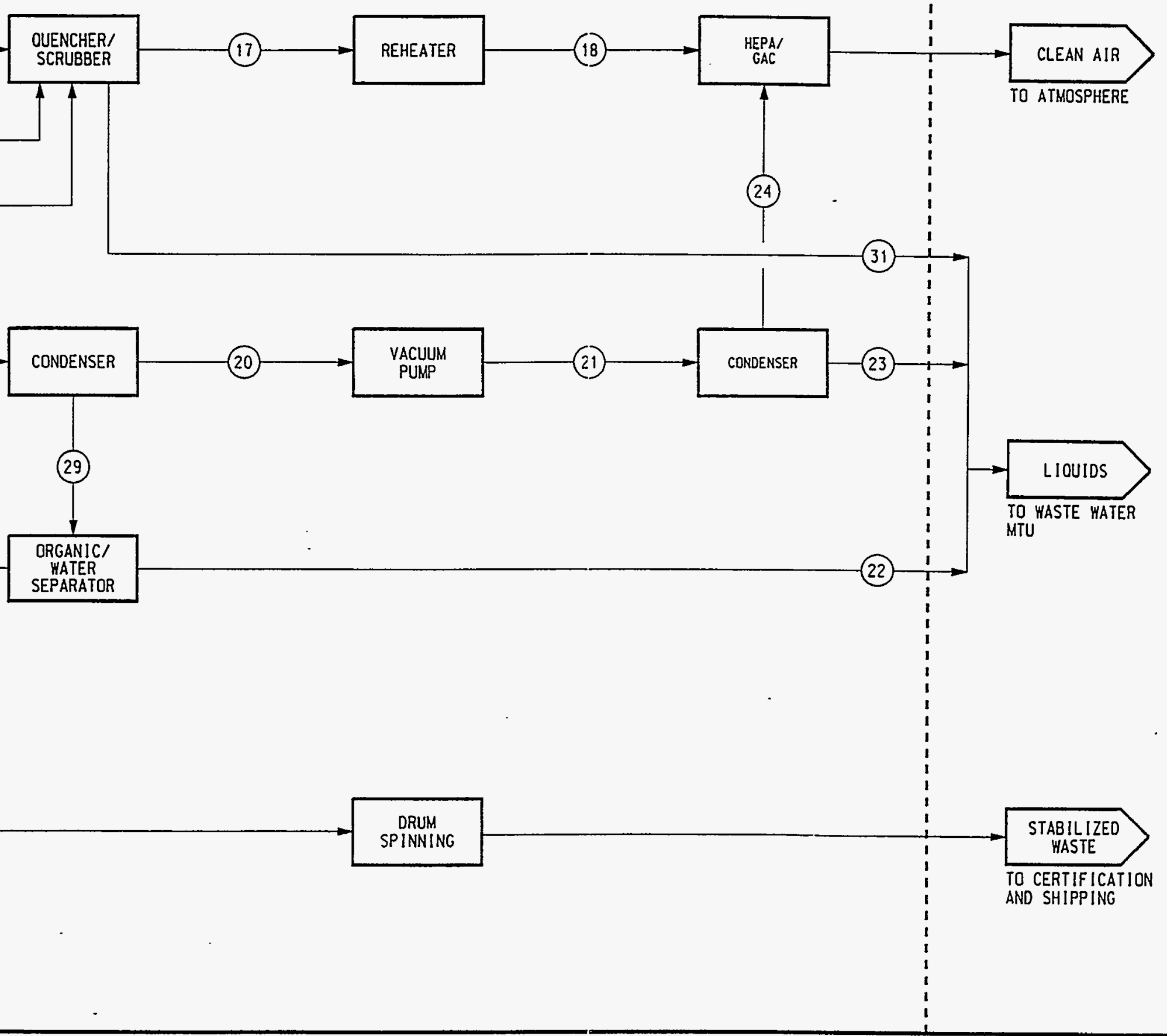

\begin{tabular}{|c|c|c|c|c|c|c|c|c|}
\hline $\begin{array}{l}\text { (B) } \\
\text { LABPACK } \\
\text { YORGANIC } \\
\text { SLUDGE }\end{array}$ & $\begin{array}{l}\text { (9) } \\
\text { MASTE } \\
\text { KAAER } \\
\text { SOL LOS }\end{array}$ & $\begin{array}{c}\text { (10) } \\
\text { FILTER } \\
\text { SOLIDS }\end{array}$ & $\begin{array}{c}\text { (111) } \\
\text { ORGANIC } \\
\text { LIOUIDS }\end{array}$ & $\begin{array}{c}\text { (12) } \\
\text { OXYGEN }\end{array}$ & $\begin{array}{l}\text { (12) } \\
\text { AIR }\end{array}$ & $\begin{array}{c}\text { (14) } \\
\text { REACTOR } \\
\text { OFFGAS }\end{array}$ & $\begin{array}{l}\text { (15) } \\
50 \% \\
\text { CAUSTIC }\end{array}$ & \\
\hline 20.5 & 50.8 & 29.4 & 305.9 & 250.0 & 1.190 .5 & 1.756 .4 & 70.2 & \\
\hline $\begin{array}{l}\text { (23) } \\
\text { NDENSATE }\end{array}$ & $\begin{array}{c}\text { (24) } \\
\text { NON- } \\
\text { CONOENSIBLES }\end{array}$ & $\begin{array}{l}\text { (25) } \\
\text { DESOREER } \\
\text { SOLIOS }\end{array}$ & $\begin{array}{l}\text { (26) } \\
\text { CENENT' } \\
\text { PQLYKER }\end{array}$ & YATER & $\begin{array}{l}28 . \\
\text { STABILIZED } \\
\text { WASTE }\end{array}$ & $\begin{array}{c}\text { (29) } \\
\text { CONDENSATE }\end{array}$ & $\begin{array}{c}\text { (30) } \\
\text { ORGANIC } \\
\text { CONDENSATE }\end{array}$ & $\begin{array}{c}\text { (31) } \\
\text { BLOWDOWN }\end{array}$ \\
\hline 1.0 & 1.0 & 307.5 & 2.095 .8 & 698.6 & 4.135 .7 & 18.0 & 10.0 & 1.015 .4 \\
\hline
\end{tabular}




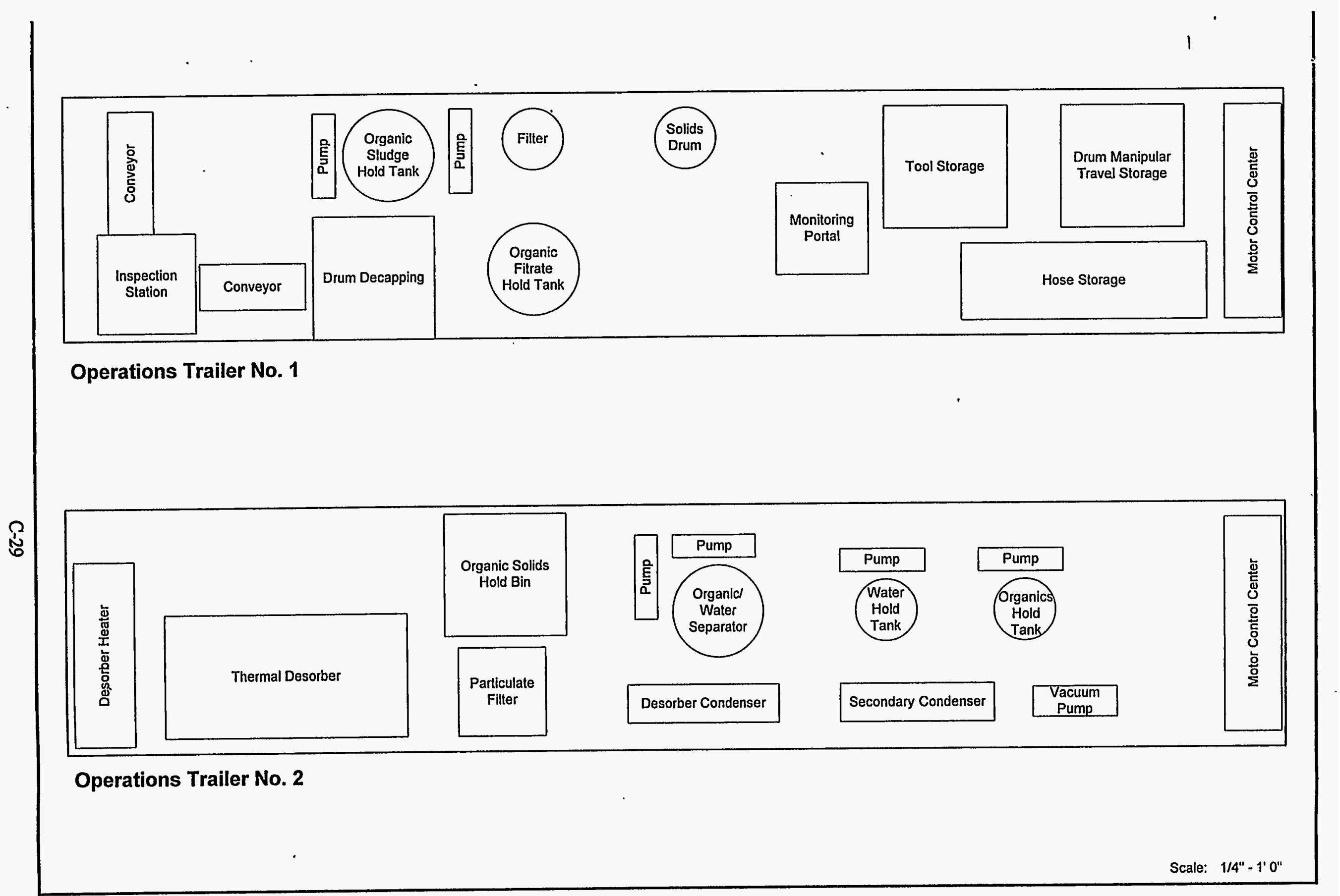




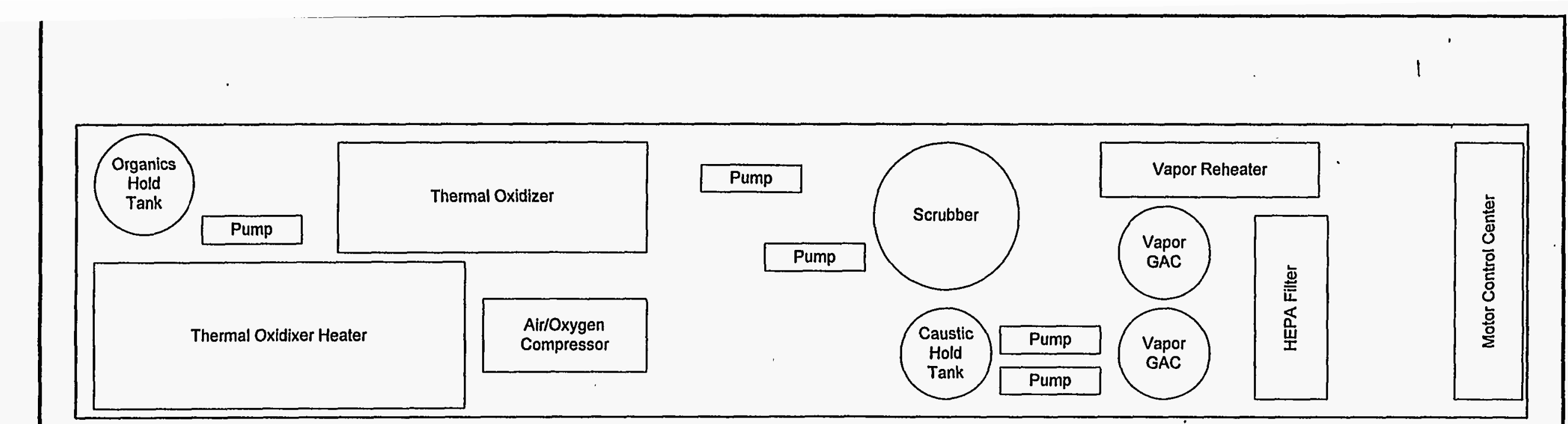

Operations Trailer No. 3
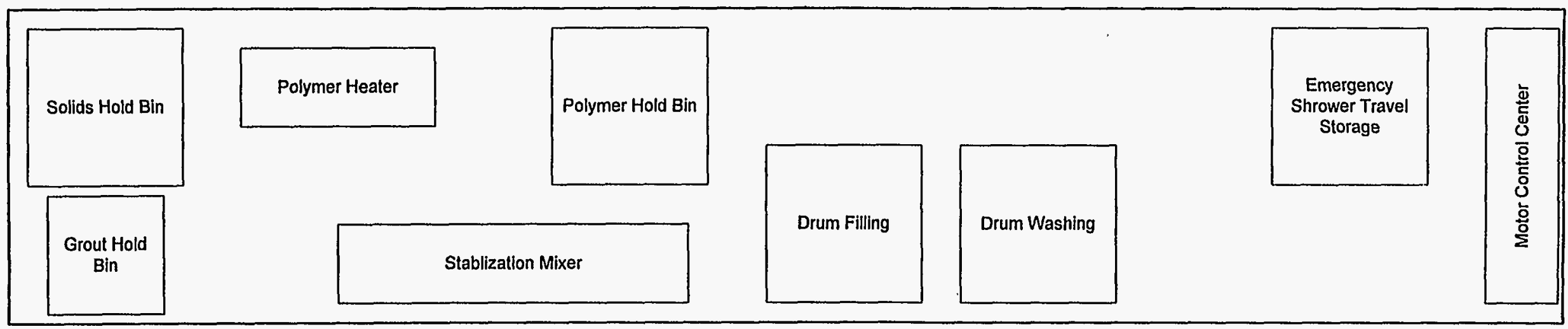

Operations Trailer No. 4

Scale: $1 / 4^{\prime \prime}-1^{\prime \prime} 0^{\prime \prime}$ 


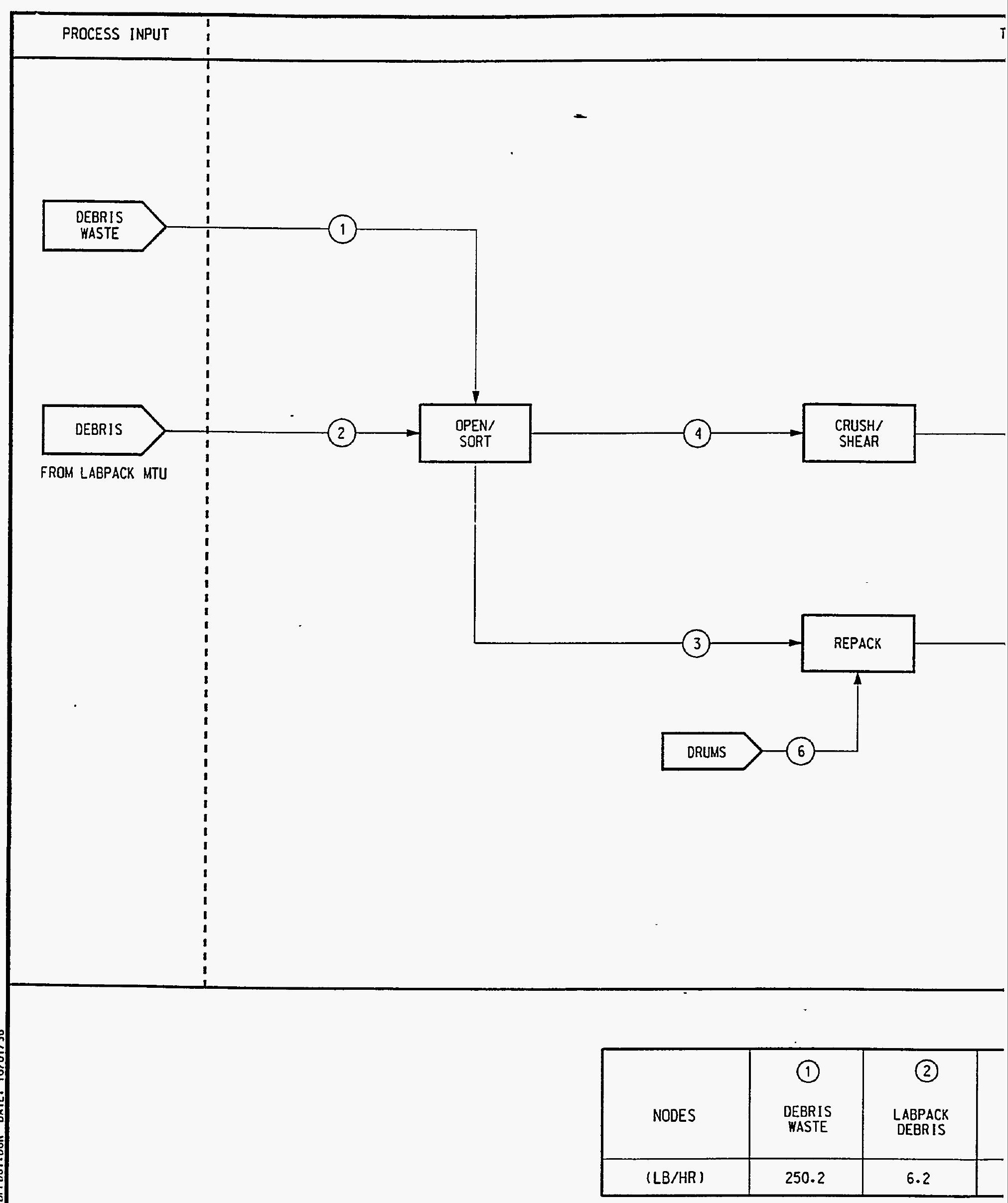

FIGURE $3-3.1$ DEBRIS 
(4)

CONTAMINATED SOLIDS

TO ORGANICS MTU

(5)

CLEAN DEBRIS

TO SUBTITLE D LANDF ILL

\begin{tabular}{|l|c|c|c|}
\hline 3 & 4 & 5 & 6 \\
EAN & $\begin{array}{c}\text { CONTAMINATED } \\
\text { SOLIDS }\end{array}$ & $\begin{array}{c}\text { REPACKED } \\
\text { CLEAN } \\
\text { OEBRIS }\end{array}$ & DRUMS \\
\hline .3 & 64.1 & 211.5 & 19.2 \\
\hline
\end{tabular}




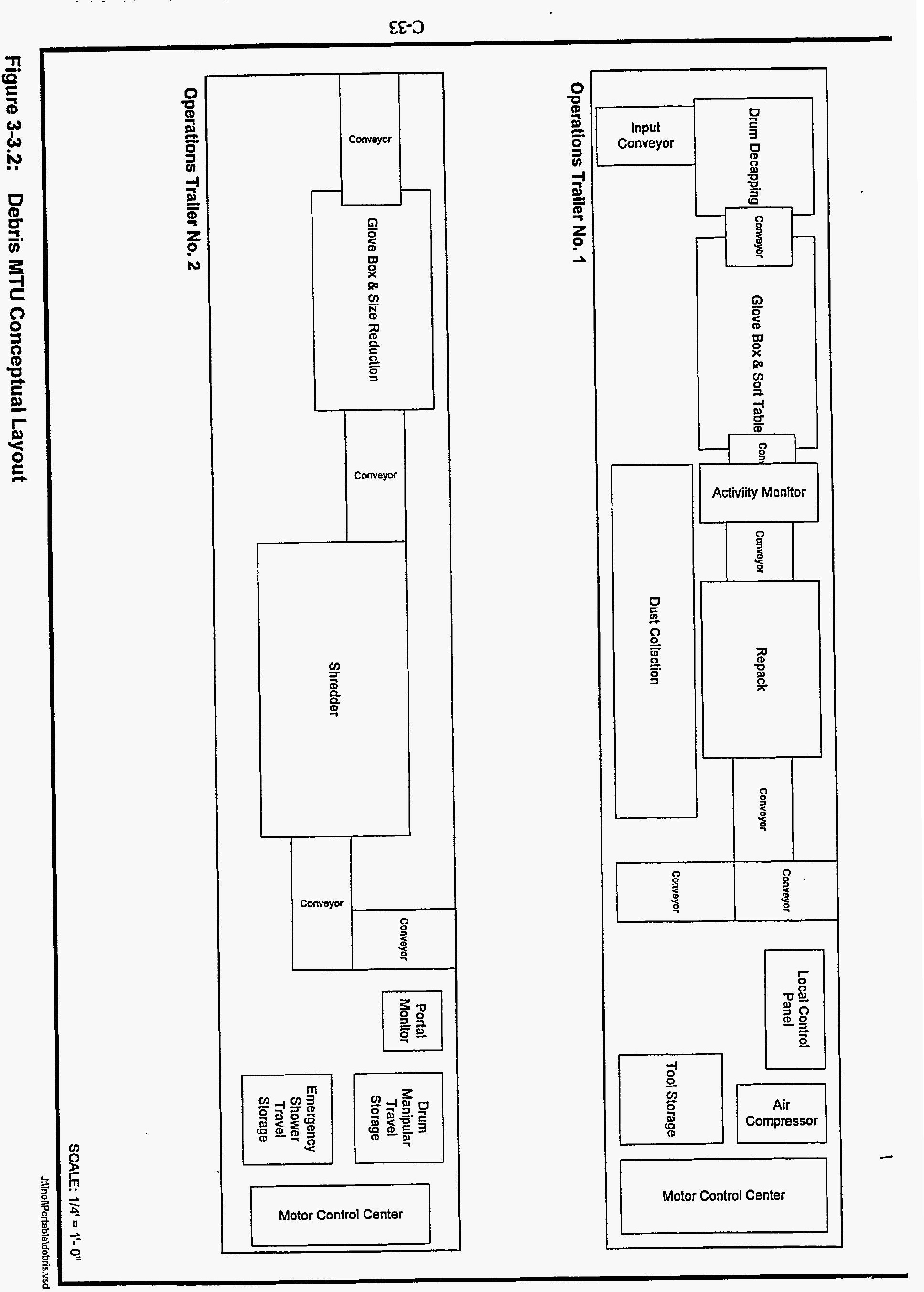


. 


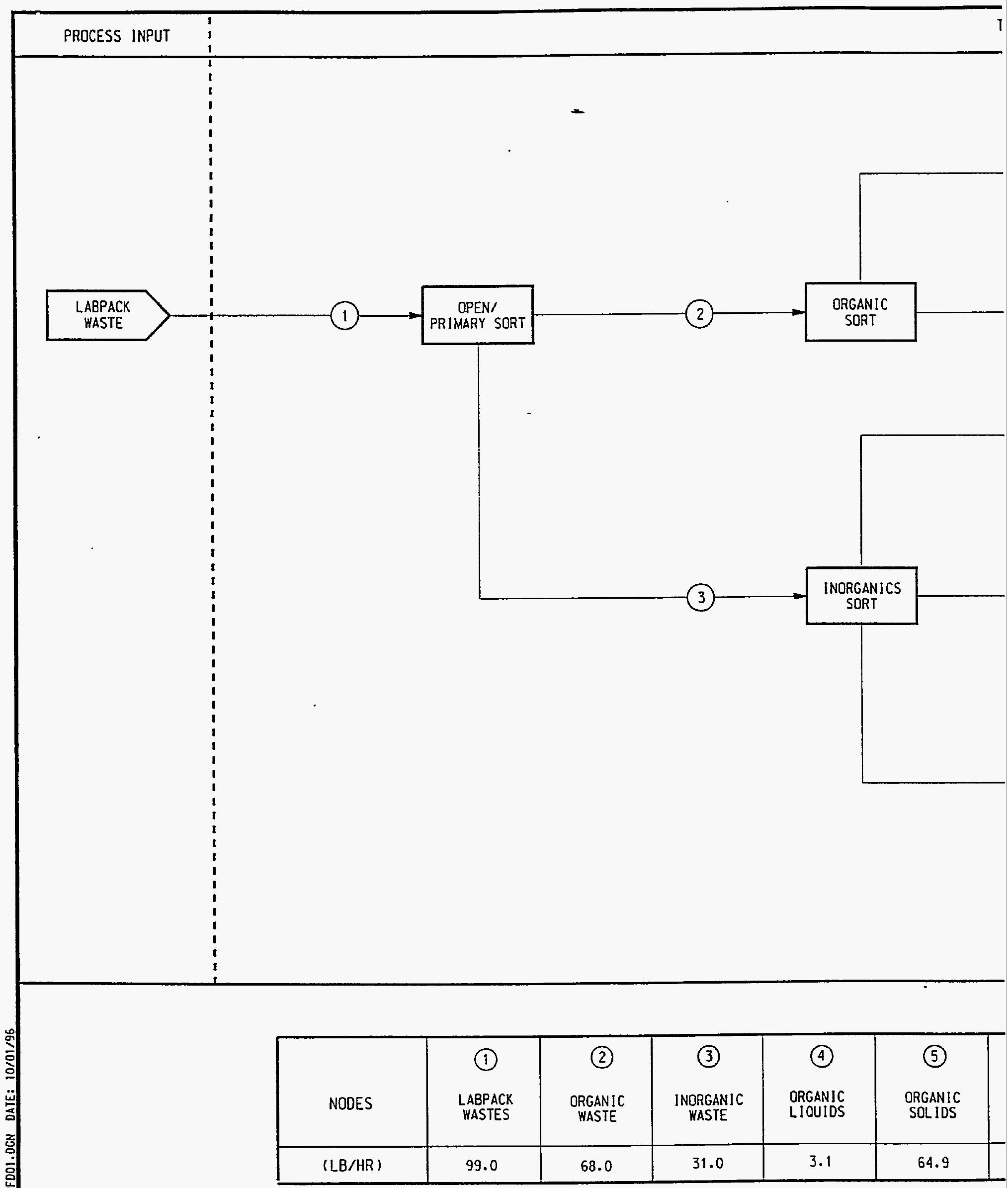

FIGURE $3-4.1$ LAB PACK 
(4)

ORGANIC

LIOUIDS

TO ORGANICS MTU

5

(8)

(12)

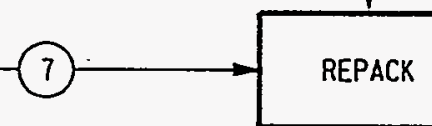

(9)

SOLID

WASTES

TO DISPOSAL

(10)
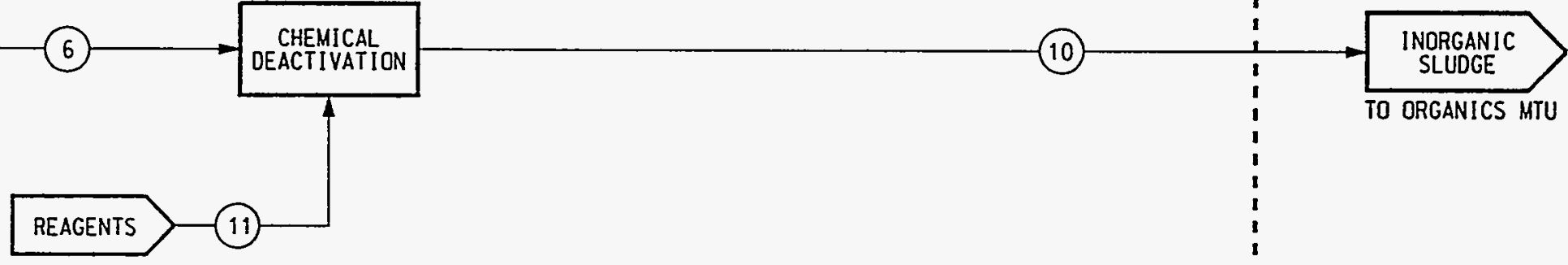

TO ORGANICS MTU

(6)

\begin{tabular}{c|c|c} 
(7) & (8) \\
SOLID \\
WASTES & DEBRIS & \\
\hline 6.2 & 6.2 & \\
\hline
\end{tabular}

\begin{tabular}{l|} 
(9) \\
REPACKED \\
SOL ID \\
MASTE \\
\hline 6.8 \\
\hline
\end{tabular}

(10)

INORGANIC SLUDGE

20.5

\begin{tabular}{|c|c|}
\hline $\begin{array}{c}\text { (11) } \\
\text { AGENTS }\end{array}$ & $\begin{array}{c}\text { (12) } \\
\text { DRUMS }\end{array}$ \\
\hline 1.9 & 0.6 \\
\hline
\end{tabular}




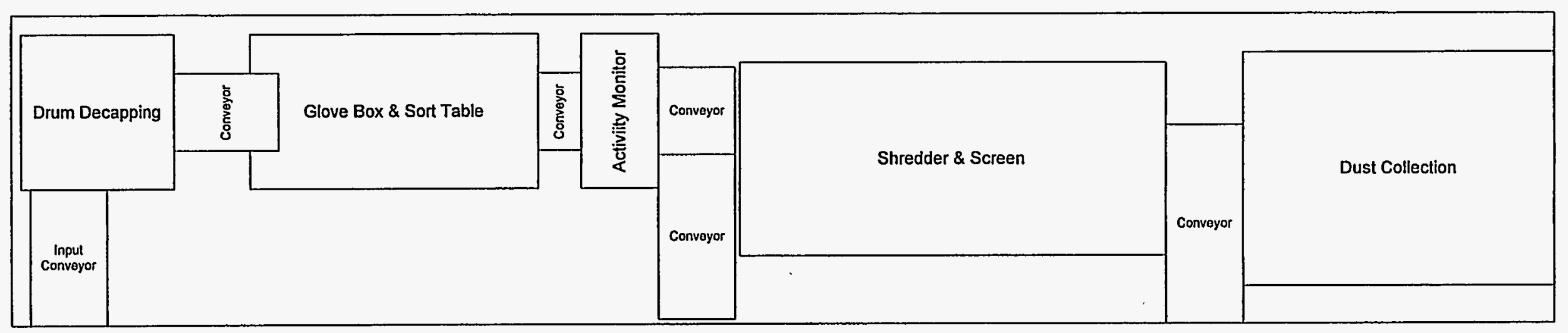

Operations Trailer No.1

$\stackrel{\leftrightarrow}{\mathcal{u}}$
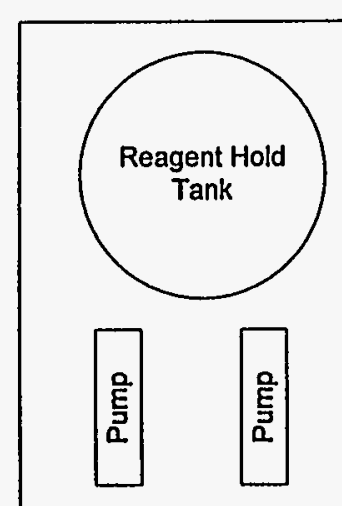
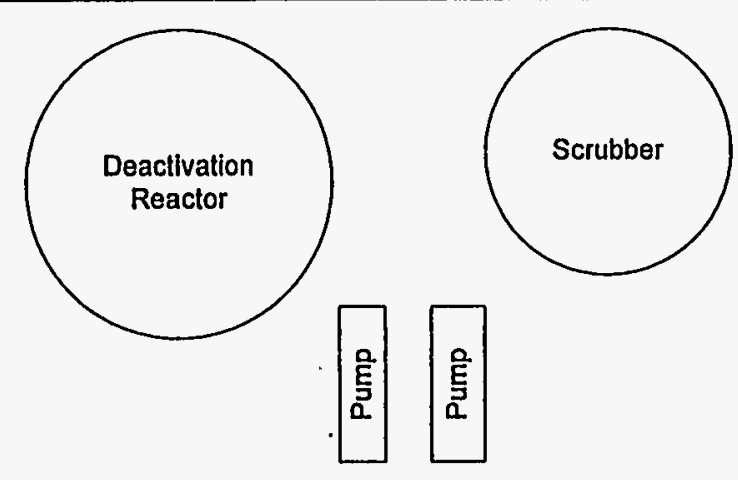
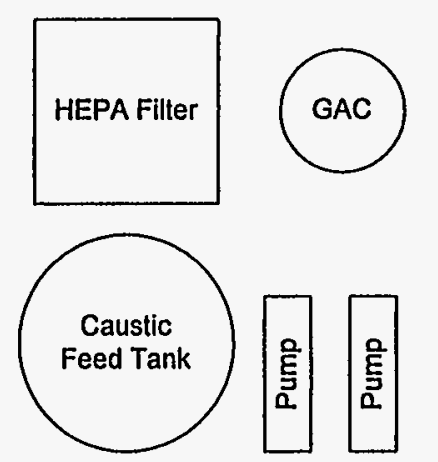
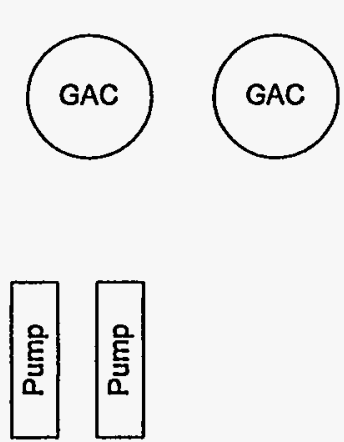
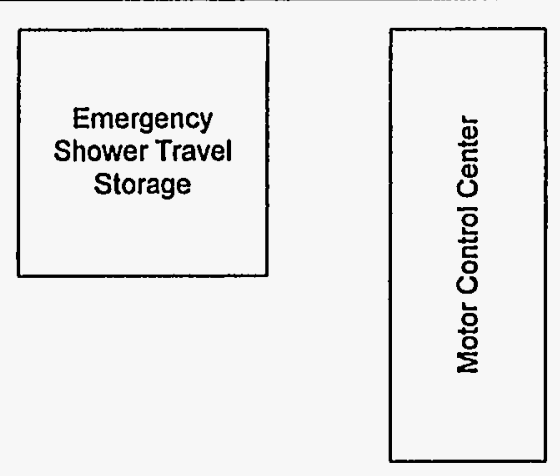

Operations Trailer No. 2

Scale: $1 / 4^{\prime \prime}=1^{\prime}-0^{\prime \prime}$

J:InenportableVlabpack.v

Figure 3-4.2 Labpack MTU Conceptual Layout 



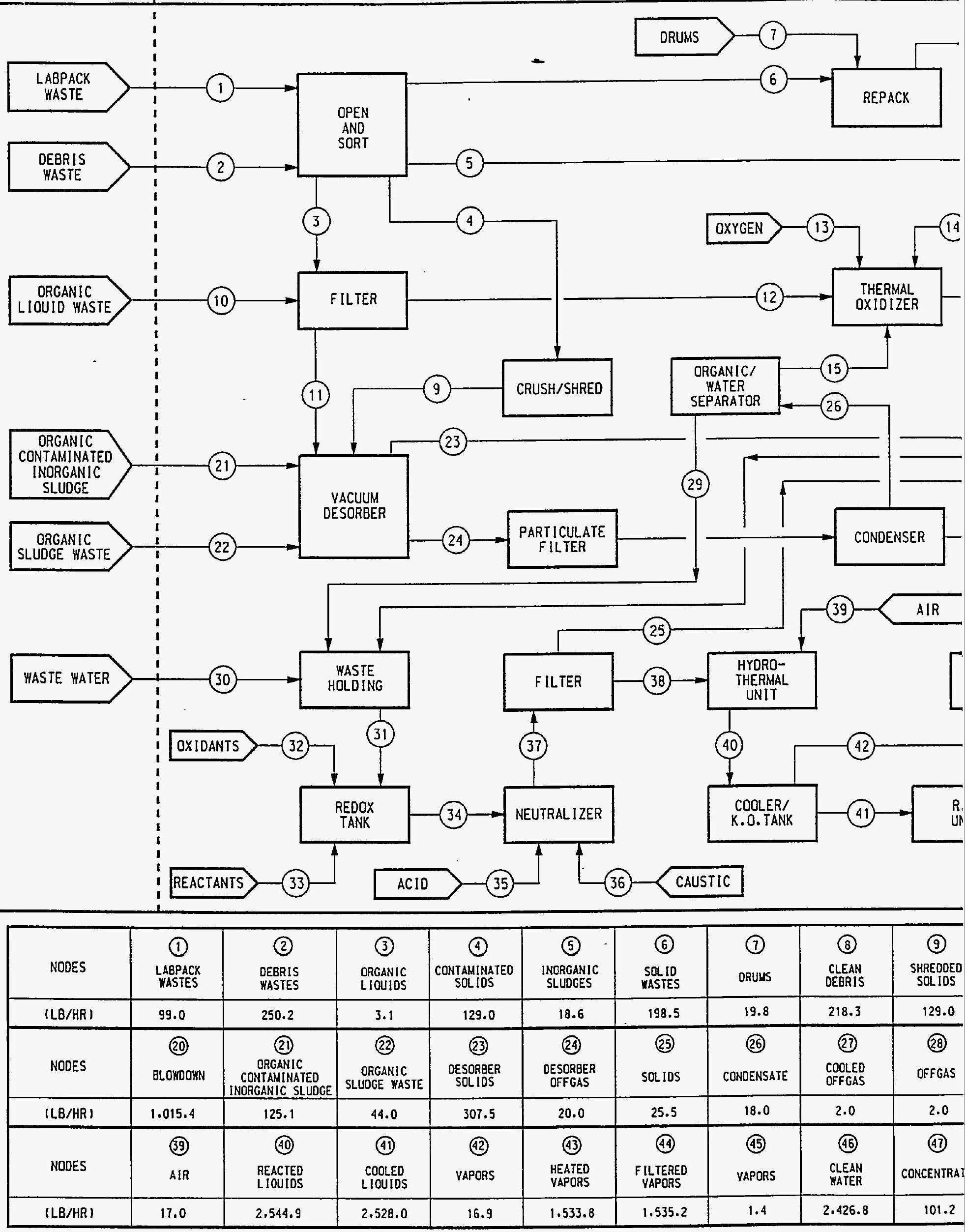




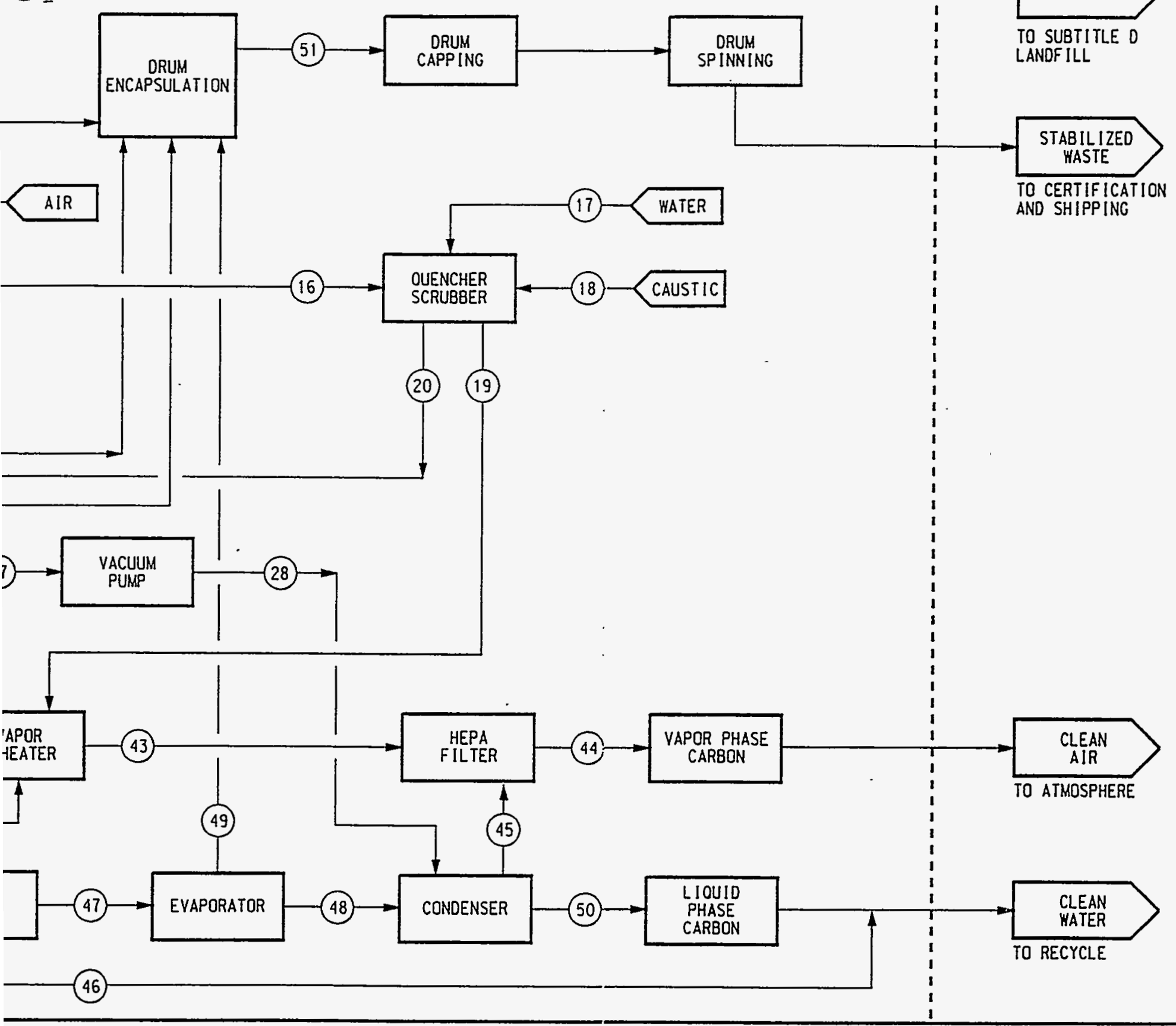

\begin{tabular}{|c|c|c|c|c|c|c|c|c|c|}
\hline $\begin{array}{c}\text { (10) } \\
\text { ORGANIC } \\
\text { IOUID XASTE }\end{array}$ & $\begin{array}{l}\text { (11) } \\
\text { FILTER } \\
\text { SOILDS }\end{array}$ & $\begin{array}{l}\text { (12) } \\
\text { ORGANIC } \\
\text { LIOUIOS }\end{array}$ & $\begin{array}{c}\text { (13) } \\
\text { OXYGEN }\end{array}$ & (14) & $\begin{array}{c}\text { (15) } \\
\text { ORIAANIC } \\
\text { CONOENSATE }\end{array}$ & $\begin{array}{c}\text { (16) } \\
\text { REACTOR } \\
\text { OFFGAS }\end{array}$ & $\begin{array}{l}\text { (17) } \\
\text { MATER }\end{array}$ & $\begin{array}{c}\text { (18) } \\
\text { CAUSTIC }\end{array}$ & $\begin{array}{c}\text { (19) } \\
\text { SCRUBBED } \\
\text { OFFGAS }\end{array}$ \\
\hline 332.2 & 29.4 & 305.9 & 250.0 & 1.190 .5 & 10.0 & 1.756 .4 & 705.7 & 70.2 & 1.516 .9 \\
\hline $\begin{array}{c}\text { (29) } \\
\text { MATER } \\
\text { CONDENSATE }\end{array}$ & $\underset{\substack{\text { WASTE } \\
\text { WATER }}}{300}$ & $\begin{array}{l}\text { REDDX } \\
\text { FEED }\end{array}$ & OXIOANTS & $\begin{array}{c}\text { (33) } \\
\text { REACTANTS }\end{array}$ & 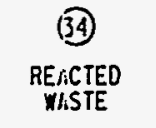 & $\begin{array}{l}\text { (35) } \\
\text { ACID }\end{array}$ & $\begin{array}{l}\text { (36) } \\
\text { CAUT } \\
\text { CAUSTIC }\end{array}$ & $\begin{array}{c}\text { (37) } \\
\text { NEUTRAL IZEO } \\
\text { WASTE }\end{array}$ & $\begin{array}{l}\text { (38) } \\
\text { LIOUIOS }\end{array}$ \\
\hline 8.0 & 1.106 .1 & 2.129 .5 & 106.5 & 106.5 & 2.342 .5 & 70.3 & 140.6 & 2.553 .4 & 2.527 .9 \\
\hline $\begin{array}{c}\text { (48) } \\
\text { MATER } \\
\text { YAPOR }\end{array}$ & $\begin{array}{c}\text { (49) } \\
\text { SLUDCE }\end{array}$ & $\begin{array}{l}\text { (50) } \\
\text { MATER }\end{array}$ & $\begin{array}{c}\text { (51) } \\
\text { STABILIIZED } \\
\text { WASTE }\end{array}$ & \multirow{2}{*}{ FIGURE } & \multirow{2}{*}{-5.1} & \multirow{2}{*}{ RAL IZE } & \multirow{2}{*}{ ACILIT } & \multirow{2}{*}{ PROCESS } & \multirow{2}{*}{ OW DIAGF } \\
\hline 75.9 & 25.3 & 76.5 & 376.9 & & & & & & \\
\hline
\end{tabular}




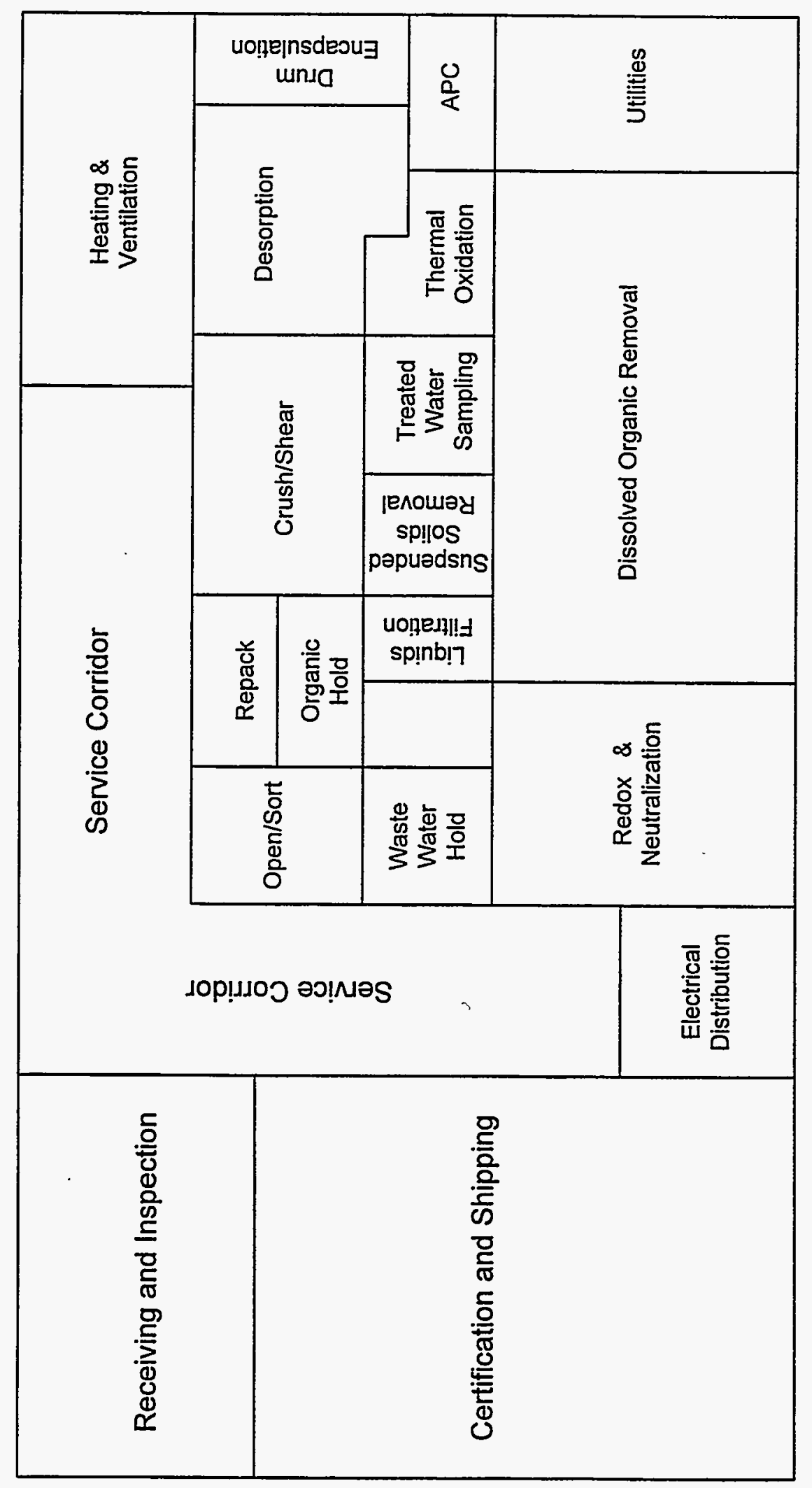

苛 


\section{PLANNING LifE-CyCLE COST Estimates}

The treatment PLCC estimate for each MTU is divided into six Work Breakdown Structure (WBS) elements. These six elements include:

- $\quad$ Studies and Bench Scale Tests

- Demonstration Costs

- Facility Construction Costs

- Preconstruction and Preoperational Activities

- Operations and Maintenance Costs

- Decontamination and Decommissioning

Refer to the previously published Integrated Thermal Treatment System (ITTS) Study, Phase I and Phase II reports or the Integrated Non-Thermal Treatment System (INTS) Study for information on the scope of these WBS elements and cost estimating methods.

Costs for certification/shipping are not included in the mobile treatment unit PLCC estimates, since it was assumed that certification/shipping capability already exist at the host site. These costs are included in the Centralized Facility

\subsection{Wastewater MTU}

The PLCC estimate for the Wastewater MTU is presented in Table 4-1. This estimate includes costs for a multi-trailer transportable facility capable of treating approximately 2130 pounds/hr of aqueous waste and operating at 800 hours per year for five years or 4,000 life cycle hours. Cost estimates for the individual WBS elements are presented in Tables A-1 through A-5 of Appendix A.

Table 4-6 presents the treatment PLCC estimate for all transportable MTUs as well as the unit cost of treatment when utilizing this MTU. The unit rate is based on a treatment rate of 2130 pounds/hr, over a 4,000 hour operating life. 


\subsection{Organics MTU}

The PLCC estimate for the Organics MTU is presented in Table 4-2. This estimate includes costs for a multi-trailer transportable facility having a capacity of approximately 1667 pounds of organic liquids, sludges and solids per hour and operating at 800 hours per year for five years $(4,000$ life cycle hours). Cost estimates for the individual WBS elements are presented in Tables A- 6 through A-10 of Appendix A.

Table 4-6 presents the treatment PLCC estimate for all transportable MTUs as well as the unit cost of treatment when utilizing this MTU. The unit rate is based on a treatment rate of 1667 pounds/hr, over a 4,000 hour operating life.

\subsection{Debris MTU}

Table 4-3 presents the PLCC estimate for the Debris MTU. This estimate includes costs for a multi-trailer transportable facility capable of separating and repackaging debris into fractions for disposal at a landfill and/or further treatment. The Debris MTU has the capability to treat approximately 256 pounds per hour while operating at 800 hours per year for five years. Cost estimates for the individual WBS elements are presented in Tables A-11 through A-15.

Table 4-6 presents the treatment PLCC estimate for all transportable MTUs as well as the unit cost of treatment when utilizing this MTU. The unit rate is based on a treatment rate of 256 pounds $/ \mathrm{hr}$, over a 4,000 hour operating life.

\subsection{Labpack MTU}

Table 4-4 presents the PLCC estimate for the Labpack MTU. This estimate includes costs for a multi-trailer transportable facility capable of separating lab packs into organic and inorganic fractions. Additionally the fractions are either repackaged for disposal at a landfill or treated further. The Labpack MTU was designed to treat approximately 99 pounds per hour while operating at 800 hours per year for. five years. Cost estimates for the individual WBS elements are presented in Tables A-16 through A-20.

Table 4-6 presents the treatment PLCC estimate for all transportable MTUs as well as the unit 
cost of treatment when utilizing this MTU. The unit rate is based on a treatment rate of 99 pounds/hr, over a 4,000 hour operating life.

\subsection{Centralized Facility}

The PLCC estimate for the Centralized Facility is presented in Table 4-5. This estimate includes costs to construct and operate a facility having the same capabilities as the four MTUs combined. In addition, the centralized facility includes costs for receiving \& inspection, administration and certification/ shipping. The costs were developed in the same manner as were the costs for the ITTS and INTS studies. Customizes treatment unit operations were developed and equipment lists were generated to meet the unit operation requirements. The cost to purchase and install this equipment was estimated using the information and procedures utilized in the Waste Management Facility Cost Information (WMFCI) reports. The WMFCI reports were the basis for the ITTS and INTS cost information. The WMFCI cost data for non-alpha systems was used for the centralized facility. As with the ITTS and INTS cost development, equipment layouts were made to determine building requirements. Operational requirements were determined by estimating the full time equivalent (FTE) manpower requirements for each unit operation and applying an annual FTE cost to establish an annuals operations cost. Maintenance costs were estimated as a percentage of installed equipment. Operations consumables were included for the appropriate unit operations. D\&D costs were estimated by applying a unit rate to the building square footage.

The centralized facility was designed to have the capability to treat 2,130 pounds/hr of waste water, 1,667 pounds of organic liquids, sludges and solids per hour, 256 pounds/hr of debris and 99 pounds/hr of lab pack wastes while operating at 800 hours per year for five years $(4,000$ life cycle hours). Table 4-6 presents the treatment PLCC estimate for the centralized facility as well as the unit cost of treatment when utilizing such a facility. The unit rate is based on a treatment rate of 1956.6 pounds/hr (see Figure 3-5.1), over a 4,000 hour operating life. Cost estimates for the individual WBS elements are presented in Tables A-21 through A-25 of Appendix A. 


\subsection{Cost Estimate Assumptions}

The following assumptions were used in developing the PLCC estimates:

\subsubsection{General}

- Disposal costs for all treated waste regardless of the treatment scenario have not been included.

\subsubsection{Portable Systems}

- $\quad$ Space and hookups exist at all sites.

- Host sites will not provide administration or maintenance services. These costs are included in the portable costs.

- Waste is adequately characterized and delivered by the host site to the treatment location to allow the portable system to begin operations.

- Cost for transportation of units between sites, set up, shut down and decontamination to allow units to be transported are included.

\subsubsection{Centralized Systems}

- Administration costs are included.

- Receiving and inspection costs are included.

- Certification/shipping costs are included

- Waste is adequately characterized to allow the appropriate treatment to be used.

- Transportation cost for the transport of wastes from other sites to the centralized facility can be ignored. 
Table 4-1: PLCC for the Waste Water Mobile Treatment Unit

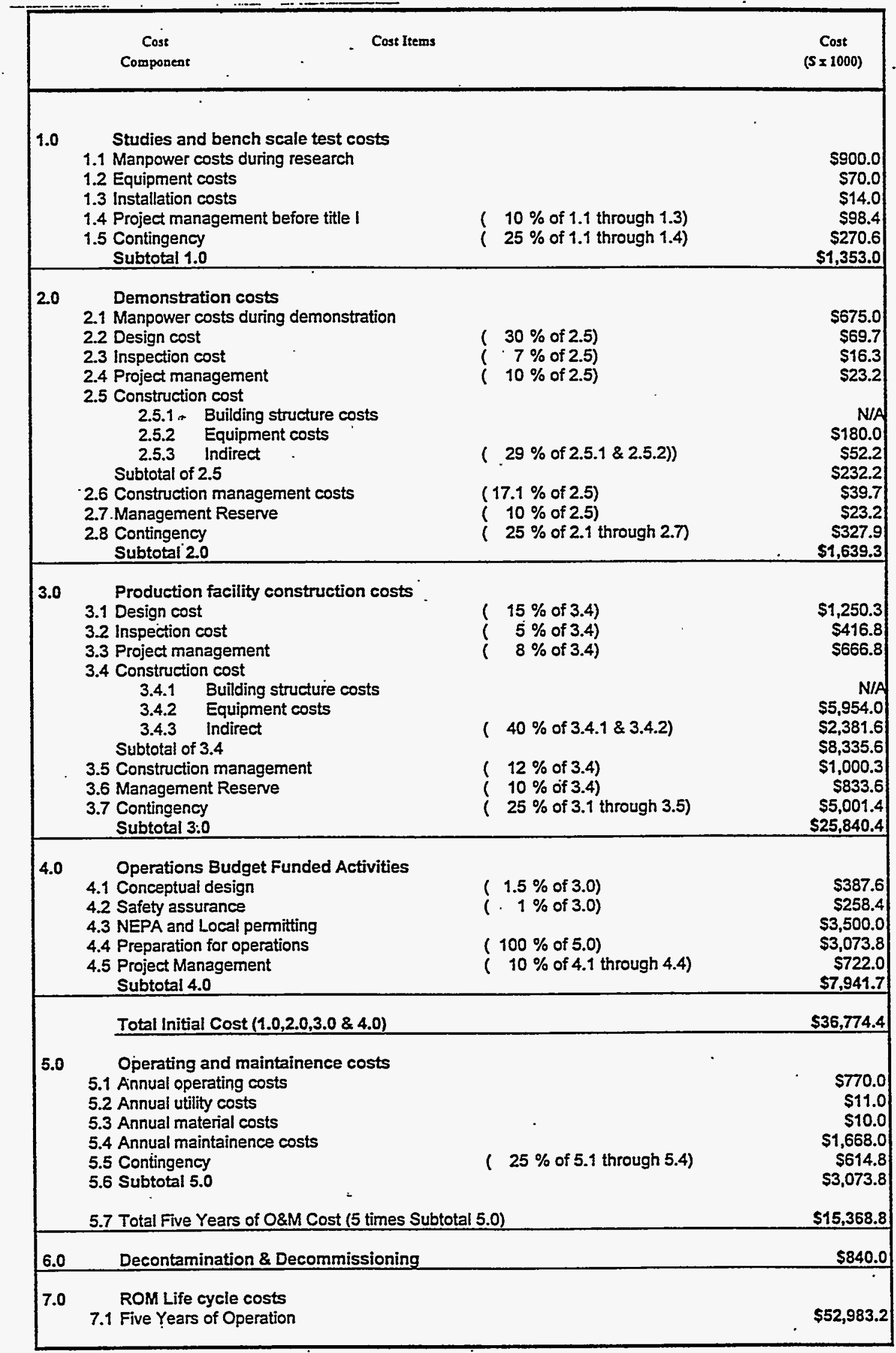


Table 4-2: PLCC for the Organics Mobile Treatment Unit

\begin{tabular}{|c|c|c|c|}
\hline & \multicolumn{2}{|l|}{$\begin{array}{c}\text { Cost } \\
\text { Component }\end{array}$} & \multirow{2}{*}{$\begin{array}{r}\begin{array}{c}\text { Cost } \\
(\$ \times 1000)\end{array} \\
\\
\\
\$ 900.0 \\
\$ 100.0 \\
\$ 47.0 \\
\$ 104.7 \\
\$ 287.9 \\
\$ 1,439.6 \\
\end{array}$} \\
\hline 1.0 & $\begin{array}{l}\text { Studies and bench scale test costs } \\
\text { 1.1 Manpower costs during research } \\
1.2 \text { Equipment costs } \\
1.3 \text { Installation costs } \\
1.4 \text { Project management before title I } \\
1.5 \text { Contingency } \\
\text { Subtotal } 1.0 \\
\end{array}$ & $\begin{array}{l}(10 \% \text { of } 1.1 \text { through } 1.3) \\
(25 \% \text { of } 1.1 \text { through } 1.4)\end{array}$ & \\
\hline 2.0 & $\begin{array}{l}\text { Demonstration costs } \\
\text { 2.1 Manpower costs during demonstration } \\
2.2 \text { Design cost } \\
2.3 \text { Inspetion cost } \\
2.4 \text { Project management } \\
2.5 \text { Construction cost } \\
2.5 .1 \text { Building structure costs } \\
2.5 .2 \text { Equipment costs } \\
2.5 .3 \text { indirect } \\
\text { Subtotal of } 2.5 \\
2.6 \text { Construction management costs } \\
2.7 \text { Management Reserve } \\
2.8 \text { Contingency } \\
\text { Subtotal } 2.0 \\
\end{array}$ & $\begin{array}{l}(29 \% \text { of } 2.5 .1 \& 2.5 .2)) \\
(17.1 \% \text { of } 2.5) \\
\left(\begin{array}{l}10 \% \text { of } 2.5) \\
(25 \% \text { of } 2.1 \text { through } 2.7)\end{array}\right.\end{array}$ & $\begin{array}{r}\$ 750.0 \\
\$ 69.7 \\
\$ 16.3 \\
\$ 23.2 \\
\mathrm{~N} / \mathrm{A} \\
\$ 180.0 \\
\$ 52.2 \\
\$ 232.2 \\
\$ 39.7 \\
\$ 23.2 \\
\$ 346.6 \\
\$ 1.733 .1 \\
\end{array}$ \\
\hline 3.0 & 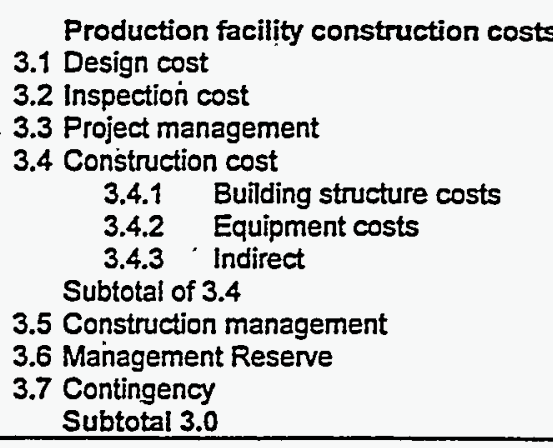 & $\begin{array}{l}(40 \% \text { of } 3.4 .1 \& 3.4 .2) \\
\left(\begin{array}{l}12 \% \text { of } 3.4) \\
10 \% \text { of } 3.4) \\
(25 \% \text { of } 3.1 \text { through } 3.5)\end{array}\right.\end{array}$ & 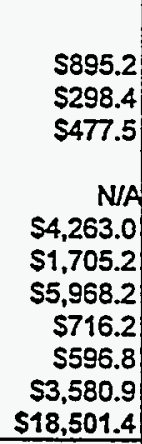 \\
\hline 4.0 & $\begin{array}{l}\text { Operations Budget Funded Activities } \\
\text { 4.1 Conceptual design } \\
\text { 4.2 Safety assurance } \\
\text { 4.3 NEPA and Local permitting } \\
\text { 4.4 Preparation for operations } \\
\text { 4.5 Project Management } \\
\text { Subtotal } 4.0 \\
\end{array}$ & $\begin{array}{l}\left(\begin{array}{c}1.5 \% \text { of } 3.0) \\
1 \% \text { of } 3.0)\end{array}\right. \\
\left(\begin{array}{c}100 \% \text { of } 5.0) \\
10 \% \text { of } 4.1 \text { through } 4.4)\end{array}\right.\end{array}$ & $\begin{array}{r}\$ 277.5 \\
\$ 185.0 \\
\$ 8,500.0 \\
\$ 2,487.5 \\
\$ 1,145.0 \\
\$ 12,595.0 \\
\end{array}$ \\
\hline & \multicolumn{2}{|l|}{ Total Initial Cost $(1.0,2.0,3.0 \& 4.0)$} & $\$ 34,269.2$ \\
\hline 5.0 & \multirow{2}{*}{\multicolumn{2}{|c|}{$\begin{array}{l}\text { Operating and maintainence costs } \\
\text { 5.1 Annual operating costs } \\
\text { 5.2 Annual utility costs } \\
\text { 5.3 Annual material costs } \\
\text { 5.4 Annual maintainence costs } \\
\text { 5.5 Contingency } \\
\text { 5.6 Subtotal } 5.0 \quad \\
\text { 5.7 Total Five Years of O\&M Cost ( } 5 \text { times Subtotal } 5.0)\end{array}$}} & $\begin{array}{r}\$ 770.0 \\
\$ 9.0 \\
\$ 19.0 \\
\$ 1,192.0 \\
\$ 497.5 \\
\$ 2,487.5 \\
\$\end{array}$ \\
\hline & & & $\$ 12,437.5$ \\
\hline 6.0 & \multicolumn{2}{|l|}{ Decontamination \& Decommissioning } & $\$ 840.0$ \\
\hline 7.0 & \multicolumn{2}{|l|}{$\begin{array}{l}\text { ROM Life cycle costs } \\
\text { 7.1 Five Years of Operation }\end{array}$} & $\$ 47,546.7$ \\
\hline
\end{tabular}

J:linellportable.wk4 
Table 4-3: PLCC for the Debris Mobile Treatment Unit

\begin{tabular}{|c|c|c|c|}
\hline & $\begin{array}{c}\text { Cost } \\
\text { Componeat }\end{array}$ & & $\begin{array}{c}\text { Cost } \\
(S \times 1000)\end{array}$ \\
\hline 1.0 & $\begin{array}{l}\text { Studies and bench scale test costs } \\
\text { 1.1 Manpower costs during research } \\
\text { 1.2 Equipment costs } \\
\text { 1.3 Installation costs } \\
\text { 1.4 Project management before title I } \\
\text { 1.5 Contingency } \\
\text { Subtotal 1.0 }\end{array}$ & $\begin{array}{l}(10 \% \text { of } 1.1 \text { through } 1.3) \\
(25 \% \text { of } 1.1 \text { through } 1.4)\end{array}$ & $\begin{array}{r}\$ 450.0 \\
\$ 50.0 \\
\$ 20.0 \\
\$ 52.0 \\
\$ 143.0 \\
\$ 715.0 \\
\end{array}$ \\
\hline 2.0 & $\begin{array}{l}\text { Demonstration costs } \\
\text { 2.1 Manpower costs during demonstration } \\
\text { 2.2 Design cost } \\
\text { 2.3 Inspection cost } \\
\text { 2.4 Project management } \\
\text { 2.5 Construction cost } \\
2.5 .1 \quad \text { Building structure costs } \\
2.5 .2 \quad \text { Equipment costs } \\
2.5 .3 \text { indirect } \\
\text { Subtotal of } 2.5 \\
\text { 2.6 Construction management costs } \\
\text { 2.7 Management Reserve } \\
\text { 2.8 Contingency } \\
\text { Subtotal 2.0 }\end{array}$ & 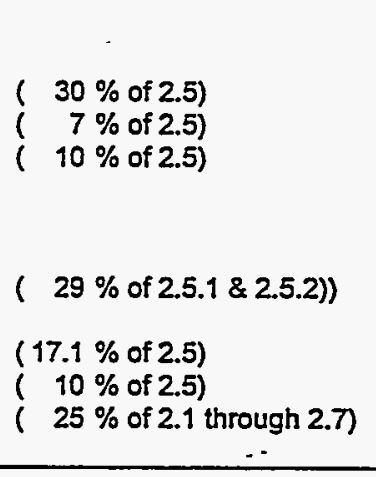 & $\begin{array}{r}\$ 300.0 \\
\$ 38.7 \\
\$ 9.0 \\
\$ 12.9 \\
\text { N/A } \\
\$ 100.0 \\
\$ 29.0 \\
\$ 129.0 \\
\$ 22.1 \\
\$ 12.9 \\
\$ 163.4 \\
\$ 817.0 \\
\end{array}$ \\
\hline 3.0 & $\begin{array}{l}\text { Production facility construction costs } \\
\text { 3.1 Design cost } \\
\text { 3.2 Inspection cost } \\
\text { 3.3 Project management } \\
\text { 3.4 Construction cost } \\
3.4 .1 \quad \text { Building structure costs } \\
3.4 .2 \quad \text { Equipment costs } \\
3.4 .3 \text { Indirect } \\
\text { Subtotal of } 3.4 \\
\text { 3.5 Construction management } \\
\text { 3.6 Management Reserve } \\
\text { 3.7 Contingency } \\
\text { Subtotal 3.0 }\end{array}$ & 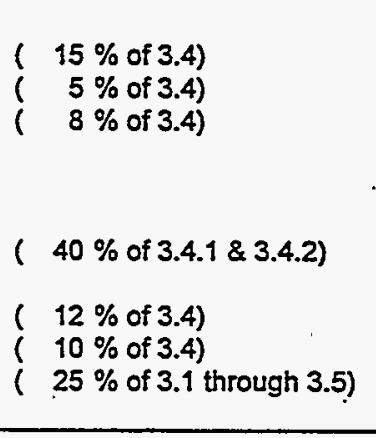 & $\begin{array}{r}\$ 641.8 \\
\$ 213.9 \\
\$ 342.3 \\
N / A \\
\$ 3,056.0 \\
\$ 1,222.4 \\
\$ 4,278.4 \\
\$ 513.4 \\
\$ 427.8 \\
\$ 2,567.0 \\
\$ 13,263.0\end{array}$ \\
\hline 4.0 & $\begin{array}{l}\text { Operations Budget Funded Activities } \\
\text { 4.1 Conceptual design } \\
\text { 4.2 Safety assurance } \\
\text { 4.3 NEPA and Local permitting } \\
\text { 4.4 Preparation for operations } \\
\text { 4.5 Project Management } \\
\text { Subtotal 4.0 } \\
\end{array}$ & 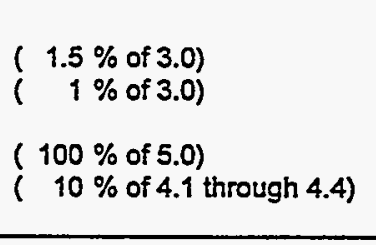 & $\begin{array}{r}\$ 198.9 \\
\$ 132.6 \\
\$ 3,500.0 \\
\$ 1,835.0 \\
\$ 566.7 \\
\$ 6,233.2 \\
\end{array}$ \\
\hline \multirow[b]{2}{*}{5.0} & Total Initial Cost $(1.0,2.0,3.0 \& 4.0)$ & $\therefore$ & $\$ 21,028.3$ \\
\hline & $\begin{array}{l}\text { - Operating and maintainence costs } \\
\text { 5.1 Annual operating costs } \\
\text { 5.2 Annual utility costs } \\
\text { 5.3 Annual material costs } \\
\text { 5.4 Annual maintainence costs } \\
\text { 5.5 Contingency } \\
\text { 5.6 Subtotal } 5.0 \\
\text { 5.7 Total Five Years of O\&M Cost ( } 5 \text { times S }\end{array}$ & ( $25 \%$ of 5.1 through 5.4 ) & $\begin{array}{r}\$ 602.0 \\
\$ 5.0 \\
\$ 5.0 \\
\$ 856.0 \\
\$ 367.0 \\
\$ 1,835.0 \\
\$ 9,175.0 \\
\end{array}$ \\
\hline 6.0 & Decontamination \& Decommissioning & & $\$ 504.0$ \\
\hline 7.0 & $\begin{array}{l}\text { ROM Life cycle costs } \\
\text { 7.1 Five Years of Operation }\end{array}$ & 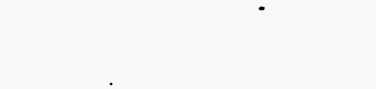 & $\$ 30,707.3$ \\
\hline
\end{tabular}


Table 4-4: PLCC for the Labpack Mobile Treatment Unit

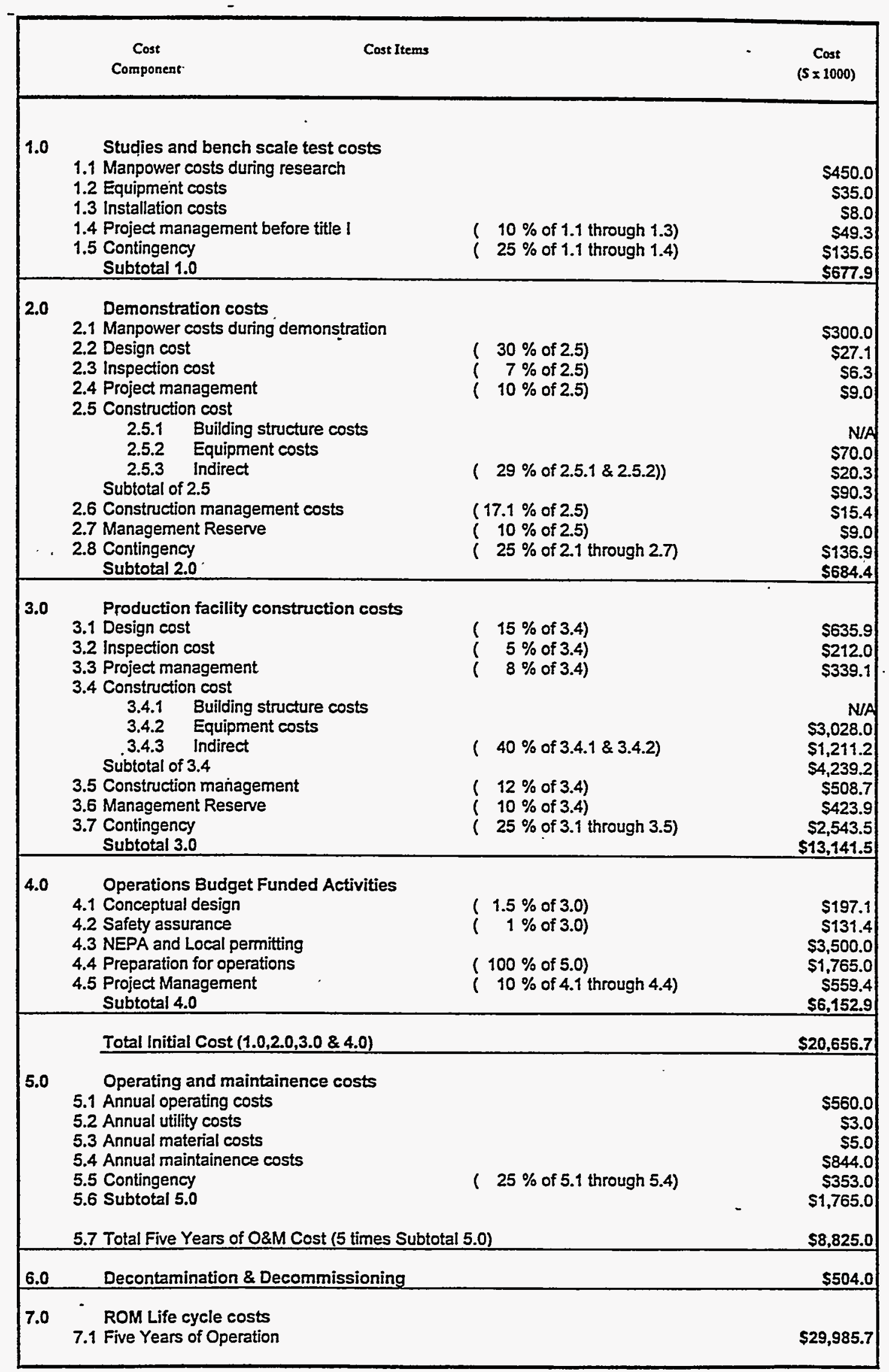


Table 4-5: PLCC for the Centralized Treatment Facility

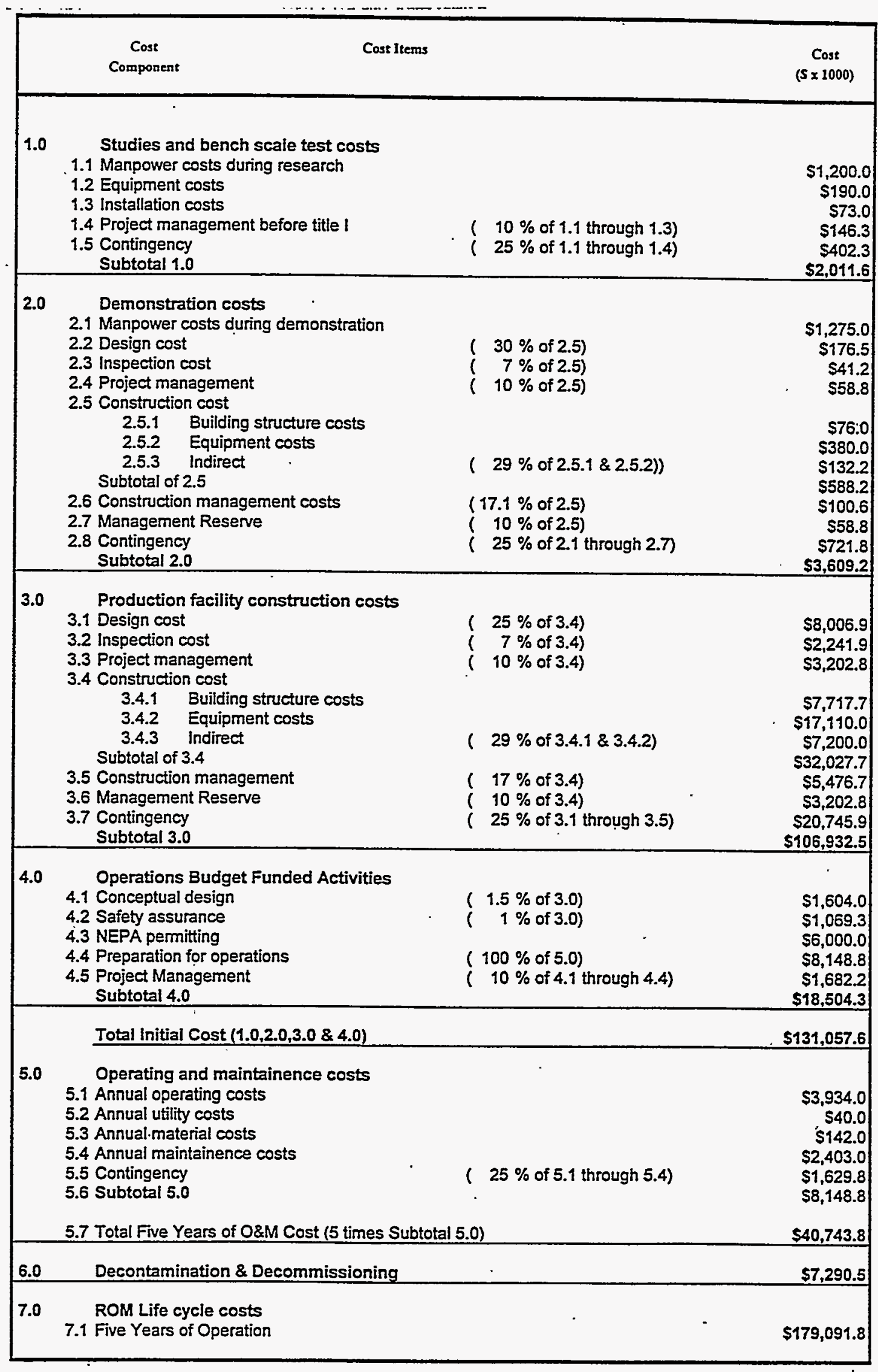

J:linellportable.wk4 
Table 4-6: PLCC Cost and Unit Rate Treatment Cost Comparison

\begin{tabular}{|c|c|c|c|c|c|c|}
\hline & \multicolumn{6}{|c|}{ Treatment Systems } \\
\hline & \multicolumn{5}{|c|}{ Mobile Treatment Units } & \multirow{2}{*}{$\frac{\text { Central }}{\text { Fixed }}$} \\
\hline & Waste Water & Organics & Debris & Labpack & $\begin{array}{l}\text { Four Units } \\
\text { Combined }\end{array}$ & \\
\hline Treatment & $\$ 52,449,400$ & $\$ 47,012,900$ & $\$ 30,173,500$ & $\$ 29,451,900$ & $\$ 159,087,700$ & $\$ 107,764,600$ \\
\hline Adminstration & $\$ 533,800$ & $\$ 533,800$ & $\$ 533,800$ & $\$ 533,800$ & $\$ 2,135,200$ & $\$ 38,649,700$ \\
\hline $\begin{array}{l}\text { Certification/ } \\
\text { Shipping }\end{array}$ & -- & -- & -- & $\because$ & -- & $\$ 32,677,500$ \\
\hline Life-Cycle Cost & $\$ 52,983,200$ & $\$ 47,546,700$ & $\$ 30,707,300$ & $\$ 29,985,700$ & $\$ 161,222,900$ & $\$ 179,091,800$ \\
\hline Cost per pound & $\$ 6.22$ & $\$ 7.13$ & $\$ 29.99$ & $\$ 75.72$ & $\$ 20.60$ & $\$ 22.88$ \\
\hline $\begin{array}{l}\text { Cost per pound } \\
\text { (excluding } \\
\text { Administration and } \\
\text { Cert/Shipping) }\end{array}$ & $\$ 6.15$ & $\$ 7.05$ & $\$ 29.47$ & $\$ 74.37$ & $\$ 20.33$ & $\$ 13.77$ \\
\hline
\end{tabular}

$\stackrel{\rho}{\leftrightarrow}$

J:linellportable.wk4 


\section{References}

1. Integrated Thermal Treatment System Study Phase 1 Report, F. Feizollahi et.al, May 1994, EGG-MS-11211.

2. Integrated Thermal Treatment System Study Phase 2 Results, F. Feizollahi, William J. Quapp August 1995, INEL-95/0129.

3. Integrated Nonthermal Treatment System Study, second Interim Draft, C. Biagi, et. al., July 1996.

4. Waste Management Facilities Cost Information for Mixed Low-Level Waste, D. Shropshire, et. al., June 1995, INEL-95/00114 Revision 1. 


\section{Appendix A}

J:UNELIPortablelReport10.96

MK Doc. No. 44436-R-S-07-849
40

October 8,1996

\section{C-53}

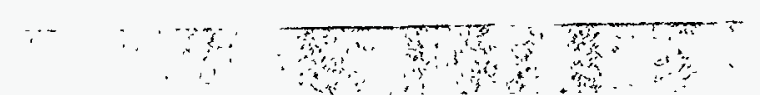


Figure A-1: Equipment List

Waste Water MTU

\begin{tabular}{|c|c|c|c|c|c|c|c|c|c|}
\hline \multirow{2}{*}{\multicolumn{2}{|c|}{ DESCRIPTION }} & \multirow{2}{*}{$\begin{array}{l}\text { FAC. } \\
\text { CAT. }\end{array}$} & \multirow[b]{2}{*}{ HP } & \multicolumn{3}{|c|}{ MATLS. \& EQUIP. } & \multicolumn{3}{|c|}{ INST. COSTS } \\
\hline & & & & QTY & $\begin{array}{l}\text { Unit Cost } \\
\text { S1000's }\end{array}$ & $\begin{array}{l}\text { Amount } \\
\text { S1000's }\end{array}$ & $\begin{array}{l}\text { Unit Cost } \\
\text { s1000's }\end{array}$ & $\begin{array}{l}\text { Amount } \\
\text { S1000's }\end{array}$ & $\begin{array}{l}\text { Total } \\
\text { U.O. }\end{array}$ \\
\hline $\mathbf{x}$ & Bateh Liquid. Wäste. & :.II & & & $\therefore \therefore$ & $\therefore \therefore$ & $\because \because \quad \because$ & $\because \because \because \because$ & $\therefore \because \cdots$ \\
\hline & - Batch Tank with Agitator (400 gal) $\left(4^{\prime}-0^{\prime \prime} \varnothing\right)$ & $E$ & & $\overline{1}$ & 16 & 16.0 & 4 & 4.0 & 20.0 \\
\hline & F Batch Tank Transfer Pump (25 gpm) & $\bar{E}$ & & 1 & 8 & 8.0 & 2 & 2.0 & 10.0 \\
\hline & - Oxidant Hold Tank (200 gals) & $\bar{E}$ & & 1 & 10 & 10.0 & 2.5 & 2.5 & 12.5 \\
\hline & - Reactant Hold Tank ( 200 gals) & $\bar{E}$ & & 2 & 10 & 20.0 & 2.5 & 5.0 & 25.0 \\
\hline & 1- Acid Hold Tank (200 gals) & $\bar{E}$ & & 1 & 10 & 10.0 & 2.5 & 2.5 & 12.5 \\
\hline & - Caustic Hold Tank (200 gals) & $\bar{E}$ & & 1 & 5 & 5.0 & 1 & 1.0 & 6.0 \\
\hline & - Oxidant Transfer Pump (5 gpm) & $\overline{\mathrm{E}}$ & & 1 & 12 & 12.0 & 2.5 & 2.5 & 14.5 \\
\hline & - Reactant Transfer Pump (5 gpm) & $\bar{E}$ & & 1 & 5 & 5.0 & 1 & 1.0 & 6.0 \\
\hline & - Acid Transfer Pump (5 gpm) & $\bar{E}$ & & 1 & 5 & 5.0 & 1 & 1.0 & 6.0 \\
\hline & - Caustic Transfer Pump (5 gpm) & $E$ & & $\overline{1}$ & 5 & 5.0 & 1 & 1.0 & 6.0 \\
\hline & - Drum Decapper & $\bar{E}$ & & 1 & 75 & 75.0 & 20 & 20.0 & 95.0 \\
\hline & - Drum Manipulator & $\bar{E}$ & & $\overline{1}$ & 50 & 50.0 & $\overline{15}$ & 15.0 & 65.0 \\
\hline & - Inspection Station & $\bar{E}$ & & 1 & 10 & 10.0 & 2.5 & 2.5 & 12.5 \\
\hline & F- Conveyor & $\bar{E}$ & & 2 & 25 & 50.0 & 6 & 12.0 & 62.0 \\
\hline & - Allowance for Piping/Mechanical & $E$ & & Lot & & 84.3 & & 43.2 & 127.5 \\
\hline & - Allowance for Electrical/Control & $E$ & & Lot & & 42.2 & & 36.0 & 78.2 \\
\hline & - Calibration, Testing \& Startup & $E$ & & Lot & & 8.1 & & 6.0 & 14.2 \\
\hline & - & & & & & & & & \\
\hline & Total Batch Liquid Waste & & $\because$ & & & 415.6 & $\therefore \quad \therefore$ & 157.2 & 572.8 \\
\hline.$: 2$ & Gross Organics.Removal. & . $\|$ & - & $\because$ & ים & $\therefore \because \because \because$ & $\therefore \cdots \cdots: \because \cdots \cdots$ & 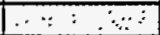 & $\because \because \cdot \because \cdot$ \\
\hline & - Oil/ Water Separator (5 gpm) & $E$ & & 1 & 35 & 35.0 & 9.0 & 9.0 & 44.0 \\
\hline & - Allowance for Piping/Mechanical & $\overline{\mathrm{E}}$ & & Lot & & 10.5 & & 5.4 & 15.9 \\
\hline & - Allowance for ElectricallControl & $\bar{E}$ & & Lot & & 5.3 & & 4.5 & 9.8 \\
\hline & - Calibration, Testing \& Startup & $\bar{E}$ & & Lot & & 1.0 & & 0.8 & 1.8 \\
\hline & ( & & & & & & & & \\
\hline & Total Gross Organics Removal & & $\therefore$ & $\therefore \ldots$ & $\because \because \ldots$ & 51.8 & 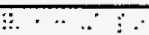 & 19.7 & 71.4 \\
\hline 3 & ARedox \& Nentralization $:-\quad: \cdots: \cdots$ & III & $\because$ & $\because$ & $\therefore \cdots !$ & अ: & $\therefore \cdots \because n$ & $\because:$ & 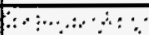 \\
\hline & 1- Redox \& Neutralization Vessel w/ Agitator (400 gals) & $E$ & & 2 & 20 & 40.0 & 5 & 10.0 & 50 \\
\hline & 1- Vessel Transfer Pump ( $25 \mathrm{gpm})$ & $\mathrm{E}$ & & 2 & 10 & 20.0 & 2.5 & 5.0 & 25 \\
\hline & - Allowance for Piping/Mechanical & $\mathbf{E}$ & & Lot & & 18.0 & & 9.0 & 27.0 \\
\hline & - Allowance for Electrical/Control & $\bar{E}$ & & Lot & & 9.0 & & .7 .5 & 16.5 \\
\hline & - Calibration, Testing \& Startup & $\bar{E}$ & & Lot & & 1.7 & & 1.3 & 3.0 \\
\hline & F & & & & & & & & \\
\hline & Total Redox \& Neutralization & & & & $\cdots$ & 88.7 & $\because .{ }^{\prime}$. & 32.8 & 121.5 \\
\hline 4 & Suspended Solids:Fitration $\quad \quad \because \cdots, \because, \quad \cdots$ &. II. & $\therefore$ & $\therefore$ & $\cdots \times$ & $\because \div \div: 4$ & $\because \cdots$ & $\therefore: \cdots$ & $\because \because 69$ \\
\hline & - Suspended Solids Filter (25 gpm) & $E$ & & 2 & 45 & 90.0 & 10.0 & 20.0 & 110.0 \\
\hline & Solids Drum Handler & $\overline{\mathrm{E}}$ & & 1 & 25 & 25.0 & 5.0 & 5.0 & 30.0 \\
\hline & - Allowance for Piping/Mechanical & $\bar{E}$ & & Lot & & 34.5 & $\cdot$ & 15.0 & 49.5 \\
\hline & - Allowance for Electrical/Control & $\bar{E}$ & & Lot & & 17.3 & & 12.5 & 29.8 \\
\hline & - Calibration, Testing \& Startup & $\overline{\mathrm{E}}$ & & Lot & & 3.3 & & 2.1 & 5.4 \\
\hline & $\mathrm{C}^{2}$ & & & & & & & & \\
\hline & Total Suspended Solids Filtration & & & $\because$ & & 170.1 & $\ldots \ldots$ & 54.6 & 224.7 \\
\hline 5 & 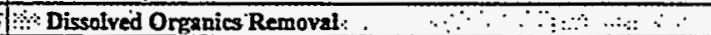 & $\therefore \|$ & $\because$ & $\because$ & 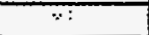 & $\because \vdots \ldots+\ldots$ & 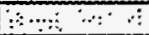 & $\therefore \because$ & $4::^{: \cdot}$ \\
\hline & F Hydrothermal Vessel (2 .5 gpm, Titanium) & $E$ & & 2 & 150 & 300.0 & 40 & 80.0 & 380.0 \\
\hline & - Hydrothermal Heating Unit (220v, $125 \mathrm{~kW})$ & $\overline{\mathrm{E}}$ & & $\overline{2}$ & 75 & 150.0 & 15 & 30.0 & 180.0 \\
\hline & - Air Compressor $(6.500 \mathrm{psi})$ & $E$ & & 2 & 75 & 150.0 & 15 & 30.0 & 180.0 \\
\hline & - Cooler (500 ft2, 7000 psi) & $\bar{E}$ & & 4 & 110 & 440.0 & 18 & 72.0 & 512.0 \\
\hline & - Knock Out Pot ( 200 gals) & $\overline{\mathrm{E}}$ & & 2 & 6 & 12.0 & 1.5 & 3.0 & 15.0 \\
\hline & - Knock Out Pot Transfer Pump (25 gpm) & $\vec{E}$ & & $\overline{2}$ & 8 & 16.0 & 2 & 4.0 & 20.0 \\
\hline & - HEPA Filter & $\mathbf{E}$ & & 2 & 10 & 20.0 & 2.5 & 5.0 & 25.0 \\
\hline & - Vapor Reheater & $\bar{E}$ & & $\frac{\pi}{1}$ & 45 & 45.0 & 12 & 12.0 & 57.0 \\
\hline & - Vapr Phase GAC & $\bar{E}$ & & 2 & 8 & 16.0 & 2 & 4.0 & 20.0 \\
\hline & - Allowance for Piping/Mechanical & $\bar{E}$ & & Lot & & 344.7 & & 144.0 & 488.7 \\
\hline & - Allowance for Electrical/Control & $\bar{E}$ & & Lot & & 172.4 & & 120.0 & 292.4 \\
\hline & - Calibration, Testing \& Startup & $\mathbf{E}$ & & Lot & & 33.3 & & 20.2 & 53.5 \\
\hline & - & & & & & & & & \\
\hline & Total Dissolved Organics Removal & & $\because$ & $\because$ & $\because \because$ & $1,699.4$ & $\therefore \because \cdots$ & 524.2 & $2,223.5$ \\
\hline$\therefore 6$ & Concentration/Dissolved Solids Remaral : & III & $\therefore:$ & $\cdots$ & $\because$ & $\because \cdots$ & $4 \%$ & 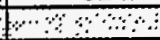 & $\therefore \therefore: \because: \because$ \\
\hline & - Liquid Phase Carbon (250\#) & $\mathrm{E}$ & & 4 & 2 & 8.0 & 0.5 & 2.0 & 10.0 \\
\hline & - R.O. Unit (25 gpm) & $\mathrm{E}$ & & 1 & 140 & 140.0 & 35 & 35.0 & 175.0 \\
\hline & - Concentrate Hold Tank & $\bar{E}$ & & 1 & 10 & 10.0 & 2.5 & 2.5 & 12.5 \\
\hline
\end{tabular}


Figure A-1: Equipment List

Waste Water MTU

\begin{tabular}{|c|c|c|c|c|c|c|c|c|c|}
\hline \multirow{2}{*}{\multicolumn{2}{|c|}{$\begin{array}{l} \\
\end{array}$}} & \multirow{2}{*}{\begin{tabular}{l|} 
FAC. \\
CAT.
\end{tabular}} & \multirow[b]{2}{*}{ HP } & \multicolumn{3}{|c|}{ MATLS. \& EQUIP. } & \multicolumn{3}{|c|}{ INST. COSTS } \\
\hline & & & & QTY & \begin{tabular}{|c|} 
Unit Cost \\
S1000's
\end{tabular} & \begin{tabular}{l|} 
Amounat \\
S1000's
\end{tabular} & $\begin{array}{c}\text { Unit Cost } \\
\text { S1000's }\end{array}$ & \begin{tabular}{l|} 
Amount \\
S1000's
\end{tabular} & $\begin{array}{l}\text { Total } \\
\text { U.O. } \\
\end{array}$ \\
\hline & & $E$ & & 1 & 10 & 10.0 & 3.5 & 3.5 & 13.5 \\
\hline & lon Exchange (25 gpm) & $\bar{E}$ & & 1 & 75 & 75.0 & 15 & 15.0 & 90.0 \\
\hline & - Evaporator with Condensor $(12 \mathrm{gpm})$ & E & & 1 & 751 & 75.0 & 20 & 20.0 & 95.0 \\
\hline & - Evaporator Transfer Pump & $\bar{E}$ & & 1 & 81 & 8.0 & 2 & 2.0 & 10.0 \\
\hline & - Condensor Liquids Pump (12 gpm) & $\mathrm{E}$ & & 1 & 51 & 5.0 & 1 & 1.0 & 6.0 \\
\hline & - Vacuum Pump (10 scfm) & $\bar{E}$ & & 1 & 15 & 15.0 & 4 & 4.0 & 19.0 \\
\hline & Allowance for Piping/Mechanical & $\bar{E}$ & & Lot & & 103.8 & & 51.0 & 154.8 \\
\hline & - Allowance for ElectricallControl & $E$ & & Lot & & 51.9 & & 42.5 & 94.4 \\
\hline & - Calibration, Testing \& Startup & $\bar{E}$ & & Lot & & 10.0 & & 7.1 & 17.2 \\
\hline & - & & & & & & & & \\
\hline & Total Concentration/Dissolved Solids Removal & & $\therefore$ & & & 511.7 & & 185.6 & 697.4 \\
\hline & Treated Water.Sampling & II: & & $\because \ldots$ & $\ddot{*}$ & & & & \\
\hline & - Treated Water Tanks ( 500 gals) & E & & 2 & 10 & 20.0 & 2.5 & 5.0 & 25.0 \\
\hline & - Treated Water Pumps & $E$ & & 2 & 5 & 10.0 & 1.0 & 2.0 & 12.0 \\
\hline & - Allowance for Piping/Mechanical & $\bar{E}$ & & Lot & & 9.0 & & 4.2 & 13.2 \\
\hline & - Allowance for Electrical/Control & $\mathbf{E}$ & & Lot & & 4.5 & & 3.5 & 8.0 \\
\hline & - Calibration. Testing \& Startup & $E$ & & Lot & & 0.9 & & 0.6 & 1.5 \\
\hline & $-2+2$ & & & & & & & & \\
\hline & Total Treated Water Sampling & & & & & 44.4 & & 15.3 & 59.7 \\
\hline & Electrical Distribution and MCC & III & & & & & & & \\
\hline & - Main Control Panel & $E$ & & 10 & 101 & 100.0 & 31 & 30.0 & 130.0 \\
\hline & - Motor Control Center & $\bar{E}$ & & 20 & 1.5 & 30.0 & 0.5 & 10.0 & 40.0 \\
\hline & - CCTV & $\bar{E}$ & & 8 & 10 & 80.0 & 2 & 16.0 & 96.0 \\
\hline & - Telecommunications Equipment & $\bar{E}$ & & 1 & 100 & 100.0 & 25 & 25.0 & 125.0 \\
\hline & - Control Trailer & $\bar{E}$ & & 1 & 200 & 200.0 & 40 & 40.0 & 240.0 \\
\hline & - Allowance for Piping/Mechanical & $\bar{E}$ & & Lot & & 5.1 & & 36.3 & 41.4 \\
\hline & - Allowance for Electrical/Control & $\bar{E}$ & & Lot & & 76.5 & & 72.6 & 149.1 \\
\hline & - Calibration, Testing \& Startup & $\bar{E}$ & & Lot & & 11.8 & & 13.8 & 25.6 \\
\hline & - & & & & & & & & \\
\hline & Total Electrical Distribution and MCC & & & & & 603.4 & & 243.7 & 847.1 \\
\hline 9 & Uthlities\& Mechninical & 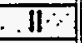 & & $\because \because$ & & $\because$ & & & \\
\hline & - Air Compressor (125 psi) & $E$ & & 1 & 30 & 30.0 & 7.5 & 7.5 & 37.5 \\
\hline & - High Pressure Water Pump & $\bar{E}$ & & 1 & 10 & 10.0 & 2.5 & 2.5 & 12.5 \\
\hline & - Fork Lift & $\bar{E}$ & & 1 & 35 & 35.0 & 2.5 & 2.5 & 37.5 \\
\hline & - Miscellaneous Tools & $\bar{E}$ & & 1 & 75 & 75.0 & 5.0 & 5.0 & 80.0 \\
\hline & - Allowance for Piping/Mechanical & $E$ & & Lot & & 45.0 & & 10.5 & 55.5 \\
\hline & - Allowance for Electrical/Control & E & & Lot & & 22.51 & & 8.8 & 31.3 \\
\hline & - Calibration. Testing \& Startup & $\bar{E}$ & & Lot & & 4.4 & & 1.5 & 5.8 \\
\hline & - & & & & & & & & \\
\hline & Total Utilities \& Mechanical & & & & & 221.9 & & 38.2 & 260.1 \\
\hline .10 & Heiting Ventilation And Exhaust: . & II & & : & & & & & \\
\hline & - Included in Building or Trailer Cost & & & & & & & & \\
\hline & - & & & & & & & & \\
\hline & - & & & & & & & & \\
\hline & Total Heating Ventilation And Exhaust & & & & & & & & \\
\hline 11 & Radiation Mónitoring $\quad ., \cdots \cdot$ & -III . & & 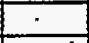 & & & & & \\
\hline & - Area Monitors & $E$ & & 4 & 4 & 16.0 & 1.5 & 6.0 & 22.0 \\
\hline & - Air Monitors & $E$ & & 8 & 10 & 80.01 & 2.0 & 16.0 & 96.0 \\
\hline & - Portal Monitors & $\bar{E}$ & & 4 & 35 & 140.0 & 5.0 & 20.0 & 160.0 \\
\hline & - Allowance for Piping/Mechanical & $E$ & & Lot & & 2.4 & & 12.6 & 15.0 \\
\hline & - Allowance for Electrical/Control & $E$ & & Lot & & 35.4 & & 25.2 & 60.6 \\
\hline & - Calibration, Testing \& Startup & $\bar{E}$ & & Lot & & 5.5 & & 4.8 & 10.3 \\
\hline & - & & & & & & & & \\
\hline & Total Radintion Monitoring & & & $\because$ & $\because$ & 279.2 & & 84.6 & 363.8 \\
\hline 12 & $\begin{array}{lll}* \text { Other.Equipment. } \cdots & \cdots\end{array}$ & .11: & & & & & & & \\
\hline & - Emergency Shower/Decon & $E$ & & Lot & 10 & 10.0 & 1.0 & 1.0 & 11.0 \\
\hline & - Allowance for Piping/Mechanical & $\bar{E}$ & & Lot & & 3.0 & & 0.6 & 3.6 \\
\hline & - Allowance for ElectricallControl & $E$ & & Lot & & 1.5 & & 0.5 & 2.0 \\
\hline & - Calibration. Testing \& Startup & $E$ & & Lot & & 0.3 & & 0.1 & 0.4 \\
\hline & - & & & & & & & & \\
\hline & Total Other Equipment & & & $\ldots$ & $\therefore$ & 14.8 & $\because$ & 2.2 & 17.0 \\
\hline & TrinsportTrailers & 1 & & $\therefore$ & $\because \because \cdot$ & $\because \therefore$ & & & \\
\hline
\end{tabular}


Figure A-1: Equipment List

Waste Water MTU

\begin{tabular}{|c|c|c|c|c|c|c|c|c|}
\hline \multirow[b]{2}{*}{ DESCRIPTION } & \multirow{2}{*}{$\begin{array}{l}\text { FAC. } \\
\text { CAT. }\end{array}$} & \multirow[b]{2}{*}{ HP } & \multicolumn{3}{|c|}{ MATLS. \& EQUIP. } & \multicolumn{3}{|c|}{ INST. COSTS } \\
\hline & & & QTY & $\begin{array}{c}\text { Unit Cost } \\
\text { S1000's }\end{array}$ & $\begin{array}{l}\text { Amount } \\
\text { S1000's }\end{array}$ & $\begin{array}{l}\text { Unit Cost } \\
\text { S1000's }\end{array}$ & $\begin{array}{l}\text { Amount } \\
\text { S1000's }\end{array}$ & $\begin{array}{l}\text { Total } \\
\text { U.O. }\end{array}$ \\
\hline 1- Process Trailer & $E$ & & 4 & 50 & 200.0 & 30 & 120.0 & 320.0 \\
\hline - Allowance for Piping/Mechanical & $\bar{E}$ & & Lot & & 10.0 & & 60.0 & 70.0 \\
\hline - Allowance for Electrical/Control & E & & Lot & & 30.0 & & 60.0 & 90.0 \\
\hline - Calibration, Testing \& Startup & $\bar{E}$ & & Lot & & 4.8 & & 9.6 & 14.4 \\
\hline 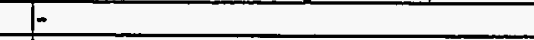 & & & & & & & & \\
\hline Total Transport Trailers & & & $\ldots$ & 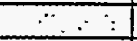 & 244.8 & $\because \because$ & 249.6 & 494.4 \\
\hline AF: $: \because \quad \therefore \quad: \because$ & $\therefore$ & & $\ldots$ & & 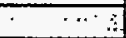 & & & : \\
\hline
\end{tabular}


Table A-2: Development, Testing \& Evaluation Cost Estimate

Waste Water MTU

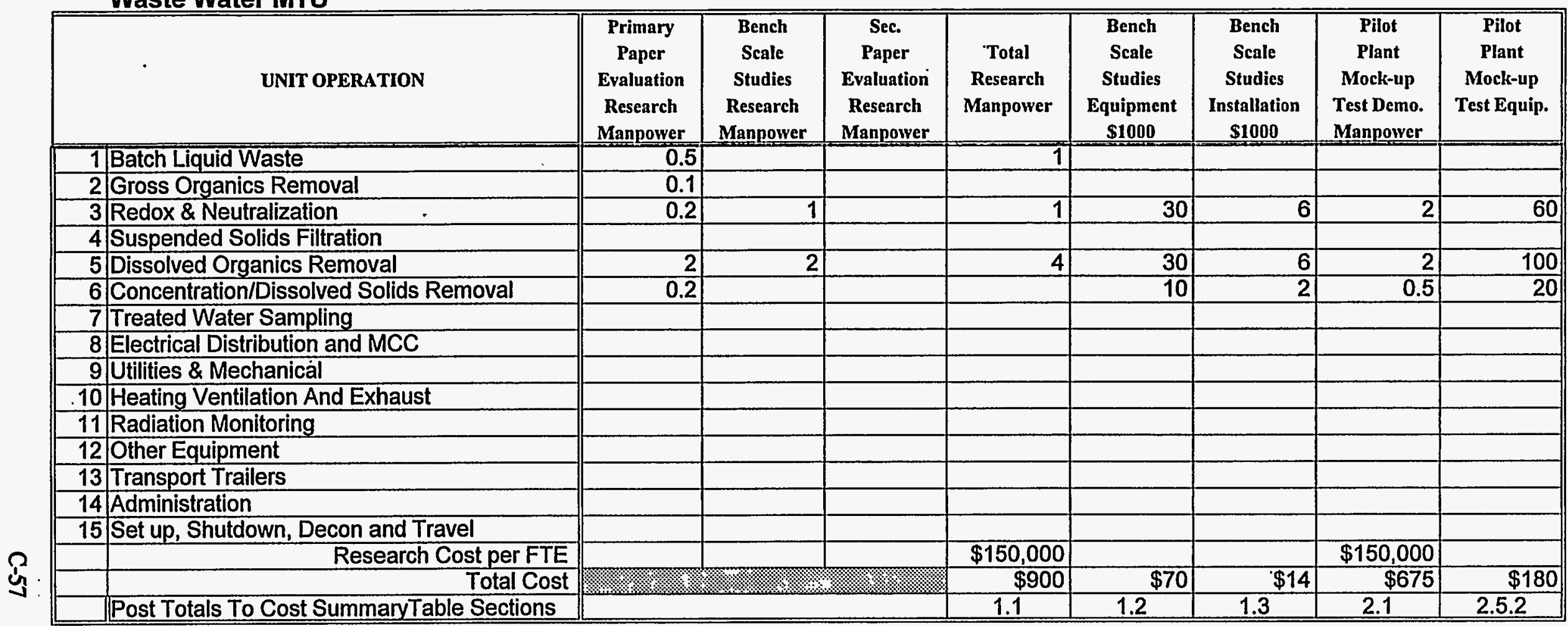


Table A-3: Materials and Equipment Cost Summary Waste Water MTU

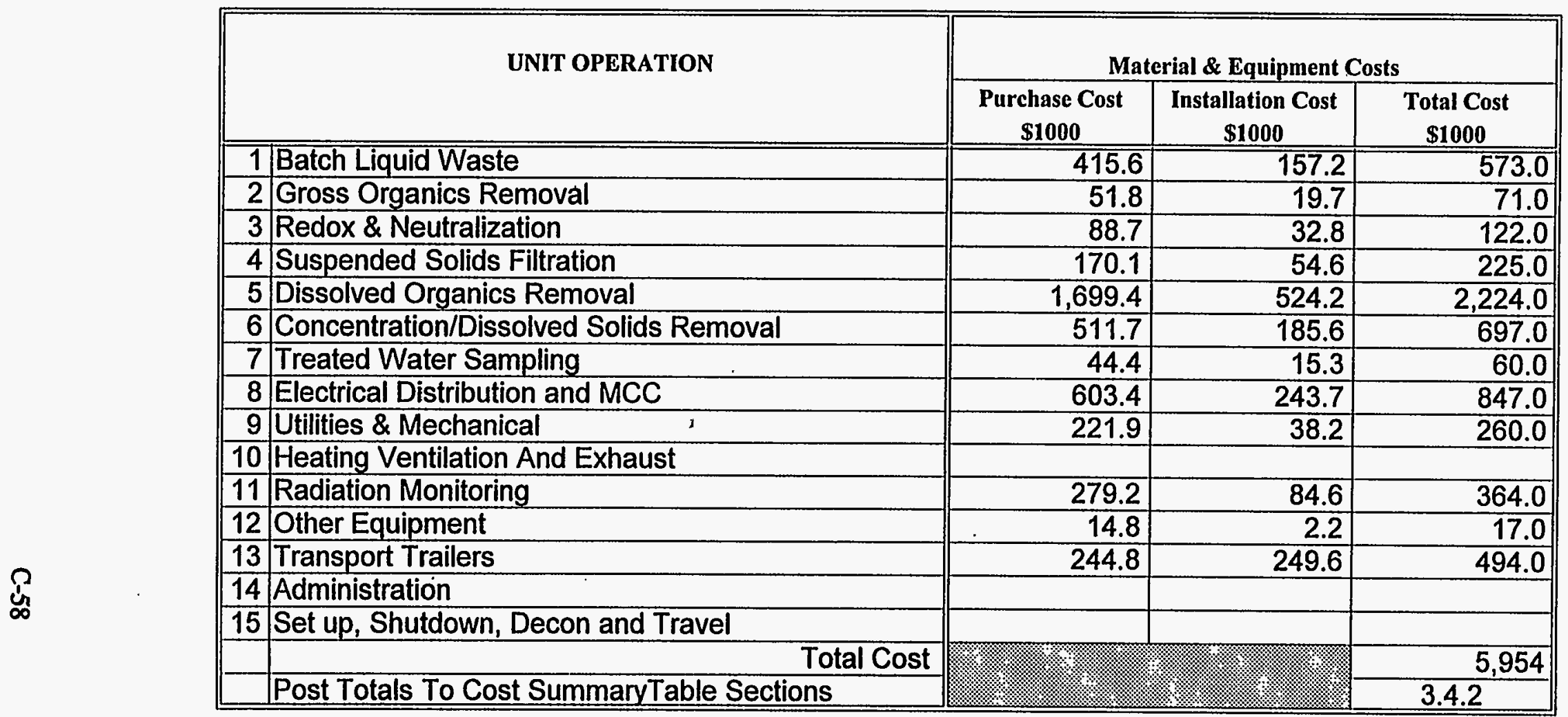


Table A-4: Annual Operating \& Maintenance Cost Summary Waste Water MTU

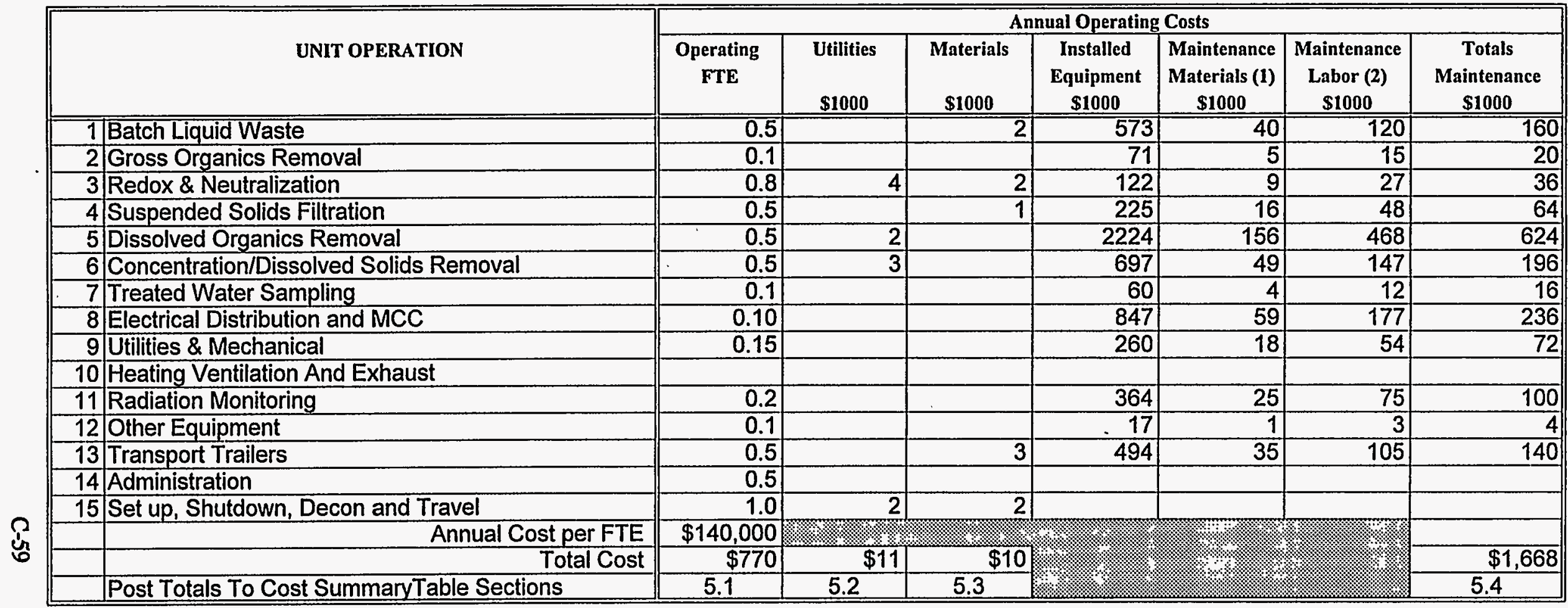

Notes:

1. Annual Maintenance Material is assumed to be $7 \%$ of equipment capital cost.

2. Annual Maintenance Labor is assumed to be $300 \%$ of maintenance material cost. 
Table A-5: Decontamination and Decommissioning Cost Summary Waste Water MTU

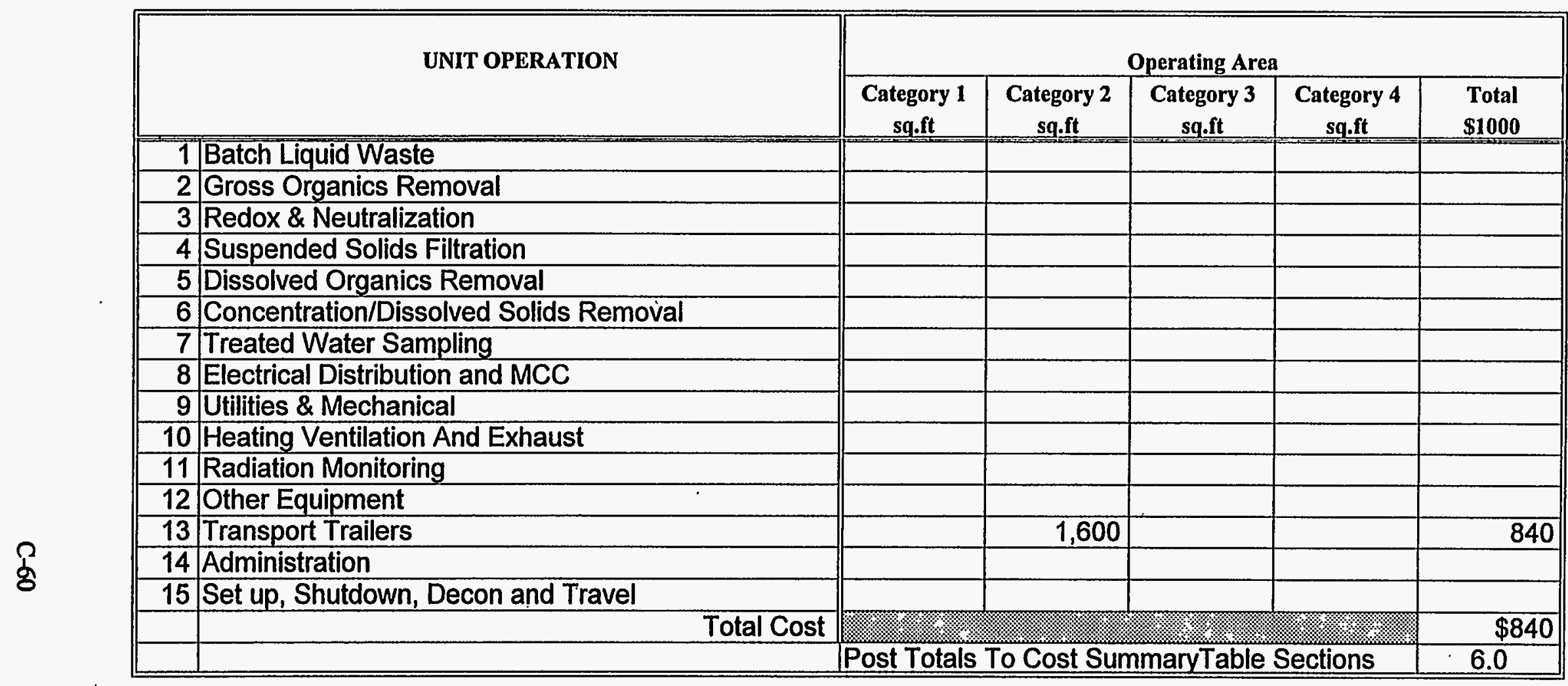


Figure A-6: Equipment List

Organics MTU

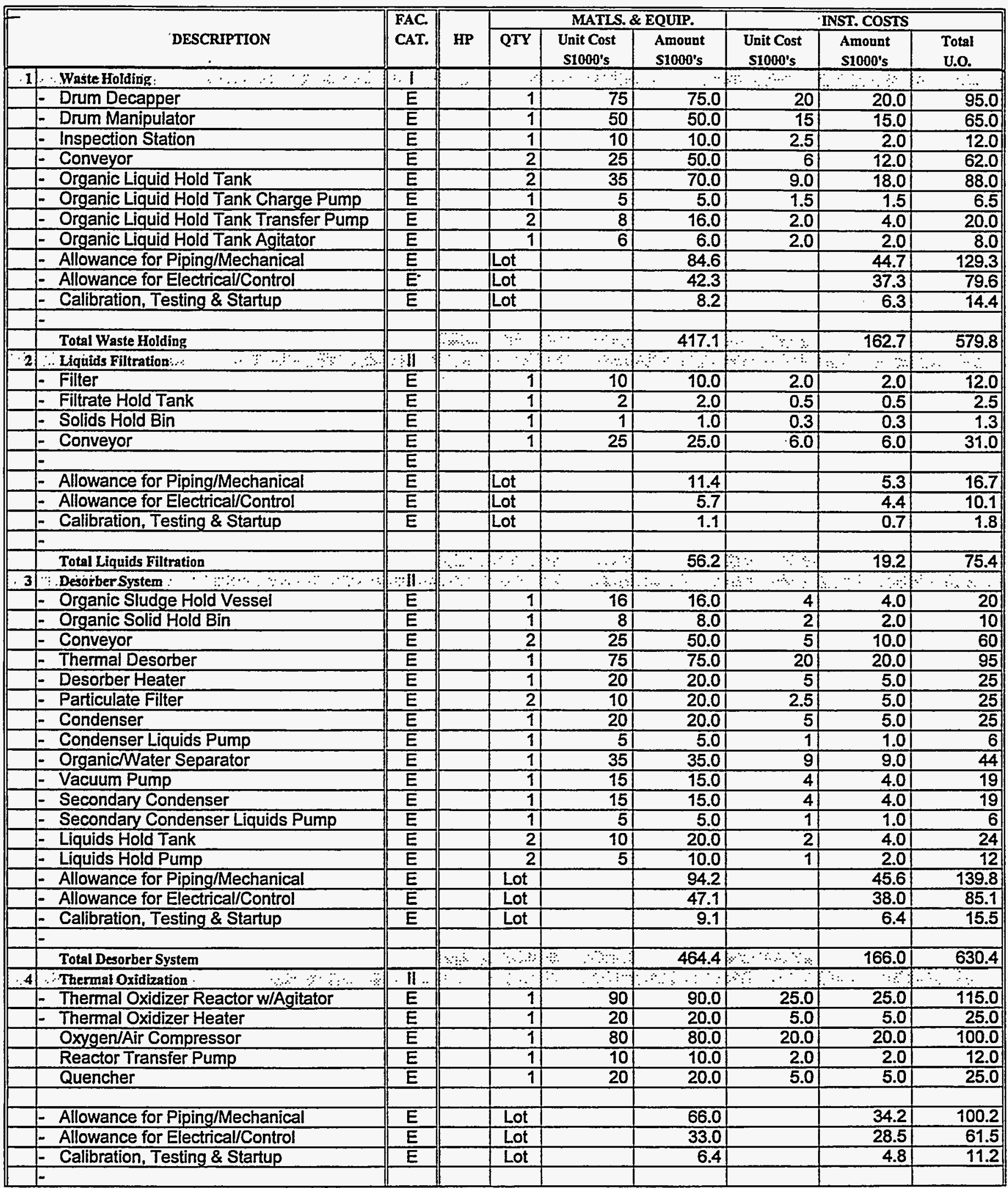


Figure A-6: Equipment List Organics MTU

\begin{tabular}{|c|c|c|c|c|c|c|c|c|c|}
\hline \multirow{2}{*}{\multicolumn{2}{|c|}{ DESCRIPTION }} & \multirow{2}{*}{$\begin{array}{l}\text { FAC. } \\
\text { CAT. }\end{array}$} & \multirow[b]{2}{*}{ HP } & \multicolumn{3}{|c|}{ MATLS.\& EQUIP. } & \multicolumn{3}{|c|}{ INST. COSTS } \\
\hline & & & & QTY & $\begin{array}{l}\text { Unit Cost } \\
\text { S1000's }\end{array}$ & $\begin{array}{l}\text { Amount } \\
\text { S1000's }\end{array}$ & $\begin{array}{l}\text { Unit Cost } \\
\text { S1000's } \\
\end{array}$ & \begin{tabular}{|l|} 
Amount \\
S1000's \\
\end{tabular} & $\begin{array}{l}\text { Total } \\
\text { U.0. } \\
\end{array}$ \\
\hline & Total Thermal Oxidization & & & & & 325.4 & & 124.5 & 449.9 \\
\hline & Air Pollution Control .. & II & & & & & $\cdot \cdot$ & & \\
\hline & - Scrubber & $\bar{E}$ & & 1 & 25 & 25.0 & 5 & 5.0 & 30.0 \\
\hline & - Scrubber Circulation Pump & $\overrightarrow{\mathrm{E}}$ & & 1 & 10 & 10.0 & 2.5 & 2.5 & 12.5 \\
\hline & - Caustic Hold Tank & $E$ & & 1 & 10 & 10.0 & 2 & 2.0 & 12.0 \\
\hline & - Caustic Hold Tank Charge Pump & $\bar{E}$ & & 1 & 5 & 5.0 & 1 & 1.0 & 6.0 \\
\hline & - Caustic Feed Pump & $\bar{E}$ & & 1 & 5 & 5.0 & 1 & 1.0 & 6.0 \\
\hline & - Hepa Filter & $\bar{E}$ & & 2 & 10 & 20.0 & 2.5 & 5.0 & 25.0 \\
\hline & - GAC Vessel & $\mathrm{E}$ & & 2 & 10 & 20.0 & 2.5 & 5.0 & 25.0 \\
\hline & F Vapor Reheater & $E$ & & 1 & 18 & 18.0 & 5 & 5.0 & 23.0 \\
\hline & - & $\bar{E}$ & & & & & & & \\
\hline & - Allowance for Piping/Mechanical & $\bar{E}$ & & Lot & & 33.9 & & 15.9 & 49.8 \\
\hline & - Allowance for Electrical/Control & $\bar{E}$ & & Lot & & 17.0 & & 13.3 & 30.2 \\
\hline & - Calibration, Testing \& Startup & $E$ & & Lot & & 3.3 & & 2.2 & 5.5 \\
\hline & - & & & & & & & & \\
\hline & Total Air Pollution Control & & & & & 167.1 & & 57.9 & 225.0 \\
\hline 6 & $\because$ Drcim Encapsulation: $\because$ & $\because \mathrm{II}$ & & & & $\therefore 1$ & $\therefore$ & & \\
\hline & - Additives Bin & $E$ & & 2 & 8 & 16.0 & 2 & 4.0 & 20.0 \\
\hline & Additives Mixer & $\overline{\mathrm{E}}$ & & 1 & 30 & 30.0 & 9 & 9.0 & 39.0 \\
\hline & Drum Wash System & $\mathbf{E}$ & & 1 & 18 & 18.0 & 4 & 4.0 & 22.0 \\
\hline & - Conveyor & $\bar{E}$ & & 2 & $25 \mid$ & 50.0 & 6 & 12.0 & 62.0 \\
\hline & - Water Supply Pump & $\bar{E}$ & & 1 & 10 & 10.0 & 2 & 2.0 & 12.0 \\
\hline & - Polymer Heater & $\bar{E}$ & & 1 & 40 & 40.0 & 5 & 5.0 & 45.0 \\
\hline & - Allowance for Piping/Mechanical & $\bar{E}$ & & Lot & & 49.2 & & 21.6 & 70.8 \\
\hline & - Allowance for Electrical/Control & $E$ & & Lot & & 24.6 & & 18.0 & 42.6 \\
\hline & - Calibration, Testing \& Startup & $E$ & & Lot & & 4.8 & & 3.0 & 7.8 \\
\hline & - & & & & & & & & \\
\hline & Total Drum Encapsulation & & & 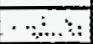 & : & 242.6 & $\therefore \cdots$ & 78.6 & 321.2 \\
\hline & IElectrical Distribution and.MCC & IIII & & $\%$ & $\because$ & $\because \because$ & $\%$ & $\because \ldots$ & 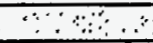 \\
\hline & - Main Control Panel & $E$ & & 10 & 10 & 100.0 & & 30.0 & 130.0 \\
\hline & - Motor Control Center & $E$ & & 20 & 1.5 & 30.0 & 0.5 & 10.0 & 40.0 \\
\hline & - CCTV & $\bar{E}$ & & 8 & .10 & 80.0 & 2 & 16.0 & 96.0 \\
\hline & - Telecommunications Equipment & $\vec{E}$ & & 1 & 100 & 100.0 & 25 & 25.0 & 125.0 \\
\hline & - Control Trailer & $\bar{E}$ & & 1 & 200 & 200.0 & 40 & 40.0 & 240.0 \\
\hline & - Allowance for Piping/Mechanical & $\bar{E}$ & & Lot & & 5.1 & & 36.3 & 41.4 \\
\hline & - Allowance for Electrical/Control & $\bar{E}$ & & Lot & & 76.5 & & 72.6 & 149.1 \\
\hline & - Calibration, Testing \& Startup & $\bar{E}$ & & Lot & & 11.8 & & 13.8 & 25.6 \\
\hline & - & & & & & & & & \\
\hline & Total Electrical Distribution and MCC & & & &.. & 603.4 & & 243.7 & 847.1 \\
\hline 8 & Utilities \& Mechanical & II & & 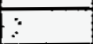 & & 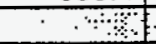 & $\because \because \quad$ & $\because$ & 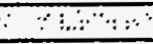 \\
\hline & - Air Compressor (125 psi) & $\bar{E}$ & & 1 & 30 & 30.0 & 7.5 & 7.5 & 37.5 \\
\hline & - High Pressure Water Pump & $E$ & & 1 & 10 & 10.0 & 2.5 & 2.5 & 12.5 \\
\hline & - Fork Lift & $E$ & & 1 & 35 & 35.0 & 2.5 & 2.5 & 37.5 \\
\hline & - Miscellaneous Tools & $\bar{E}$ & & 1 & 75 & 75.0 & 5.0 & 5.0 & 80.0 \\
\hline & - Allowance for Piping/Mechanical & $E$ & & Lot & & 45.0 & & 10.5 & 55.5 \\
\hline & - Allowance for Electrical/Control. & $E$ & & Lot & & 22.5 & & 8.8 & 31.3 \\
\hline & - Calibration, Testing \& Startup & $E$ & & Lot & & 4.4 & & 1.5 & 5.8 \\
\hline & - & & & & & & & & \\
\hline & Total Utilities \& Mechanical & & $\cdots$ & i? & $\therefore$ & 221.9 & $\because .0$ & 38.2 & 260.1 \\
\hline 9 & Hèating Yëntilation And Exhaust- & ill. & $\because$ & & 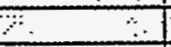 & $\therefore \because$ & $5: \because: 2$ & 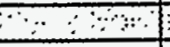 & Q \\
\hline & - Included in Building or Trailer Cost. & & & & & & & & \\
\hline & & & & & & & & & \\
\hline & & & & & & & & & \\
\hline & Total Heating Ventilation And Exhaust & & & $\because \cdots:$ & $\because \dot{k}$ & & 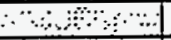 & & \\
\hline 10 & 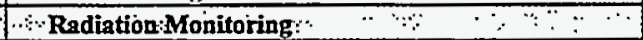 & \|\|$^{*}$ & & $\because \div$ & $\%$ & $\therefore \ldots$ & m & $\div \because \ldots$ & $\therefore$ \\
\hline & Area Monitors & $E$ & & 4 & 4 & 16.0 & 1.5 & 6.0 & 22.0 \\
\hline
\end{tabular}


Figure A-6: Equipment List Organics MTU

\begin{tabular}{|c|c|c|c|c|c|c|c|c|c|}
\hline \multirow[t]{2}{*}{-} & \multirow[b]{2}{*}{ DESCRIPTION } & \multirow{2}{*}{$\begin{array}{l}\text { FAC. } \\
\text { CAT. }\end{array}$} & \multirow[b]{2}{*}{$\mathbf{H P}$} & \multicolumn{3}{|c|}{ MATLS. \& EQUTP. } & \multicolumn{3}{|c|}{ INST. COSTS } \\
\hline & & & & QTY & $\begin{array}{l}\text { Unit Cost } \\
\text { S1000's }\end{array}$ & $\begin{array}{l}\text { Amount } \\
\text { S1000's }\end{array}$ & $\begin{array}{l}\text { Unit Cost } \\
\text { S1000's }\end{array}$ & $\begin{array}{l}\text { Amount } \\
\text { S1000's }\end{array}$ & $\begin{array}{l}\text { Total } \\
\text { U.O. }\end{array}$ \\
\hline & - Air Monitors & $E$ & & 8 & 10 & 80.0 & 2.0 & 16.0 & 96.0 \\
\hline & - Allowance for Piping/Mechanical & $\bar{E}$ & & Lot & & 2.4 & & 12.6 & 15.0 \\
\hline & - Allowance for Electrical/Control & $E$ & & Lot & & 35.4 & & 25.2 & 60.6 \\
\hline & - Calibration, Testing \& Startup & $\overline{\mathrm{E}}$ & & Lot & & 5.5 & & 4.8 & 10.3 \\
\hline 11 & - Other Equipment:" & $\because 11$ & & & & $\because$ & & & \\
\hline & - Emergency Shower/Decon & $E$ & & Lot & 10 & 10.0 & 1.0 & 1.0 & 11.0 \\
\hline & - Allowance for Piping/Mechanical & $\bar{E}$ & & Lot & & 3.0 & & 0.6 & 3.6 \\
\hline & - Allowance for Electrical/Control & $\bar{E}$ & & Lot & & 1.5 & & 0.5 & 2.0 \\
\hline & - Calibration, Testing \& Startup & $E$ & & Lot & & 0.3 & & 0.1 & 0.4 \\
\hline & - & & & & & & & & \\
\hline & - Allowance for Electrical/Control & $E$ & & Lot & & 30.0 & & 60.0 & 90.0 \\
\hline & - Calibration, Testing \& Startup & $E$ & & Lot & & 4.8 & & 9.6 & 14.4 \\
\hline & - & & & & & & & & \\
\hline & Total Transport Trailers & & & & & 244.8 & & 249.6 & 494.4 \\
\hline & $\because \because \because \because, \because$ & $\because \because$ & & & & & & & \\
\hline
\end{tabular}


Table A-7: Development, Testing \& Evaluation Cost Estimate Organics MTU

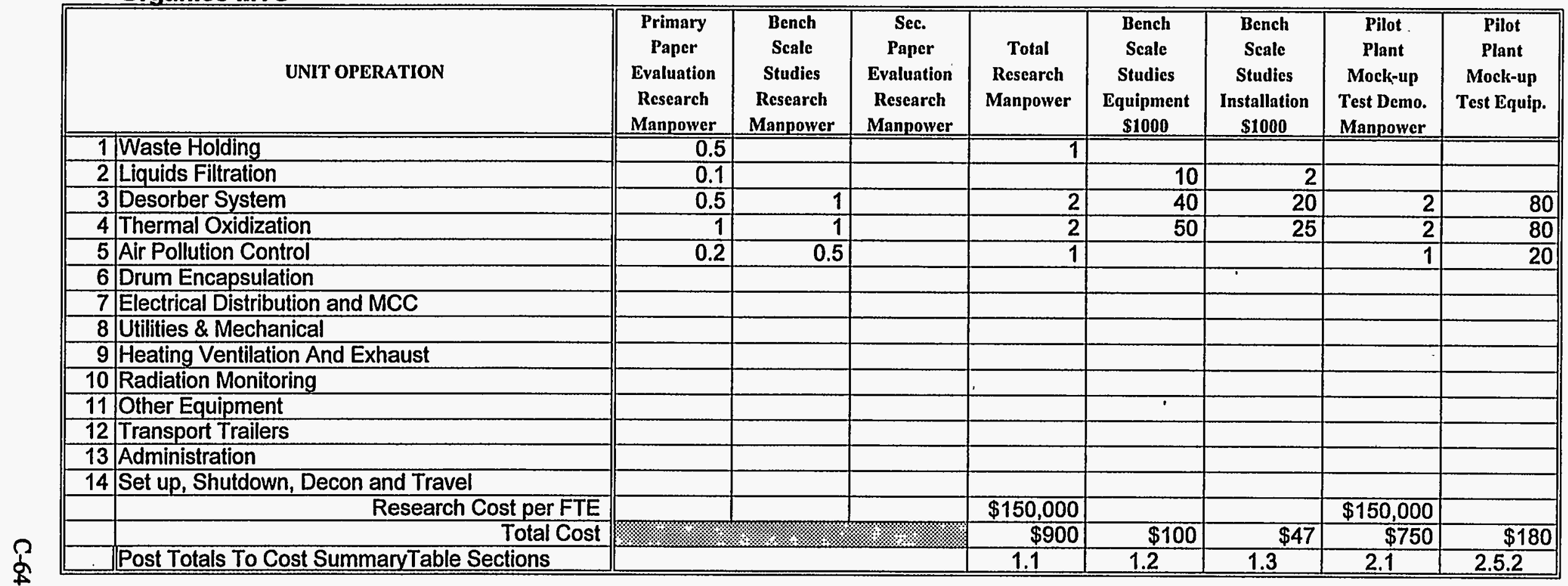


Table A-8: Materials and Equipment Cost Summary Organics MTU

\&

\begin{tabular}{|c|c|c|c|c|}
\hline \multirow{2}{*}{\multicolumn{2}{|c|}{ UNIT OPERATION }} & \multicolumn{3}{|c|}{ Material \& Equipment Costs } \\
\hline & & $\begin{array}{c}\text { Purchase Cost } \\
\$ 1000 \\
\end{array}$ & \begin{tabular}{|c} 
Installation Cost \\
$\$ 1000$
\end{tabular} & $\begin{array}{c}\text { Total Cost } \\
\$ 1000 \\
\end{array}$ \\
\hline & Waste Holding & 417.1 & 162.7 & 580 \\
\hline & Liquids Filtration & 56.2 & 19.2 & 75 \\
\hline & Desorber System & 464.4 & 166.0 & 630 \\
\hline 4 & Thermal Oxidization & 325.4 & 124.5 & 450 \\
\hline & Air Pollution Control & 167.1 & 57.9 & 225 \\
\hline & Drum Encapsulation & 242.6 & 78.6 & 321 \\
\hline & Electrical Distribution and MCC & 603.4 & 243.7 & 847 \\
\hline 8 & Utilities \& Mechanical & 221.9 & 38.2 & 260 \\
\hline \multicolumn{5}{|c|}{9 Heating Ventilation And Exhaust } \\
\hline 10 & Radiation Monitoring & 279.2 & 84.6 & 364 \\
\hline 11 & Other Equipment & 14.8 & 2.2 & 17 \\
\hline 12 & Transport Trailers & 244.8 & 249.6 & 494 \\
\hline \multicolumn{5}{|c|}{13 Administration } \\
\hline \multicolumn{5}{|c|}{14 Set up, Shutdown, Decon and Travel } \\
\hline & & & & \\
\hline & Total Cost & & & $\$ 4,263$ \\
\hline & Post Totals To Cost SummaryTable Sections & & & 3.4 .2 \\
\hline
\end{tabular}

J:linellportable.wk4 
Table A-9: Annual Operating \& Maintenance Cost Summary

Organics MTU

\begin{tabular}{|c|c|c|c|c|c|c|c|c|}
\hline \multirow{2}{*}{\multicolumn{2}{|c|}{ UNIT OPERATION }} & \multicolumn{7}{|c|}{ Annual Operating Costs } \\
\hline & & $\begin{array}{c}\text { Operating } \\
\text { FTE }\end{array}$ & $\begin{array}{l}\text { Utilities } \\
\$ 1000 \\
\end{array}$ & $\begin{array}{c}\text { Materials } \\
\$ 1000 \\
\end{array}$ & $\begin{array}{c}\text { Installed } \\
\text { Equipment } \\
\$ 1000 \\
\end{array}$ & $\begin{array}{c}\text { Maintenance } \\
\text { Materials (1) } \\
\$ 1000 \\
\end{array}$ & \begin{tabular}{c|} 
Maintenance \\
Labor (2) \\
$\$ 1000$ \\
\end{tabular} & $\begin{array}{c}\text { Totals } \\
\text { Maintenance } \\
\$ 1000 \\
\end{array}$ \\
\hline & Waste Holding & 0.5 & & 2 & 580 & 41 & 123 & 164 \\
\hline & Liquids Filtration & 0.4 & & 1 & 75 & 5 & 15 & 20 \\
\hline 3 & Desorber System & 0.8 & 3 & 1 & 630 & 44 & 132 & 176 \\
\hline 4 & Thermal Oxidization & 0.75 & 2 & 1 & 450 & 32 & 96 & 128 \\
\hline 5 & Air Pollution Control & 0.1 & 1 & 3 & 225 & 16 & 48 & 64 \\
\hline 6 & Drum Encapsulation & 0.5 & 1 & 6 & 321 & 22 & 66 & 88 \\
\hline 7 & Electrical Distribution and MCC & 0.1 & & & 847 & 59 & 177 & 236 \\
\hline 8 & Utilities \& Mechanical & 0.10 & & & 260 & 18 & 54 & 72 \\
\hline 9 & Heating Ventilation And Exhaust & & & & & & & \\
\hline 10 & Radiation Monitoring & 0.20 & & & 364 & 25 & 75 & 100 \\
\hline 11 & Other Equipment & 0.1 & & & 17 & 1 & 3 & 4 \\
\hline 12 & Transport Trailers & 0.5 & & 3 & 494 & 35 & 105 & 140 \\
\hline 13 & Administration & 0.5 & & & & & & \\
\hline 14 & Set up, Shutdown, Decon and Travel & 1.0 & $\overline{2}$ & 2 & & & & \\
\hline & Annual Cost per FTE & $\$ 140,000$ & & & & & & \\
\hline & $\begin{aligned} & \text { Total Cost } \\
&\end{aligned}$ & $\$ 770$ & $\$ 9$ & $\$ 19$ & & & 1/. & $\$ 1,192$ \\
\hline & Post Totals To Cost SummaryTable Sections & 5.1 & 5.2 & 5.3 & & $=$ & 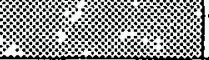 & 5.4 \\
\hline
\end{tabular}

Notes:

1. Annual Maintenance Material is assumed to be $7 \%$ of equipment capital cost.

2. Annual Maintenance Labor is assumed to be $300 \%$ of maintenance material cost. 
Table A-10: Decontamination and Decommissioning Cost Summary Organics MTU

\begin{tabular}{|c|c|c|c|c|c|c|}
\hline \multirow{2}{*}{\multicolumn{2}{|c|}{ UNIT OPERATION }} & \multicolumn{5}{|c|}{ Operating Area } \\
\hline & & $\begin{array}{c}\text { Category } 1 \\
\text { sq.ft } \\
\end{array}$ & $\begin{array}{c}\text { Category } 2 \\
\text { sq.it } \\
\end{array}$ & $\begin{array}{c}\text { Category } 3 \\
\text { sq.ft } \\
\end{array}$ & $\begin{array}{c}\text { Category } 4 \\
\text { sq.it } \\
\end{array}$ & $\begin{array}{r}\text { Total } \\
\$ 1000 \\
\end{array}$ \\
\hline \multicolumn{7}{|c|}{1 Waste Holding } \\
\hline \multicolumn{7}{|c|}{2 Liquids Filtration } \\
\hline \multicolumn{7}{|c|}{3 Desorber System } \\
\hline \multicolumn{7}{|c|}{\begin{tabular}{|l|l|}
4 & Thermal Oxidization \\
\end{tabular}} \\
\hline \multicolumn{7}{|c|}{\begin{tabular}{l|l}
5 & Air Pollution Control \\
\end{tabular}} \\
\hline \multicolumn{7}{|c|}{6 Drum Encapsulation } \\
\hline \multicolumn{7}{|c|}{7 Electrical Distribution and MCC } \\
\hline \multicolumn{7}{|c|}{8 Utilities \& Mechanical } \\
\hline \multicolumn{7}{|c|}{9 Heating Ventilation And Exhaust } \\
\hline \multicolumn{7}{|c|}{10 Radiation Monitoring } \\
\hline \multicolumn{7}{|c|}{11 Other Equipment } \\
\hline 12 & \multicolumn{6}{|l|}{2 Transport Trailers } \\
\hline 13 & \multicolumn{6}{|l|}{3 Administration } \\
\hline \multirow[t]{2}{*}{14} & \multicolumn{6}{|l|}{ Set up, Shutdown, Decon and Travel } \\
\hline & Total Cost & 18. & 4 & 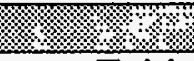 & & $\$ 840$ \\
\hline & & Post Totals & To Cost Sur & ImaryTable & Sections & 6.0 \\
\hline
\end{tabular}


Figure A-11: Equipment List

Debris MTU

\begin{tabular}{|c|c|c|c|c|c|c|c|c|c|}
\hline \multirow{2}{*}{\multicolumn{2}{|c|}{ DESCRIPTION }} & \multirow{2}{*}{$\begin{array}{l}\text { FAC. } \\
\text { CAT. }\end{array}$} & \multirow[b]{2}{*}{ HP } & \multicolumn{3}{|c|}{ MATLS. \& EQUIP. } & \multicolumn{3}{|c|}{ INST. COSTS } \\
\hline & & & & QTY & $\begin{array}{c}\text { Unit Cost } \\
\text { S1000's } \\
\end{array}$ & $\begin{array}{l}\text { Amount } \\
\text { S1000's } \\
\end{array}$ & $\begin{array}{c}\text { Unit Cost } \\
\text { s1000's } \\
\end{array}$ & $\begin{array}{l}\text { Amount } \\
\text { S1000's } \\
\end{array}$ & $\begin{array}{l}\text { Total } \\
\text { U.0. } \\
\end{array}$ \\
\hline & L OpeilSort: $\quad: \quad: \quad \because \quad \cdots$ & $\mathrm{i}$ & $\therefore$ & & $\because: \ldots$ & & & & \\
\hline & - Drum Decapper & $E$ & & 1 & 75 & 75.0 & 20 & 20.0 & 95.0 \\
\hline & - Input Conveyor & $E$ & & 1 & 25 & 25.0 & 6 & 2.0 & 27.0 \\
\hline & - Glove Box & E & & 1 & 75 & 75.0 & 15 & 15.0 & 90.0 \\
\hline & - Sort Table & $E$ & & 2 & 5 & 10.0 & 1.5 & 3.0 & 13.0 \\
\hline & - Drum Manipulator & $E$ & & 1 & 50 & 50.0 & 15 & 15.0 & 65.0 \\
\hline & - Exit Conveyor & $E$ & & 1 & 25 & 25.0 & 6 & 6.0 & 31.0 \\
\hline & - Geiger Counter & $E$ & & 1 & 10 & 10.0 & 1 & 1.0 & 11.0 \\
\hline & - Alpha Counter & $E$ & & 1 & 50 & 50.0 & 1 & 1.0 & 51.0 \\
\hline & - Gamma Counter & $E$ & & 1 & 50 & 50.0 & 1 & 1.0 & 51.0 \\
\hline & - Dust Collection & $E$ & & 1 & 100 & 100.0 & 25 & 25.0 & 125.0 \\
\hline & - Allowance for Piping/Mechanical & $E$ & & Lot & & 23.5 & & 44.5 & 68.0 \\
\hline & - Allowance for Electrical/Control & $E$ & & Lot & & 70.5 & & 44.5 & 115.0 \\
\hline & - Calibration, Testing \& Startup & $E$ & & Lot & & 11.3 & & 7.1 & 18.4 \\
\hline & F & & & & & & & & \\
\hline & Total Open/Sort & & $\cdots$ & $\ldots$ & 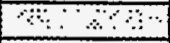 & 575.3 & $\because$ & 185.1 & 760.4 \\
\hline 2 & Reprek : : : : & $1 \ldots$ & & $a$ & $\therefore$ & $\because \ldots$ & $\therefore \because$ & & \\
\hline & - Drum Conveyor & $E$ & & 3 & 25 & 75.0 & 5 & 15.0 & 90.0 \\
\hline & - Glove Box & $E$ & & 1 & 75 & 75.0 & 15 & 15.0 & 90.0 \\
\hline & - Drum Manipulator & $E$ & & 1 & 50 & 50.0 & 15 & 15.0 & 65.0 \\
\hline & - & & & & & & & & \\
\hline & - Allowance for Piping/Mechanical & $\bar{E}$ & & Lot & & 10.0 & & 22.5 & 32.5 \\
\hline & - Allowance for Electrical/Control & $\bar{E}$ & & Lot & & 30.0 & & 22.5 & 52.5 \\
\hline & - Calibration, Testing \& Startup & $\mathbf{E}$ & & Lot & & 4.8 & & 3.6 & 8.4 \\
\hline & - & & & & & & & & \\
\hline & \begin{tabular}{|l} 
Total Repack \\
\end{tabular} & & \# & $\because$ & $\%$ & 244.8 & $\because \%$ & 93.6 & 338.4 \\
\hline & Grishistiear: & $1 \%$ & $\because$ & ( ) & mas & \%० & , $\cdots$ & $\cdots$ & \\
\hline & - Size Reduction Table & $E$ & & 1 & 20 & 20.0 & 5 & 5.0 & 25 \\
\hline & - Glove Box & $E$ & & 1 & 75 & 75.0 & 25 & 25.0 & 100 \\
\hline & - Dust Collection & $E$ & & 1 & 100 & 100.0 & 25 & 25.0 & 125 \\
\hline & - Conveyor & $\bar{E}$ & & 2 & 25 & 50.0 & 5 & 10.0 & 60 \\
\hline & - Shredder & $E$ & & 1 & 100 & 100.0 & 25 & 25.0 & 125 \\
\hline & - Allowance for Piping/Mechanical & $E$ & & Lot & & 17.3 & & 45.0 & 62.3 \\
\hline & - Allowance for Electrical/Control & $\bar{E}$ & & Lot & & 51.8 & & 45.0 & 96.8 \\
\hline & - Calibration, Testing \& Startup & $E$ & & Lot & & 8.3 & & 7.2 & 15.5 \\
\hline & - & & & & & & & & \\
\hline & Total Crush/Shear & & &..$:$ & $\because \cdots::$ & 422.3 & 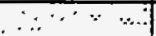 & 187.2 & 609.5 \\
\hline 4 & al Distribution and'MCC & IIIL: & $\therefore$ & $\therefore$ & ब & 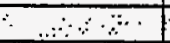 & ध & & $\because \because$ \\
\hline & - Main Control Panel & $E$ & & 6 & 10 & 60.0 & 3 & 18.0 & 78.0 \\
\hline & - Motor Control Center & $\bar{E}$ & & 10 & 1.5 & 15.0 & 0.5 & 5.0 & 20.0 \\
\hline & - CCTV & $E$ & & 4 & 10 & 40.0 & 2 & 8.0 & 48.0 \\
\hline & - Telecommunications Equipment & $\bar{E}$ & & 1 & 100 & 100.0 & 25 & 25.0 & 125.0 \\
\hline & - Control Trailer & $\bar{E}$ & & 1 & 200 & 200.0 & 40 & 40.0 & 240.0 \\
\hline & - Allowance for Piping/Mechanical & $\bar{E}$ & & Lot & & 4.2 & & 28.8 & 33.0 \\
\hline & - Allowance for Electrical/Control & $E$ & & Lot & & 62.3 & & 57.6 & 119.9 \\
\hline & - Calibration, Testing \& Startup & $\mathrm{E}$ & & Lot & & 9.6 & & 10.9 & 20.6 \\
\hline & - & & & & & & & & \\
\hline & Total Electrical Distribution and MCC & & $\because \cdots$ & 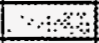 & 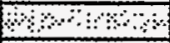 & 491.0 & n+: & 193.3 & 684.4 \\
\hline 5 & 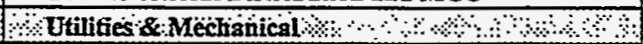 & Ill.: & $\therefore \cdots$ & m & $\because \because \cdots$ & $\because$ & से & $\because \%$ & 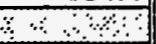 \\
\hline & - Air Compressor (125 psi) & $E$ & & 1 & 30 & 30.0 & 7.5 & 7.5 & 37.5 \\
\hline & - High Pressure Water Pump & $\mathbf{E}$ & & 1 & 10 & 10.0 & 2.5 & 2.5 & 12.5 \\
\hline & Fork Lift & $E$ & & 1 & 35 & 35.0 & 2.5 & 2.5 & 37.5 \\
\hline & - Miscellaneous Tools & $\bar{E}$ & & 1 & 50 & 50.0 & 3.0 & 3.0 & 53.0 \\
\hline & - Allowance for Piping/Mechanical & $\bar{E}$ & & Lot & & 37.5 & & 9.3 & 46.8 \\
\hline & - Allowance for ElectricallControl & $\bar{E}$ & & Lot & & 18.8 & & 7.8 & 26.5 \\
\hline & - Calibration, Testing \& Startup & $\bar{E}$ & & Lot & & 3.6 & & 1.3 & 4.9 \\
\hline & & & & & & & & & \\
\hline
\end{tabular}


Figure A-11: Equipment List Debris MTU

\begin{tabular}{|c|c|c|c|c|c|c|c|c|c|}
\hline & \multirow[b]{2}{*}{ DESCRIPTION } & \multirow{3}{*}{$\begin{array}{l}\text { FAC. } \\
\text { CAT. }\end{array}$} & \multirow[b]{2}{*}{ HP } & \multicolumn{3}{|c|}{ MATLS. \& EQUIP. } & \multicolumn{3}{|c|}{ INST. COSTS } \\
\hline & & & & QTY & $\begin{array}{l}\text { Unit Cost } \\
\text { S1000's }\end{array}$ & $\begin{array}{l}\text { Amount } \\
\text { S1000's }\end{array}$ & $\begin{array}{l}\text { Unit Cost } \\
\text { S1000's }\end{array}$ & $\begin{array}{l}\text { Amount } \\
\text { S1000's }\end{array}$ & $\begin{array}{l}\text { Total } \\
\text { U.O. }\end{array}$ \\
\hline & Total Utilities \& Mechanical & & & & $\therefore \quad \therefore$ & 184.9 & $=$ & 33.9 & 218.7 \\
\hline \multirow{3}{*}{6} & - Included in Building or Trailer Cost & & & & & & & & \\
\hline & - & & & & & & & & \\
\hline & - & & & & & & & & \\
\hline \multirow{6}{*}{7} & - Area Monitors & $E$ & & 2 & 4 & 8.0 & $1.5 \mid$ & 3.0 & 11.0 \\
\hline & - Air Monitors & $E$ & & 4 & 10 & 40.0 & 2.0 & 8.0 & 48.0 \\
\hline & Portal Monitors & $\bar{E}$ & & 2 & 35 & 70.0 & 5.0 & 10.0 & 80.0 \\
\hline & - Allowance for Piping/Mechanical & $E$ & & Lot & & 1.2 & & 6.3 & 7.5 \\
\hline & - Allowance for Electrical/Control & $E^{\prime}$ & & Lot & & 17.7 & & 12.6 & 30.3 \\
\hline & - Calibration, Testing \& Startup & $\bar{E}$ & & Lot & & 2.7 & & 2.4 & 5.1 \\
\hline \multirow{5}{*}{8} & - Allowance for Piping/Mechanical & $E$ & & Lot & & 3.0 & & 0.6 & 3.6 \\
\hline & - Allowance for Electrical/Control & $\bar{E}$ & & Lot & & 1.5 & & 0.5 & 2.0 \\
\hline & - Calibration, Testing \& Startup & $\overline{\mathrm{E}}$ & & Lot & & 0.3 & & 0.1 & 0.4 \\
\hline & - & & & & & & & & \\
\hline & Total Other Equipment & & & & $;$ & 14.8 & . & 2.2 & 17.0 \\
\hline \multirow[t]{7}{*}{99} & Transport Trailers $\quad, \quad \because \cdots$ & $\mathrm{T}$ & & & 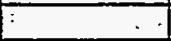 & $\cdots$ & & & \\
\hline & - Process Trailer - & $E$ & & 2 & 50 & 100.0 & 30 & 60.0 & 160.0 \\
\hline & - Allowance for Piping/Mechanical & $\bar{E}$ & & Lot & & 5.0 & & 30.0 & 35.0 \\
\hline & - Allowance for Electrical/Control & $\mathrm{E}$ & & Lot & & 15.0 & & 30.0 & 45.0 \\
\hline & - Calibration, Testing \& Startup & $\bar{E}$ & & Lot & & 2.4 & & 4.8 & 7.2 \\
\hline & - & & & & & & & & \\
\hline & Total Transport Trailers & & &.. & $\therefore$ & 122.4 & & 124.8 & 247.2 \\
\hline
\end{tabular}


Table A-12: Development, Testing \& Evaluation Cost Estimate Debris MTU

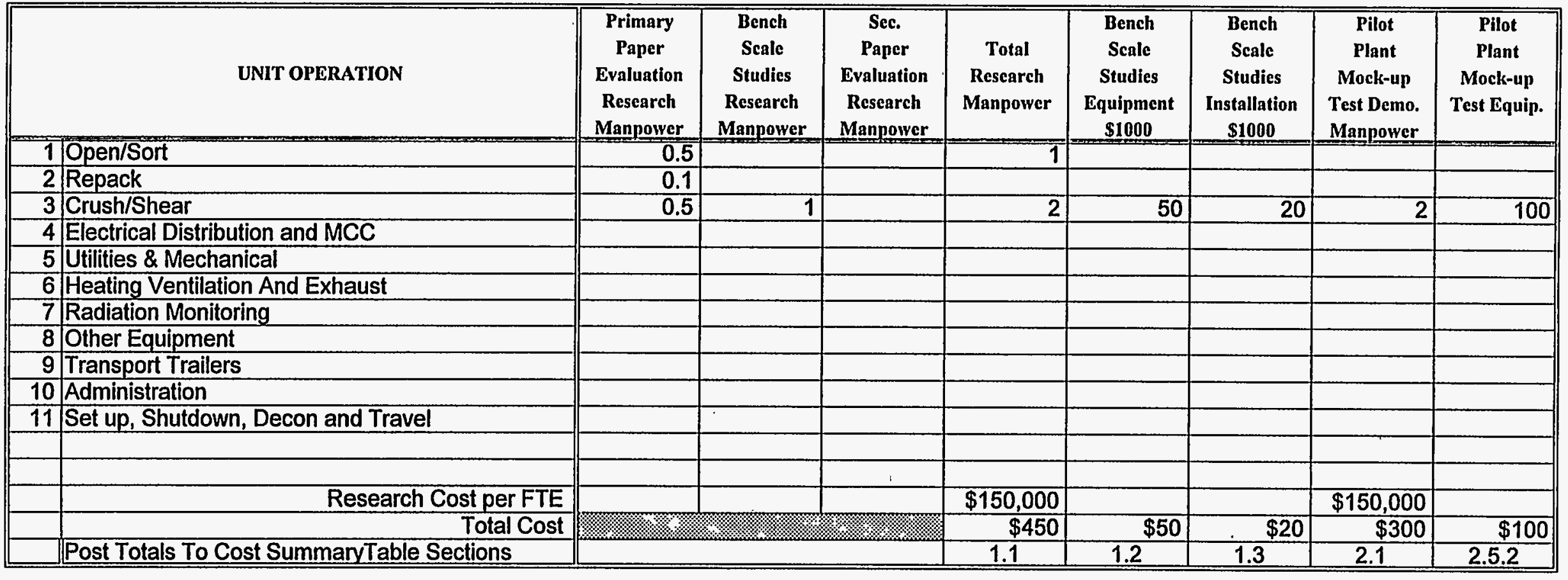

章 
Table A-13: Materials and Equipment Cost Summary Debris MTU

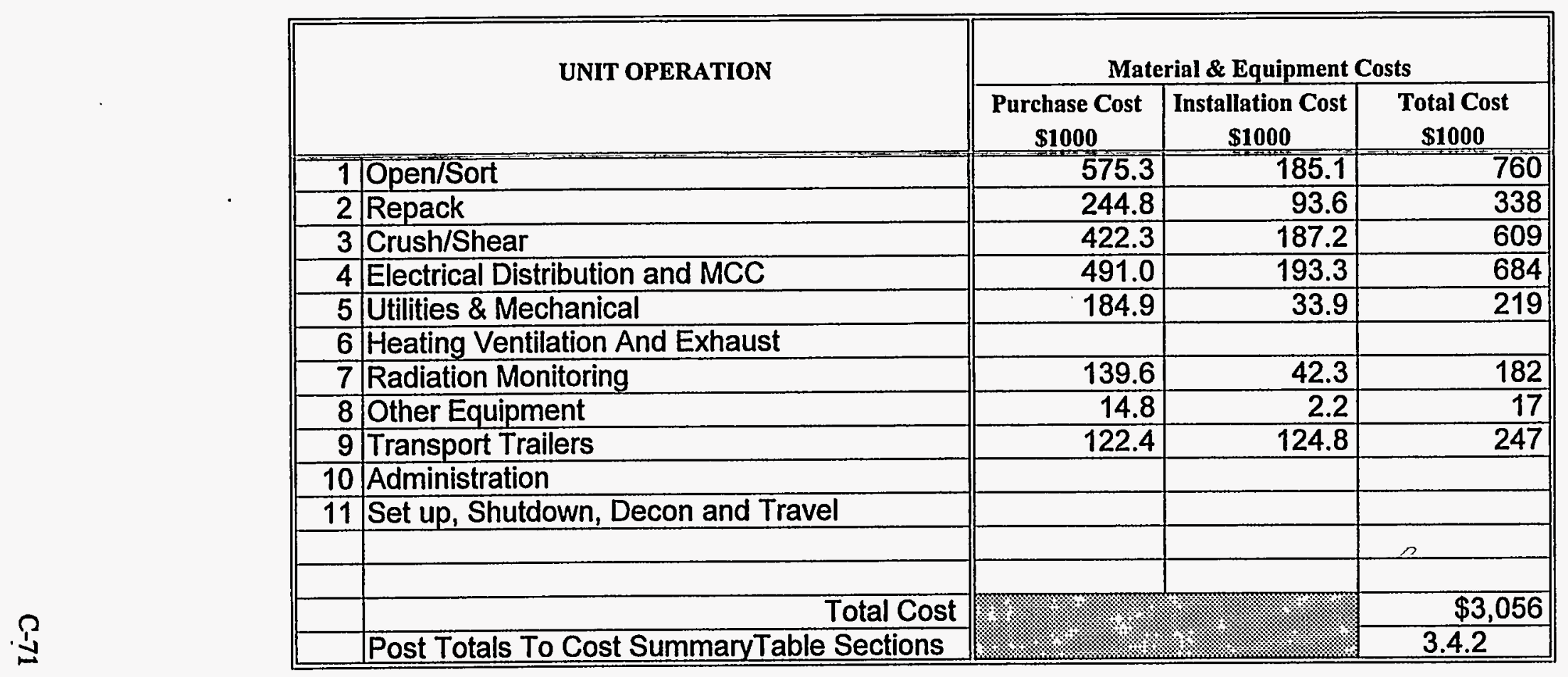


Table A-14: Annual Operating \& Maintenance Cost Summary

Debris MTU

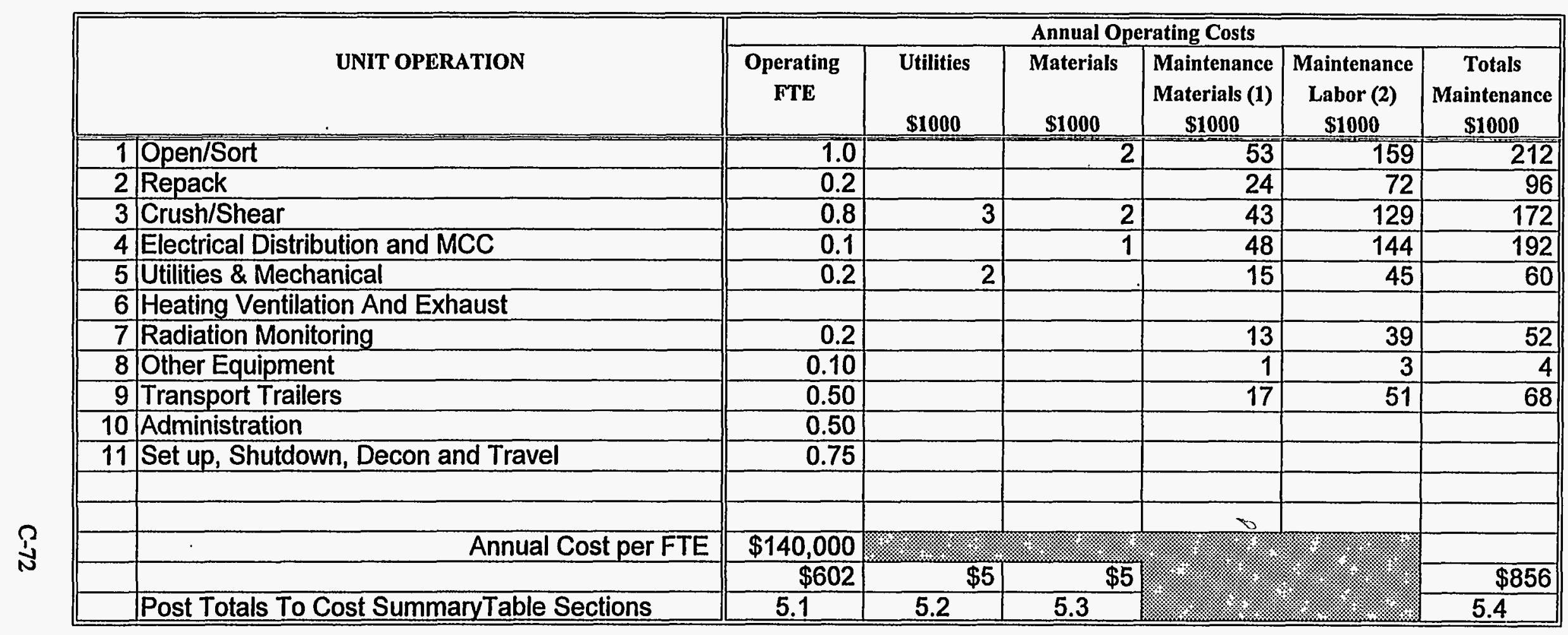

Notes:

1. Annual Maintenance Material is assumed to be $7 \%$ of equipment capital cost.

2. Annual Maintenance Labor is assumed to be $300 \%$ of maintenance material cost. 
Table A-15: Decontamination and Decommissioning Cost Summary

Debris MTU

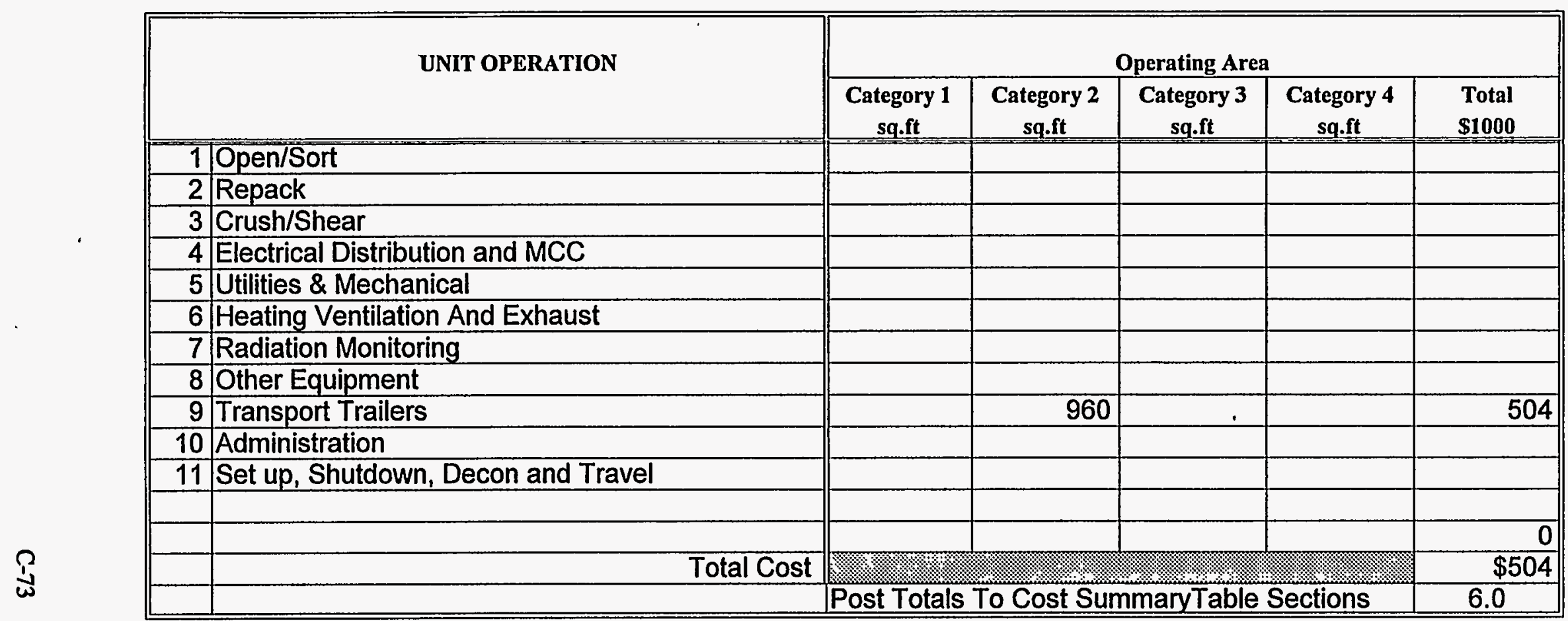

J:linellportable.wk4 
Figure A-16: Equipment List Labpack MTU

\begin{tabular}{|c|c|c|c|c|c|c|c|c|c|}
\hline & \multirow{2}{*}{$\begin{array}{l}\text { FAC. } \\
\text { CAT. }\end{array}$} & \multirow[b]{2}{*}{ HP } & \multicolumn{3}{|c|}{ MATLS.\& EQUIP. } & \multicolumn{3}{|c|}{ INST. COSTS } \\
\hline & & & & QTY & \multirow[t]{2}{*}{\begin{tabular}{|c|}
$\begin{array}{c}\text { Unit Cost } \\
\text { s1000's }\end{array}$ \\
\end{tabular}} & \multirow[t]{2}{*}{$\begin{array}{l}\text { Amount } \\
\text { S1000's }\end{array}$} & \multirow[t]{2}{*}{\begin{tabular}{l} 
Unit Cost \\
s1000's \\
\hdashline$: ?$
\end{tabular}} & $\begin{array}{l}\text { Amount } \\
\text { S1000's }\end{array}$ & \multirow[t]{2}{*}{$\begin{array}{l}\text { Total } \\
\text { U.0. } \\
\end{array}$} \\
\hline & 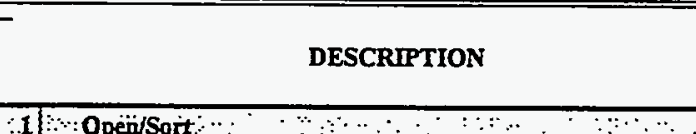 & $\therefore$ & & & & & & & \\
\hline & - Drum Decapper & $E$ & & 1 & 75 & 75.0 & 20 & 20.0 & 95.0 \\
\hline & - Input Conveyor & $\overrightarrow{\mathrm{E}}$ & & 1 & 25 & 25.0 & $\frac{6}{6}$ & 2.0 & 27.0 \\
\hline & - Glove Box & $\bar{E}$ & & 1 & 75 & 75.0 & 15 & 15.0 & 90.0 \\
\hline & - Sort Table & $\bar{E}$ & & $\overline{2}$ & 5 & 10.0 & 1.5 & 3.0 & 13.0 \\
\hline & - Drum Manipulator & $\bar{E}$ & & 1 & 50 & 50.0 & 15 & 15.0 & 65.0 \\
\hline & - Exit Conveyor & $\bar{E}$ & & 1 & 25 & 25.0 & 6 & 6.0 & 31.0 \\
\hline & - Crusher/Shredder & $\bar{E}$ & & 1 & 100 & 100.0 & 25 & 25.0 & 125.0 \\
\hline & - Screen & $\bar{E}$ & & 1 & 30 & 30.0 & 7 & 7.0 & 37.0 \\
\hline & - Dust Collection & $\bar{E}$ & & 1 & 100 & 100.0 & 25 & 25.0 & 125.0 \\
\hline & - Allowance for Piping/Mechanical & $\bar{E}$ & & Lot & & 24.5 & & 59.0 & 83.5 \\
\hline & - Allowance for ElectricallControl & $E$ & & Lot & & 73.5 & & 59.0 & 132.5 \\
\hline & - Calibration, Testing \& Startup & $E$ & & Lot & & 11.8 & & 9.4 & 21.2 \\
\hline - & - & & & & & & & & \\
\hline & Total Open/Sort & & ए & . & $\therefore \therefore$ & 599.8 & 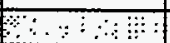 & 245.4 & 845.2 \\
\hline & 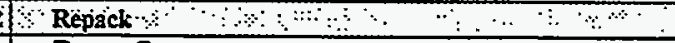 & $1 \%$ & $\therefore$ & & $\because$ & \% & \% & $\therefore$ & \\
\hline & - Drum Conveyor & $\bar{E}$ & & 3 & 25 & 75.0 & 5 & 15.0 & 90.0 \\
\hline & - Glove Box & $\bar{E}$ & & 1 & 75 & 75.0 & 15 & 15.0 & 90.0 \\
\hline & - Drum Manipulator & $E$ & & 1 & 50 & 50.0 & 15 & 15.0 & 65.0 \\
\hline & - & & & & & & & & \\
\hline & - Allowance for Piping/Mechanical & $\bar{E}$ & & Lot & & 10.0 & & 22.5 & 32.5 \\
\hline & 1- Allowance for Electrical/Control & $\mathbf{E}$ & & Lot & & 30.0 & & 22.5 & 52.5 \\
\hline & - Calibration, Testing \& Startup & $\bar{E}$ & & Lot & & 4.8 & & 3.6 & 8.4 \\
\hline & - & & & & & & & & \\
\hline & Total Repack & & $\% \%$ & $\ldots$ & & 244.8 & $\ldots \ldots$ & 93.6 & $\overline{338.4}$ \\
\hline & 1. Chemical Deactivation: & II: & 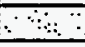 & & 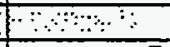 & सम & 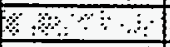 & $\Leftrightarrow$ & \\
\hline & - Reagent Hold Tank & $E$ & & 3 & 5 & 15.0 & 1 & 3.0 & 18.0 \\
\hline & - Reagent Tank Charge Pump & $\bar{E}$ & & 3 & 5 & 15.0 & 1 & 3.0 & 18.0 \\
\hline & - Reagent Tank Transfer Pump & $\overline{\mathrm{E}}$ & & 3 & 5 & 15.0 & $\dot{1}$ & 3.0 & 18.0 \\
\hline & - Deactivation Reactor & $\overline{\mathrm{E}}$ & & 1 & 50 & 50.0 & 12 & 12.0 & 62.0 \\
\hline & I- Deactivation Reactor Agitator & $\bar{E}$ & & 1 & 6 & 6.0 & 1.5 & 1.5 & 7.5 \\
\hline & - Deactivation Reactor Transfer Pump & $\mathbf{E}$ & & 1 & 8 & 8.0 & 2 & 2.0 & 10.0 \\
\hline & I Vent Scrubber & $\bar{E}$ & & 1 & 25 & 25.0 & 5 & 5.0 & 30.0 \\
\hline & - Scrubber Circulation Pump & $\mathbf{E}$ & & 1 & 10 & 10.0 & 2.5 & 2.5 & 12.5 \\
\hline & - Hepa Filter & $\overline{\mathrm{E}}$ & & 1 & 10 & 10.0 & 2.5 & 2.5 & 12.5 \\
\hline & - GAC Vessels & $E$ & & 2 & 10 & 20.0 & 2.5 & 5.0 & 25.0 \\
\hline & - Caustic Feed Tank & $\overline{\mathrm{E}}$ & & $\overline{1}$ & 8 & 8.0 & 12 & 12.0 & 20.0 \\
\hline & - Caustic Feed Tank Charge Pump & $\bar{E}$ & & 1 & 5 & 5.0 & 12 & 12.0 & 17.0 \\
\hline & - Caustic Feed Tank Transfer Pump & $\bar{E}$ & & 1 & 5 & 5.0 & 12 & 12.0 & 17.0 \\
\hline & - & & & & & & & & \\
\hline & - & & & & & & & & \\
\hline & - Allowance for Piping/Mechanical & $\bar{E}$ & & Lot & & 57.6 & & 45.3 & 102.9 \\
\hline & - Allowance for Electrical/Control & $\mathrm{E}$ & & Lot & & 28.8 & & 37.8 & 66.6 \\
\hline & - Calibration, Testing \& Startup & $\overline{\mathrm{E}}$ & & Lot & & 5.6 & & 6.3 & 11.9 \\
\hline & - & & & & & & & & \\
\hline & Total Chemical Deactivation & & 3 & $\ldots$ & $\therefore \cdots$ & 284.0 & अ. & 164.9 & 448.9 \\
\hline & Fetectrical Distribütion and MCC: & III: & & & $\because \because$ & मील & मी & $\because \because \quad 6$ & थण \\
\hline & - Main Control Panel & $E$ & & 6 & 10 & 60.0 & 3 & 18.0 & 78.0 \\
\hline & - Motor Control Center & $\bar{E}$ & & 12 & 1.5 & 18.0 & 0.5 & 6.0 & 24.0 \\
\hline & - CCTV & $\bar{E}$ & & 4 & 10 & 40.0 & 2 & 8.0 & 48.0 \\
\hline & - Telecommunications Equipment & 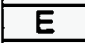 & & 1 & 100 & 100.0 & 25 & 25.0 & 125.0 \\
\hline & - Control Trailer & $\bar{E}$ & & 1 & 200 & 200.0 & 40 & 40.0 & 240.0 \\
\hline & I Allowance for Piping/Mechanical & $\bar{E}$ & & Lot & & 4.2 & & 29.1 & 33.3 \\
\hline & - Allowance for Electrical/Control & $E$ & & Lot & & 62.7 & & 58.2 & 120.9 \\
\hline & - Calibration, Testing \& Startup & $\bar{E}$ & & Lot & & 9.7 & & 11.1 & 20.8 \\
\hline & - & & & & & & & & \\
\hline & Total Electrical Distribution and MCC & & : & $\ldots$ & $\therefore \ldots$ & 494.6 & का & 195.4 & 689.9 \\
\hline 5 & Aüthities \& Mechänīal & $11 \%$ & $\because$ & 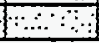 & m: & आय & था & अaा & $\ldots \ldots \%$ \\
\hline
\end{tabular}




\section{Figure A-16: Equipment List}

Labpack MTU

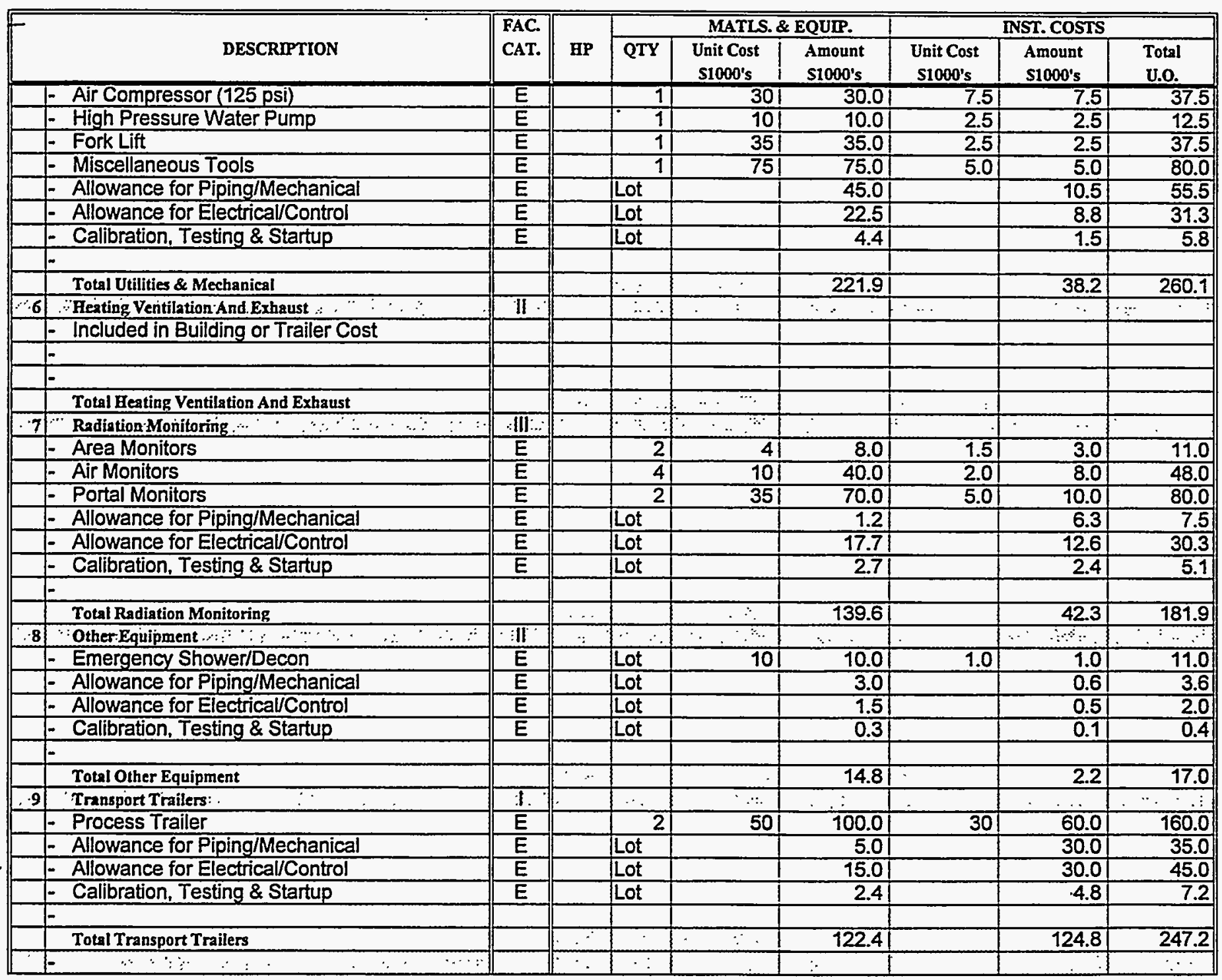


Table A-17: Development, Testing \& Evaluation Cost Estimate

Labpack MTU

\begin{tabular}{|c|c|c|c|c|c|c|c|c|c|}
\hline \multicolumn{2}{|r|}{ UNIT OPERATION } & $\begin{array}{c}\text { Primary } \\
\text { Paper } \\
\text { Evaluation } \\
\text { Research } \\
\text { Manpower } \\
\end{array}$ & $\begin{array}{c}\text { Bench } \\
\text { Scale } \\
\text { Studies } \\
\text { Research } \\
\text { Manpower }\end{array}$ & $\begin{array}{c}\text { Sec. } \\
\text { Paper } \\
\text { Evaluation } \\
\text { Research } \\
\text { Manpower }\end{array}$ & $\begin{array}{c}\text { Total } \\
\text { Research } \\
\text { Manpower }\end{array}$ & $\begin{array}{c}\text { Bench } \\
\text { Scale } \\
\text { Studies } \\
\text { Equipment } \\
\text { \$1000 } \\
\end{array}$ & $\begin{array}{c}\text { Bench } \\
\text { Scale } \\
\text { Studies } \\
\text { Installation } \\
\$ 1000 \\
\end{array}$ & $\begin{array}{c}\text { Pilot } \\
\text { Plant } \\
\text { Mock-up } \\
\text { Test Demo. } \\
\text { Manpower }\end{array}$ & $\begin{array}{c}\text { Pilot } \\
\text { Plant } \\
\text { Mock-up } \\
\text { Test Equip. }\end{array}$ \\
\hline & Open/Sort & 0.5 & & & 1 & & & & \\
\hline & Repack & 0.1 & & & & & & & \\
\hline & Chemical Deactivation & 0.5 & 1 & & 2 & 35 & 8 & 2 & 70 \\
\hline \multicolumn{10}{|c|}{4 Electrical Distribution and MCC } \\
\hline \multicolumn{10}{|c|}{\begin{tabular}{l|l}
5 & Utilities \& Mechanical \\
\end{tabular}} \\
\hline \multicolumn{10}{|c|}{6 Heating Ventilation And Exhaust } \\
\hline \multicolumn{10}{|c|}{\begin{tabular}{l|l}
7 & Radiation Monitoring \\
\end{tabular}} \\
\hline \multicolumn{10}{|c|}{8 Other Equipment } \\
\hline \multicolumn{10}{|c|}{9 Transport Trailers } \\
\hline \multicolumn{10}{|c|}{10 Administration } \\
\hline \multirow{2}{*}{\multicolumn{10}{|c|}{11 Set up, Shutdown, Decon and Travel }} \\
\hline \\
\hline & & & & & & & & & \\
\hline & Research Cost per FTE & & & & $\$ 150,000$ & & & $\$ 150,000$ & \\
\hline & Total Cost & & 19 & & $\$ 450$ & $\$ 35$ & $\$ 8$ & $\$ 300$ & $\$ 70$ \\
\hline & Post Totals To Cost SummaryTable Sections & & & & 1.1 & 1.2 & 1.3 & 2.1 & 2.5 .2 \\
\hline
\end{tabular}


Table A-18: Materials and Equipment Cost Summary

\section{Labpack MTU}

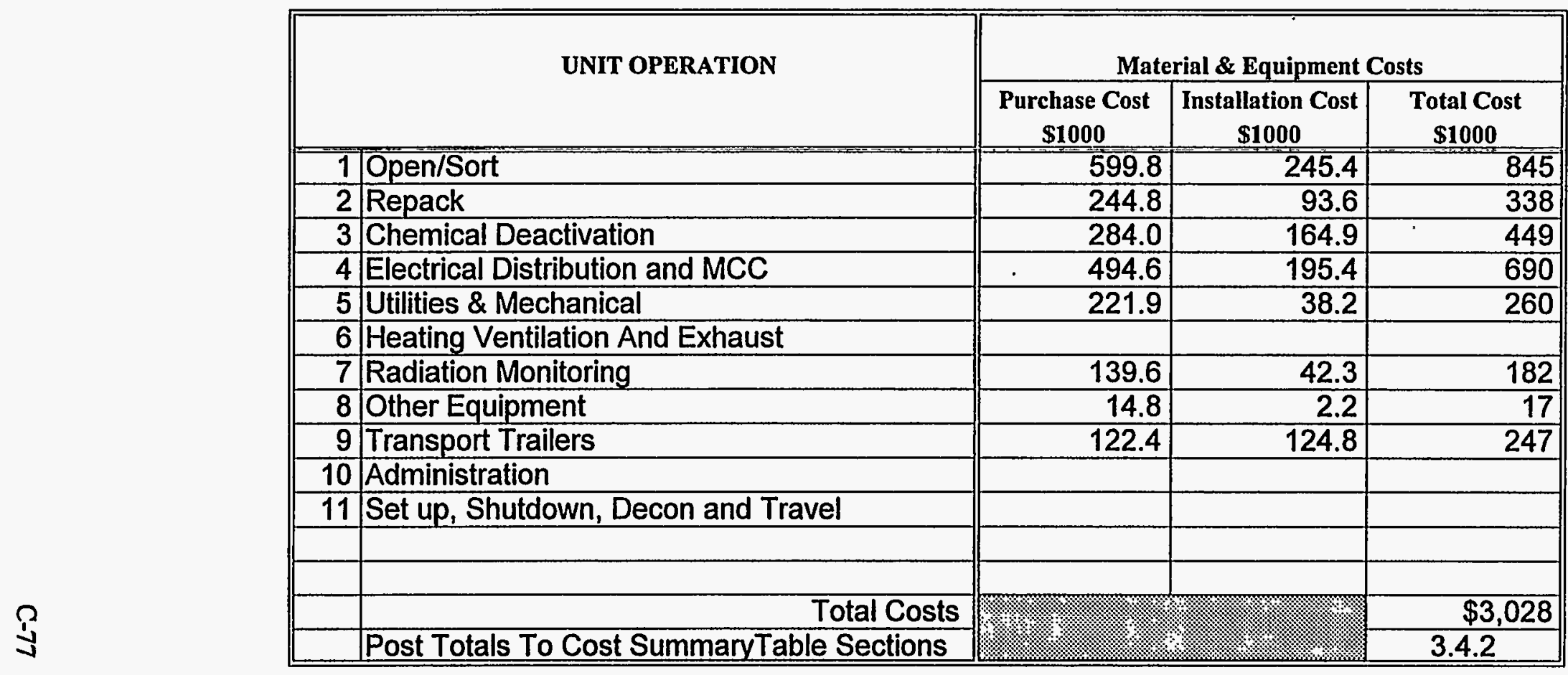


Table A-19: Annual Operating \& Maintenance Cost Summary Labpack MTU

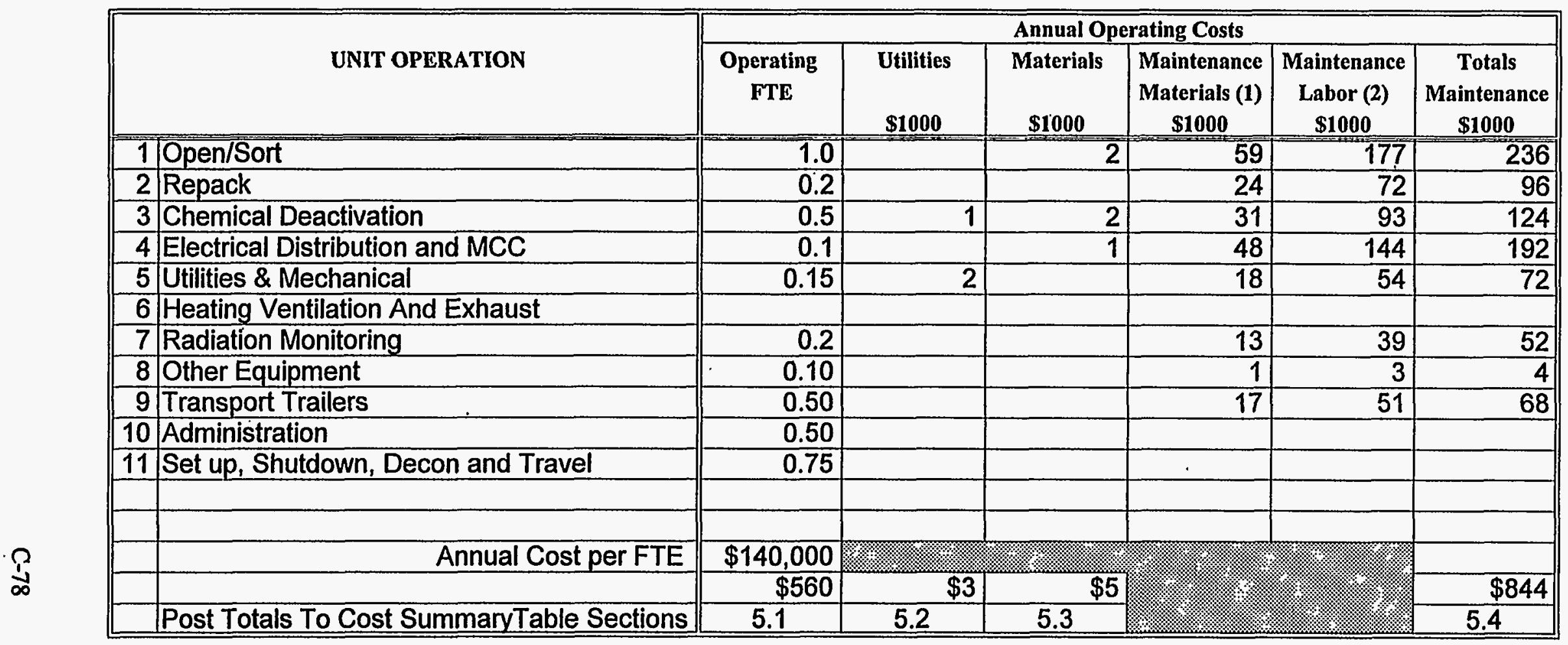

Notes:

1. Annual Maintenance Material is assumed to be $7 \%$ of equipment capital cost.

2. Annual Maintenance Labor is assumed to be $300 \%$ of maintenance material cost. 
Table A-20: Decontamination and Decommissioning Cost Summary Labpack MTU

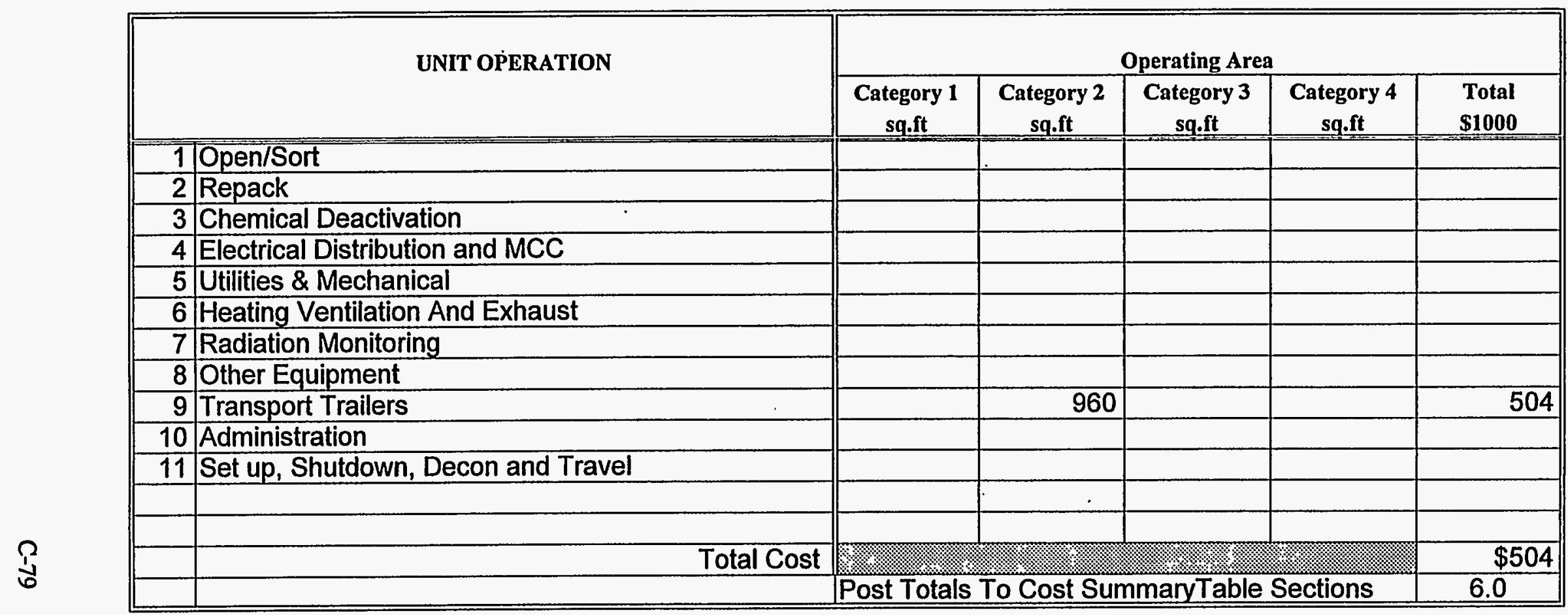


Figure A-21: Equipment List Centralized Facility

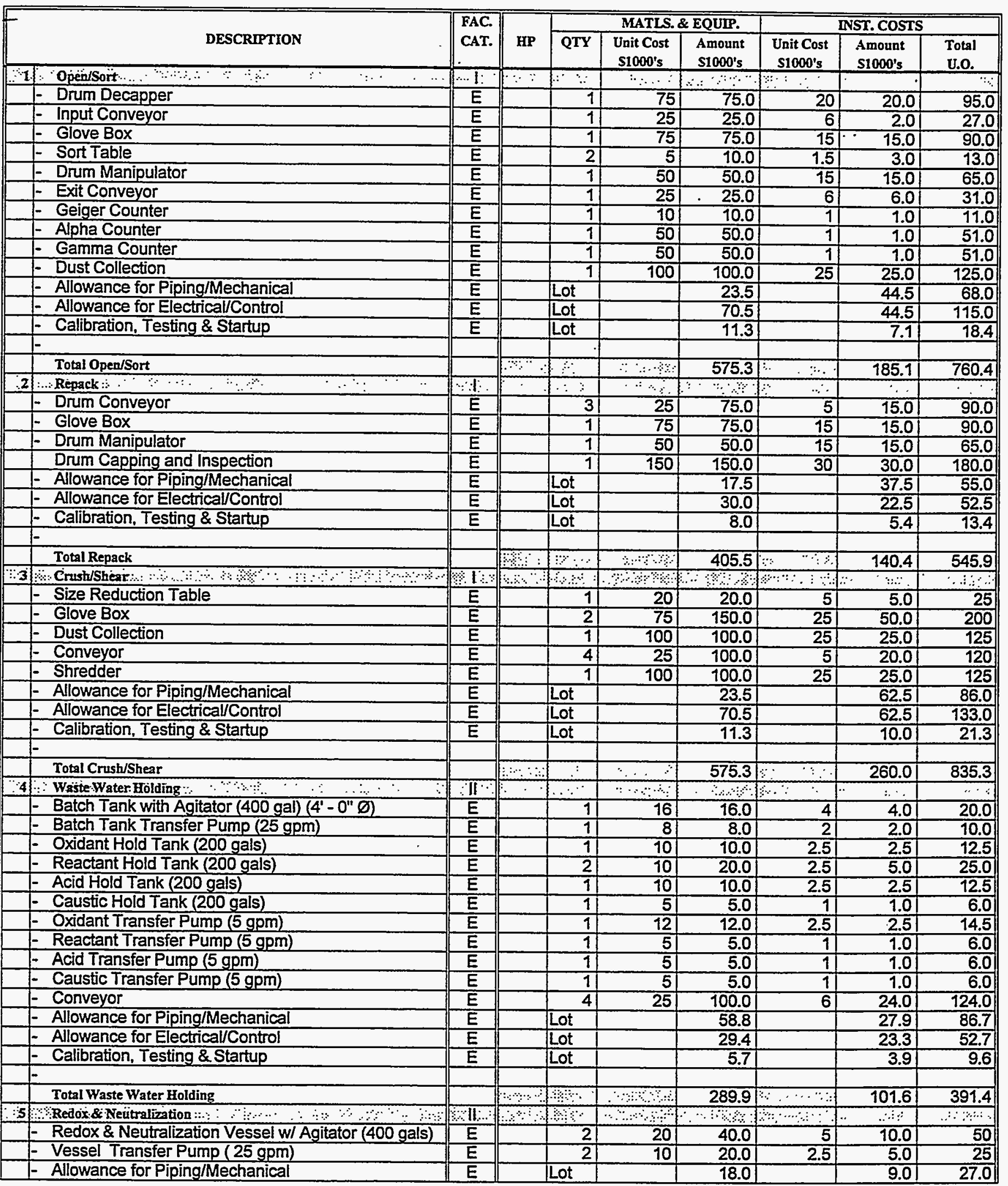


Figure A-21: Equipment List

Centralized Facility

\begin{tabular}{|c|c|c|c|c|c|c|c|c|c|}
\hline \multirow{2}{*}{\multicolumn{2}{|c|}{ DESCRIPTION }} & \multirow{2}{*}{$\begin{array}{l}\text { FAC. } \\
\text { CAT. }\end{array}$} & \multirow[b]{2}{*}{ HP } & \multicolumn{3}{|c|}{ MATLS. \& EQUIP. } & \multicolumn{3}{|c|}{ INST. COSTS } \\
\hline & & & & QTY & $\begin{array}{c}\text { Unit Cost } \\
\text { S1000's }\end{array}$ & $\begin{array}{l}\text { Amount } \\
\text { S1000's }\end{array}$ & $\begin{array}{l}\text { Unit Cost } \\
\text { s1000's }\end{array}$ & $\begin{array}{l}\text { Amount } \\
\text { S1000's }\end{array}$ & $\begin{array}{l}\text { Total } \\
\text { U.o. }\end{array}$ \\
\hline & - Allowance for Electrical/Control & $E$ & & Lot & & 9.0 & & 7.5 & 16.5 \\
\hline & - Calibration. Testing \& Startup & $E$ & & Lot & & 1.7 & & 1.3 & 3.0 \\
\hline & - & & & & & & & & \\
\hline & Total Redox \& Neutralization & & $\because$ & & & 88.7 & & 32.8 & 121.5 \\
\hline 6 & Suspended Solids Filtration .... & II. & & $\because$ & $\therefore$ & & & $\because$ & \\
\hline & - Suspended Solids Filter ( $25 \mathrm{gpm})$ & $E$ & & 2 & 45 & 90.0 & 10.0 & 20.0 & 110.0 \\
\hline & Solids Drum Handler & $E$ & & 11 & 25 & 25.0 & 5.0 & 5.0 & 30.0 \\
\hline & - Allowance for Piping/Mechanical & $E$ & & Lot & & 34.5 & & 15.0 & 49.5 \\
\hline & - Allowance for Electrical/Control & $E$ & & Lot & & 17.3 & & 12.5 & 29.8 \\
\hline & - Calibration, Testing \& Startup & $E$ & & Lot & & 3.3 & & 2.1 & 5.4 \\
\hline & - & & & & & & & & \\
\hline & Total Suspended Solids Filtration & & $\because \because$ & & $\therefore$ & 170.1 & 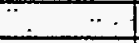 & 54.6 & 224.7 \\
\hline .7 & Dissolved.Organics Removal $\cdots, \quad \cdots, \cdots$ & $\therefore$ II. & & $\ldots$ & $\because$ & & $\ldots$ & & $\ldots$ \\
\hline & - Hydrothermal Vessel (2.5 gpm, Titanium) & $\bar{E}$ & & 2 & 150 & 300.0 & 40 & 80.01 & 380.0 \\
\hline & - Hydrothermal Heating Unit (220v, $125 \mathrm{~kW})$ & $E$ & & 2 & 75 & 150.0 & 15 & 30.0 & 180.0 \\
\hline & - Air Compressor $(6,500$ psi) & $\bar{E}$ & & 2 & 751 & 150.0 & 15 & 30.0 & 180.0 \\
\hline & - Cooler $(500 \mathrm{ft} 2.7000 \mathrm{psi})$ & $E$ & & 4 & 110 & 440.0 & 18 & 72.0 & 512.0 \\
\hline & - Knock Out Pot (200 gals) & $E$ & & 2 & 61 & 12.0 & 1.5 & 3.0 & 15.0 \\
\hline & - Knock Out Pot Transfer Pump (25 gpm) & $E$ & & 2 & 8 & 16.0 & 2 & 4.0 & 20.0 \\
\hline & - HEPA Filter & $\bar{E}$ & & 2 & 10 & 20.0 & 2.5 & 5.0 & 25.0 \\
\hline & - Vapor Reheater & $E$ & & 1 & 45 & 45.0 & 12 & 12.0 & 57.0 \\
\hline & - Vapor Phase GAC & $\bar{E}$ & & 2 & 8 & 16.0 & 2 & 4.0 & 20.0 \\
\hline & - Allowance for Piping/Mechanical & $E$ & & Lot & & 344.7 & & 144.0 & 488.7 \\
\hline & - Allowance for Electrical/Control & $E$ & & Lot & & 172.4 & & 120.0 & 292.4 \\
\hline & - Calibration, Testing \& Startup & $E$ & & Lot & & 33.3 & & 20.2 & 53.5 \\
\hline & - & & & & & & & & \\
\hline & \begin{tabular}{|l|} 
Total Dissolved Organies Removal \\
\end{tabular} & & & $\because$ & $\cdots$ & $1,699.4$ & & 524.2 & $2,223.5$ \\
\hline & Concentration/Dissolved Solids Removal & $I^{\circ}$ & & & & & $\ldots$ & & \\
\hline & - Liquid Phase Carbon (250\#) & $E$ & & 4 & 2 & 8.0 & 0.5 & 2.0 & 10.0 \\
\hline & - R.O. Unit (25 gpm) & $E$ & & 11 & 140 & 140.0 & 35 & 35.0 & 175.0 \\
\hline & - lon Exchange $(25 \mathrm{gpm})$ & $E$ & & 1 & 75 & 75.0 & 15 & 15.0 & 90.0 \\
\hline & - Evaporator with Condensor (12 gpm) & $\mathbf{E}$ & & 1 & 75 & 75.0 & 20 & 20.0 & 95.0 \\
\hline & - Evaporator Transfer Pump & $\mathbf{E}$ & & 1 & 8 & 8.0 & 2 & 2.0 & 10.0 \\
\hline & - Condensor Liquids Pump (12 gpm) & $E$ & & 1 & 5 & 5.0 & 1 & 1.0 & 6.0 \\
\hline & - Vacuum Pump $(10 \mathrm{scfm})$ & $\bar{E}$ & & 1 & 15 & 15.0 & 4 & 4.0 & 19.0 \\
\hline & - Allowance for Piping/Mechanical & $\bar{E}$ & & Lot & & 97.8 & & 47.4 & 145.2 \\
\hline & - Allowance for Electrical/Control & $\bar{E}$ & & Lot & & 48.9 & & 39.5 & 88.4 \\
\hline & - Calibration, Testing \& Startup & $\bar{E}$ & & Lot & & 9.5 & & 6.6 & 16.1 \\
\hline & - & & & & & & & & \\
\hline & Total Concentration/Dissolved Solids Removal & & & & & 482.2 & & 172.5 & 654.7 \\
\hline 9 & Treated.Water Sampling & II & & $\because$ & & & & & \\
\hline & - Treated Water Tanks (500 gals) & $E$ & & 2 & 10 & 20.0 & 2.5 & 5.0 & 25.0 \\
\hline & - Treated Water Pumps & $\bar{E}$ & & 2 & 5 & 10.0 & 1.0 & 2.0 & 12.0 \\
\hline & - Allowance for Piping/Mechanical & $\bar{E}$ & & Lot & & 9.0 & & 4.2 & 13.2 \\
\hline & - Allowance for Electrical/Control & $E$ & & Lot & & 4.5 & & 3.5 & 8.0 \\
\hline & - Calibration, Testing \& Startup & $\bar{E}$ & & Lot & & 0.9 & & 0.6 & 1.5 \\
\hline & - & & & & & & & & \\
\hline & Total Treated Water Sampling & & & & & 44.4 & & 15.3 & 59.7 \\
\hline 10 & : Organic Liquid. Waste floolding : & 1: & $\therefore$ & & & & & & \\
\hline & - Organic Liquid Hold Tank & $\bar{E}$ & & 2 & 35 & 70.0 & 9.0 & 18.0 & 88.0 \\
\hline & - Organic Liquid Hold Tank Charge Pump & $\bar{E}$ & & 1 & 5 & 5.0 & 1.5 & 1.5 & 6.5 \\
\hline & - Organic Liquid Hold Tank Transfer Pump & $\overline{\mathrm{E}}$ & & 2 & 8 & 16.0 & 2.0 & 4.0 & 20.0 \\
\hline & - Organic Liquid Hold Tank Agitator & $\bar{E}$ & & 1 & 6 & 6.0 & 2.0 & 2.0 & 8.0 \\
\hline & - Allowance for Piping/Mechanical & $\bar{E}$ & & Lot & & 29.1 & & 15.3 & 44.4 \\
\hline & - Allowance for Electrical/Control & $\bar{E}$ & & Lot & & 14.6 & & 12.8 & 27.3 \\
\hline & - Calibration, Testing \& Startup & $\bar{E}$ & & Lot & & 2.8 & & 2.1 & 5.0 \\
\hline & $x^{2}$ & & & & & & & & \\
\hline & Total Organic Liquid Waste Holding & & & & & 143.5 & & 55.7 & 199.2 \\
\hline
\end{tabular}


Figure A-21: Equipment List

Centralized Facility

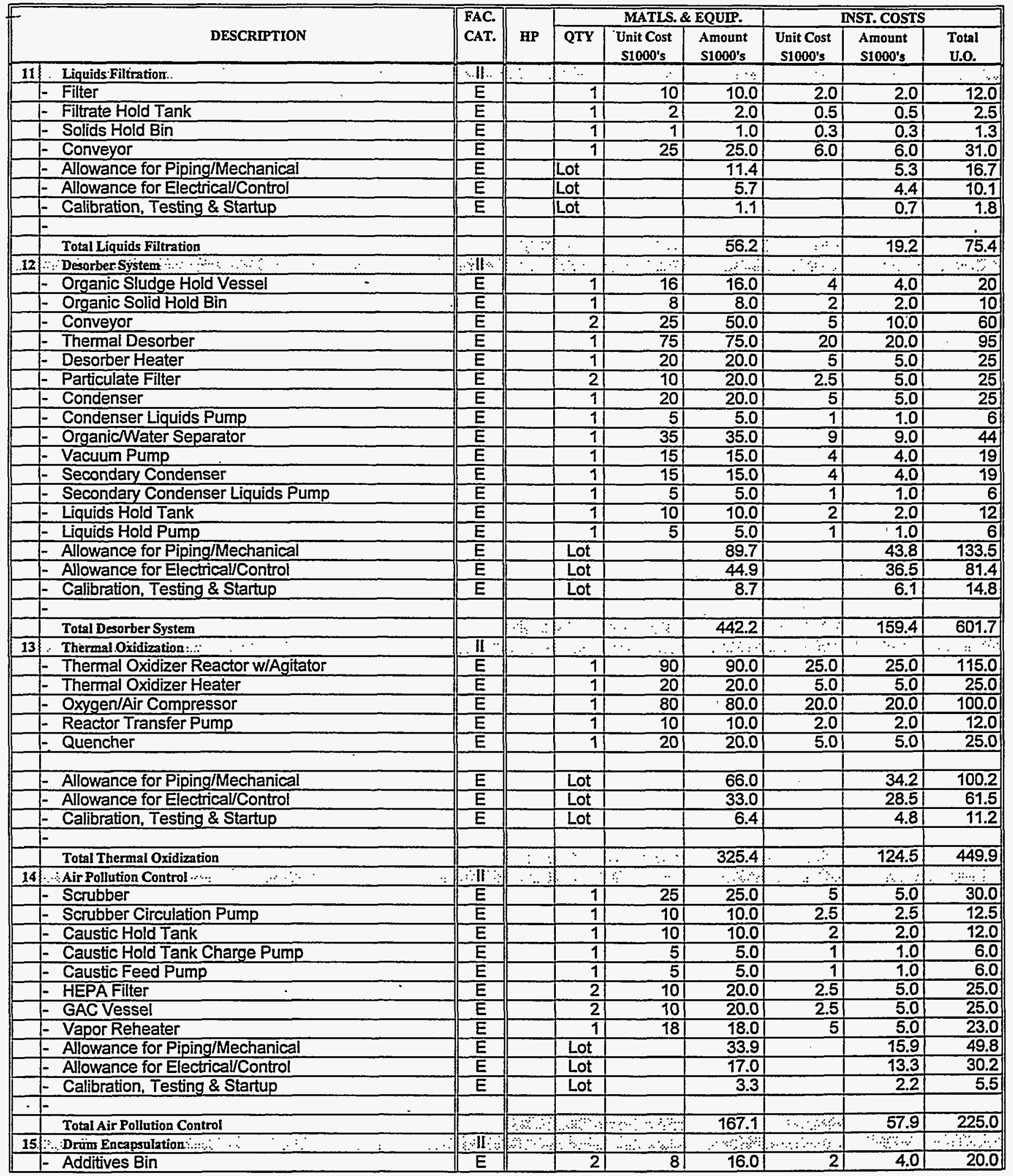


Figure A-21: Equipment List

Centralized Facility

\begin{tabular}{|c|c|c|c|c|c|c|c|c|c|}
\hline & \multirow[b]{2}{*}{ DESCRIPTION } & \multirow{2}{*}{$\begin{array}{l}\text { FAC. } \\
\text { CAT. }\end{array}$} & \multirow[b]{2}{*}{ HP } & \multicolumn{3}{|c|}{ MATLS. \& EQUIP. } & \multicolumn{3}{|c|}{ INST. COSTS } \\
\hline & & & & QTY & $\begin{array}{c}\text { Unit Cost } \\
\text { S1000's }\end{array}$ & $\begin{array}{l}\text { Amount } \\
\text { S1000's } \\
\end{array}$ & $\begin{array}{c}\text { Unit Cost } \\
\text { s1000's }\end{array}$ & $\begin{array}{l}\text { Amount } \\
\text { S1000's } \\
\end{array}$ & $\begin{array}{l}\text { Total } \\
\text { U.o. } \\
\end{array}$ \\
\hline & F Additives Mixer & $E$ & & 1 & 301 & 30.0 & 9 & 9.0 & 39.0 \\
\hline & - Drum Wash System & $E$ & & 1 & 181 & 18.0 & 4 & 4.0 & 22.0 \\
\hline & - Conveyor & $E$ & & 2 & 251 & 50.0 & 6 & 12.0 & 62.0 \\
\hline & - Water Supply Pump & $E$ & & 1 & 10 & 10.0 & 2 & 2.0 & 12.0 \\
\hline & - Drum Capping and Inspection & $E$ & & 1 & 150 & 150.0 & 30 & 30.0 & 180.0 \\
\hline & - Allowance for Piping/Mechanical & $E$ & & Lot & & 82.2 & & 36.6 & 118.8 \\
\hline & - Allowance for Electrical/Control & $E$ & & Lot & & 41.1 & & 30.5 & 71.6 \\
\hline & - Calibration, Testing \& Startup & $E$ & & Lot & & 7.9 & & 5.1 & 13.1 \\
\hline & - & & & & & & & & \\
\hline & Total Drum Encapsulation & & & & & 405.2 & 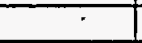 & 133.2 & 538.5 \\
\hline 16 & Electrical Distribution and MCC & III: & & & & & & & \\
\hline & - Main Control Panel & $E$ & & 15 & 10 & 150.0 & 3 & 45.0 & 195.0 \\
\hline & - Motor Control Center & $E$ & & 30 & 1.5 & 45.0 & 0.5 & 15.0 & 60.0 \\
\hline & CCTV & $E$ & & 12 & $10 \mid$ & 120.0 & 2 & 24.0 & 144.0 \\
\hline & - Allowance for Piping/Mechanical & $E$ & & Lot & & 3.2 & & 25.2 & 28.4 \\
\hline & - Allowance for Electrical/Control & $E$ & & Lot & & 47.3 & & 50.4 & 97.7 \\
\hline & - Calibration, Testing \& Startup & $E$ & & Lot & & 7.3 & & 9.6 & 16.9 \\
\hline & - & & & & & & & & \\
\hline & Total Eleetrical Distribution and MCC & & & & & 372.7 & & 169.2 & 541.9 \\
\hline 17 & Utilities \& Mechanical & II & & & & & & & \\
\hline & - Air Compressor (125 psi) & $E$ & & 1 & 30 & 30.0 & 7.5 & 7.5 & 37.5 \\
\hline & - High Pressure Water Pump & $E$ & & 1 & 10 & 10.0 & 2.5 & 2.5 & 12.5 \\
\hline & F Fork Lift & $E$ & & 3 & 35 & 105.0 & 2.5 & 7.5 & 112.5 \\
\hline & - Miscellaneous Tools & $\mathbf{E}$ & & 1 & 75 & 75.0 & 5.0 & 5.0 & 80.0 \\
\hline & - Allowance for Piping/Mechanical & $\bar{E}$ & & Lot & & 66.0 & & 13.5 & 79.5 \\
\hline & - Allowance for Electrical/Control & $E$ & & Lot & & 33.0 & & 11.3 & 44.3 \\
\hline & - Calibration, Testing \& Startup & $\bar{E}$ & & Lot & & 6.4 & & 1.9 & 8.3 \\
\hline & - & & & & & & & & \\
\hline & Total Utilities \& Mechanical & & & .. & & 325.4 & & 49.1 & 374.5 \\
\hline 18 & Heating Ventilation And Exhaust. & II & & & & & & & \\
\hline & - Included in Building Cost & & & & & & & & \\
\hline & - & & & & & & & & \\
\hline & $F$ & & & & & & & & \\
\hline & Total Heating Ventilation And Exhaust & & & & & & & & \\
\hline 19 & \begin{tabular}{|l|} 
Radiation Monitoring: \\
\end{tabular} & III & & & & & & & \\
\hline & - Area Monitors & $\mathrm{E}$ & & 4 & 4 & 16.0 & 1.5 & 6.0 & 22.0 \\
\hline & - Air Monitors & $E$ & & 8 & 10 & 80.0 & 2.0 & 16.0 & 96.0 \\
\hline & 1- Portal Monitors & $\bar{E}$ & & 4 & 35 & 140.0 & 5.0 & 20.0 & 160.0 \\
\hline & T- Allowance for Piping/Mechanical & $E$ & & Lot & & 2.4 & & 12.6 & 15.0 \\
\hline & - Allowance for Electrical/Control & $\bar{E}$ & & Lot & & 35.4 & & 25.2 & 60.6 \\
\hline & - Calibration, Testing \& Startup & $\bar{E}$ & & Lot & & 5.5 & & 4.8 & 10.3 \\
\hline & - & & & & & & & & \\
\hline & Total Radiation Monitoring & & & & & 279.2 & & 84.6 & 363.8 \\
\hline 20 & Other Ë̈uipment $\ldots$ & II & . & & $\ldots$ & & $\because$ & & \\
\hline & - Emergency Shower/Decon & $\mathrm{E}$ & & Lot & 10 & 10.0 & 1.0 & 1.0 & 11.0 \\
\hline & - Allowance for Piping/Mechanical & $E$ & & Lot & & 3.0 & & 0.6 & 3.6 \\
\hline & - Allowance for Electrical/Control & $\bar{E}$ & & Lot & & 1.5 & & 0.5 & 2.0 \\
\hline & - Calibration, Testing \& Startup & $\bar{E}$ & & Lot & & 0.3 & & 0.1 & 0.4 \\
\hline & - & & & & & & & & \\
\hline & Total Other Equipment & & - & & & 14.8 & & 2.2 & 17.0 \\
\hline 21 & Administration Building Subsystem & II & & $\ldots$ & & & $\cdots$ & & \\
\hline & I- Office Furniture - Employee & $\mathrm{E}$ & & 20 & 7 & 140.0 & 1.0 & 20.0 & 160.0 \\
\hline & F Computers & $\bar{E}$ & & Lot & 200 & 200.0 & 20.0 & 20.0 & 220.0 \\
\hline & F Communication & $\bar{E}$ & & Lot & 125 & 125.0 & 12.5 & 12.5 & 137.5 \\
\hline & F Testing Lab Equipment & $\bar{E}$ & & Lot & 2000 & $2,000.0$ & 200.0 & 200.0 & $2,200.0$ \\
\hline & - Office Equipment \& Furnishing & $\bar{E}$ & & Lot & 80 & 80.0 & 8.0 & 8.0 & 88.0 \\
\hline & 1- Allowance for Piping/Mechanical & $E$ & & Lot & & 763.5 & & 156.3 & 919.8 \\
\hline & - Allowance for Electrical/Control & $\bar{E}$ & & Lot & & 381.8 & & 130.3 & 512.0 \\
\hline
\end{tabular}


Figure A-21: Equipment List

Centralized Facility

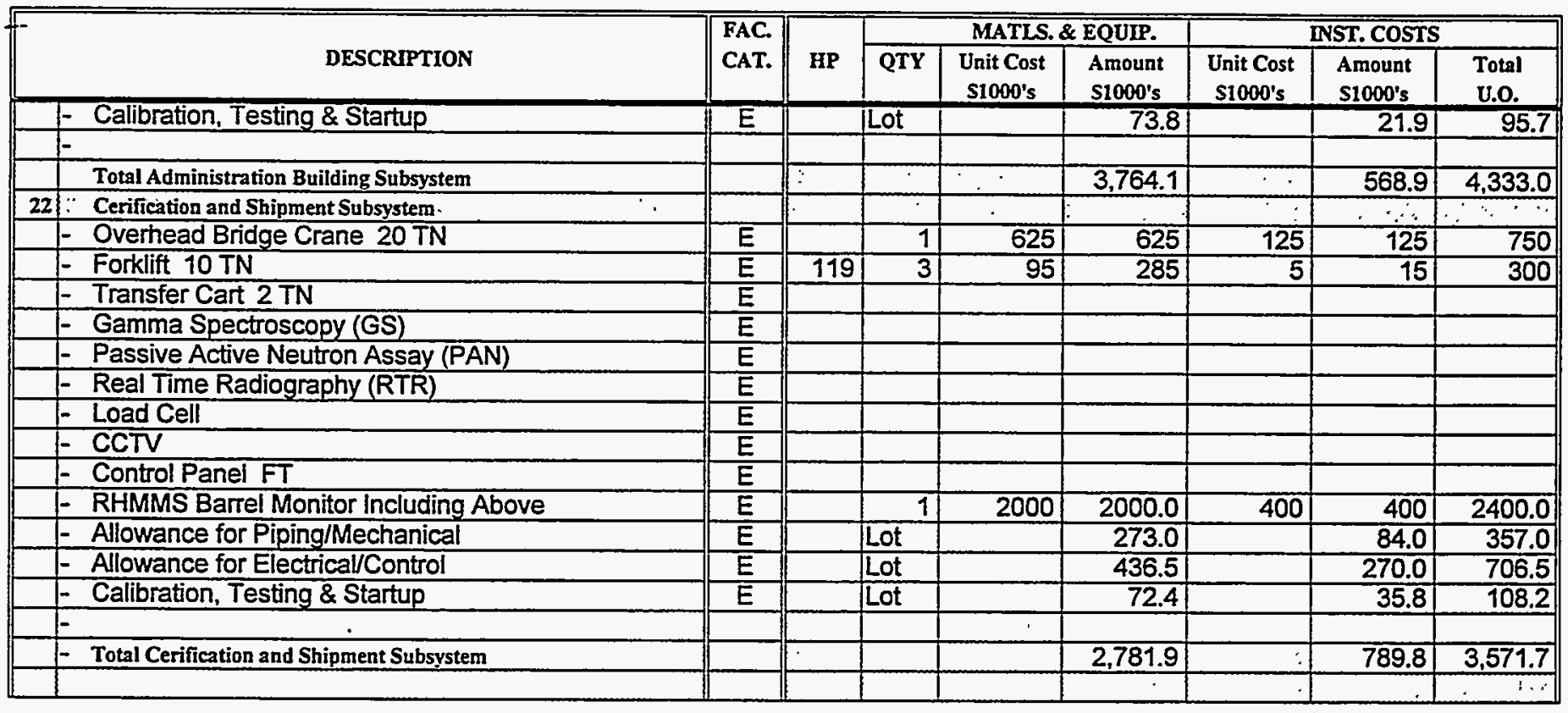


Table A-22: Development, Testing \& Evaluation Cost Estimate

\section{Centralized Facility}

\begin{tabular}{|c|c|c|c|c|c|c|c|c|c|c|}
\hline \multicolumn{2}{|r|}{ UNIT OPERATION } & $\begin{array}{c}\text { Primary } \\
\text { Paper } \\
\text { Evaluation } \\
\text { Research } \\
\text { Manpower } \\
\end{array}$ & $\begin{array}{c}\text { Bench } \\
\text { Scale } \\
\text { Studies } \\
\text { Research } \\
\text { Manpower } \\
\end{array}$ & $\begin{array}{c}\text { Sec. } \\
\text { Paper } \\
\text { Evaluation } \\
\text { Research } \\
\text { Manpower }\end{array}$ & $\begin{array}{c}\text { Total } \\
\text { Resenrch } \\
\text { Manpower }\end{array}$ & $\begin{array}{c}\text { Bench } \\
\text { Scale } \\
\text { Studics } \\
\text { Equipment } \\
\text { S1000 } \\
\end{array}$ & $\begin{array}{c}\text { Bench } \\
\text { Scale } \\
\text { Studies } \\
\text { Installation } \\
\$ 1000 \\
\end{array}$ & $\begin{array}{c}\text { Pilot } \\
\text { Plant } \\
\text { Mlock-up } \\
\text { Test Demo. } \\
\text { Manpower }\end{array}$ & $\begin{array}{c}\text { Pilot } \\
\text { Plant } \\
\text { Mock-up } \\
\text { Test Bldg. } \\
\text { S1000 }\end{array}$ & $\begin{array}{c}\text { Pilot } \\
\text { Plant } \\
\text { Mock-up } \\
\text { Test Equip. }\end{array}$ \\
\hline 1 & Open/Sort & 0.5 & & & 1 & & & & & \\
\hline 2 & Repack & 0.1 & & & & & $=$ & & & \\
\hline 3 & Crush/Shear & 0.5 & 1 & & 2 & 50 & 20 & 2 & 20 & $\overline{100}$ \\
\hline 4 & Waste Water Holding & 0.1 & & & & & & & & \\
\hline 5 & Redox \& Neutralization & 0.2 & & & & & & & & \\
\hline 6 & Suspended Solids Filtration & & & & & & & & & \\
\hline$\overline{7}$ & Dissolved Organics Removal & 0.5 & & & 1 & 30 & 6 & 2 & 20 & 100 \\
\hline 8 & Concentration/Dissolved Solids Removal & 0.2 & & & & 10 & 2 & 0.5 & 4 & 20 \\
\hline 9 & Treated Water Sampling & & & & & & & & & \\
\hline 10 & Organic Liquid Waste Holding & & & & & & & & & \\
\hline 11 & Liquids Filtration & & & & & & & & & \\
\hline 12 & Desorber System & 0.5 & 1 & & 2 & 50 & 20 & 2 & 16 & 80 \\
\hline 13 & Thermal Oxidization & 1 & 1 & & 2 & 50 & 25 & 2 & 16 & 80 \\
\hline 14 & Air Pollution Control & 0.2 & 0.5 & & & & & & & \\
\hline 15 & Drum Encapsulation & & & & & & & & & \\
\hline 16 & Electrical Distribution and MCC & & & & & & & & & \\
\hline 17 & Utilities \& Mechanical & & & & & & & & & \\
\hline 18 & Heating Ventilation And Exhaust & & & & & & & & & \\
\hline 19 & Radiation Monitoring & & & & & & & & & \\
\hline 20 & Other Equipment & & & & & & & & & \\
\hline 21 & Administration Building Subsystem & & & & & & & & & \\
\hline 22 & Receiving, Certification and Shipment Subsystem & $\%$ & & & & & & & & \\
\hline & Research Cost per FTE & & & & $\$ 150,000$ & & & $\$ 150,000$ & & \\
\hline & Total Cost & \% & & & $\$ 1,200$ & $\$ 190$ & $\$ 73$ & $\$ 1,275$ & $\$ 76$ & $\$ 380$ \\
\hline & 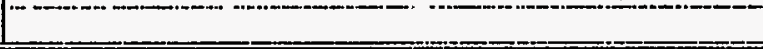 & Post Totals & o Table 4-5, & Sections & 1.1 & 1.2 & 1.3 & 2.1 & 2.5 .1 & 2.5 .2 \\
\hline
\end{tabular}


Table A-23: . Building, Materials and Installed Equipment Cost Summary

Centralized Facility

\begin{tabular}{|c|c|c|c|c|c|c|c|c|}
\hline & \multirow[b]{3}{*}{ UNIT OPERATION } & \multicolumn{7}{|c|}{ Centralized Facility } \\
\hline & & \multicolumn{4}{|c|}{ Building Area } & \multicolumn{3}{|c|}{ Material \& Equipment Costs } \\
\hline & & $\begin{array}{l}\text { Cost } \\
\text { Category } 1 \\
\text { sq.ft } \\
\end{array}$ & $\begin{array}{l}\text { Cost } \\
\text { Category } 2 \\
\quad \text { sq.ft } \\
\end{array}$ & $\begin{array}{l}\text { Cost } \\
\text { Category } 3 \\
\quad \text { sq.ft }\end{array}$ & $\begin{array}{c}\text { Total } \\
\text { Area Cost } \\
\$ 1000\end{array}$ & $\begin{array}{c}\text { Purchase } \\
\text { Cost } \\
\$ 1000\end{array}$ & $\begin{array}{c}\text { Installation } \\
\text { Cost } \\
\$ 1000\end{array}$ & $\begin{array}{c}\text { Total } \\
\text { Cost } \\
\$ 1000\end{array}$ \\
\hline 1 & Open/Sort & & 90 & 300 & 277.8 & 575.3 & 185.1 & 760 \\
\hline 2 & Repack & & 60 & 220 & 201.2 & 405.5 & 140.4 & 546 \\
\hline 3 & Crush/Shear & & 150 & 640 & 575 & 575.3 & 260.0 & 835 \\
\hline 4 & Waste Water Holding & & 60 & 252 & 226.8 & 289.9 & 101.6 & 391 \\
\hline 5 & Redox \& Neutralization & & 125 & 610 & 540.5 & 88.7 & 32.8 & 122 \\
\hline 6 & Suspended Solids Filtration & & 34 & 165 & 146.28 & 170.1 & 54.6 & 225 \\
\hline 7 & Dissolved Organics Removal & & 374 & 1330 & 1221.08 & $1,699.4$ & 524.2 & $2,2 \overline{24}$ \\
\hline 8 & Concentration/Dissolved Solids Removal & & 52 & 252 & 223.44 & 482.2 & 172.5 & 655 \\
\hline 9 & Treated Water Sampling & & 80 & 390 & 345.6 & 44.4 & 15.3 & 60 \\
\hline 10 & Organic Liquid Waste Holding & & 60 & 248 & 223.6 & 143.5 & 55.7 & 199 \\
\hline 11 & Liquids Filtration & & $3 \overline{4}$ & $16 \overline{5}$ & 146.28 & 56.2 & 19.2 & 75 \\
\hline 12 & Desorber System & & 175 & 570 & 529.5 & 442.2 & 159.4 & 602 \\
\hline 13 & Thermal Oxidization & . & 45 & 215 & 190.9 & 325.4 & 124.5 & 450 \\
\hline 14 & Air Pollution Control & & 80 & 260 & 241.6 & 167.1 & 57.9 & $\overline{2} \overline{5}$ \\
\hline 15 & Drum Encapsulation & & 80 & 260 & 241.6 & 405.2 & 133.2 & 538 \\
\hline 16 & Electrical Distribution and MCC & & 420 & & 176.4 & 372.7 & 169.2 & 542 \\
\hline$\overline{17}$ & Utilities \& Mechanical & & 825 & & 346.5 & 325.4 & 49.1 & 375 \\
\hline 18 & Heating Ventilation And Exhaust & & 930 & & 390.6 & & & \\
\hline 19 & Radiation Monitoring & & & & & 279.2 & 84.6 & $36 \overline{4}$ \\
\hline 20 & Öther Equipment & & 150 & & 63 & 14.8 & 2.2 & 17 \\
\hline 21 & Administration Building Subsystem & 1,500 & 1,000 & & 690 & $3,764.1$ & 568.9 & 4,333 \\
\hline 22 & Receiving, Certification and Shipment Subsystem & 4,000 & & & 720 & $2,781.9$ & 789.8 & 3,572 \\
\hline & Total Cost & & & & 7,718 & & \% $1 \%$ & 17,110 \\
\hline & & Post Totals & o Table 4-5 & & 3.4 .1 & & & 3.4 .2 \\
\hline
\end{tabular}


Table A-24: Annual Operating \& Maintenance Cost Summary Centralized Facility

\begin{tabular}{|c|c|c|c|c|c|c|c|}
\hline \multirow[b]{2}{*}{ UNIT OPERATION } & \multicolumn{7}{|c|}{ Annual Operating Costs } \\
\hline & $\begin{array}{l}\text { Operating } \\
\text { FTE }\end{array}$ & $\begin{array}{l}\text { Utilities } \\
\$ 1000\end{array}$ & $\begin{array}{c}\text { Materials } \\
\$ 1000 \\
\end{array}$ & $\begin{array}{c}\text { Installed } \\
\text { Equipment } \\
\$ 1000\end{array}$ & \begin{tabular}{|c|} 
Maintenance \\
Materials (1) \\
$\$ 1000$ \\
\end{tabular} & $\begin{array}{c}\text { Maintenance } \\
\text { Labor (2) } \\
\$ 1000\end{array}$ & $\begin{array}{c}\text { Totals } \\
\text { Maintenance } \\
\$ 1000\end{array}$ \\
\hline 11Open/Sort & $\overline{1.5}$ & & & $7 \overline{760}$ & 30 & 75 & 105 \\
\hline$2 \longdiv { \text { Repack } }$ & 0.5 & & & 546 & 22 & 55 & 77 \\
\hline 3 Crush/Shear & 1.0 & 8 & & 835 & 33 & 83 & 116 \\
\hline 4 Waste Water Holding & 0.5 & & & 391 & 16 & 40 & 56 \\
\hline 5 Redox \& Neutralization & 0.5 & 5 & 50 & 122 & 5 & 13 & 18 \\
\hline 6 Suspended Solids Filtration & 0.3 & 3 & 10 & 225 & 9 & 23 & 32 \\
\hline 7 Dissolved Organics Removal & 0.8 & & & 2,224 & 89 & 223 & 312 \\
\hline 8 Concentration/Dissolved Solids Removal & 0.5 & 5 & 25 & $\frac{1265}{655}$ & 26 & $\frac{260}{65}$ & $\frac{01}{91}$ \\
\hline 9 Treated Water Sampling & 0.1 & & & 60 & $\frac{<0}{2}$ & 5 & $\frac{51}{7}$ \\
\hline 10 Organic Liquid Waste Holding & 0.5 & & & 199 & $\frac{6}{8}$ & 20 & $\frac{1}{28}$ \\
\hline 11 Liquids Filtration & 0.3 & & 7 & 75 & 3 & $\frac{20}{8}$ & $\frac{20}{11}$ \\
\hline \begin{tabular}{l|l}
12 & Desorber System \\
\end{tabular} & 1.0 & 8 & & 602 & 24 & 60 & 84 \\
\hline 13 Thermal Oxidization & 0.8 & 6 & & 450 & 18 & 45 & 63 \\
\hline 14 Air Pollution Control & 0.3 & & & 225 & 9 & 23 & 32 \\
\hline 15 Drum Encapsulation & 0.5 & 5 & 50 & 538 & 22 & 55 & 77 \\
\hline 16 Electrical Distribution and MCC & 0.2 & & & 542 & 22 & 55 & 77 \\
\hline 17 Utilities \& Mechanical & 0.4 & & & 375 & 15 & 38 & 53 \\
\hline$1 8 \longdiv { \text { Heating Ventilation And Exhaust } }$ & 0.5 & & & & & & \\
\hline 19 Radiation Monitoring & 0.5 & & & 364 & 15 & 38 & 53 \\
\hline 20 Other Equipment & 0.2 & & & 17 & 1 & 3 & 4 \\
\hline 21 Administration Building Subsystem & 10.0 & & & 4,333 & 173 & 433 & 606 \\
\hline$2 2 \longdiv { \text { Receiving, Certification and Shipment Subsystem } }$ & 7.5 & 8 & & 3,572 & 143 & 358 & 501 \\
\hline Annual Cost per FTE & 140,000 & 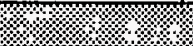 & & & & & \\
\hline Total Cost & 3,934 & 40 & 142 & 3 & & & 2,403 \\
\hline Post Totals To Cost SummaryTable Sections & 5.1 & 5.2 & 5.3 & & ই ৪ & & 5.4 \\
\hline
\end{tabular}

Notes:

1. Annual Maintenance Material is assumed to be $4 \%$ of equipment capital cost.

2. Annual Maintenance Labor is assumed to be $250 \%$ of maintenance material cost. 
Table A-25:- Decontamination and Decommissioning Cost Summary Centralized Facility

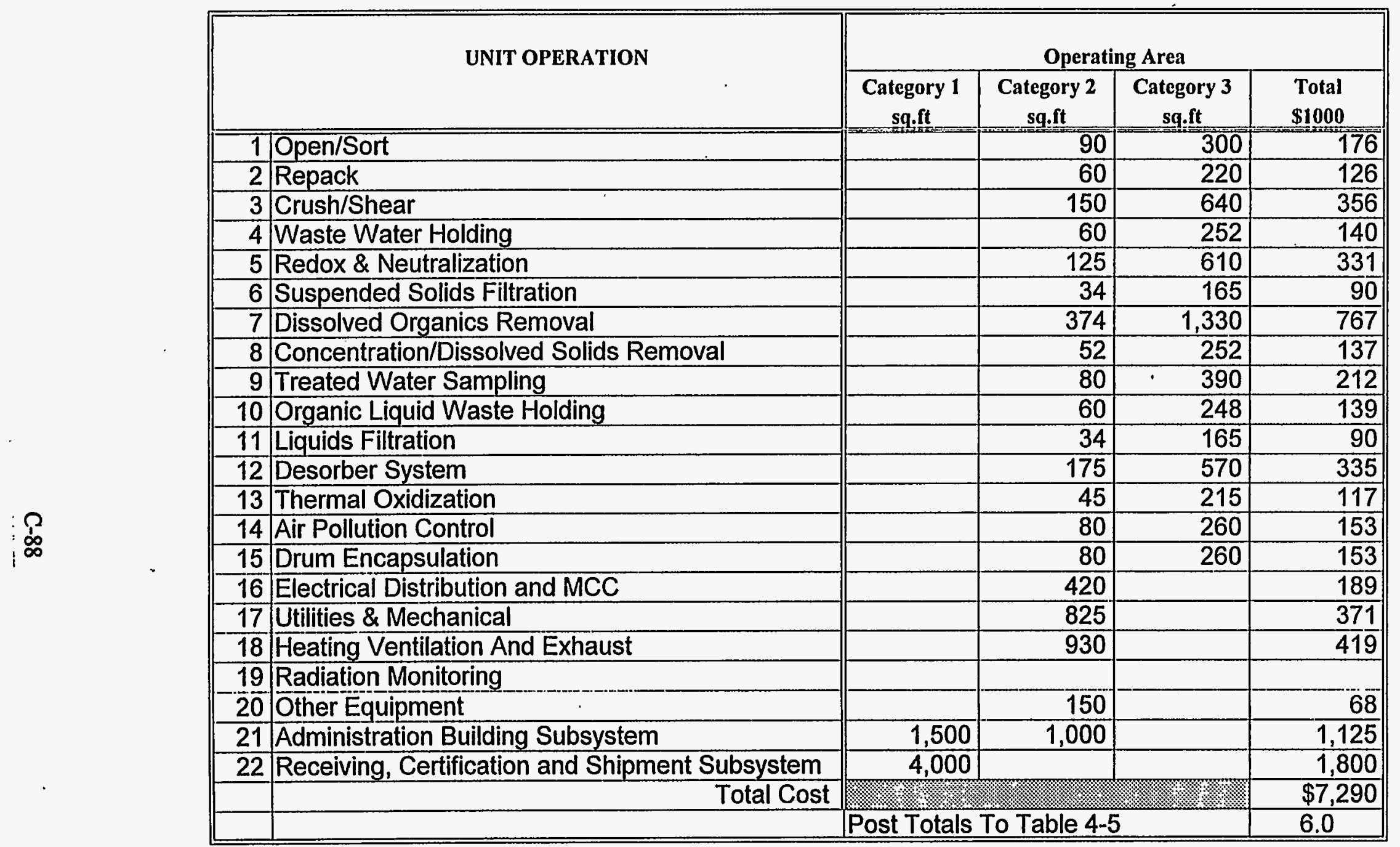




\section{Appendix D}

\section{Technical Issues Assessment}




\title{
PORTABLE TREATMENT SYSTEMS STUDY
}

\author{
Technical Issues Associated with \\ Portable Treatment of Mixed Waste
}

\section{Introduction}

As a supplement to the Portable Treatment Systems Study (PTSS) Functional and Operational Requirements (F\&ORs), this paper provides a listing and brief discussion of the technical issues that appear important and potentially critical to the successful implementation of the portable systems formulated in the F\&ORs. The issues are categorized both from a general portable treatment perspective as well as those specific to the technologies and concepts assumed in the F\&ORs. Political, regulatory, and stakeholder issues, all of which will be critical to implementation of portable systems, are not discussed in this paper.

\section{Technical Issues Specific to the PTSS F\&ORs}

In order to prepare the F\&ORs, a number of assumptions had to be made relative to the waste feed compositions, selection of technologies for the various unit operations, and the process flowsheets. Table 1 gives an assessment of the impacts and sensitivity of these major assumptions to the Portable Treatment Systems. As shown in Table 1, the assumptions concerning waste feed compositions, specifically chlorine, moisture, and inerts content, will have a significant effect on the quantity of intermediate transfer streams between the portable treatment units.

\section{Status of the Technologies}

Along with these assumptions, the status of the various technologies will determine the time required for implementation and the reliability of these technologies to perform their designated functions. All of the processes used in the development of these F\&ORs were examined for status of the technology. The only processes that may not be judged as readily available were the Thermal Desorption (Organics Portable Treatment) and Hydrothermal (Wastewater Portable Treatment) processes. Therefore, these two processes were further examined for state of development.

The Thermal Desorption technology has been judged as proven commercially available ${ }^{1}$ and has been used in soil remediation work for years. The only real questions are how does this type of Thermal Desorption process perform with the types of mixed wastes envisioned for treatment in a portable system. The issue is to further define its required operating envelope, not whether it will or will not work at all. This can be done as an optimization study using full size equipment with minimal risk. A skid-mounted unit is under construction at the DOE Grand Junction facility; however, the program is underfunded by about $50 \%$ and completion of the unit is questionable ${ }^{2}$.

\footnotetext{
1 Telecon with Ron Nakaoka of LANL on October 8, 1996.

${ }^{2}$ Telecon with Joel Grimm of DOE-Albuquerque on October 8, 1996.
} 
Table 1. Sensitivity of the Major Assumptions used in the F\&ORs

\begin{tabular}{|c|c|c|}
\hline Treatment & Assumption & Impact or Sensitivity \\
\hline \multirow[t]{5}{*}{ Organics } & $\begin{array}{l}\text { Chlorine content of Aqueous/Organic } \\
\text { and pure Organic Liquids }\end{array}$ & $\begin{array}{l}\text { Will have major impact on the amount of aqueous blowdown to the Wastewater } \\
\text { Portable Treatment Unit. }\end{array}$ \\
\hline & $\begin{array}{l}\text { Chlorine content of Inorganic } \\
\text { Homogeneous Solids }\end{array}$ & $\begin{array}{l}\text { Will have major impact on the amount of condensate transferred to the Wastewater } \\
\text { Portable Treatment Unit. }\end{array}$ \\
\hline & $\begin{array}{l}\text { Water and inerts content of Aqueous/ } \\
\text { Organic Liquids }\end{array}$ & $\begin{array}{l}\text { Determining factor on amount of aqueous blowdown transferred to the Wastewater } \\
\text { Portable Treatment Unit from the Thermal Desorption process. }\end{array}$ \\
\hline & Quench temperature of $\sim 180^{\circ} \mathrm{F}$ & $\begin{array}{l}\text { May be too high for reliable HEPA filter operation and life. Good for rejecting } \\
\text { maximum amount of water to atmosphere. Scrubber solution cooling may be required } \\
\text { to reduce the offgas dew point temperature to avoid moisture condensation in the } \\
\text { HEPA filters. }\end{array}$ \\
\hline & $\begin{array}{l}460 \text { SCFM purge air through Thermal } \\
\text { Desorber to Condenser }\end{array}$ & $\begin{array}{l}\text { This value was taken from the AL work and seems much higher than necessary. It is } \\
\text { equivalent to } 148 \% \text { of the combustion air required by Thermal Oxidation. It will also } \\
\text { require an unnecessarily large condenser unit for proper condenser gas space } \\
\text { velocity design. A low sweep gas flowrate through the Thermal Desorber should be } \\
\text { adequate. }\end{array}$ \\
\hline Labpacks & Separate Portable Treatment System & $\begin{array}{l}\text { Due to a small on-stream factor ( } 2 \%) \text {, a separate dedicated treatment system may not } \\
\text { be warranted? It is possible that the Labpacks could be shredded (contents and all) } \\
\text { and treated as a solid waste stream. }\end{array}$ \\
\hline Debris & Trommel screen in manual sorting & $\begin{array}{l}\text { Probably not necessary for the small amount of material to be processed. There will } \\
\text { be manual handling of the large items anyway to feed them to the size reduction } \\
\text { devices. Fine material ( }<60 \mathrm{~mm} \text { ) can be simply swept into a container. }\end{array}$ \\
\hline \multirow[t]{2}{*}{ Wastewater } & $\begin{array}{l}\text { Cartridge filters downstream of the } \\
\text { Neutralization Tank }\end{array}$ & $\begin{array}{l}\text { These filters could potentially receive heavy, gelatinous, slimy, and periodically large } \\
\text { quantities of precipitates. A different type of solid/liquid separation device or filter may } \\
\text { be more suitable for this service. }\end{array}$ \\
\hline & $\begin{array}{l}\text { Hydrothermal process pressure letdown } \\
\text { to atmospheric pressure }\end{array}$ & $\begin{array}{l}\text { It may be better to let the pressure down to the RO unit inlet pressure rather than to } \\
\text { atmospheric pressure. This approach would not require the RO feed pump for re-- } \\
\text { pressurization. }\end{array}$ \\
\hline
\end{tabular}


The same general concern applies to the Hydrothermal technology. A 1,000 gal/day unit is currently in production operation at a Texaco refinery. The process would have to be optimized for actual waste stream compositions encountered in mixed waste portable treatment system operation. This can again be accomplished using full size equipment in a statistically designed experimental program to evaluate destruction removal efficiency (DRE) as a function of operating parameters and residence time. A major concern is selection of acceptable materials of construction, equipment life, and the capital equipment costs for chlorinated organics service. The chloride corrosion issue is accentuated by the high operating pressure $(-400 \mathrm{~atm})$ because of potentially higher corrosion rates and the safety consequences of a reactor rupture.

As mentioned in the F\&OR document, these processes were chosen in the F\&ORs because they had been selected by the DOE Albuquerque (AI) Operations Office as the preferred technologies for mobile treatment at AL sites. No attempt was made to optimize selection or seriously consider alternatives. However, should the decision be made to move forward with a mixed waste portable treatment program for the DOE complex, alternative technologies should be thoroughly investigated. Experience from the commercial sector with regard to mobile treatment should be drawn upon as much as possible. An example is the fact that most commercial thermal desorption systems specifically used for remediation of organic-contaminated soils have been atmospheric pressure-operated rotary kilns, infrared furnaces, and thermal screw-type systems ${ }^{3}$.

\section{Importance of Transfer Streams}

When planning a suite of portable treatment units as assumed in the F\&ORs, the intermediate streams generated by the various units for processing by another unit must not be overlooked. Table 2 shows the significance of transfer streams as a percentage of the total waste stream input for each of the portable treatment units. In some cases the transfer streams amount to more material than the primary waste stream to be processed by a given portable treatment unit. This indeed is the case for the Wastewater Portable Treatment Unit where fully $60 \%$ of the waste to be processed comes from other units.

Optimal selection of the processes and unit operations within the portable treatment units will involve minimizing the generation of intermediate (transfer) streams without sacrificing overall process performance.

\footnotetext{
${ }^{3}$ Standard Handbook of Hazardous Waste Treatment and Disposal, Harry M. Freeman, Ed., McGraw-Hill, New York, 1989.
} 
Table 2. Transfer Streams in the PTSS F\&ORs

\begin{tabular}{||l|l|c||}
\hline $\begin{array}{c}\text { Portable } \\
\text { Treatment } \\
\text { System }\end{array}$ & \multicolumn{1}{|c|}{ Transfer Stream } & $\begin{array}{c}\text { Transfer Stream Rate } \\
\text { (\% of Total Waste } \\
\text { Stream Input) }\end{array}$ \\
\hline Organics & $\begin{array}{l}\text { Organic Liquids from Labpacks } \\
\text { Organic Solids \& Sludges from Labpacks }\end{array}$ & $\begin{array}{c}8.3 \% \\
\end{array}$ \\
& $\begin{array}{l}\text { Inorganic Solids and Sludges from Labpacks and } \\
\text { Wastewater }\end{array}$ & $29.2 \%$ \\
\hline Labpacks & None & \\
\hline Debris & Packaging Materials etc., from Labpacks & $22.4 \%$ \\
\hline Wastewater & Condensate from Organics & $25.7 \%$ \\
& Blowdown from Organics & $33.9 \%$ \\
& Aqueous Liquids from Labpacks & $0.8 \%$ \\
\hline
\end{tabular}

\section{General Portable Treatment Technical Issues}

We have categorized the general technical issues into the following areas: logistical, decontamination, containment, safety, design, and process operation. None of these categories can be looked at in isolation; each is influenced by one or more of the other areas. Following are brief discussions of the issues related to each area. The intent here is to raise each issue so that it will be documented for future work, not to offer solutions to the problems at this time.

\section{Logistical Issues}

The assumption was made in the F\&OR study that there would be available the suite of portable treatment units at any particular site to provide complete treatment capability for all primary and secondary (inter-unit transfer) waste streams. The following issues should be considered in planning and design.

- The ability to interface the various portable treatment units so that straightforward transfer of the various intermediate waste streams is possible.

- Adequate surge capacity should be factored into design of the systems to accommodate differences in on-stream factor and unscheduled shutdowns of the various portable treatment units.

- Well defined waste processing requirements, scheduling of processing campaigns, and dispatching for transport from site to site will be critical to meet the design on-stream factors for the portable treatment systems.

\section{Decontamination Issues}

Both radioactive and RCRA chemical decontamination will likely be required between campaigns of dissimilar wastes and at the end of each processing campaign at a particular site before the portable treatment units can be prepared for transport to another site. The following factors should be considered. 
- Thorough decontamination of internal surfaces of process components may be difficult or impossible but may not be required provided the trailers themselves function as secondary containment.

- Decontamination of external process component surfaces that are smooth and water resistant will be relatively straightforward and should be accommodated in design.

- Surge capacity should be provided for decontamination solutions that cannot be processed until the next campaign when the processes have been disabled for transport. This capacity could also be provided by the site.

- Standard design for decontamination should be employed that 1) minimizes pockets and low spots for holdup of contaminated material, 2) locates valves for full drainage, and 3) provides smooth surface finishes of process hardware.

- All auxiliary equipment (see Design Issues below) that does not need to contact mixed waste should be located outside of radiologically-controlled treatment areas, preferably on dedicated trailers.

- Decontamination systems should be integrated into the overall process design of each portable treatment unit.

- RCRA closure and decommissioning procedures would have to be performed at the end of the operating life of a portable treatment unit.

\section{Containment Issues}

If the waste to be processed is mixed low-level radioactive waste, sophisticated glove-box type containment normally associated with handling of high alpha-containing materials, would probably not be required. However, TRU waste processing would require such containment, making the design and operation of the processes selected in the F\&ORs much more difficult.

- The advisability of treating TRU waste with high alpha activity content should be carefully examined given the increased hazards and difficulties associated with design of containment, decontamination, risks of operator exposure to alpha activity via inhalation, and maintenance.

- All portable treatment units that handle liquids should have secondary containment that meets all RCRA requirements for containment of liquid spills.

- Areas of the processes that will generate airborne particulate during normal operation, such as the handling of finely divided dry solids, will require adequate ventilation and possibly the use of personnel protective equipment including respirators.

- The routine changeout of HEPA filters and other instances where contaminated process internals must be accessed for maintenance, will require "bag-in/bag-out" operations or the use of temporary containment devices such as tents to confine the contamination to a local area within the portable treatment unit.

\section{$\underline{\text { Safety Issues }}$}

- The Process Hazards Analysis (PHA) methodology adopted by AL during their mobile treatment work should be reviewed and considered for any future mixed waste portable treatment effort within the DOE complex. The safety analysis should include 1) risks associated uncertainties in waste characteristics, 2) site characteristics, and 3) the suite of 
portable treatment units.

- If the portable treatment units are limited to low-level radioactive waste processing, it is likely that design for criticality safety would not be required.

- Safe design for operation and transport will be driven by both requirements developed in a Safety Analysis Report (SAR) and applicable regulations (DOT, DOE orders, EPA, etc.).

\section{Design Issues}

- The assumption was made in these F\&ORs that the portable units would be fully operable on the transport trailers. An analysis should be made on a case-by-case basis to determine when it makes sense to have skid-mounted modules that can be off-loaded from the transport trailers for temporary operation in the site's facilities (i.e. the AL concept) vs. on-trailer treatment.

- Standardized design features should be incorporated into all the portable treatment units as much as possible to facilitate maintenance, training, and operations. This should include standardized brands of instrumentation and hardware to the extent possible.

- The design of each of the processes should take into account required feed turn-down requirements.

- Space constraints (footprint and height), for operation on trailers may preclude the use of certain technologies or unit operations that would otherwise have been preferred in fixed treatment systems.

- Auxiliary systems and facilities - the auxiliary systems that are required for treatment at fixed facilities may also be required for portable treatment if not provided by the site at which the. waste is processed. These may include the following: HEPA/activated carbon filtered ventilation, emergency electric generator, uninterruptible power supply (UPS), auxiliary fuel supply, caustic supply, water (potable and process), deionized water, compressed dried air, steam generator, spare parts storage, on-site analytical lab, shower and change facilities with capability for personnel decontamination, and offices.

- Air pollution control systems are expected to be similar in configuration and meet the same performance requirements as fixed treatment systems. As with all the equipment associated with the portable treatment systems, the air pollution control system must be capable of withstanding the rigors of transportation on the highways.

- Design must comply with applicable industry standards (ASME, ASTM, DOT, etc.), DOE Orders, permits, quality assurance (QA) requirements, and health and safety requirements.

\section{Process Operational Issues}

Startup and shutdown procedures, process control, and process sampling and monitoring are all expected to be generally similar to the approach used for fixed treatment systems.

- Hookups, including utilities and process lines, between the portable treatment units and the site are required prior to startup and after final shutdown at each site. These tasks represent additional procedures that must be worked out beyond that normally required of fixed systems. Surge capacity must be provided for additional intermediate waste generated during startup above that encountered during normal steady state operation. 
- To the extent possible, waste feed characterization, sorting, and repackaging should be performed in facilities at the site rather than in the portable treatment systems.

- The operational reliability of the processes and equipment used in the portable treatment units will be directly related to uncertainties in the waste feed's physical characteristics and chemical composition. Therefore, good characterization through waste assay and assessment will be critical in assuring the safety and reliability of these processes.

- Process control and monitoring requirements should be similar to those required of fixed treatment systems with the additional requirement of meeting the rigors of transportation on the highways. 